Florida International University FIU Digital Commons

\title{
Double diffusive convection during solidification of ammonium chloride - water (NH4CL-H20) mixture in a trapezoidal cavity
}

Ravi Kumar Duggirala

Florida International University

DOI: $10.25148 /$ etd.FI15101238

Follow this and additional works at: https://digitalcommons.fiu.edu/etd

Part of the Mechanical Engineering Commons

\section{Recommended Citation}

Duggirala, Ravi Kumar, "Double diffusive convection during solidification of ammonium chloride - water (NH4CL-H20) mixture in a trapezoidal cavity" (2004). FIU Electronic Theses and Dissertations. 3095.

https://digitalcommons.fiu.edu/etd/3095 
FLORIDA INTERNATIONAL UNIVERSITY

Miami, Florida

DOUBLE DIFFUSIVE CONVECTION DURING SOLIDIFICATION OF AMMONIUM CHLORIDE - WATER $\left(\mathrm{NH}_{4} \mathrm{Cl}-\mathrm{H}_{2} \mathrm{O}\right)$ MIXTURE IN A TRAPEZOIDAL CAVITY

A thesis submitted in partial fulfillment of the requirements for the degree of

MASTER OF SCIENCE

in

MECHANICAL ENGINEERING

by

Ravi Kumar Duggirala 
To: Dean Vish Prasad

College of Engineering

This thesis, written by Ravi Kumar Duggirala, and entitled Double Diffusive Convection during Solidification of Ammonium Chloride - Water $\left(\mathrm{NH}_{4} \mathrm{Cl}-\mathrm{H}_{2} \mathrm{O}\right)$ mixture in a Trapezoidal Cavity, having been approved in respect to style and intellectual content, is referred to you for judgment.

We have read this thesis and recommend that it be approved.

Chaouki Ghenai

C. X. Lin

Yong X. Tao, Major Professor

Date of Defense: July 16, 2004

The thesis of Ravi Kumar Duggirala is approved.

\author{
Dean Vish Prasad \\ College of Engineering
}

Dean Douglas Wartzok University Graduate School

Florida International University, 2004 


\section{DEDICATION}

This thesis is dedicated to my parents Ratnaji Rao Duggirala and Ratna Kumari, all my family members for their immense love, understanding, constant support and encouragement towards academic pursuits during my school and college years. 


\section{ACKNOWLEDGMENTS}

I would like to sincerely thank my supervisor at HCET - FIU, Dr. Chaouki Ghenai for valuable advice, support, inspiration and care throughout my study at Florida International University and guidance during the course of the research and preparation of manuscript. I would also like to thank Dr. Yong X. Tao for serving as my major professor. Also my hearty thanks to Dr. C. X. Lin for his support, encouragement and providing me with the opportunity to work on this project at HCET - FIU and also for serving on my committee.

My sincere appreciation also goes to other members in the research group, in particular Dr. Peter Skudarnov for his valuable suggestions and for his help at any point of time. I also want to thank my colleagues, friends and room mates for their friendship and intellectual contributions. I also wish to thank my family members, especially my mom, Ratna Kumari for her love, support and encouragement.

The financial support for this project provided by HBCU/MI Environmental Technology Consortium to Hemispheric Center for Environmental Technology is also gratefully acknowledged. 


\section{ABSTRACT OF THE THESIS \\ DOUBLE DIFFUSIVE CONVECTION DURING SOLIDIFICATION OF \\ AMMONIUM CHLORIDE - WATER $\left(\mathrm{NH}_{4} \mathrm{Cl}-\mathrm{H}_{2} \mathrm{O}\right)$ MIXTURE IN A \\ TRAPEZOIDAL CAVITY \\ by}

Ravi Kumar Duggirala

Florida International University, 2004

Miami, Florida

Professor Yong X. Tao, Major Professor

The effect of the initial concentration of ammonium chloride (sub eutectic: $\mathrm{C}<$ 19.8 wt. $\%$ and eutectic $\mathrm{C}_{\mathrm{e}}=19.8$ wt. \%) and boundary temperatures $\left(\mathrm{T}_{\text {cold }}=-30{ }^{\circ} \mathrm{C}\right.$ to -10 ${ }^{0} \mathrm{C}$ ) on the solidification process is examined. Particle Image Velocimetry (PIV) is used in this study to measure the velocity fields in the melt during the solidification process. The distributions of temperatures at discrete locations in the solution and the boundary walls were measured. This study focuses on the solidification of an ammonium chloride-water $\left(\mathrm{NH}_{4} \mathrm{Cl}-\mathrm{H}_{2} \mathrm{O}\right)$ solution in a trapezoidal cavity with one and two inclined cooling walls.

The thermosolutal convective flow strongly influenced the rate of freezing. An increase in thermal driving force increased the rate of freezing. Increased initial concentration retarded the freezing process and primarily affected the structure of the solid and mush regions.

The results of this study will contribute in understanding the phenomena and bridge the gap between the engineering aspect and physics background for the dynamics of solid phase formation during castings, ingots, and polymerization. 


\section{TABLE OF CONTENTS}

CHAPTER

1. INTRODUCTION 1

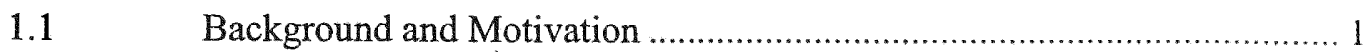

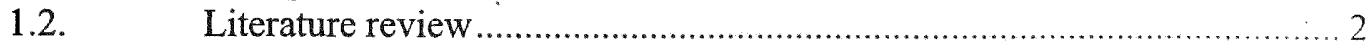

1.2.1 Phase Change Heat Transfer .............................................................. 3

1.2.2 The Physics of Multicomponent Solidification ........................................ 5

1.2.3 Double Diffusive Convection ........................................................6

1.2.4 Experimental Investigation of Solidification in Binary Systems..............11

1.2.4.1 One Dimensional Studies......................................................... II

1.2.4.2 Two Dimensional Studies ..................................................... 14

1.3. Objectives of the Current Research .............................................. 17

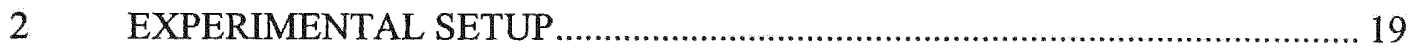

2.1 Experimental Apparatus.............................................................. 19

2.1.1 Test Enclosure........................................................................... 19

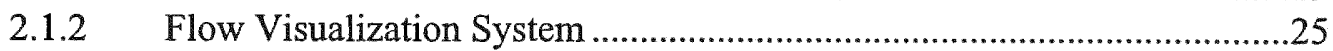

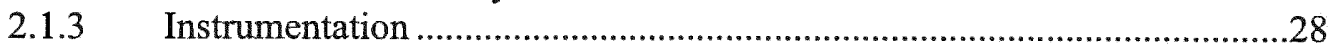

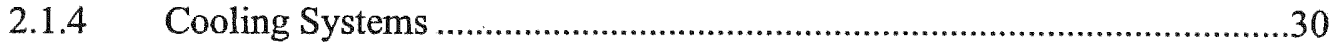

2.1.5 Phase Change Material .................................................................... 30

$2.2 \quad$ Experimental Procedures .............................................................. 32

Experimental Uncertainty ......................................................... 33

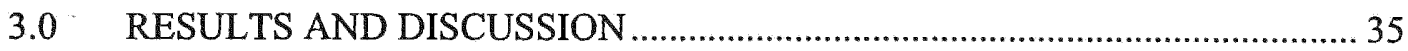

3.1. Experimental Conditions Performed in the Study .............................. 35

Results of Simulations .................................................................... 38

3.2.1 Effect of Initial Concentration - One Wall Cooled .....................................38

3.2.2 Effect of Initial Concentration - Two Wall Cooled..................................67

3.2.3 Effect of Initial Boundary Conditions..................................................93

3.2.4 Temperature Distribution inside the cavity.......................................114

3.2.5 Comparison of Solidification process in Trapezoidal Cavity with Rectangular Chamber................................................................121

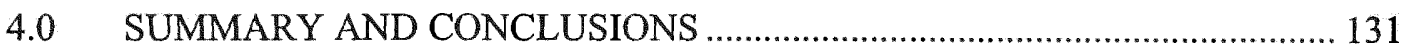

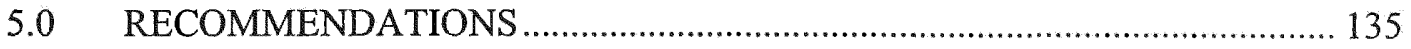

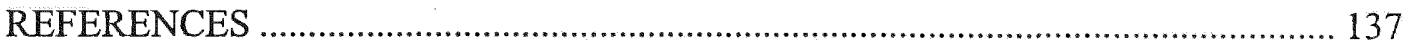




\section{LIST OF FIGURES}

FIGURE

PAGE

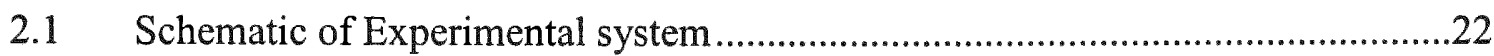

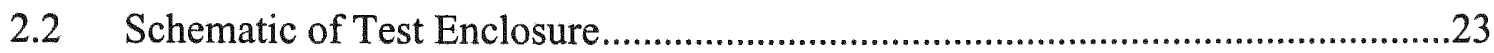

2.3 Distribution of Thermocouples inside the cavity ..............................................24

2.5 Equilibrium Phase Diagram for the binary $\mathrm{NH}_{4} \mathrm{Cl}-\mathrm{H}_{2} \mathrm{O}$ system $\left(\mathrm{T}_{\mathrm{e}}=-15.4\right.$ ${ }^{0} \mathrm{C}, \mathrm{C}_{\mathrm{e}}=19.8 \%$ ).

3.1 PIV Images of the solidification of water: One cooled side, $T_{L}=-30^{\circ} \mathrm{C}, \mathrm{T}_{R}$ $=+20 \mathrm{C}$.

3.2 PIV Images of the solidification of $5 \% \mathrm{NH}_{4} \mathrm{Cl}-\mathrm{H}_{2} \mathrm{O}$; One cooled side, $\mathrm{T}_{\mathrm{L}}=$ $-30^{\circ} \mathrm{C}, \mathrm{T}_{\mathrm{R}}=+20^{0} \mathrm{C}$.

3.3 PIV Images of the solidification of $12 \% \mathrm{NH}_{4} \mathrm{Cl}-\mathrm{H}_{2} \mathrm{O}$; One cooled side, $\mathrm{T}_{\mathrm{L}}$ $=-30^{\circ} \mathrm{C}, \mathrm{T}_{\mathrm{R}}=+20^{\circ} \mathrm{C}$.

3.4 PIV Images of the solidification of $19.8 \% \mathrm{NH}_{4} \mathrm{Cl}-\mathrm{H}_{2} \mathrm{O}$; One cooled side, $\mathrm{T}_{\mathrm{L}}=-30 \mathrm{C}, \mathrm{T}_{\mathrm{R}}=+20^{\circ} \mathrm{C}$.

3.5 Effect of the Initial Concentration on the Solidification Process One cooled side: Time $(t)=64$ Minutes, $T_{L}=-30{ }^{\circ} \mathrm{C}, \mathrm{T}_{\mathrm{R}}=+20{ }^{\circ} \mathrm{C}$.

3.6 Effect of the Initial Concentration on the Solidification Process One cooled side: Time $(t)=64$ Minutes, $T_{L}=-20{ }^{\circ} \mathrm{C}, T_{R}=+20^{\circ} \mathrm{C}$.

3.7 Effect of the Initial Concentration on the Solidification Process One cooled side: Time $(t)=64$ Minutes, $T_{L}=-10{ }^{\circ} \mathrm{C}, T_{R}=+20{ }^{\circ} \mathrm{C}$.

3.8 Solidification Contours for water: One cooled side, $T_{L}=-30{ }^{0} \mathrm{C}, \mathrm{T}_{\mathrm{R}}=+20$ C.

3.9 Solidification Contours for $5 \% \mathrm{NH}_{4} \mathrm{Cl}-\mathrm{H}_{2} \mathrm{O}$ : One cooled side, $\mathrm{T}_{\mathrm{L}}=-30^{0} \mathrm{C}$, $\mathrm{T}_{\mathrm{R}}=+20^{\circ} \mathrm{C}$. 
3.10 Solidification Contours for $12 \% \mathrm{NH}_{4} \mathrm{Cl}-\mathrm{H}_{2} \mathrm{O}$ : One cooled side, $\mathrm{T}_{\mathrm{L}}=-30$

${ }^{0} \mathrm{C}, \mathrm{T}_{\mathrm{R}}=+20^{0} \mathrm{C}$

3.11 Solidification Contours for $19.8 \% \mathrm{NH}_{4} \mathrm{Cl}-\mathrm{H}_{2} \mathrm{O}$ : One cooled side, $\mathrm{T}_{\mathrm{L}}=-30$

${ }^{\circ} \mathrm{C}, \mathrm{T}_{\mathrm{R}}=+20^{\circ} \mathrm{C}$

3.12 Solidification Contours for Different Concentrations at $\mathrm{t}=56 \mathrm{~min} ; \mathrm{T}_{\mathrm{L}}=-30$

${ }^{0} \mathrm{C} \& \mathrm{~T}_{\mathrm{R}}=+20{ }^{\circ} \mathrm{C}$.

3.13 Effect of initial concentration on thickness of the frozen layer ( $Y=37 \mathrm{~mm}$ ): One cooled side, $\mathrm{T}_{\mathrm{L}}=-30{ }^{\circ} \mathrm{C}, \mathrm{T}_{\mathrm{R}}=+20^{\circ} \mathrm{C}$.

3.14 Effect of initial concentration on thickness of the frozen layer ( $\mathrm{Y}=37 \mathrm{~mm})$ :

One cooled side, $\mathrm{T}_{\mathrm{L}}=-20^{\circ} \mathrm{C}, \mathrm{T}_{\mathrm{R}}=+20^{\circ} \mathrm{C}$.

3.15 Effect of initial concentration on Velocity of Moving Interface ( $\mathrm{Y}=37 \mathrm{~mm})$ :

One cooled side, $\mathrm{T}_{\mathrm{L}}=-30{ }^{\circ} \mathrm{C}, \mathrm{T}_{\mathrm{R}}=+20^{\circ} \mathrm{C}$

3.16 Effect of initial concentration on Velocity of Moving Interface ( $\mathrm{Y}=37 \mathrm{~mm}$ ): One cooled side, $\mathrm{T}_{\mathrm{L}}=-20^{\circ} \mathrm{C}, \mathrm{T}_{\mathrm{R}}=+20^{\circ} \mathrm{C}$.

3.17 Frozen layer thickness at three different positions in the cavity: Pure Water; One cooled side, $\mathrm{T}_{\mathrm{L}}=-30{ }^{\circ} \mathrm{C}, \mathrm{T}_{\mathrm{R}}=+20^{\circ} \mathrm{C}$.

3.18 Solidus and Liquidus Temperatures with Time ( $\mathrm{Y}=37)$, Pure Water; One cooled side, $\mathrm{T}_{\mathrm{L}}=-30^{\circ} \mathrm{C}, \mathrm{T}_{\mathrm{R}}=+20^{\circ} \mathrm{C}$.

3.19 Variation of heat rate with Time $(\mathrm{Y}=37)$, Pure Water; One cooled side, $\mathrm{T}_{\mathrm{L}}=$ $-30{ }^{\circ} \mathrm{C}, \mathrm{T}_{\mathrm{R}}=+20{ }^{\circ} \mathrm{C}$. (b).

3.20 Variation of heat rate and Moving Interface Velocity with Time ( $\mathrm{Y}=37)$ One cooled side, $\mathrm{T}_{\mathrm{L}}=-30^{\circ} \mathrm{C}, \mathrm{T}_{\mathrm{R}}=+20^{\circ} \mathrm{C}$.

3.21 Velocity Vectors in the melt during the solidification of water: One cooled side, $\mathrm{T}_{\mathrm{L}}=-30^{\circ} \mathrm{C}, \mathrm{T}_{\mathrm{R}}=+20^{\circ} \mathrm{C}$

3.22 Velocity Vectors in the melt during the solidification of $5 \mathrm{Wt} . \% \mathrm{NH}_{4} \mathrm{Cl}-$ $\mathrm{H}_{2} \mathrm{O}$ : One cooled side, $\mathrm{T}_{\mathrm{L}}=-30^{\circ} \mathrm{C}, \mathrm{T}_{\mathrm{R}}=+20^{\circ} \mathrm{C}$.

3.23 Velocity Vectors in the melt during the solidification of $12 \mathrm{Wt} . \% \mathrm{NH}_{4} \mathrm{Cl}-$ $\mathrm{H}_{2} \mathrm{O}$ : One cooled side, $\mathrm{T}_{\mathrm{L}}=-30^{\circ} \mathrm{C}, \mathrm{T}_{\mathrm{R}}=+20^{\circ} \mathrm{C}$. 
3.24 Velocity Vectors in the melt during the solidification of $19.8 \mathrm{Wt} \% \mathrm{NH}_{4} \mathrm{Cl}$ $-\mathrm{H}_{2} \mathrm{O}$ : One cooled side, $\mathrm{T}_{\mathrm{L}}=-30^{\circ} \mathrm{C}, \mathrm{T}_{\mathrm{R}}=+20^{\circ} \mathrm{C}$.

3.25 Velocity Vectors showing the effect of the Initial Concentration on the Solidification Process; One cooled side: Time $(t)=64$ Minutes, $T_{L}=-30$ ${ }^{0} \mathrm{C}, \mathrm{T}_{\mathrm{R}}=+20{ }^{0} \mathrm{C}$

3.26 Effect of Initial Concentration on Temperature Distribution inside the cavity; $\mathrm{Y}=37 \mathrm{~mm}$; One wall Cooled; Time $(\mathrm{t})=16$ Minutes, $\mathrm{T}_{\mathrm{L}}=-30{ }^{\circ} \mathrm{C}$; $\mathrm{T}_{\mathrm{R}}=+20{ }^{\circ} \mathrm{C}$.

3.27 Effect of Initial Concentration on Temperature Distribution inside the cavity; $\mathrm{Y}=37 \mathrm{~mm}$; One wall Cooled; Time $(\mathrm{t})=72$ Minutes, $\mathrm{T}_{\mathrm{L}}=-30{ }^{\circ} \mathrm{C}$; $\mathrm{T}_{\mathrm{R}}=+20{ }^{\circ} \mathrm{C}$.

3.28 Effect of Initial Concentration on Temperature Distribution inside the cavity; $\mathrm{Y}=37 \mathrm{~mm}$; One wall Cooled; Time $(\mathrm{t})=128$ Minutes, $\mathrm{T}_{\mathrm{L}}=-30{ }^{\circ} \mathrm{C}$; $\mathrm{T}_{\mathrm{R}}=+20^{0} \mathrm{C}$

3.29 Effect of Initial Concentration on Temperature Distribution inside the cavity; $\mathrm{Y}=37 \mathrm{~mm}$; One wall Cooled; Time $(\mathrm{t})=72$ Minutes, $\mathrm{T}_{\mathrm{L}}=-20{ }^{\circ} \mathrm{C}$; $\mathrm{T}_{\mathrm{R}}=+20^{\circ} \mathrm{C}$.

3.30 Effect of Initial Concentration on Temperature Distribution inside the cavity; $\mathrm{Y}=37 \mathrm{~mm}$; One wall Cooled; Time $(\mathrm{t})=72$ Minutes, $\mathrm{T}_{\mathrm{L}}=-10{ }^{\circ} \mathrm{C}$; $\mathrm{T}_{\mathrm{R}}=+20{ }^{\circ} \mathrm{C}$.

3.31 PIV Images of the solidification of water: Two Wall cooled side, $T_{L}=T_{R}=$ $30{ }^{\circ} \mathrm{C}$.

3.32 PIV Images of the solidification of $5 \% \mathrm{NH}_{4} \mathrm{Cl}-\mathrm{H}_{2} \mathrm{O}$ : Two Wall cooled side, $\mathrm{T}_{\mathrm{L}}=\mathrm{T}_{\mathrm{R}}=-30^{\circ} \mathrm{C}$.

3.33 PIV Images of the solidification of $12 \% \mathrm{NH}_{4} \mathrm{Cl}-\mathrm{H}_{2} \mathrm{O}$ : Two Wall cooled side, $T_{L}=T_{R}=-30{ }^{\circ} \mathrm{C}$.

3.34 PIV Images of the solidification of $19.8 \% \mathrm{NH}_{4} \mathrm{Cl}-\mathrm{H}_{2} \mathrm{O}$ : Two Wall cooled side, $T_{L}=T_{R}=-30{ }^{\circ} \mathrm{C}$.

3.35 Effect of the Initial Concentration on the Solidification Process Two cooled side: Time $(\mathrm{t})=64$ Minutes, $\mathrm{T}_{\mathrm{L}}=\mathrm{T}_{\mathrm{R}}=-30^{\circ} \mathrm{C}$.

3.36 Effect of the Initial Concentration on the Solidification Process; Two cooled side: Time $(t)=64$ Minutes, $T_{L}=-30{ }^{\circ} \mathrm{C} \& T_{R}=-10^{\circ} \mathrm{C}$. 
3.37 Solidification Contours for water: Two wall cooled, $T_{L}=T_{R}=-30^{0} \mathrm{C}$. .75

3.38 Solidification Contours for $5 \% \mathrm{NH}_{4} \mathrm{Cl}-\mathrm{H}_{2} \mathrm{O}$ : Two wall cooled, $\mathrm{T}_{\mathrm{L}}=\mathrm{T}_{\mathrm{R}}=-$ $30 \mathrm{C}$.

3.39 Solidification Contours for $12 \% \mathrm{NH}_{4} \mathrm{Cl}-\mathrm{H}_{2} \mathrm{O}$ : Two wall cooled, $\mathrm{T}_{\mathrm{L}}=\mathrm{T}_{\mathrm{R}}=$ $-30 \mathrm{C}$.

3.40 Solidification Contours for $19.8 \% \mathrm{NH}_{4} \mathrm{Cl}-\mathrm{H}_{2} \mathrm{O}$ : Two wall cooled, $\mathrm{T}_{\mathrm{L}}=\mathrm{T}_{\mathrm{R}}$ $=-30 \mathrm{C}$.

3.41 Solidification Contours for Different Concentrations at $t=64 \mathrm{~min}$; Two

Wall Cooled; $\mathrm{T}_{\mathrm{L}}=\mathrm{T}_{\mathrm{R}}=-30^{\circ} \mathrm{C}$.

3.42 Solidification Contours for Different Concentrations at $\mathrm{t}=64 \mathrm{~min}$; Two Wall Cooled; $\mathrm{T}_{\mathrm{L}}=-30{ }^{\circ} \mathrm{C} \& \mathrm{~T}_{\mathrm{R}}=-10^{\circ} \mathrm{C}$.

3.43 Effect of initial concentration on thickness of the frozen layer ( $Y=37 \mathrm{~mm})$ :

Two wall cooled, $\mathrm{T}_{\mathrm{L}}=\mathrm{T}_{\mathrm{R}}=-30^{\circ} \mathrm{C}$.

3.44 Effect of initial concentration on thickness of the frozen layer ( $\mathrm{Y}=37 \mathrm{~mm})$ :

Two wall cooled, $\mathrm{T}_{\mathrm{L}}=-30{ }^{\circ} \mathrm{C}, \mathrm{T}_{\mathrm{R}}=-10^{\circ} \mathrm{C}$.

3.45 Effect of initial concentration on Velocity of Moving Interface ( $Y=37 \mathrm{~mm}$ ):

One cooled side, $\mathrm{T}_{\mathrm{L}}=\mathrm{T}_{\mathrm{R}}=-30^{\circ} \mathrm{C}$

3.46 Effect of initial concentration on Velocity of Moving Interface ( $Y=37 \mathrm{~mm})$ :

Two wall cooled, $\mathrm{T}_{\mathrm{L}}=-30{ }^{\circ} \mathrm{C}, \mathrm{T}_{\mathrm{R}}=-10{ }^{\circ} \mathrm{C}$.

3.47 Frozen layer thickness on left and right side walls: $0 \%$ \& $12 \% \mathrm{NH}_{4} \mathrm{Cl}-\mathrm{H}_{2} \mathrm{O}$;

Two wall cooled side, $T_{L}=T_{R}=-30^{\circ} \mathrm{C}$.

3.48 Frozen layer thickness on left and right side walls: $5 \%$ \& $19.8 \% \mathrm{NH}_{4} \mathrm{Cl}-$ $\mathrm{H}_{2} \mathrm{O} ;$ Two wall cooled side, $\mathrm{T}_{\mathrm{L}}=\mathrm{T}_{\mathrm{R}}=-30^{\circ} \mathrm{C}$.

3.49 Moving Interface Velocity on left and right side walls: $0 \% \& 12 \% \mathrm{NH}_{4} \mathrm{Cl}$ $\mathrm{H}_{2} \mathrm{O} ;$ Two wall cooled side, $\mathrm{T}_{\mathrm{L}}=\mathrm{T}_{\mathrm{R}}=-30^{\circ} \mathrm{C}$.

3.50 Moving Interface Velocity on left and right side walls: $5 \%$ \& $19.8 \% \mathrm{NH}_{4} \mathrm{Cl}$ $\mathrm{H}_{2} \mathrm{O}$; Two wall cooled side, $\mathrm{T}_{\mathrm{L}}=\mathrm{T}_{\mathrm{R}}=-30{ }^{\circ} \mathrm{C}$.

3.51 Velocity Vectors in the melt during the solidification of water; Two Wall Cooled, $T_{L}=T_{R}=-30 \mathrm{C}$. 
3.52 Velocity Vectors in the melt during the solidification of $5 \mathrm{Wt} . \% \mathrm{NH}_{4} \mathrm{Cl}-$ $\mathrm{H}_{2} \mathrm{O}$ : Two Wall Cooled, $\mathrm{T}_{\mathrm{L}}=\mathrm{T}_{\mathrm{R}}=-30^{\circ} \mathrm{C}$

3.53 Velocity Vectors in the melt during the solidification of $12 \mathrm{Wt}$. $\% \mathrm{NH}_{4} \mathrm{Cl}-$ $\mathrm{H}_{2} \mathrm{O}$ : Two Wall Cooled, $\mathrm{T}_{\mathrm{L}}=\mathrm{T}_{\mathrm{R}}=-30^{\circ} \mathrm{C}$.

3.54 Velocity Vectors in the melt during the solidification of $19.8 \mathrm{Wt} . \% \mathrm{NH}_{4} \mathrm{Cl}$ $-\mathrm{H}_{2} \mathrm{O}$ : Two Wall Cooled, $\mathrm{T}_{\mathrm{L}}=\mathrm{T}_{\mathrm{R}}=-30^{\circ} \mathrm{C}$

3.55 Velocity Vectors showing the effect of the Initial Concentration on the Solidification Process; Two Wall Cooled: Time $(t)=64$ Minutes, $T_{L}=T_{R}$ $=-30{ }^{\circ} \mathrm{C}$.

3.56 Velocity Vectors showing the effect of the Initial Concentration on the Solidification Process; Two Wall Cooled: Time $(t)=64$ Minutes, $T_{L}=$ $30{ }^{\circ} \mathrm{C}, \mathrm{T}_{\mathrm{R}}=-10{ }^{\circ} \mathrm{C}$

3.57 Effect of Initial Concentration on Temperature Distribution inside the cavity; $\mathrm{Y}=37 \mathrm{~mm}$; Two wall Cooled; Time $(\mathrm{t})=16$ Minutes, $\mathrm{T}_{\mathrm{L}}=\mathrm{T}_{\mathrm{R}}=-30$ ${ }^{0} \mathrm{C}$.

3.58 Effect of Initial Concentration on Temperature Distribution inside the cavity; $\mathrm{Y}=37 \mathrm{~mm}$; Two wall Cooled; Time $(\mathrm{t})=72$ Minutes, $\mathrm{T}_{\mathrm{L}}=\mathrm{T}_{\mathrm{R}}=-30$ ${ }^{0} \mathrm{C}$.

3.59 Effect of Initial Concentration on Temperature Distribution inside the cavity; $\mathrm{Y}=37 \mathrm{~mm}$; Two wall Cooled; Time $(\mathrm{t})=128$ Minutes, $\mathrm{T}_{\mathrm{L}}=\mathrm{T}_{\mathrm{R}}=$ $30{ }^{\circ} \mathrm{C}$.

3.60 Effect of Initial Concentration on Temperature Distribution inside the cavity; $\mathrm{Y}=37 \mathrm{~mm}$; Two wall Cooled; Time $(\mathrm{t})=72$ Minutes, $\mathrm{T}_{\mathrm{L}}=-30{ }^{0} \mathrm{C}$; $\mathrm{T}_{\mathrm{R}}=-10{ }^{\circ} \mathrm{C}$

3.61 Effect of Initial Concentration on Temperature Distribution inside the cavity; $\mathrm{Y}=37 \mathrm{~mm}$; Two wall Cooled; Time $(\mathrm{t})=128$ Minutes, $\mathrm{T}_{\mathrm{L}}=-30{ }^{\circ} \mathrm{C}$; $\mathrm{T}_{\mathrm{R}}=-10^{\circ} \mathrm{C}$

3.62 Effect of Initial Boundary Temperature on Solidification Process for Pure Water; Time $(t)=24$ Minutes.

3.63 Effect of Initial Boundary Temperature on Solidification Process for 5\% $\mathrm{NH}_{4} \mathrm{Cl}-\mathrm{H}_{2} \mathrm{O}$; Time $(\mathrm{t})=24$ Minutes 
3.64 Effect of Initial Boundary Temperature on Solidification Process for $12 \%$ $\mathrm{NH}_{4} \mathrm{Cl}-\mathrm{H}_{2} \mathrm{O}$; Time $(\mathrm{t})=24$ Minutes.

3.65 Effect of Initial Boundary Temperature on Solidification Process for $19.8 \%$ $\mathrm{NH}_{4} \mathrm{Cl}-\mathrm{H}_{2} \mathrm{O}$; Time $(\mathrm{t})=24$ Minutes.

3.66 Solidification Contours showing the effect of Initial Boundary Condition; Pure Water at Time $(t)=72$ Minutes .98

3.67 Solidification Contours showing the effect of Initial Boundary Condition; $5 \% \mathrm{NH}_{4} \mathrm{Cl}-\mathrm{H}_{2} \mathrm{O}$ at Time $(\mathrm{t})=72$ Minutes

3.68 Solidification Contours showing the effect of Initial Boundary Condition; $12 \% \mathrm{NH}_{4} \mathrm{Cl}-\mathrm{H}_{2} \mathrm{O}$ at Time $(\mathrm{t})=72$ Minutes

3.69 Solidification Contours showing the effect of Initial Boundary Condition; $19.8 \% \mathrm{NH}_{4} \mathrm{Cl}-\mathrm{H}_{2} \mathrm{O}$ at Time $(\mathrm{t})=72$ Minutes

3.70 Effect of Initial Boundary Conditions on Frozen Layer thickness ( $Y=37$ $\mathrm{mm})$ : Pure Water.

3.71 Effect of Initial Boundary Conditions on Frozen Layer thickness ( $\mathrm{Y}=37$ $\mathrm{mm}): 5 \% \mathrm{NH}_{4} \mathrm{Cl}-\mathrm{H}_{2} \mathrm{O}$.

3.72 Effect of Initial Boundary Conditions on Frozen Layer thickness ( $\mathrm{Y}=37$ $\mathrm{mm}): 12 \% \mathrm{NH}_{4} \mathrm{Cl}-\mathrm{H}_{2} \mathrm{O}$.

3.73 Effect of Initial Boundary Conditions on Frozen Layer thickness ( $\mathrm{Y}=37$ $\mathrm{mm}): 19.8 \% \mathrm{NH}_{4} \mathrm{Cl}-\mathrm{H}_{2} \mathrm{O}$

3.74 Effect of Initial Boundary Conditions on Velocity of Moving Interface ( $\mathrm{Y}=37 \mathrm{~mm}$ ): Pure Water 103

3.75 Effect of Initial Boundary Conditions on Velocity of Moving Interface $(\mathrm{Y}=37 \mathrm{~mm}): 5 \% \mathrm{NH}_{4} \mathrm{Cl}-\mathrm{H}_{2} \mathrm{O}$

3.76 Effect of Initial Boundary Conditions on Velocity of Moving Interface $(\mathrm{Y}=37 \mathrm{~mm}): 12 \% \mathrm{NH}_{4} \mathrm{Cl}-\mathrm{H}_{2} \mathrm{O}$ 104

3.77 Effect of Initial Boundary Conditions on Velocity of Moving Interface $\left(\mathrm{Y}=37 \mathrm{~mm}\right.$ ): $19.8 \% \mathrm{NH}_{4} \mathrm{Cl}-\mathrm{H}_{2} \mathrm{O}$

3.78 Effect of Initial Boundary Temperature on Convection Flow Pattern; Pure Water; Time $(t)=24$ Minutes. 
3.79 Effect of Initial Boundary Temperature on Convection Flow Pattern; 5\% $\mathrm{NH}_{4} \mathrm{Cl}-\mathrm{H}_{2} \mathrm{O}$; Time $(\mathrm{t})=24$ Minutes.

3.80 Effect of Initial Boundary Temperature on Convection Flow Pattern; $12 \%$ $\mathrm{NH}_{4} \mathrm{Cl}-\mathrm{H}_{2} \mathrm{O}$; Time $(\mathrm{t})=24$ Minutes.

3.81 Effect of Initial Boundary Temperature on Convection Flow Pattern; 19.8\% $\mathrm{NH}_{4} \mathrm{Cl}-\mathrm{H}_{2} \mathrm{O}$; Time $(\mathrm{t})=24$ Minutes.

3.82 Effect of Initial Boundary Conditions on Temperature Distribution inside the cavity; $Y=37 \mathrm{~mm}$; Pure Water One wall Cooled; Time $(\mathrm{t})=40$ Minutes.

3.83 Effect of Initial Boundary Conditions on Temperature Distribution inside the cavity; $\mathrm{Y}=37 \mathrm{~mm}$; Pure Water One wall Cooled; Time $(\mathrm{t})=72$ Minutes.

3.84 Effect of Initial Boundary Conditions on Temperature Distribution inside the cavity; Y $=37 \mathrm{~mm}$; Pure Water One wall Cooled; Time $(\mathrm{t})=104$ Minutes.

3.85 Effect of Temperature on right side wall on Frozen layer thickness; $\mathrm{Y}=37$ $\mathrm{mm}$; Pure Water; Two Wall Cooled $\left(\mathrm{T}_{\mathrm{L}}=-30^{\circ} \mathrm{C}\right)$.

3.86 Effect of Temperature on Frozen layer thickness; $\mathrm{Y}=37 \mathrm{~mm}$; Pure Water; Left side wall; Two Wall Cooled $\left(\mathrm{T}_{\mathrm{L}}=-30^{\circ} \mathrm{C}\right)$

3.87 Effect of Temperature on Frozen layer thickness; $\mathrm{Y}=37 \mathrm{~mm}$; Pure Water; Right side wall; Two Wall Cooled $\left(\mathrm{T}_{\mathrm{L}}=-30^{\circ} \mathrm{C}\right)$

3.88 Temperature variation during solidification process on left and right side wall of the cavity; One wall Cooled; $T_{L}=-30{ }^{\circ} \mathrm{C} \& T_{R}=+20{ }^{\circ} \mathrm{C}$.

3.89 Temperature Distribution during solidification of Pure Water at different times; One wall Cooled; $Y=37 \mathrm{~mm} ; \mathrm{T}_{\mathrm{L}}=-30^{\circ} \mathrm{C} \& \mathrm{~T}_{\mathrm{R}}=+20^{\circ} \mathrm{C}$

3.90 Temperature Distribution during solidification of Pure Water at different times; One wall Cooled; $\mathrm{Y}=88 \mathrm{~mm} ; \mathrm{T}_{\mathrm{L}}=-30^{\circ} \mathrm{C} \& \mathrm{~T}_{\mathrm{R}}=+20^{\circ} \mathrm{C}$

3.91 Temperature Distribution during solidification of Pure Water at different Positions; One wall Cooled; $\mathrm{Y}=37 \mathrm{~mm} ; \mathrm{T}_{\mathrm{L}}=-30{ }^{\circ} \mathrm{C} \& \mathrm{~T}_{\mathrm{R}}=+20^{\circ} \mathrm{C}$.

3.92 Temperature Distribution during solidification of Pure Water at different Positions; One wall Cooled; $\mathrm{Y}=88 \mathrm{~mm} ; \mathrm{T}_{\mathrm{L}}=-30{ }^{\circ} \mathrm{C} \& \mathrm{~T}_{\mathrm{R}}=+20{ }^{\circ} \mathrm{C}$. 
3.93 Temperature Distribution during solidification of Pure Water at different Times; Two walls Cooled; $\mathrm{Y}=37 \mathrm{~mm} ; \mathrm{T}_{\mathrm{L}}=-30^{\circ} \mathrm{C} \& \mathrm{~T}_{\mathrm{R}}=-30^{\circ} \mathrm{C}$.

3.94 Temperature Distribution during solidification of Pure Water at different Times; Two walls Cooled; $\mathrm{Y}=88 \mathrm{~mm} ; \mathrm{T}_{\mathrm{L}}=-30{ }^{\circ} \mathrm{C} \& \mathrm{~T}_{\mathrm{R}}=-30^{\circ} \mathrm{C}$.

3.95 Temperature Distribution during solidification of Pure Water at different Positions; Two walls Cooled; $\mathrm{Y}=88 \mathrm{~mm} ; \mathrm{T}_{\mathrm{L}}=-30{ }^{\circ} \mathrm{C} \& \mathrm{~T}_{\mathrm{R}}=-30{ }^{\circ} \mathrm{C}$.

3.96 Temperature Distribution during solidification of Pure Water at different Positions; Two walls Cooled; $\mathrm{Y}=88 \mathrm{~mm} ; \mathrm{T}_{\mathrm{L}}=-30{ }^{\circ} \mathrm{C} \& \mathrm{~T}_{\mathrm{R}}=-30{ }^{\circ} \mathrm{C}$.

3.97 Schematic of the test enclosure and thermocouple positions (Rectangular Enclosure)

3.98 Effect of Volume of the Liquid on Volume of frozen ice for Trapezoidal Cavity

3.99 Effect of Volume of the Liquid Solidification Process for Trapezoidal Cavity

3.100 Comparison of Solidification Process among Trapezoidal and Rectangular Cavities.

3.101 Comparison of Convection Patterns among Trapezoidal and Rectangular Cavities for Pure Water; $T_{L}=-30{ }^{\circ} \mathrm{C} \& \mathrm{~T}_{R}=+20{ }^{\circ} \mathrm{C}$

3.102 Comparison of Convection Patterns among Trapezoidal and Rectangular Cavities at time $(\mathrm{t})=56$ minutes; $\mathrm{T}_{\mathrm{L}}=-30^{\circ} \mathrm{C} \& \mathrm{~T}_{\mathrm{R}}=+20^{\circ} \mathrm{C}$

3.103 Comparison of Temperature among Trapezoidal and Rectangular Cavities at $\mathrm{X}^{\prime}=0.1 \& \mathrm{Y}^{\prime}=0.32 ; \mathrm{T}_{\mathrm{L}}=-20{ }^{\circ} \mathrm{C} \& \mathrm{~T}_{\mathrm{R}}=+20{ }^{\circ} \mathrm{C}$

3.104 Comparison of Temperature among Trapezoidal and Rectangular Cavities at $\mathrm{X}^{\prime}=0.2 \& \mathrm{Y}^{\prime}=0.32 ; \mathrm{T}_{\mathrm{L}}=-20{ }^{\circ} \mathrm{C} \& \mathrm{~T}_{\mathrm{R}}=+20^{\circ} \mathrm{C}$

3.105 Comparison of Temperature among Trapezoidal and Rectangular Cavities at $\mathrm{X}^{\prime}=0.1 \& \mathrm{Y}^{\prime}=0.793 ; \mathrm{T}_{\mathrm{L}}=-20{ }^{\circ} \mathrm{C} \& \mathrm{~T}_{\mathrm{R}}=+20^{\circ} \mathrm{C}$

3.106 Comparison of Temperature among Trapezoidal and Rectangular Cavities at $\mathrm{X}^{\prime}=0.2 \& \mathrm{Y}^{\prime}=0.793 ; \mathrm{T}_{\mathrm{L}}=-20^{\circ} \mathrm{C} \& \mathrm{~T}_{\mathrm{R}}=+20^{\circ} \mathrm{C}$ 
DEFINITION

T Temperature

C Concentration

L Length

$\mathrm{t}$

R.I Refractive Index Value

V Volume

$V \quad$ Velocity

H Height (Y direction)

D Diameter

g Acceleration due to gravity

GREEK SYMBOLS

$\mu \quad$ dynamic viscosity

$\rho \quad$ density

$\theta \quad$ Angle

$\Delta \quad$ incremental time step

SUBSCRIPTS

e eutectic

b bottom

t top

h height
SIUNITS

Celsius

$w t \% \mathrm{NH}_{4} \mathrm{Cl}$

$\mathrm{cm}$

S

dimensionless

$\mathrm{ml}$

$\mathrm{m} / \mathrm{s}$

$\mathrm{cm}$

$\mathrm{cm}$

$\mathrm{m} / \mathrm{s}^{2}$

$\mathrm{kg} / \mathrm{m}-\mathrm{s}$

$\mathrm{kg} / \mathrm{m}^{3}$

degrees

$\mathrm{S}$ 


$\begin{array}{ll}\mathrm{d} & \text { depth } \\ \mathrm{p} & \text { particle } \\ \mathrm{s} & \text { seeding } \\ \mathrm{c} & \text { coolant } \\ \text { liq } & \text { liquidus } \\ \text { sol } & \text { solidus } \\ \mathrm{i} & \text { initial } \\ \mathrm{L} & \text { left } \\ \mathrm{R} & \text { right } \\ \mathrm{F} & \text { frozen } \\ \mathrm{T} & \text { total } \\ & \text { SUPERSCRIPTS } \\ 0 & \text { degrees }\end{array}$




\section{INTRODUCTION}

\subsection{Background and Motivation}

The process of solidification and melting were present at the beginning of earth and is known to man throughout the ages. These processes continue to affect the natural and industrial world and created the earth's crust and affect the dynamics of magmas and ice floes, which in turn affect the circulation of oceans and the pattern of climate and weather.

The solidification of liquid or the melting of the solid involves a complex interplay of many physical effects. Latent heat is liberated during phase transformation from active free boundary i.e., solid - liquid interface. One characteristic of many multicomponent solutions is that the solubility of a particular component may be different in the solid and liquid phases. Thus a component may be rejected or absorbed, thereby creating local compositional gradients adjacent to the phase change interface during solidification. These solutal gradients may coexist with temperature gradients, and in the presence of a gravitational field, cause solutal and thermal buoyancy forces, which may aid for oppose each other. This convective flow, produced by combined thermal and solutal buoyancy forces is known as thermosolutal convection or thermohaline convection or double diffusive convection.

The various applications such as in metallurgy, engineering, geophysics and other fields motivated for the research on the solidification of multicomponent systems. The phase change (liquid - solid transformation) of binary solutions occurs in a wide variety of engineering, environmental, and industrial processes. Environmental applications include the solidification of magma. The effects of thermosolutal convection have 
recently been used to explain compositional variations in magma chambers [Turner and Gustafson, 1981], and the formation of sea ice [Huppert and Tuner, 1980]. Material processing application relate to alloy casting, the solidification of ingots [Fisher, 1981; Viskanta, 1988], and growth of semiconductor materials [Ostrach, 1983; Kim and Brown, 1989]. The performance, quality and reliability of the casting are heavily dependent on their crystal structure and homogeneity. Recently the interest has risen in the use of Latent Heat Thermal Energy Storage (LHTES) devices [Viskanta, 1983], which have applications in the aerospace industries, electrical power and also in microelectronics.

As described above, applications involving thermosolutal convective flow are widespread. In order to control the manufacturing of products and explain certain natural occurrences, it is first necessary to understand and document the complex heat and mass transfer processes, which may significantly affect the solidification of multicomponent systems.

\subsection{Literature review}

A clear understanding of the physical transport on the system is needed inorder to predict numerically the occurrences during solidification and their affect on final castings. The physical understanding includes mass, momentum, energy and species transfer. Mathematical models that are date back in 1960's were implemented into numerical algorithms as the availability of digital computers have become prevalent and these models are modified and improving throughout years inorder to predict the final cast. Experimental data were used to modify the numerical models. Phase Interface motion, velocity and temperature gradients play a significant role in interface structure during solidification. Material quality and thermo physical properties of a solid are 
largely determined by the interface structure, shape and velocity of the solid liquid interface. This flourished research in the area of experimental simulations to study the effect of boundary and initial conditions on the frozen layer and moving interface. Since it's inception in the late 1930's and quite possibly earlier, transparent simulants have been used to study crystal growth. Because these transparent simulants were known to solidify in a cubic fashion as in most metals, they have since been widely implemented into physical systems for experimental simulations of solidification and melting of alloys. The need for experimental data was increased as the numerical simulations reached a point where micro scale occurrences hindered further development. This leads to solidification process in various geometries with different cooling configurations and initial and boundary conditions. Until now, all the previous simulations using transparent simulants were done in regular enclosures with either one wall or two walls cooled. The first known published research in numerical simulation in irregular chambers is made by Dong Z.F et al., (1994). This is the first known published research [Ghenai et al., 2004; Duggirala et al., 2004] in an irregular chamber using a transparent simulants to study the effect of initial and boundary conditions on double diffusive convection.

The following sections in this chapter will provide a comprehensive review of the previous works on phase change heat transfer, double diffusive convection, experimental and numerical works in both one dimensional and two dimensional studies.

\subsubsection{Phase Change Heat Transfer}

When the Rayleigh number of a liquid melt layer exceeds is critical value, natural convection in the liquid phase must be accounted for in the prediction of the solid-liquid 
boundary motion. The first attempt to describe mathematically the phase change problem including buoyancy forces was made by Tien and Yen (1966).

An experimental and analytical investigation of solid-liquid interface motion during freezing and melting from above as well as below was performed by Hale and Viskanta (1980) for several normal materials including stearic acid, sodium phosphate decahydrate, sodium sulfate decahydrate, and n-octadecane, which has be suggested as latent heat of fusion thermal energy storage materials by them.

In the freezing experiments, the material was initially in its liquid phase and was precooled to a uniform temperature just above the fusion temperature before solidification was started. The assumption of negligible phase change effect on convective heat transfer in the liquid region was made and the correlation was employed in the analysis.

The location of phase change interface is the difficult task in the phase change problems. The phase change heat transfer problem becomes non linear when the location of the interface must be determined as part of the solution. Only a few exact solutions exist, applicable only too certain one-dimensional cases. Most one dimensional phase change problems normally require numerical solution methods. Fukusako et al., (1987) have discussed the different methods both in numerical and analytical, available for solving phase change heat transfer problems. The phenomenon of natural convection, driven by a single buoyancy force during phase transformations has been studied extensively and is now well understood.

Before leaving this subsection, it should be mentioned that under certain circumstances the process of crust formation over a liquid layer may not be thermally 
stable. Laboratory observation of a water layer heated internally at high Rayleigh number and cooled to freezing from above, for example, found that for large internal heating and negative ambient temperature there were thermal oscillations in the system with ice forming and disappearing periodically. Using the boundary layer model the process of turbulent natural convection in the liquid layer and transient heat conduction in the crust layer were modeled. The conditions leading to periodic self sustained oscillations were identified and the oscillatory behavior of the system discusses. This interesting phenomenon was believed to exist in some geophysical and nuclear reactor systems.

\subsubsection{The Physics of Multicomponent Solidification}

The density of the mixture varies with both temperature and concentration during the casting of multicomponent systems. The density gradients induced thermally and solutally lead to natural convection. These gradients can occur on microscale (between dendritic arms) or on the macroscopic scale (in the bulk liquid). Solute lean fluid will be rejected from the mushy region for a hypereutectic concentrations and solute rich fluid will be rejected from the mushy region for a hypoeutectic concentrations while system reaching equilibrium. These species rejections will occurs perpendicular to heat flow usually between primary dendritic arms and is responsible for secondary arm growth during dendritic solidification. It is known that tertiary arm growth can quickly compensate for large primary arm spacing and grow from a secondary arm in the direction of the primary arms. The density of the fluid is significantly different from that of the region it is entering than it is rejected into the bulk liquid melt which resulting the strong solutally driven flow that can occur in the liquid melt. Depending on the 
hypereutectic or hypoeutectic conditions, the solutally driven flows may enhance or deplete thermal flow strengths and also affect local solidification rates.

The convective flow along with solid front progression is responsible for the macro segregation. Solutal layering and the formation of solutal plumes exits during alloy solidification as the mass diffusivity is much smaller than the thermal diffusivity in the melt. The progression of the solidus during columnar dendritic growth is reduced and the change in the solidification rates will occur due to solutal layering [Beckermann et al., 1988; DeZego et al., 1996]. Solutal plumes are known to be responsible for channel segregates of freckles [Copley et al., 1970; Sample et al., 1984]. Along the central line from the solute rich conditions in the local areas, these segregates are formed in $\mathrm{V}$ shaped pattern and are also termed as A - segregates [Flemings, 1974] which is formed from the interdendtritic flow during multicomponent solidification. The phase being rejected from the mushy region is compositionally lighter that the remaining bulk liquid. The rising fluid causes remelting in the mushy region prior to the existence of liquidus interface.

\subsubsection{Double Diffusive Convection}

The solidification of liquid or the melting of the solid involves a complex interplay of many physical effects. Latent heat is liberated during phase transformation from active free boundary i.e., solid - liquid interface. One characteristic of many multicomponent solutions is that the solubility of a particular component may be different in the solid and liquid phases. Thus a component may be rejected or absorbed, thereby creating local compositional gradients adjacent to the phase change interface during solidification. These solutal gradients may coexist with temperature gradients, and in the presence of a gravitational field, cause solutal and thermal buoyancy forces, which may aid for oppose 
each other. This convective flow, produced by combined thermal and solutal buoyancy forces is known as thermosolutal convection or thermohaline convection or double diffusive convection [Huppert, 1990; Huppert et al., 1984].

Studies of double - diffusive convection were first conducted in the oceanographic sciences, and emphasis was placed on the development of the linear stability theory for a simple salt stratified fluid heat from below. Much of the early work on solidification of multicomponent systems was conducted by researchers in the field of metallurgy and involved experimental studies of binary alloys such as $\mathrm{Al}-\mathrm{Cu}, \mathrm{Sb}-\mathrm{Pb}$, and $\mathrm{Sn}-\mathrm{Pb}$ [Cole and Bolling, 1965; Streat et al., 1974]. In general, these studies were limited to obtaining temperature data at a few preselected locations during the solidification of an alloy, and inspection (both microscopically and macroscopically) of the sample after solidification. Based on this information the researcher concluded that natural convection significantly affected the solidification of castings. Copley et al., (1970) studied the origin of freckles during one dimensional solidification of casting and ingots from below. They used aqueous $\mathrm{NH}_{4} \mathrm{Cl}$ solution as an analog to the $\mathrm{Ni}-\mathrm{Al}$ and $\mathrm{Ni}-\mathrm{Ta}$ systems. Based on visual observations of the solidification process, they concluded that freckling in unidirectionally solidified castings is caused by convective jets and that in binary alloys the location of the freckles is influenced by the shape and orientation of the two phase region. A review of the metallurgical applications of phase change heat transfer, including a discussion of solidification of binary and multicomponent alloys has been done by Viskanta (1988)

The various applications such as in metallurgy, engineering, geophysics and other fields motivated for the research on the solidification of multicomponent systems. The 
phase change (liquid - solid transformation) of binary solutions occurs in a wide variety of engineering, environmental, and industrial processes. Environmental applications include the solidification of magma. The effects of thermosolutal convection have recently been used to explain compositional variations in magma chambers [Turner and Gustafson, 1981], and the formation of sea ice [Huppert et al., 1980]. Material processing application relate to alloy casting, the solidification of ingots [Fisher, 1981], and growth of semiconductor materials [Ostrach, 1983; Kim et al., 1989]. The performance, quality and reliability of the casting are heavily dependent on their crystal structure and homogeneity. Recently the interest has risen in the use of Latent Heat Thermal Energy Storage (LHTES) devices [Viskanta, 1983], which have applications in the aerospace industries, electrical power and also in microelectronics.

As described above, applications involving thermosolutal convective flow are widespread. In order to control the manufacturing of products and explain certain natural occurrences, it is first necessary to understand and document the complex heat and mass transfer processes, which may significantly affect the solidification of multicomponent systems.

Various studies have been made on the solidification of binary mixtures using $\mathrm{NH}_{4} \mathrm{Cl}$ $\mathrm{H}_{2} \mathrm{O}, \mathrm{NaCl}-\mathrm{H}_{2} \mathrm{O}$ and $\mathrm{Na}_{2} \mathrm{CO}_{3}-\mathrm{H}_{2} \mathrm{O}$. In previous research, Beckermann et al., (1987) and Christenson et al., (1989 a \& b) have performed various studies on multiple-point measurements of temperature and concentration fields during solidification of an aqueous ammonium chloride solution. Nishimura et al., (1991) performed temperature and flow visualization using liquid crystals during solidification of an aqueous ammonium chloride solution in a rectangular chamber with lateral cooling in order to obtain detailed 
information on the development of double - diffusive convection during the solidification process. Temperature and concentration at several positions were simultaneously measured by thermocouples and by the sample extraction method using microsyringes. Nishimura et al., (1991) found that the concentration in each convective cell remained nearly constant, although the thickness of each cell increased, with the progression of solidification. Diffusion was dominant in the diffusive interface between the cells due to the solute field with a vertical concentration. Recently, Wang et al., (1999 a \& b) reported interesting phenomena that occurred during solidification of a low concentration of the binary mixture in a rectangular cavity. They showed that vortex flow occurred in the liquid region of the test rectangular cavity during the later stage of the solidification process. During the solidification process, this vortex flow changed the original flow direction (downward along the vertical frozen surfaces in the liquid region of the test chamber) to the opposite direction [Kowalewski et al., 1988] and experimental and numerical studies are reported on free convection of pure water during phase change in a differentially heated cavity [Giangi et al., 1990]. They have used new experimental techniques based on computational analysis of the color and displacement of thermochromic liquid crystal tracers to determine both the temperature and velocity fields of natural convection in freezing water. For both experimental and numerical studies, they have used only pure water, and no binary mixture has been investigated. Christenson and Incropera (1989) studied the solidification of $\mathrm{NH}_{4} \mathrm{Cl}-\mathrm{H}_{2} \mathrm{O}$ solution in a rectangular chamber with varying initial concentration and boundary conditions.

Measuring velocity using the conventional techniques is difficult because the solidification process is time - dependent and the magnitude of the velocity is small. This 
is especially true in casting systems. Since liquid metals are opaque, convective flow visualization is almost impossible. Moreover, most molten metals of commercial interest have higher melting temperatures, rendering them difficult to work with in the laboratory under controlled conditions. However, metal model material permits direct optical access into the material, leading to a direct observation of the thermal and concentration fields in real time by classical optical techniques based on a refractive index change of the material. Ammonium chloride $\left(\mathrm{NH}_{4} \mathrm{Cl}\right)$ is a material whose water solution can be used to model metal alloy solidification because it freezes, as does a molten metal of commercial interest. The flow visualization is achievable because an $\mathrm{NH}_{4} \mathrm{Cl}-\mathrm{H}_{2} \mathrm{O}$ solution is transparent.

The capability of an ammonium chloride-water system to simulate metallic systems physically has been established in previous experiments [Copley et al., 1969]. The solution is similar to liquid metal during solidification in terms of the dendritic growth of the solid phase [McCay et al., 1994; McCay et al., 1995]. The eutectic temperature and composition $\left(\mathrm{NH}_{4} \mathrm{Cl}\right.$ mass fraction) of aqueous ammonium chloride are $\mathrm{T}_{\mathrm{e}}=-15.4{ }^{\circ} \mathrm{C}$ and $\mathrm{C}_{\mathrm{e}}=19.8 \%$, respectively. A solution with a composition less than the eutectic value $(\mathrm{C}<$ $19.8 \%$ ) releases more dense fluid during solidification (sub-eutectic growth), while a solution with greater than the eutectic value $(C>19.8 \%)$ releases less dense fluid (supereutectic growth). Super-eutectic system compositions should provide excellent simulations of Al-Si casting alloys, and sub-eutectic and near-eutectic compositions should provide analogs for cast iron.

Based on the literature on double diffusive convection and solidification of binary mixtures, the experimental studies on double diffusive convection in irregular geometry 
has scarcely found. Therefore the experimental investigation of double diffusive convection in irregular geometry with the lateral thermal and solutal gradients imposed on the sidewall has been made.

\subsubsection{Experimental Investigation of Solidification in Binary Systems}

Because direct observation of the phase change process can not be readily observed in solidifying alloys, many researchers in the area of metallurgy have resorted to transparent simulants [Hunt et al., 1966; Copley et al., 1970]. Interest was focused on transparent systems that solidify like alloys (i.e., in a cellular or dendritic fashion).

\subsubsection{One Dimensional Studies}

Solutal rejection during the one dimensional solidification of aqueous sodium chloride solutions was studied experimentally by Terwilliger et al., (1970). The experimental conditions approximated a semi-infinite slab. Micro conductance probes were used to measure solute concentration. Solute redistribution was found to be controlled by the liquid phase interface concentration and thermal driving force.

Grange et al., (1976) studied experimentally and analytically, solute redistribution during one dimensional solidification of an aqueous sodium chloride solution in a rectangular cavity cooled from below. An interferometer was used to measure the liquid concentration at the solid liquid interface. An approximate analytical solution, which employed a heat balance integral and finite difference techniques was used to predict temperature and concentration distributions as well as the rate of phase change. The predicted values agreed well with experimental data. They found that the common assumption of constant solute distribution within semi infinite domains is not valid for freezing in a region of finite thickness. 
The one dimensional solidification of aqueous sodium chloride solutions in cells was studied analytically and experimentally by Hayashi et al., (1979). An approximation using apparent heat capacity involving the latent heat of fusion in the solid-liquid region and Neumann's exact solution for a semi-infinite body with phase change was used to predict temperature profiled and the position of the phase change front. Solute rejection as found to cause constitutional super cooling of the liquid, however no concentration data was presented.

Kober et al., (1983) studied experimentally, the one dimensional freezing of an aqueous sodium permanganate solution. Concentration data was obtained using a microscope spectrometer. Concentration distributions were found to vary with both time and interface velocity. Concentration profiles and interface positions predicted by a diffusion based mathematical model were found to agree well with experimental measurements during initial transience.

The solidification of aqueous sodium chloride solutions on a sub cooled ice slab was studied experimentally and numerically by Fang et al., (1984). The Temperature of the ice slab was above the eutectic temperature during experimental, and therefore a pure solid region was not formed; only the two phase region and liquid region were present. As the solution was cooled from below, the liquid was hydrodynamically stable and convection was absent. A set of similarity equations were solved using a Runge - Kutta method; a cubic spline interpolation scheme was employed to approximate the liquidus from the phase diagram and thereby determine values of concentration based on predicted temperature. Predicted and measured values of temperature, concentration, and the growth of the mush were found to agree well. 
Huppert et al., (1985) studied, experimentally and analytically, the onedimensional solidification of $\mathrm{Na}_{2} \mathrm{CO}_{3}$ solutions cooled from below. A similarity solution which assumed that diffusion governs heat transfer in both the mush and liquid regions was used; in addition, solute diffusion was not considered in the model. Predicted values of temperature and concentration were found to agree "reasonably well" with experimental results.

Wollhover et al., (1985) studied numerically, the solidification of aqueous sodium chloride solutions contained between two vertical walls extending from each wall were assumed to be vertically planar. Similar to Fang et al., (1984) a function was used to approximate the liquidus; conditions of local thermodynamic equilibrium were assumed in order to couple heat and mass. Solute transport was assumed to be by diffusion only. An iterative technique was used to solve a set of three coupled partial differential equations. Based on the results of the study, the authors questioned the assumptions that the phase change interface remains planar.

The one dimensional freezing of aqueous solutions of isopropanol and sodium sulphate has been studied experimentally and numerically by Kerr et al., (1989). In addition to the solid and mush formed adjacent to the cold top surface, secondary crystallization was observed on the insulated bottom surface. Nonlinear diffusion equations were solved numerically, neglecting solute diffusion and convection. Agreement between predicted and measured values for the growth of the mushy layer, the cooling rate, and solute concentration was good.

The solidification of aqueous sodium chloride and ammonium chloride solutions on the top of a horizontal surface in the absence of convection was studied 
experimentally and analytically by Braga et al., (1990). Similar to previous workers, a set of similarity equations was solved using an iterative scheme, and heat and mass diffusion were coupled by assuming local thermodynamic equilibrium; a third degree polynomial obtained by a least squares fit was used to approximate the temperature-concentration relationship specified by the phase diagram (the liquidus). They considered the liquid region as a semi infinite medium. Good agreement was obtained between the measured and predicted values. They found that concentration was as significant as initial and wall temperatures in affecting the growth of the mushy region.

Cao et al., (1990) have studied experimentally, the one dimensional solidification of aqueous ammonium chloride solutions in a rectangular cavity cooled from above. They observed a sizeable mushy region. The temperature distribution in this region was found to be linear, indicating that conduction is dominant mode of heat transfer in the mush. Salt fingers were observed at the solid liquid interface for high concentration solutions. Photograph of the solidification process are presented, however no concentration data was reported.

\subsubsection{Two Dimensional Studies}

Szekely et al., (1978) studied experimentally and numerically, two dimensional solidification of the aqueous ammonium chloride system on one vertical wall of a rectangular cavity. They used an energy balance approach and the laminar Navier-Strokes equations, for both the liquid and two phase region to model the solidification process. Predicted temperature and velocity profiles were found to be in good agreement with experimentally measured values. However, solutal convection was not included in the model and concentration data (experimental or numerical) was not reported. 
A set of microscopic equations based on the continuum approach for binary solidliquid phase change problems were developed by Bennon et al., (1897 a). These equations were obtained by integrating semi-empirical laws and descriptions of classical mixture theory. This methodology was used to model the two dimensional solidification of aqueous ammonium chloride solutions on a vertical wall of a rectangular cavity (1987 b). They found that macroscopic solute redistribution significantly affected the solidification process. Also, the interaction of thermal and solutal buoyancy forces was strongly influenced by external boundary conditions. However, the numerical results were not compared to experimental data due to the paucity of such data for the solidification of binary systems.

The solidification of sodium chloride solutions on a vertical wall of a rectangular cavity was investigated experimentally by Chellaiah et al., (1987). They found that natural convection, driven by combined thermal ad solutal buoyancy forces, significantly affected the shape of the fusion front. Flow visualization was performed using a tracer derived from fish scales and by passing a sheet of light (laser) through the liquid. Solute rejected at the fusion front was found to accumulate at the bottom of the test cell forming a solutally stratified region where convection was absent. However, concentration measurements were not reported.

An experimental study of the solidification of aqueous ammonium chloride solutions on one vertical wall of a rectangular enclosure was performed by Beckermann et al., (1988). The phase change and convection processes were studied by shadowgraph and flow visualization techniques as well as temperature and concentration measurements. A variety of double diffusive convection phenomena, such as plumes and 
solute layers, were observed in the liquid. The progress of solidification was found to be significantly affected by convection.

An experimental and numerical study of the solidification of an aqueous ammonium chloride solution on a vertical wall of a rectangular cavity was conducted by Christenson et al., (1989 a) and Christenson, et al., (1989 b). An elliptic, control volume based finite difference scheme was used to solve continuum equations governing mass, momentum, energy and species. Solutions of varying initial concentration were studied. They found that a slight change in initial (i.e., 1\%) significantly affected the accuracy of the model.

Leitch (1989) has reported an experimental and numerical study of the solidification of aqueous sodium carbonate solutions in a semi infinite liquid and in a rectangular enclosure. The solidification process was modeled based on short term, transitional, long term behavior. Separate sets of second order nonlinear equations were solved for each time period, using a predictor-corrector method with starting values provided by a fourth order Runge - Kutta scheme. The model employed was one dimensional and therefore assumed that the phase change interface during solidification on a vertical wall was planar; it was further assumed that properties in the liquid did not vary with height. Predicted values of temperature, concentration an solid thickness were found to be in agreement with experimental data.

Chellaiah et al., (1991) have reported an experimental study of the solidification of aqueous sodium chloride solution in a rectangular cavity with solidification initiated on a vertical wall. The effect of initial superheat and concentration on the solidification process was reported. These effects were found to be significant. Temperature 
distributions through out the solid, mush and liquid regions were reported as well as transient concentration distributions at the bottom of the cavity.

Zampino et al., (1991 a) studied experimentally, the effect of initial concentration on the two dimensional solidification of aqueous sodium chloride solutions on one vertical wall of a rectangular cavity. In addition to the solid and mush, two distinct liquid regions were observed. An upper region where convection was present and the solution concentration did not increase or decrease from the initial concentration, and a lower solute rich region. Solute concentrations at various locations in the liquid were reported. The maximum increase in solute concentration in this lower region was observed for the low $(5 \%)$ rather than high $(20 \%)$ concentration experiment. Initial concentration was also found to significantly affect the morphology.

Zampino et al., (1991 b) also studied the effects of cold wall temperature and initial superheat for the water sodium chloride system. The geometry was the same as for their previous study (1991 a). They found that although the volume fraction increased for lower cold wall temperatures, concentration and temperature distributions in the liquid region were not significantly affected. Further, the height of the lower solute rich region was not strongly affected by the cold wall temperature. In contrast, the initial superheat was found to significantly affect temperature and concentration distributions, as well as the height of the solute rich region in the liquid region.

\subsection{Objectives of the Current Research}

Experimental studies are essential and can provide valuable information for further development of the previous models which cannot fully describe solidification 
process at this time. Transparent analogue solutions are used as an acceptable substitution due to their semi transparency and micro structure growth similar to that of most metals. The study of double diffusive convection in a trapezoidal enclosure with the lateral thermal and solutal gradients imposed on the sidewalls is investigated in this current study. Many researchers have studied in the process using analogue solution to study the effects of morphology growth and flow patterns that develop in static enclosures.

Until now double diffusive convection in irregular geometries has scarcely been investigated experimentally or numerically. Basic understanding of double diffusive convection in the irregular geometries such as trapezoidal chambers is absent. The numerical investigation on these irregular chambers has done by Dong et al., (1994). A laboratory scale trapezoidal enclosure will be constructed using analogue solutions to more accurately depict the solidification process of metal analogue. It is also the intent to use both quantitative and qualitative techniques to measure thermally and solutally induced flow fields in the liquid pool which is the basis for understanding double diffusive convection.

Studies of eutectic, hypoeutectic and hypereutectic initial concentrations along with varying initial boundary conditions and for various concentrations will be performed. These techniques will provide in-depth analysis of the effects of double diffusive phenomenon occurring in the critical liquid region during continuous casting.

The objectives of this study are the effect of initial concentration and initial boundary conditions on the frozen layer thickness, moving interface velocity, temperature distribution and thermo-solutal convection in the liquid pool. 
The specific objectives of this research work are to:

(i) Design and Construct a test enclosure for analogue binary solutions.

(ii) Implement a unique method for flow visualization

a. Adjust the height between the laser and the test section inorder to get a nice a light sheet.

b. Make the light sheet thin enough to get a nice visualization.

(iii) Perform experimental simulations to demonstrate the effect of initial concentration and boundary conditions on melt convection, frozen layer thickness, moving interface velocity.

(iv) Determine how frozen layer thickness and moving interface velocity is affected by the test enclosure.

(v) Develop a bench mark for the numerical study and also to construct a control system which explains the effect of initial concentration and initial boundary conditions on the solidification process in a trapezoidal cavity.

\subsection{EXPERIMENTAL SETUP}

\subsection{Experimental Apparatus}

A schematic of the experimental system is shown in Figure 2.1. The system consists of the following subsystems: laser source, test section, cooling systems, PIV processor and data acquisition system.

\subsubsection{Test Enclosure}

The schematic diagram of the test enclosure used in this experimental study is shown in Figure 2.2. A trapezoidal cavity has been used. The cavity measures $65 \mathrm{~mm}$ and $165 \mathrm{~mm}$ at bottom $\left(L_{b}\right)$ and top $\left(L_{t}\right)$ respectively, $130 \mathrm{~mm}$ in height $\left(L_{h}\right)$, and $150 \mathrm{~mm}$ in 
depth $\left(L_{d}\right)$. The depth is sufficiently large to render the three-dimensional effects negligible. The aspect ratio was $2\left(\mathrm{~L}_{h} / \mathrm{L}_{b}\right)$. The inclined walls are made of copper plates in which circulating coolant channel were drawn through with coolant is passed and make the walls cooled to the required temperatures. The front and back walls are made of Plexiglas ( 0.5 in. of thickness). High-quality Plexiglas was used in the front of the chamber to allow the acquisition of good PIV images.

The upper portion of the chamber is covered with Plexiglas coated with black paint (to reduce the reflections from the laser), and it has small slit. Slit is used to illuminate the flow region by laser sheet.

Copper heat exchangers with milled serpentine countercurrent channels constituted the two inclined walls. Silicon II was used to provide a water tight seal between the heat exchangers and the Plexiglas side walls. Copper Constantan (Type T) thermocouples embedded in the heat exchangers at various locations, monitored their temperature throughout the experiments. The two inclined walls of the test enclosure are cooled with two different chillers, (1) NESLAB HX-540 endocal recirculating chiller and (2) NESLAB ULT-90 recirculating chiller; both the chillers use the ethylene glycol as the cooling medium.

Figure 2.3 shows the distribution of the thermocouples to measure the temperature inside the cavity. The temperature readings in side the cavity is being recorded using LabView based data acquisition system. Measured values of the temperature are saved onto a PC hard drive for further use. $10 \mathrm{E}$ type thermocouples were used to measure the temperature on the inclined walls and $22 \mathrm{~T}$ type thermocouples were used to measure the temperature distribution inside the test cavity. The rake was positioned at two vertical 
locations within the test chamber, corresponding to elevations of $\mathrm{h}=37 \mathrm{~mm}$ and $87 \mathrm{~mm}$ from the bottom of the chamber to measure the temperature distribution at the bottom of the chamber and also at the top of the chamber where the liquid is in contact with the air. A thermocouple grid was affixed to the back side wall of the cavity. Holes, approximately 3 millimeters in diameter, were drilled in the plate to allow for placement of thermocouple immersion probes. The deviation of temperature with the position of the grid is observed to be negligible. If the grid is placed near the cross section where light sheet is focused, it may disturb the flow. So the grid is placed at $65 \mathrm{~mm}$ from the light sheet.

The test cell was insulated with 50 millimeter thick Styrofoam on all sides to prevent heat gain from the ambience. A Plexiglas with a slit of 1 millimeter at the center is used to cover the top of the chamber. The Plexiglas is coated with black color to avoid the reflections from the other sources and inorder to get a good visualization. 


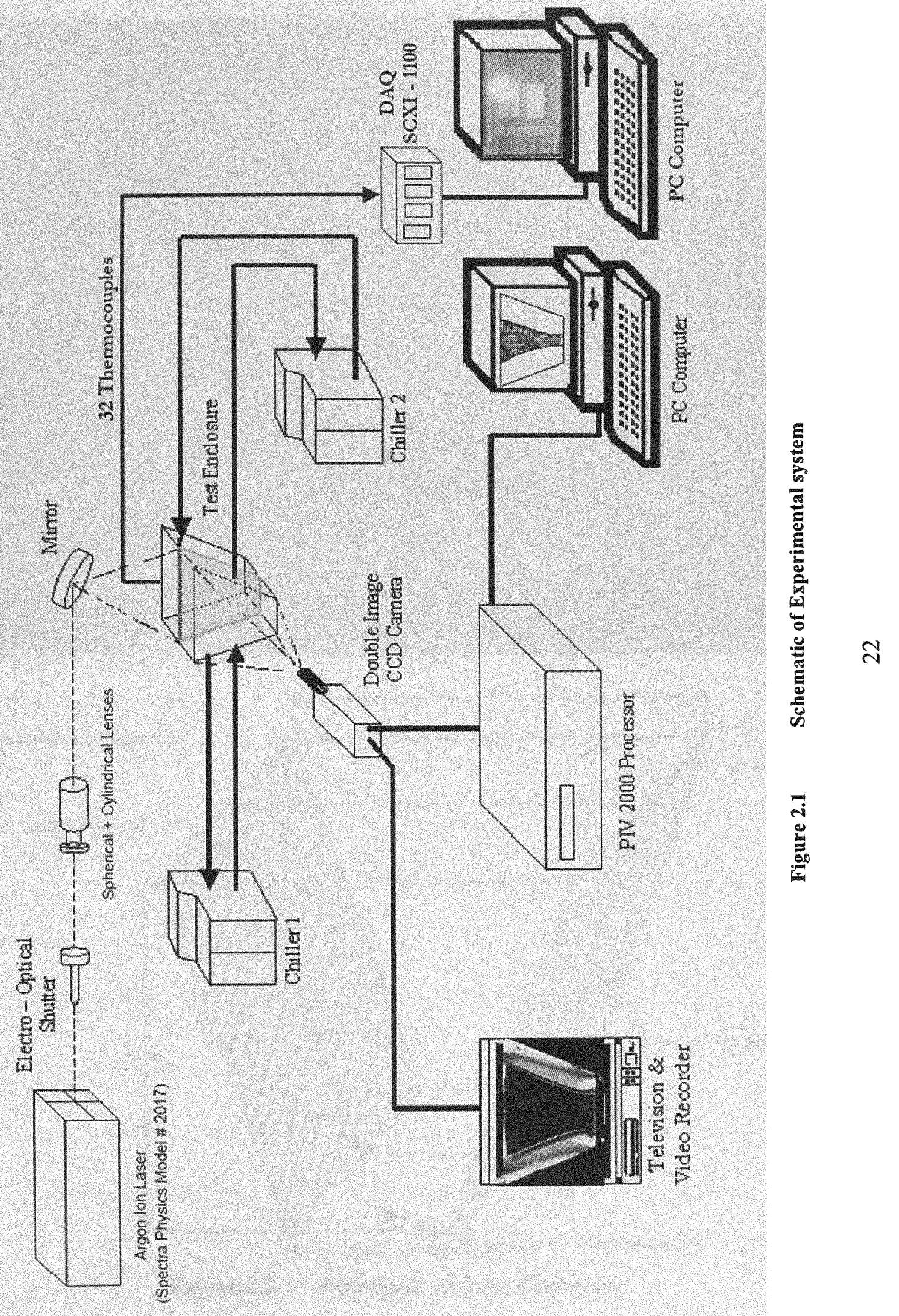



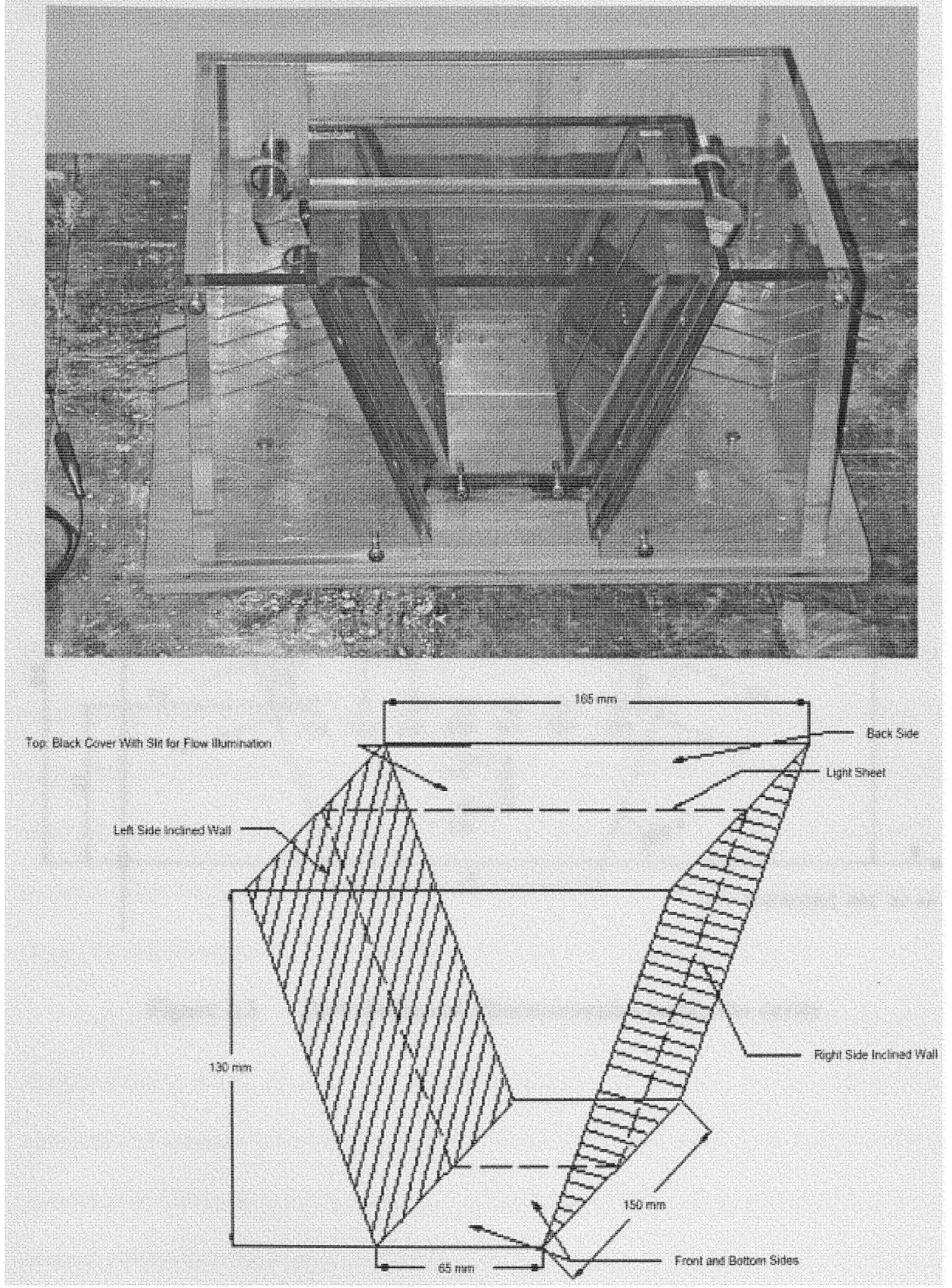

Figure 2.2 Schematic of Test Enclosure 


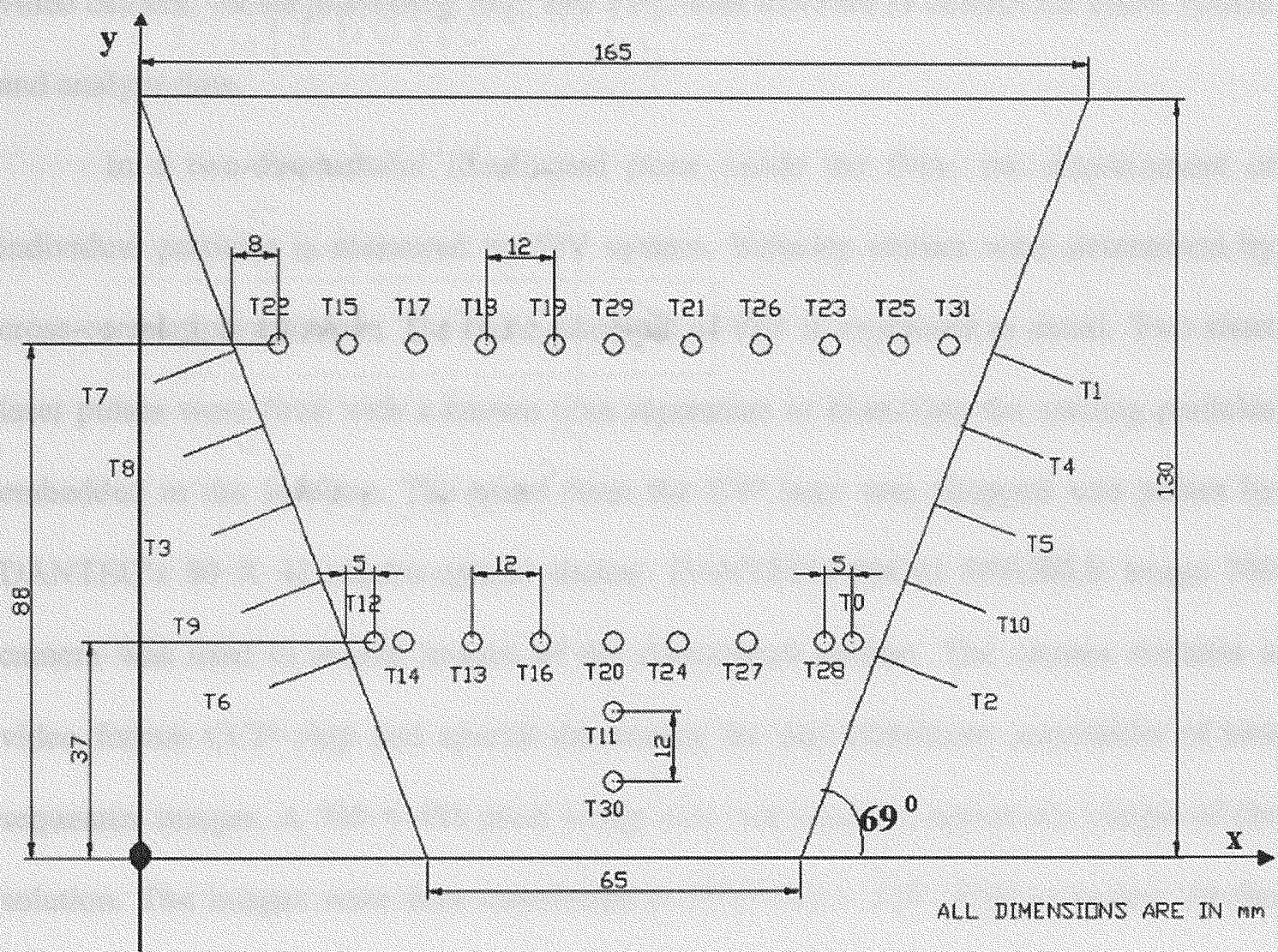

Figure 2.3 Distribution of Thermocouples inside the cavity 


\subsubsection{Flow Visualization System}

Particle Image Velocimetry (PIV) technique is used to obtain velocity vector plots containing both velocity magnitude and direction for whole visualized flow field with high accuracy and high resolution. The PIV system consists of an illumination system, video camera, vector processing unit, and a $\mathrm{PC}$ with software to control the entire system and analyze data.

In a two-dimensional illuminated plane inside the flow, the displacement of individual particles is measured by PIV system. Velocity vectors were determined by cross-correlation principle. The basic principle of PIV is explained in detail. Two short laser pulses were fired with a known time separation to illuminate the seeding particles embedded in the solution. The beam from the CW laser was chopped into pulses by DANTEC's 80 X 41 electro-optical shutter. DANTEC's 80C42 DOUBLE Image 700 camera was used to record images of the illuminated section. The camera contains a video format $\mathrm{CCD}$ chip and special electronics for fast interframe acquisition of two sequential images. A $768 \times 484$ pixel image size was used to capture the images of the solution. The images were then transferred to DANTEC's PIV 2000 processor via the digital connector and to a host computer for the data processing and analysis.

First, the camera was focused to ensure that there was sufficient illumination energy density to see images of the seeding particles. Then the seeding density was optimized to examine whether there was sufficient seeding to obtain good quality results consistently. Once good seeding density had been established, other data acquisition and control parameters were then optimized. The time between pulses and the duration of 
each pulse were set, respectively, to $6000 \mu \mathrm{s}$ and $3000 \mu \mathrm{s}$. The processing technique used in this study was a cross-correlation method. Two sequential images maps were subsampled to get the velocity vectors. The resolution of the sub-sampling or the interrogation window area was $32 \times 32$ pixels. The "No-DC" filter was used in this study to remove the light reaching the camera through multiple particle reflections and background light in general, which consequently improves the signal-to-noise ratio. This filter also reduced the effect of the variation of the background light within an integration area or other low frequency distortions from optics and camera on the peak detection and sub-pixel interpolation procedures. The overlaps of the interrogation area in the horizontal and vertical directions were, respectively, $50 \%$ and $50 \%$. Overlapping interrogation areas increased the chance that all particle pairs were completely within at least one interrogation area. For peak detection and sub-pixel interpolation, parabolic interpolation of the Gaussian curve was used.

Seeding particles also have to be neutrally buoyant in the liquid under current investigation. Their settling velocities have to be much smaller than the fluid velocity of the flow field. In the present study, Polyamide seeding particles were used. These particles have a mean particle diameter of 20 microns and a density of $1.03 \mathrm{~g} / \mathrm{cm}^{3}$. The settling velocity of the particle in the solution was calculated using the formula given below.

$$
V_{s}=\frac{g \times\left(\rho_{p}-\rho\right) \times D_{p}^{2}}{18 \mu}
$$


Where $\rho_{p}$ is particle density, $D_{p}$ is particle diameter, $\rho$ is density of the solution, $\mu$ is dynamic viscosity of the solution, and $g$ is the acceleration due to gravity $\left(9.81 \mathrm{~m} / \mathrm{sec}^{2}\right)$. The calculated settling velocity was $2.3 \times 10^{-6} \mathrm{~m} / \mathrm{sec}$. The average flow velocity determined from the experimental observation was approximately $10^{-3} \mathrm{~m} / \mathrm{sec}$. Thus, these seeding particles are suitable because the flow velocity is considerably higher than the particle settling velocity.

The PIV does not actually measure the velocity of fluid but, instead, the velocity of particles suspended in the fluid. In this respect, these seeding particles can be considered as probes, and thus seeding conditions are important in the PIV. The particles must be small enough to track the fluid flow accurately. Otherwise, the particle size can affect the convection flow in the chamber.

The settings for the PIV software called Flow Manager are as follows

\section{SETUP Settings}

Camera: 80C42 Double Image 700/Type 8; Laser: Continuous Wave ACQUISITION CONTROL Settings

Time between Pulses

Light Pulses Per Recording

Duration of Each Pulse

Time between Recordings

Time between Bursts

Number of recording per burst

Number of bursts

IMAGE MAP Settings
$6000 \mu \mathrm{s}$

2

$3000 \mu \mathrm{s}$

$1000 \mathrm{~ms}$

$1000 \mathrm{~ms}$

1

1 
Image Width: $\quad 768$ Pixels $\quad$ Height: 484 Pixels

Offset, Horizontal: $\quad 0$ Pixels $\quad$ Vertical: $\quad 0$ Pixels

CROSS CORRELATION Settings

Image Width: $\quad 768$ Pixels $\quad$ Height: 484 Pixels

Offset: Horizontal: 0 Pixels Vertical: 0 Pixels

Interrogation area: Horizontal: 32 Pixels Vertical: 32 Pixels

Overlap: $\quad$ Horizontal: $\quad \mathbf{5 0} \% \quad$ Vertical: $\quad \mathbf{5 0} \%$

Number of Vectors: $47 \times 29=1363$

The settings shown above are chosen depending on the low velocity. As the flow in side the cavity during the solidification process is slow the time between pulses and the time between recordings and the bursts were chosen higher values. If the flow is fast the values chosen should be small enough to get the accurate velocities.

\subsubsection{Instrumentation}

Temperature data were continuously collected every 5 seconds by National Instruments data acquisition system and a PC from 32 thermocouples (10 T Type and 22 E Type). Since the thermocouples were mounted in the rear face of the cavity, the $3 D$ effects are negligible. A computer algorithm using LABVIEW was developed to take the temperature data from 32 thermocouples and separate those in the region of interest. These separated data were used to produce isothermal contour plot.

Inorder to reduce the error in preparing the required concentration, refractive index measurements were performed by using refractrometer. Four samples of the solution are taken and the refractive index is measured. The averages of these refractive indices along 
with the temperature were used to calculate the concentration of the solution using the data shown in Table 2.1. (Obtained from the Hand Book of Chemistry).

Table 2.1. Refractive Index Data for $\mathrm{NH}_{4} \mathrm{Cl}-\mathrm{H}_{2} \mathrm{O}$

\begin{tabular}{|c|c|c|c|c|c|c|c|c|c|}
\hline Conc & 0.5 & 1 & 2 & 3 & 4 & 5 & 6 & 7 & 8 \\
\hline R.I & 1.334 & 1.3349 & 1.3369 & 1.3388 & 1.3407 & 1.3426 & 1.3445 & 1.3464 & 1.3483 \\
\hline Conc & 9 & 10 & 12 & 14 & 16 & 18 & 20 & 22 & 24 \\
\hline R.I & 1.3502 & 1.3521 & 1.3559 & 1.3596 & 1.3634 & 1.3671 & 1.3708 & 1.3745 & 1.3782 \\
\hline
\end{tabular}

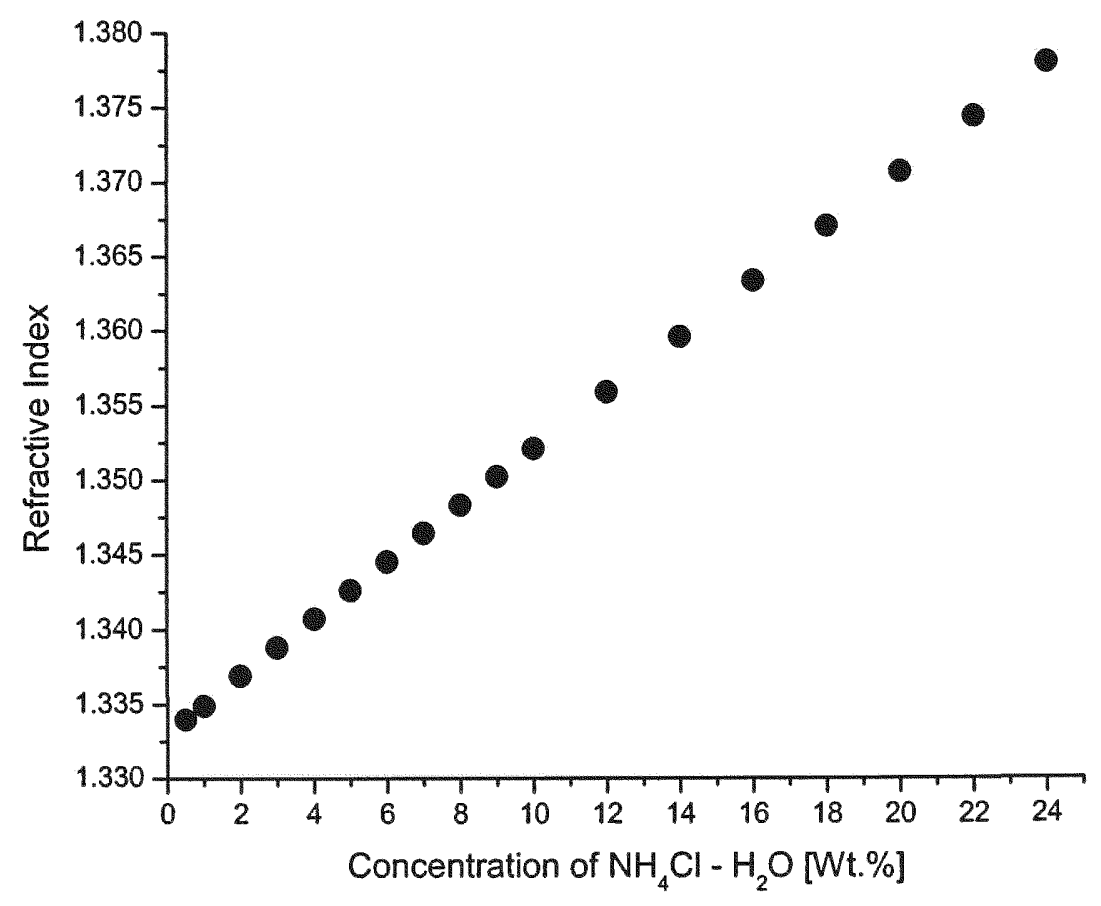

Figure 2.4 Refractive Index Vs Concentration 


\subsubsection{Cooling Systems}

The cooling system of the experimental setup consisted of two chillers. Each of the chillers is used to cool the each inclined side walls. Left side inclined wall is cooled using NESLAB HX-540 with a maximum heat rejection of $7500 \mathrm{~W}$. Right side inclined wall is cooled using NESLAB ULT-80 with a $600 \mathrm{~W}$ maximum heat rejection and $350 \mathrm{~W}$ at $-45{ }^{\circ} \mathrm{C}$. Both were run through parallel copper coiled heat exchanger immersed in the secondary coolant reservoir.

The secondary coolant is Ethylene Glycol and water mixed at a ratio of $50 \%$ by volume. The coolant is transported on to the copper side walls of the test cavity. Thermocouples were used to monitor the coolant temperature where $\mathrm{T}_{\mathrm{C}}=-30{ }^{\circ} \mathrm{C}$ is the minimum temperature sustained. After the viscous coolant stream is uniformly deposited on the cavity side walls, it is then collected into the reservoir where it is re-cooled and circulated through the system.

\subsubsection{Phase Change Material}

The experiments in this study are conducted using Ammonium chloride $\left(\mathrm{NH}_{4} \mathrm{Cl}\right)$ in water $\left(\mathrm{H}_{2} \mathrm{O}\right)$ as a binary phase change material. The solution is semitransparent, which facilitates the possibility of flow visualization. Experiments conducted in the past established the capability of ammonium chloride - water system to physically simulate metallic systems. Hyper-eutectic compositions of the system should provide excellent simulation of Al-Si casting alloys which solidify in pro eutectic and eutectic steps. Hypoeutectic and near eutectic compositions provide an analog for cast-iron, with ice playing a similar role analogous to graphite in reducing, eliminating or even producing negative shrinkage [Metal Analog Systems, NASA Literature]. The availability of thermal- 
physical property data facilitates the CFD numerical simulation as well. The equilibrium phase diagram for the ammonium chloride-water system is shown in Figure 2.5. Corresponding eutectic temperature $\left(\mathrm{T}_{\mathrm{e}}\right)$ and eutectic concentration $\left(\mathrm{C}_{\mathrm{e}}\right)$, based on wt\% $\mathrm{NH}_{4} \mathrm{Cl}$, can be seen to be $-15.4{ }^{\circ} \mathrm{C}$ and $19.8 \%$ respectively. According to this phase diagram, when a liquid mixture of concentration less than about $\mathrm{C}=19.8 \%$ is cooled at static conditions below the temperature of the liquidus curve, ice grows from the liquid mixture creating a mixed phase region (ice + liquid mixture). The last liquid to solidify forms a eutectic solid mixture of ice and ammonium chloride. On the other hand, if the temperature of a mixture of concentration greater than approximately $\mathrm{C}=19.8 \%$ is lowered below liquidus temperature; ammonium chloride grows from the liquid.

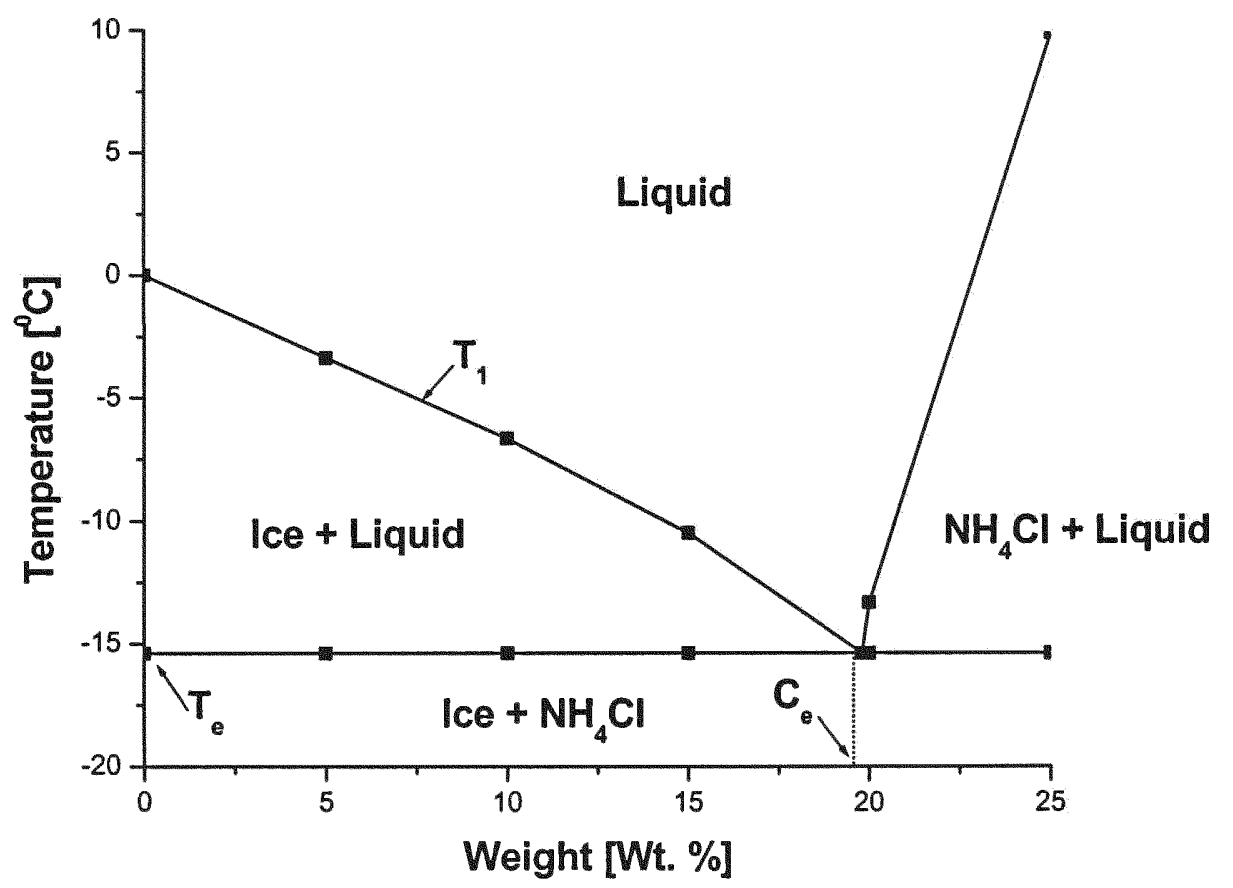

Figure 2.5 Equilibrium Phase Diagram for the binary $\mathrm{NH}_{4} \mathrm{Cl}-\mathrm{H}_{2} \mathrm{O}$ system $\left(\mathrm{T}_{\mathrm{e}}=-15.4^{\circ} \mathrm{C}, \mathrm{C}_{\mathrm{e}}=19.8 \%\right)$ 


\subsection{Experimental Procedures}

A solution with desired composition was prepared by mixing the corresponding amounts of ammonium chloride and deionized distilled water at the beginning of the experiments. $\mathrm{NH}_{4} \mathrm{Cl}$ has an extremely corrosive nature, and special care had to be taken with all experimental equipment that came into contact with it. The $\mathrm{NH}_{4} \mathrm{Cl}$ was slowly mixed into the water by means of a magnetic stirrer/hotplate. In order to minimize error in concentration measurement, refractive index test is performed with four samples of solution and is compared with the data showed in section 2.1.3. The total volume of the solution was kept the same $(1800 \mathrm{ml})$ for all concentrations. While the solution was prepared, the circulating bath was brought to the required cooling temperature. After the temperature of the coolant was established, the coolant circulation through the test chamber wall was started. For the one cooled side, the left side of the cavity was cooled to the desired temperature $\left(-30{ }^{\circ} \mathrm{C},-20{ }^{\circ} \mathrm{C}\right.$, or $\left.-10{ }^{\circ} \mathrm{C}\right)$ and the right side of the cavity was kept constant at $+20{ }^{\circ} \mathrm{C}$. For the two cooled sides, the left and right sides of the cavity were cooled simultaneously to the desired temperature. The solution at temperature $20{ }^{\circ} \mathrm{C}$ was then poured into the cavity and the solidification process started. A few seconds elapsed until equilibrium was reached and data acquisition was started. The LabView data acquisition system and the PIV Flow Manager started recording the data simultaneously. The LabView data acquisition system was turned on to record the temperature profile continuously. DANTEC's Flow Manager Software was used to capture the image maps and to determine the velocity fields during the course of the solidification process. The image maps, the velocity fields were taken for every eight minutes during 128 minutes of the solidification process. Every experiment was 
performed in the same way for all cases tested in this study. Operating conditions such as ambient air temperature in and out of the experimental facility, coolant temperature flow rate and solution flow rate were continuously monitored to ensure repeatable experiments.

\subsection{Experimental Uncertainty}

There are three types of PIV errors: acquisition, processing, and analysis errors. Typical PIV acquisition errors include $0.3 \%$ due to the deviation of the light sheet from flatness, $0.2 \%$ from the illumination interval, $0.3 \%$ from image magnification, $0.3 \%$ from image distortion, $0.1 \%$ from illumination plane thickness, and $0.1 \%$ from seeding particles not following the flow. For correlation errors in PIV processing, because PIV is based on the statistical correlation of imaged subregions to determine local flow velocities, processing is subject to inherent errors that arise from finite tracer particle numbers, sample volume size, and image resolution. The correlation error from PIV processing is about $1 \%$. The analysis errors are composed of random and systematic errors that depend on velocity gradients present in the flow.

The random errors are between $0.3 \%$ and $0.5 \%$ due to uncertainty in location of the center of the correlation peak because of the random sampling of the particles in the interrogation area. The systematic error associated with the displacement gradients tends to bias the average displacement measurement toward the lower displacements. By careful control of the experimental parameters, the systematic errors can be kept small, to within $1 \%$. From all these errors, the overall error on PIV data is estimated to be less than $3 \%$. 
The standard limit of uncertainty of type $\mathrm{E}$ thermocouples is $\pm 1.7^{\circ} \mathrm{C}$, while the reference junctions in the multiplexes have an uncertainty of $\pm 0.3{ }^{\circ} \mathrm{C}$. The thermocouple time response of $<50 \mathrm{~ms}$ was well below the time required for a change in temperature of $1{ }^{\circ} \mathrm{C}$ at a specific location in the cavity. Uncertainty of the location of the thermocouple with respect to the other in the cavity was determined to be $\pm 0.5 \mathrm{~mm}$. in $\mathrm{x}, \mathrm{y}$ and $\mathrm{z}$ directions. The uncertainty in preparing the solution of desired concentration was determined to be $0.5-0.9 \%$. The uncertainty in measuring the frozen layer thickness measurements is $5 \%$. The temperature readings throughout the cross section were obtained from interpolation/extrapolation of the reading from the thermocouples at specified locations using software called ORIGIN 6.1. It was observed that the maximum uncertainty in this interpolation/extrapolation was $<2{ }^{\circ} \mathrm{C}$. 


\subsection{RESULTS AND DISCUSSION}

\subsection{Experimental Conditions Performed in the Study}

In this study, three experimental conditions are varied:

1) Left side Inclined Wall Temperature $\left[\mathrm{T}_{\mathrm{L}}\right]$

2) Right side Inclined Wall Temperature $\left[T_{R}\right]$

3) Initial Concentration of the Solution $\left[\mathrm{C}_{\mathrm{i}}\right]$

The effect on solidification process due to the variation of these experimental conditions will be examined, part of the results were previously reported by Ghenai et al. (2004), Duggirala et al. (2004). However in this study the effect of each experimental condition was studied separately, e.g. left side inclined wall temperature is varied keeping the initial concentration and the right side inclined wall temperature constant. The effect of the right side wall temperature on the solidification process is studied only for pure water.

In this thesis, the discussion is intended to integrate the single parameter results previously reported and to examine the combined effects of

1) Initial boundary Conditions

2) Initial Concentration of the Solution.

To meet this objective, an experimental matrix of 22 experiments, shown in table 3.1 , was performed. Solidification process for hypereutectic mixture of $\mathrm{NH}_{4} \mathrm{Cl}-\mathrm{H}_{2} \mathrm{O}(22 \mathrm{wt}$. $\%)$ is observed. But the results obtained are not good to measure the velocity, frozen layer thickness and moving interface velocity. So those data were not discussed in this study. 
Table 3.1 Experimental Conditions [a]

\begin{tabular}{|c|c|c|c|c|c|}
\hline Exp & Name & Solution & $\begin{array}{c}\text { Conc. of } \\
\mathrm{NH}_{4} \mathrm{Cl} \\
\mathrm{C}_{\mathrm{i}} \\
{[\mathrm{Wt} . \%]}\end{array}$ & $\begin{array}{l}\text { Left Side } \\
\text { Temp } \\
\mathrm{T}_{\mathrm{L}}\left[{ }^{0} \mathrm{C}\right]\end{array}$ & $\begin{array}{c}\text { Right Side } \\
\text { Temp } \\
\mathrm{T}_{\mathrm{R}}\left[{ }^{0} \mathrm{C}\right]\end{array}$ \\
\hline 1 & WAT30 & $\mathrm{NH}_{4} \mathrm{Cl}-\mathrm{H}_{2} \mathrm{O}$ & 0 & -30 & +20 \\
\hline 2 & WAT20 & $\mathrm{NH}_{4} \mathrm{Cl}-\mathrm{H}_{2} \mathrm{O}$ & 0 & -20 & +20 \\
\hline 3 & WAT10 & $\mathrm{NH}_{4} \mathrm{Cl}-\mathrm{H}_{2} \mathrm{O}$ & 0 & -10 & +20 \\
\hline 4 & WAT3030 & $\mathrm{NH}_{4} \mathrm{Cl}-\mathrm{H}_{2} \mathrm{O}$ & 0 & -30 & -30 \\
\hline 5 & WAT3025 & $\mathrm{NH}_{4} \mathrm{Cl}-\mathrm{H}_{2} \mathrm{O}$ & 0 & -30 & -25 \\
\hline 6 & WAT3015 & $\mathrm{NH}_{4} \mathrm{Cl}-\mathrm{H}_{2} \mathrm{O}$ & 0 & -30 & -15 \\
\hline 7 & WAT3010 & $\mathrm{NH}_{4} \mathrm{Cl}-\mathrm{H}_{2} \mathrm{O}$ & 0 & -30 & -10 \\
\hline 8 & AMC530 & $\mathrm{NH}_{4} \mathrm{Cl}-\mathrm{H}_{2} \mathrm{O}$ & 5 & -30 & +20 \\
\hline 9 & AMC520 & $\mathrm{NH}_{4} \mathrm{Cl}-\mathrm{H}_{2} \mathrm{O}$ & 5 & -20 & +20 \\
\hline 10 & AMC510 & $\mathrm{NH}_{4} \mathrm{Cl}-\mathrm{H}_{2} \mathrm{O}$ & 5 & -10 & +20 \\
\hline 11 & AMC53030 & $\mathrm{NH}_{4} \mathrm{Cl}-\mathrm{H}_{2} \mathrm{O}$ & 5 & -30 & -30 \\
\hline 12 & AMC53010 & $\mathrm{NH}_{4} \mathrm{Cl}-\mathrm{H}_{2} \mathrm{O}$ & 5 & -30 & -10 \\
\hline 13 & AMC1230 & $\mathrm{NH}_{4} \mathrm{Cl}-\mathrm{H}_{2} \mathrm{O}$ & 12 & -30 & +20 \\
\hline 14 & $\mathrm{AMC1220}$ & $\mathrm{NH}_{4} \mathrm{Cl}-\mathrm{H}_{2} \mathrm{O}$ & 12 & -20 & +20 \\
\hline 15 & $\mathrm{AMC} 1210$ & $\mathrm{NH}_{4} \mathrm{Cl}-\mathrm{H}_{2} \mathrm{O}$ & 12 & -10 & +20 \\
\hline 16 & AMC123030 & $\mathrm{NH}_{4} \mathrm{Cl}-\mathrm{H}_{2} \mathrm{O}$ & 12 & -30 & -30 \\
\hline 17 & AMC123010 & $\mathrm{NH}_{4} \mathrm{Cl}-\mathrm{H}_{2} \mathrm{O}$ & 12 & -30 & -10 \\
\hline 18 & AMC1930 & $\mathrm{NH}_{4} \mathrm{Cl}-\mathrm{H}_{2} \mathrm{O}$ & 19.8 & -30 & +20 \\
\hline 19 & AMC1920 & $\mathrm{NH}_{4} \mathrm{Cl}-\mathrm{H}_{2} \mathrm{O}$ & 19.8 & -20 & +20 \\
\hline 20 & AMC1910 & $\mathrm{NH}_{4} \mathrm{Cl}-\mathrm{H}_{2} \mathrm{O}$ & 19.8 & -10 & +20 \\
\hline 21 & AMC193030 & $\mathrm{NH}_{4} \mathrm{Cl}-\mathrm{H}_{2} \mathrm{O}$ & 19.8 & -30 & -30 \\
\hline 22 & AMC193010 & $\mathrm{NH}_{4} \mathrm{Cl}-\mathrm{H}_{2} \mathrm{O}$ & 19.8 & -30 & -10 \\
\hline
\end{tabular}

WAT: Water ; AMC: Ammonium Chloride 
Also a comparative study has been made between the results obtained in this study using trapezoidal cavity and previous study using a rectangular chamber (Ghenai et al, 2003) to study the effect of inclined wall on the solidification process. To meet this objective, an experimental matrix of 6 experiments, shown in table 3.2, was performed.

Table 3.2 Experimental Conditions [b]

\begin{tabular}{|c|c|c|c|c|c|c|}
\hline Exp & Name & Solution & $\begin{array}{c}\text { Volume } \\
{[\mathrm{ml}]}\end{array}$ & $\begin{array}{c}\text { Left Side } \\
\text { Temp } \\
\mathrm{T}_{\mathrm{L}}\left[{ }^{0} \mathrm{C}\right]\end{array}$ & $\begin{array}{c}\text { Right Side } \\
\text { Temp } \\
\mathrm{T}_{\mathrm{R}}\left[{ }^{0} \mathrm{C}\right]\end{array}$ & Chamber \\
\hline 1 & WAT30_1800_T & $\mathrm{H}_{2} \mathrm{O}$ & 1800 & -30 & +20 & Trapezoidal \\
\hline 2 & WAT30_900_T & $\mathrm{H}_{2} \mathrm{O}$ & 900 & -30 & +20 & Trapezoidal \\
\hline 3 & WAT30_500_T & $\mathrm{H}_{2} \mathrm{O}$ & 500 & -30 & +20 & Trapezoidal \\
\hline 4 & WAT30_250_S & $\mathrm{H}_{2} \mathrm{O}$ & 750 & -30 & +20 & Rectangular \\
\hline 5 & WAT30_500_S & $\mathrm{H}_{2} \mathrm{O}$ & 500 & -30 & +20 & Rectangular \\
\hline 6 & WAT30_900_S & $\mathrm{H}_{2} \mathrm{O}$ & 250 & -30 & +20 & Rectangular \\
\hline
\end{tabular}

The experiments in the table 3.1 are named based on the initial concentration and boundary temperature, e.g. for $5 \%$ ammonium chloride solution with $\mathrm{T}_{\mathrm{L}}=-30{ }^{0} \mathrm{C}$ and $\mathrm{T}_{\mathrm{R}}=-10{ }^{\circ} \mathrm{C}$ the name of the experiment is given as AMC53010 ([Solution] [Conc.] $\left[\mathrm{T}_{\mathrm{L}}\right]$ $\left.\left[T_{R}\right]\right)$. For the experiments in the table 3.2 it is named based on the volume of the solution and the geometry of the chamber ([Solution] $\left[\mathrm{T}_{\mathrm{L}}\right]$ [Volume] [Geometry]). 


\subsection{Results of Simulations}

\subsubsection{Effect of Initial Concentration - One Wall Cooled}

The results reported in this study include the PIV images that show the shape of the frozen layer, the velocity vectors (convection patterns) of the solution, the frozen thickness for each time step, and the temperature profiles acquired at the same time as the flow field. The convection flow pattern during the solidification of the ammonium chloride-water solution was acquired using the PIV technique. Three cooling conditions (temperature of the output coolant in the chiller: $-30^{\circ} \mathrm{C},-20^{\circ} \mathrm{C},-10^{\circ} \mathrm{C}$ ) were tested for all tested solution concentrations. For the one cooled side, the temperature of the left sidewall was cooled, and the right side wall was kept constant at $+20^{\circ} \mathrm{C}$. For the two cooled sides, the left and right sides of the cavity were cooled simultaneously. The initial concentration of ammonium chloride-water solution covered a range from $0 \mathrm{wt} \%$ to 19.8 wt $\%$.

The PIV images during the solidification of ammonium chloride-water solution in the trapezoidal cavity with one side cooled to $-30^{\circ} \mathrm{C}$ and other side is maintained at room temperature with various initial concentration are shown in Figures 3.1 to 3.4. It is noted that the right, left, and bottom bounding lines are walls, and the top bounding line is the free surface. The PIV images show (1) the position of the seeding particles in the melt which will be used to get the velocity vectors and (2) the thickness and the shape of the frozen surface. The results are recorded till the solidification process came to a stable position i.e., 128 minutes. 


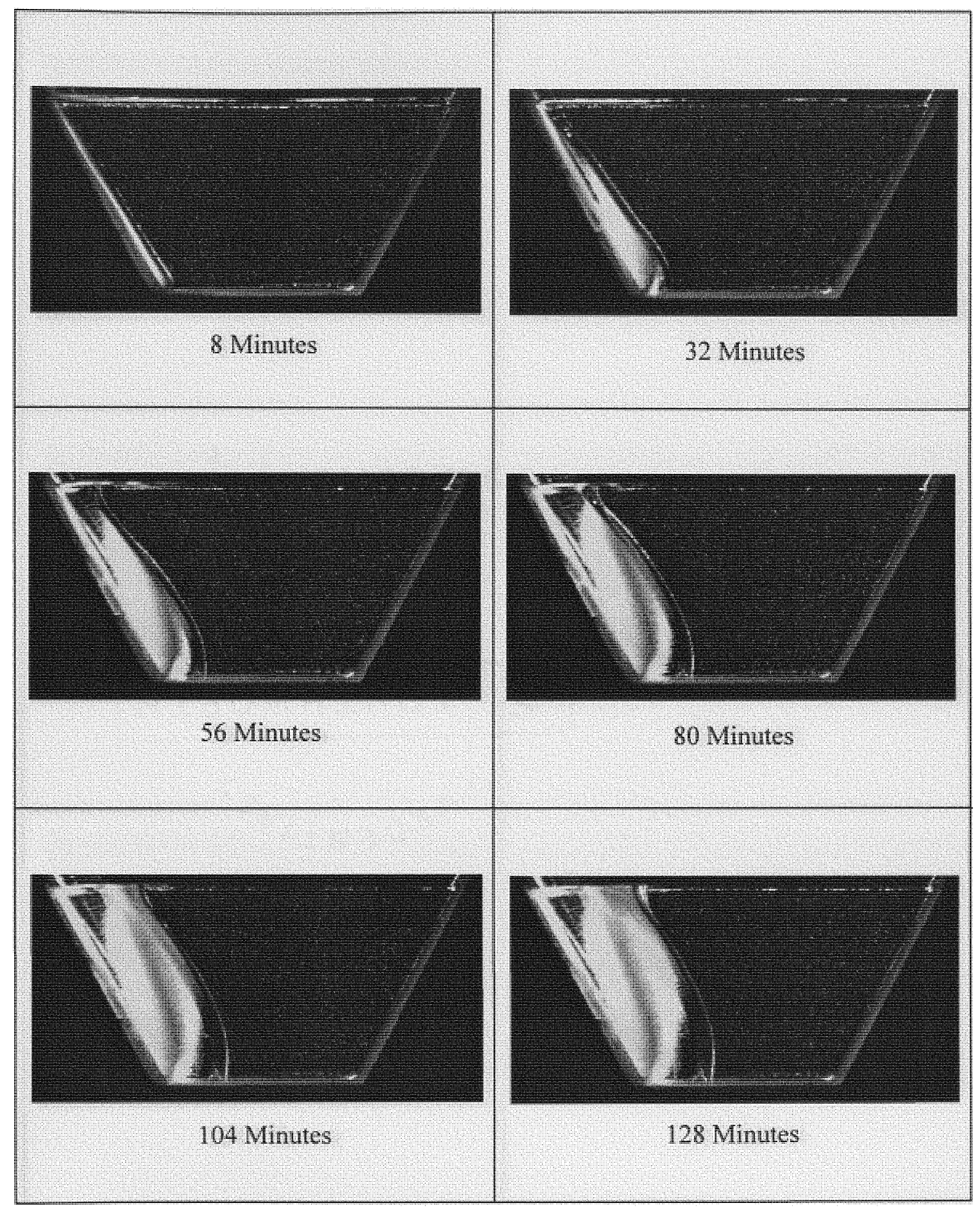

Figure 3.1 PIV Images of the solidification of water: One cooled side, $T_{L}=-30^{\circ} \mathrm{C}, \mathrm{T}_{\mathrm{R}}=+20^{\circ} \mathrm{C}$. 


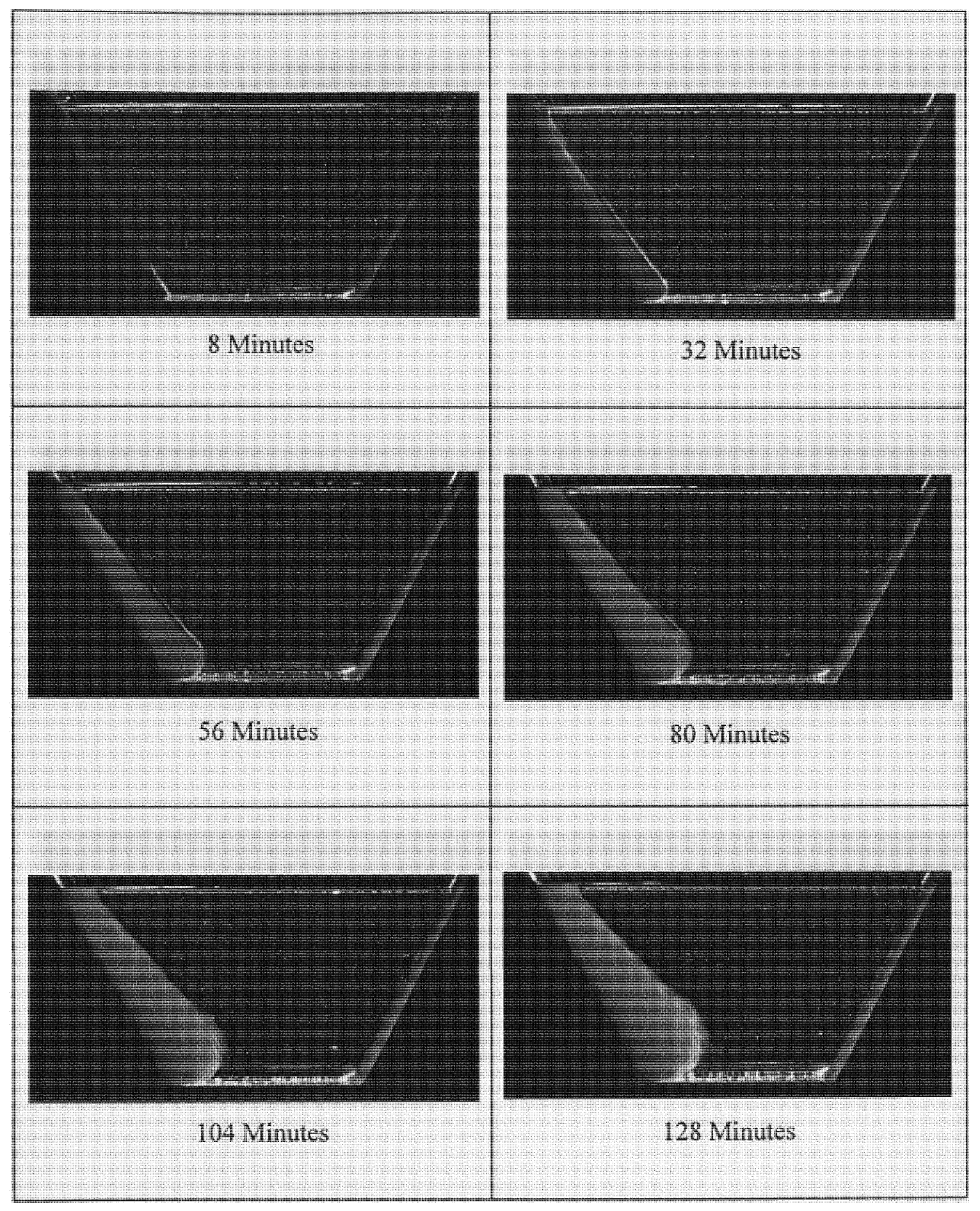

Figure 3.2 PIV Images of the solidification of $5 \% \mathrm{NH}_{4} \mathrm{Cl}-\mathrm{H}_{2} \mathrm{O}$;

One cooled side, $T_{L}=-30{ }^{\circ} \mathrm{C}, \mathrm{T}_{\mathrm{R}}=+20^{\circ} \mathrm{C}$. 


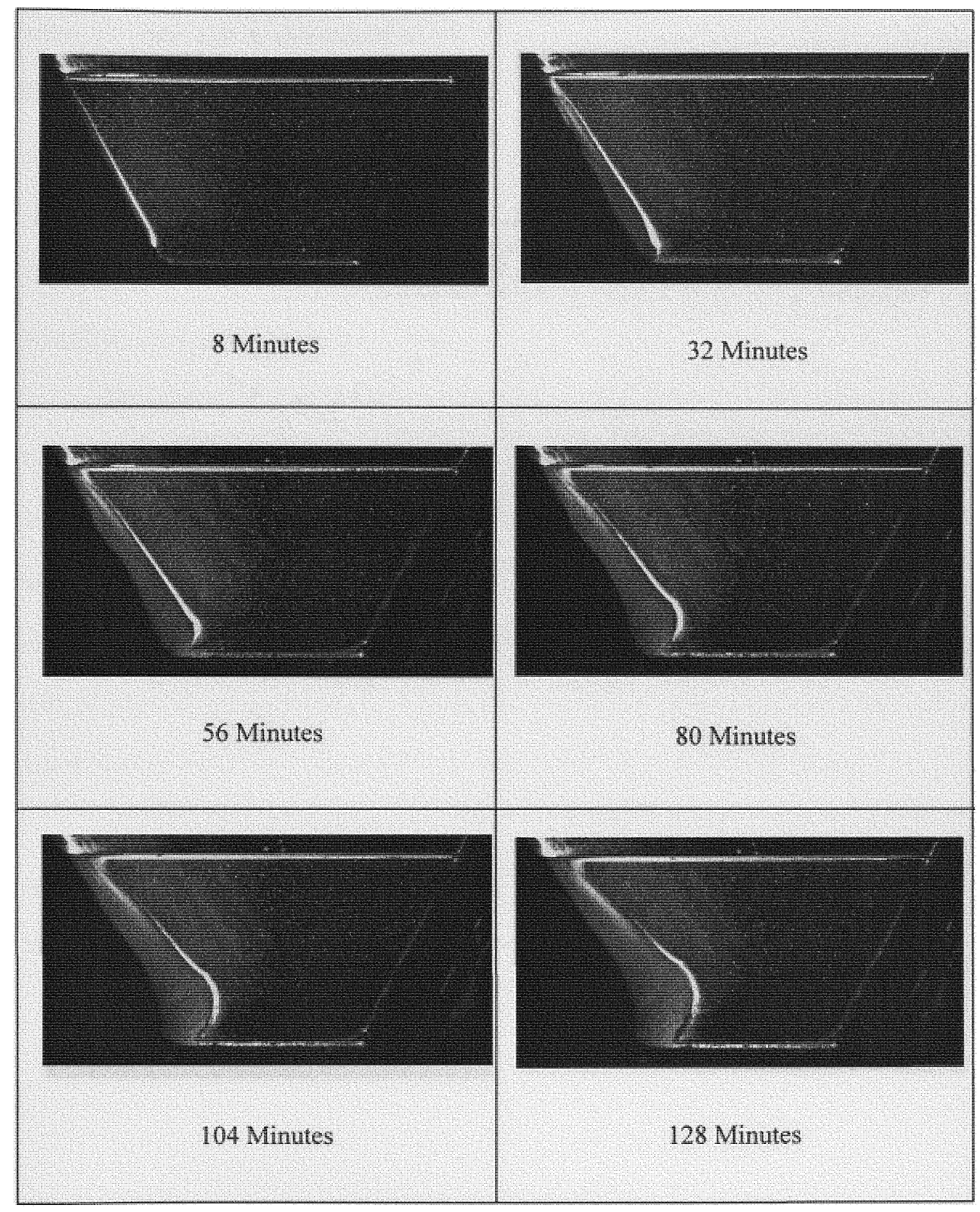

Figure 3.3 PIV Images of the solidification of $12 \% \mathrm{NH}_{4} \mathrm{Cl}-\mathrm{H}_{2} \mathrm{O}$; One cooled side, $T_{L}=-30^{\circ} \mathrm{C}, \mathrm{T}_{\mathrm{R}}=+20^{\circ} \mathrm{C}$. 


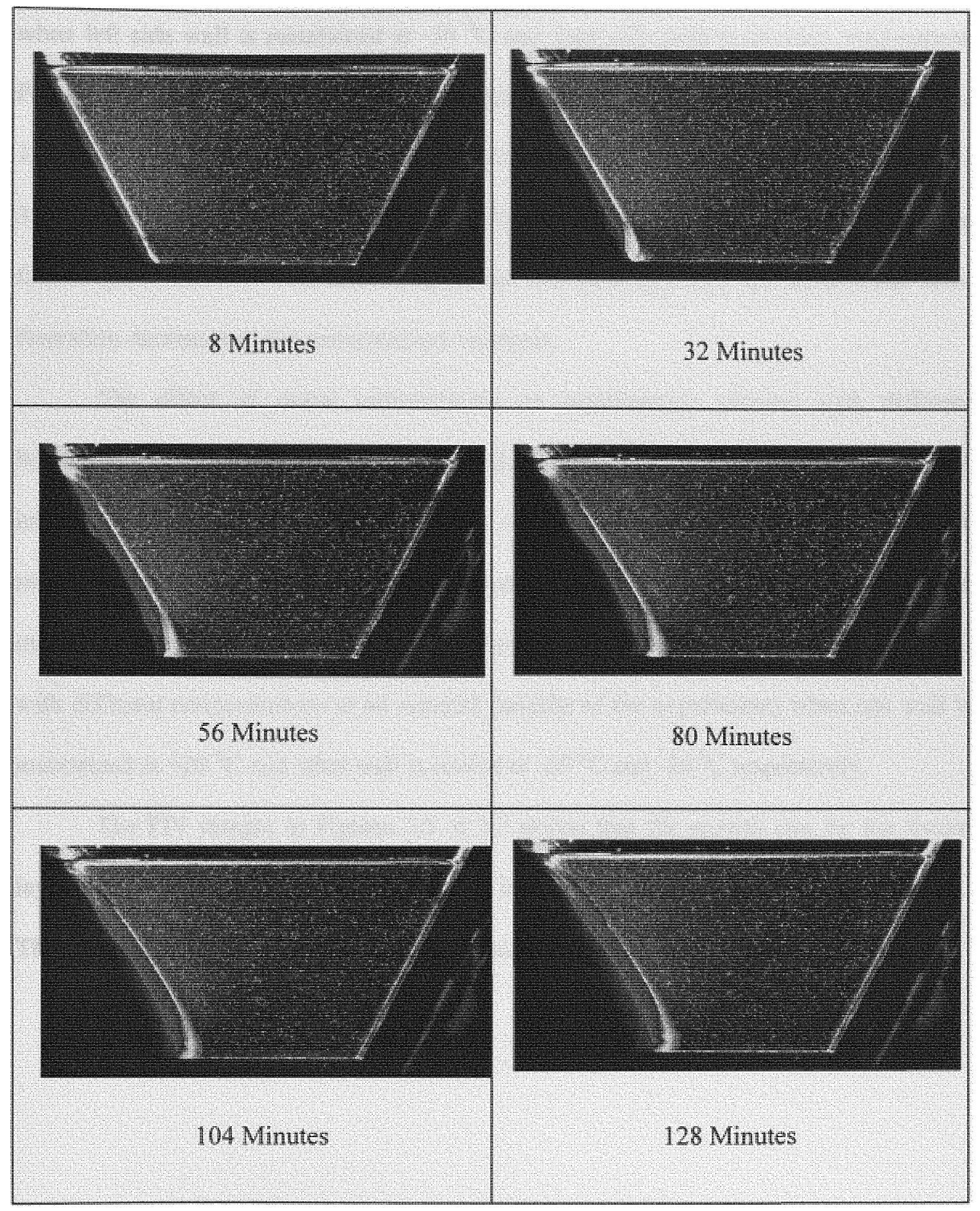

Figure 3.4 PIV Images of the solidification of $19.8 \% \mathrm{NH}_{4} \mathrm{Cl}-\mathrm{H}_{2} \mathrm{O}$;

One cooled side, $T_{L}=-30^{\circ} \mathrm{C}, T_{R}=+20^{\circ} \mathrm{C}$. 
Figure 3.1 shows the PIV images obtained during the solidification of pure water when left side wall is maintained at $-30{ }^{\circ} \mathrm{C}$ and right side wall is at room temperature. Figures $3.2,3.3, \& 3.4$ shows the PIV images obtained during the solidification of $5 \%$, $12 \%, \& 19.8 \% \mathrm{NH}_{4} \mathrm{Cl}-\mathrm{H}_{2} \mathrm{O}$ solution respectively when left side wall is maintained at $30{ }^{\circ} \mathrm{C}$ and right side wall is at room temperature. We observe the mushy region increases from Figures 3.2 to 3.4 as the concentration increases and also we observe the solid formation decreases as the concentration increases.

The effect of initial concentration on solidification process with different boundary conditions can be seen in Figure 3.5 to Figure 3.7. Figure 3.5 shows the PIV images of solidification process of $\mathrm{NH}_{4} \mathrm{Cl}-\mathrm{H}_{2} \mathrm{O}$ with different concentrations at 64 minutes (middle of the experiment) when one wall is cooled to $-30{ }^{\circ} \mathrm{C}$ and other wall is maintained at $+20{ }^{\circ} \mathrm{C}$. Figures $3.6 \& 3.7$ shows the solidification process of $\mathrm{NH}_{4} \mathrm{Cl}-\mathrm{H}_{2} \mathrm{O}$ with different concentrations at 64 minutes (middle of the experiment) when one wall is maintained at $+20{ }^{\circ} \mathrm{C}$ and other wall is cooled to $-20{ }^{\circ} \mathrm{C}$ and $-10{ }^{\circ} \mathrm{C}$ respectively.

The PIV images in Figures 3.5 to 3.7 shows that the growth rate for the frozen layer slows down when the concentration is increased for different boundary conditions. The initial concentration level plays a significant role in the solidification process. 


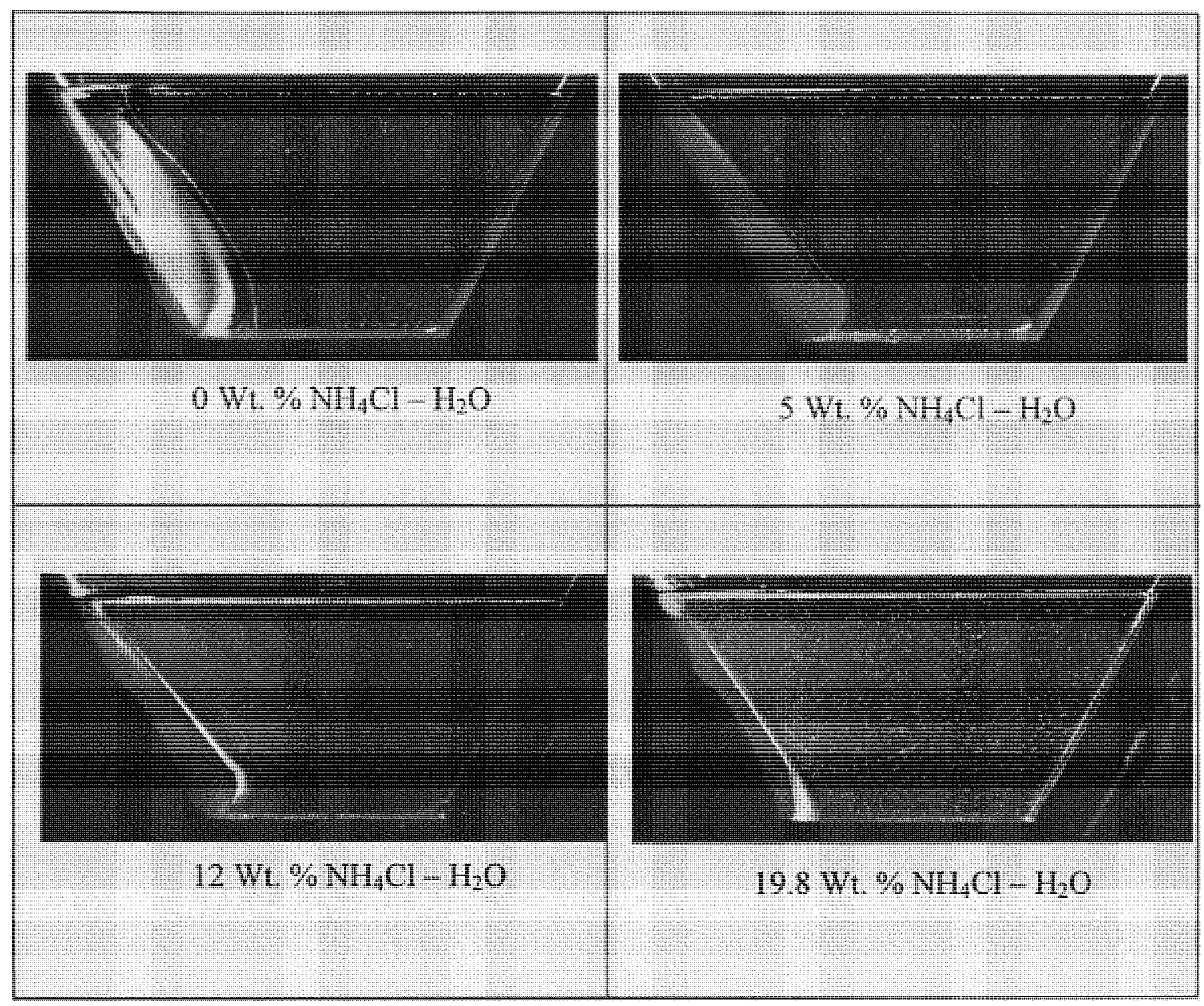

Figure 3.5 Effect of the Initial Concentration on the Solidification Process One cooled side: Time $(t)=64$ Minutes, $T_{L}=-30^{\circ} \mathrm{C}, T_{R}=+20^{\circ} \mathrm{C}$. 


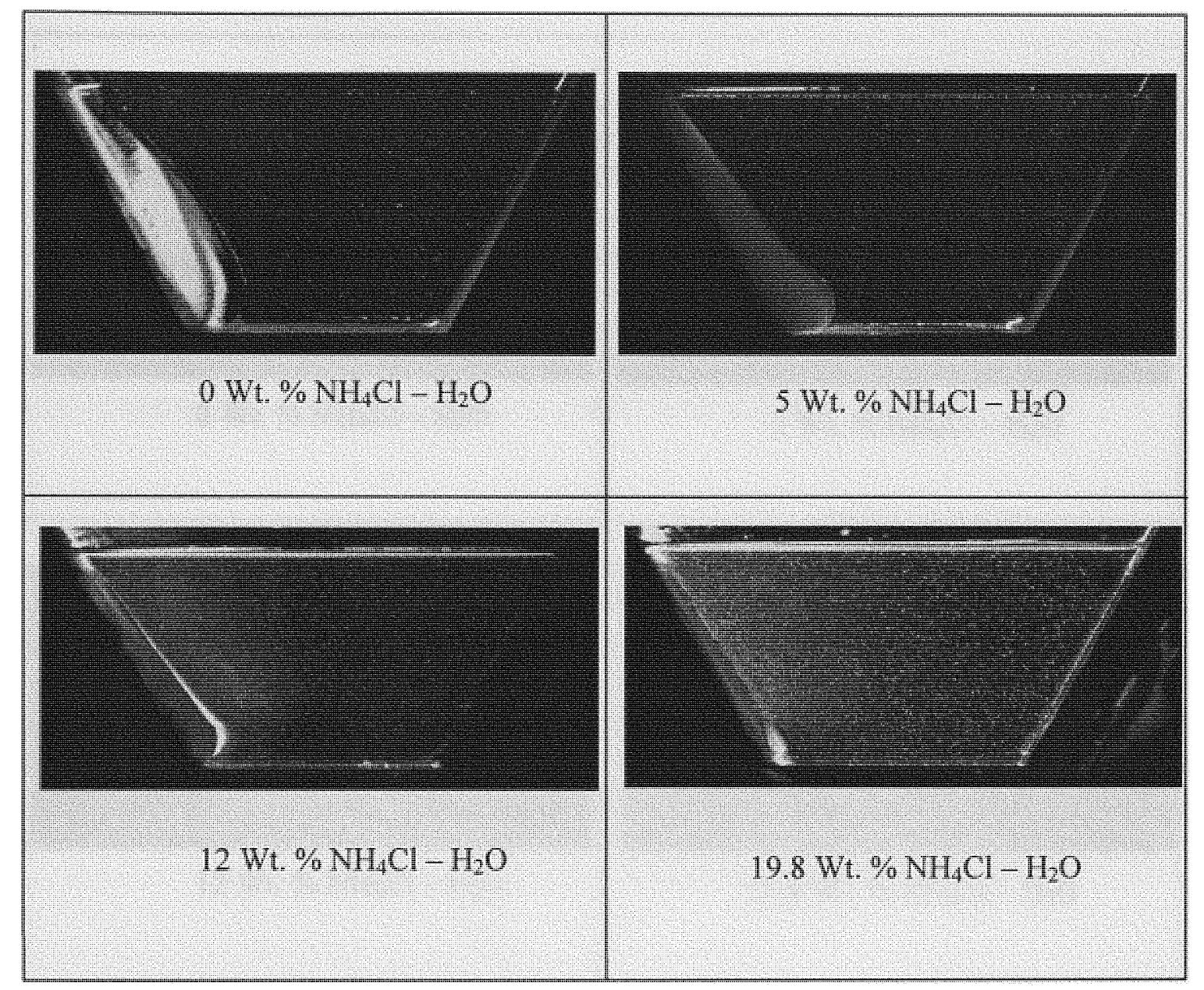

Figure 3.6 Effect of the Initial Concentration on the Solidification Process One cooled side: Time $(t)=64$ Minutes, $T_{L}=-20^{\circ} \mathrm{C}, T_{R}=+20^{\circ} \mathrm{C}$. 


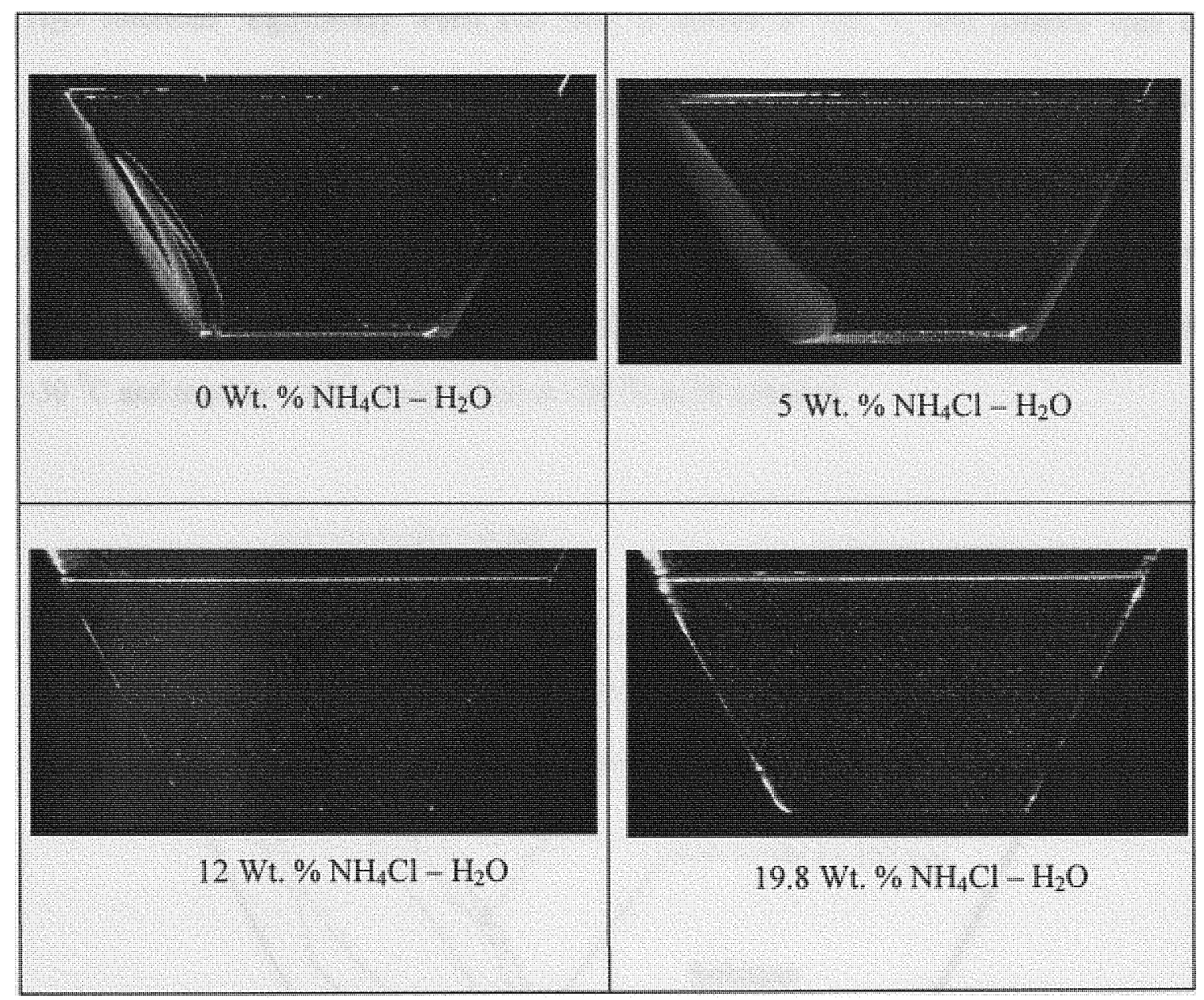

Figure 3.7 Effect of the Initial Concentration on the Solidification Process One cooled side: Time $(t)=64$ Minutes, $T_{L}=-10^{\circ} \mathrm{C}, T_{R}=+20^{\circ} \mathrm{C}$. 
Figure 3.1 to 3.5 shows the PIV images which show the location of the seeding particles and also the ice formation. The moving interface and the solidification can be well understood by looking at the solidification contours for different times. Figure 3.8 to 3.11 shows the solidification contours at different times for $0 \%, 5 \%, 12 \%, 19.8 \% \mathrm{NH}_{4} \mathrm{Cl}-$ $\mathrm{H}_{2} \mathrm{O}$ solutions respectively when one wall is cooled to $-30{ }^{\circ} \mathrm{C}$ and another wall is maintained at $+20{ }^{\circ} \mathrm{C}$. It is observed from these figures that the solidification process is fast during first half of the experiments and is gradually decreasing which we have seen from the moving interface velocity profiles (Figures $3.15 \& 3.16$ ). Figure 3.12 shows the effect of initial concentration on the solidification process when one wall is cooled to $-30{ }^{\circ} \mathrm{C}$ and another wall is maintained at $+20{ }^{\circ} \mathrm{C}$ at 56 minutes.

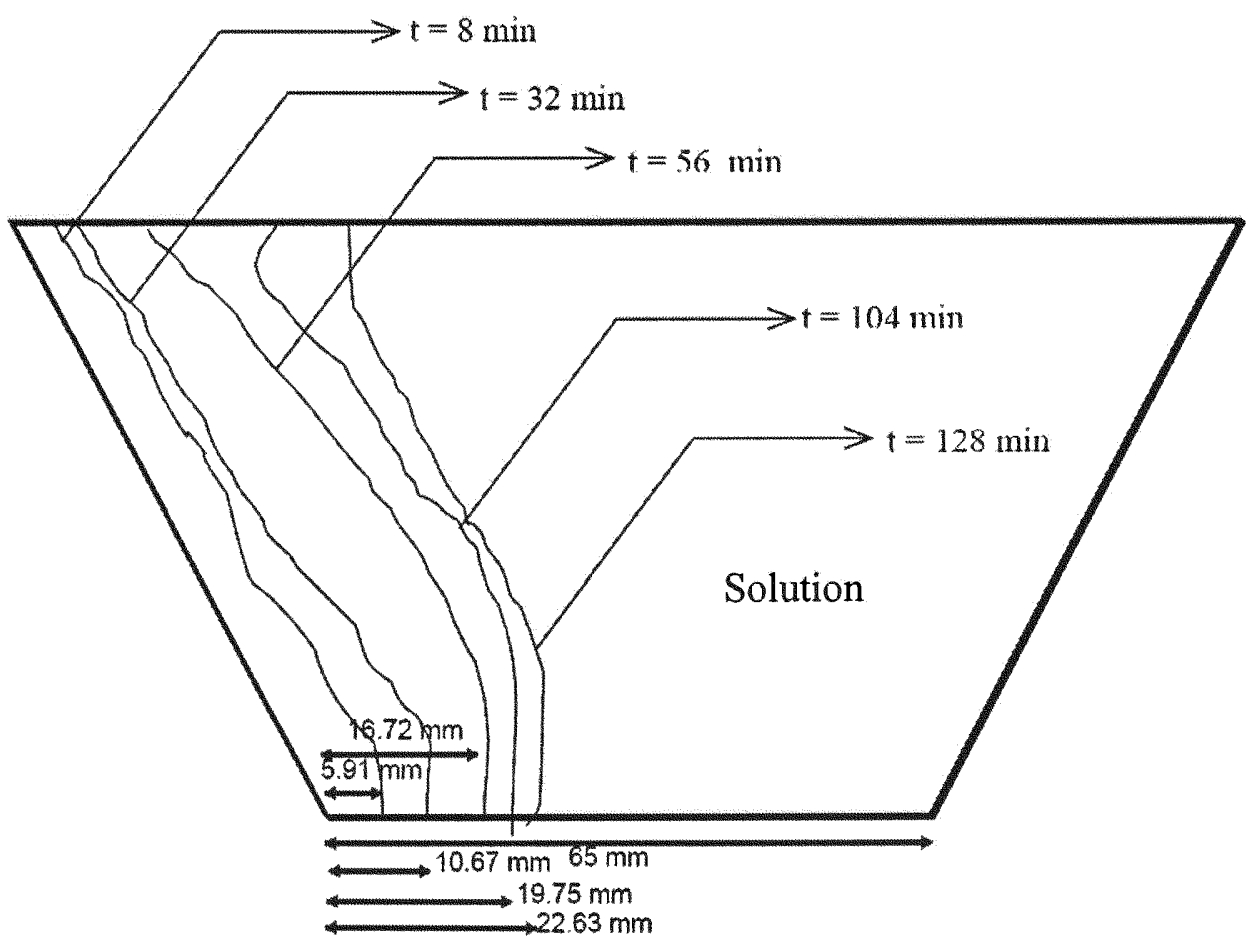

Figure 3.8 Solidification Contours for water: One cooled side, $T_{L}=-30{ }^{\circ} \mathrm{C}, \mathrm{T}_{R}=+20^{\circ} \mathrm{C}$. 


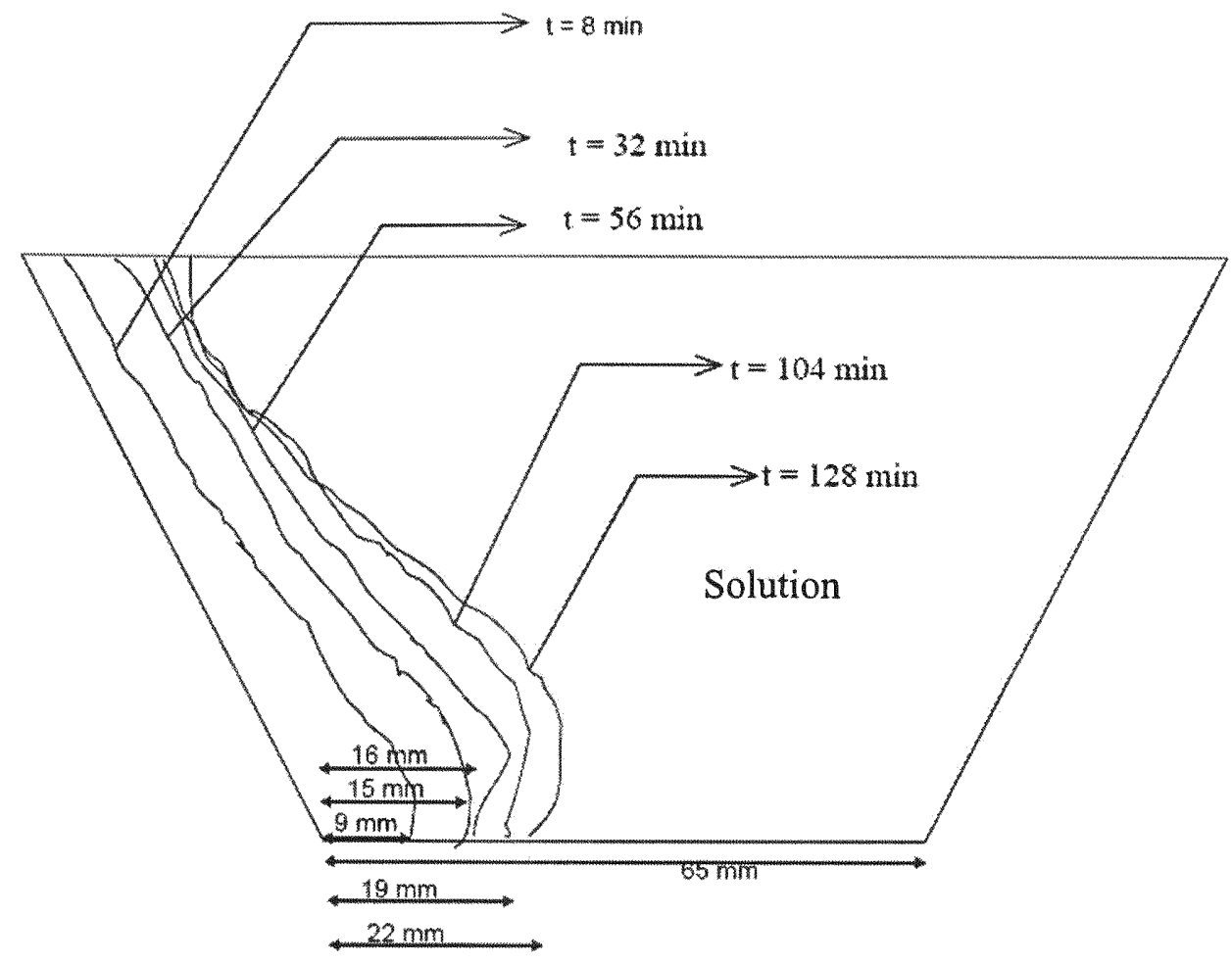

Figure 3.9 Solidification Contours for $5 \% \mathrm{NH}_{4} \mathrm{Cl}-\mathrm{H}_{2} \mathrm{O}$ :

One cooled side, $T_{L}=-30{ }^{\circ} \mathrm{C}, \mathrm{T}_{\mathrm{R}}=+20^{\circ} \mathrm{C}$.

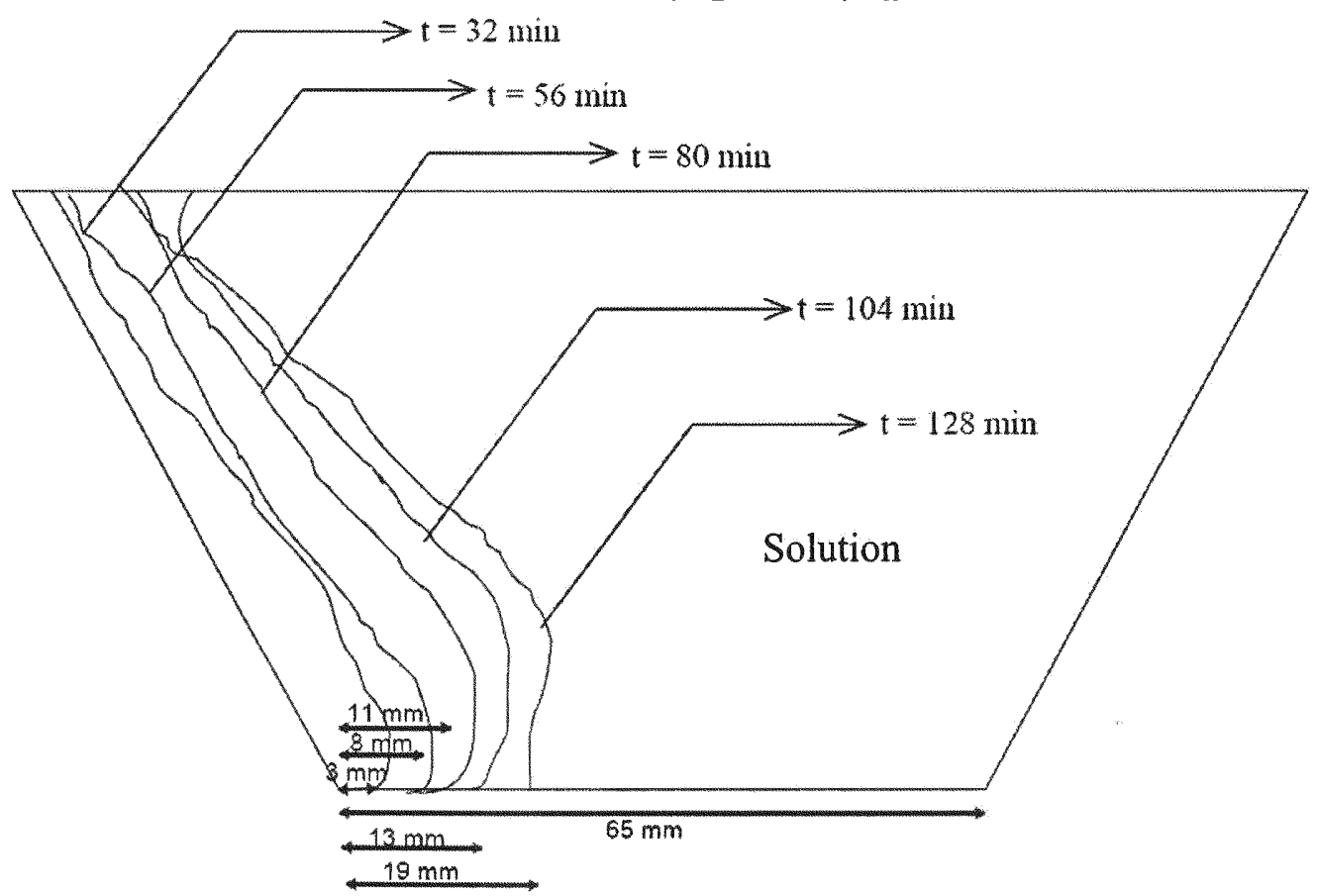

Figure 3.10 Solidification Contours for $12 \% \mathrm{NH}_{0} \mathrm{Cl}-\mathrm{H}_{2} \mathrm{O}$ :

One cooled side, $T_{L}=-30^{\circ} \mathrm{C}, \mathrm{T}_{\mathrm{R}}=+20^{\circ} \mathrm{C}$. 


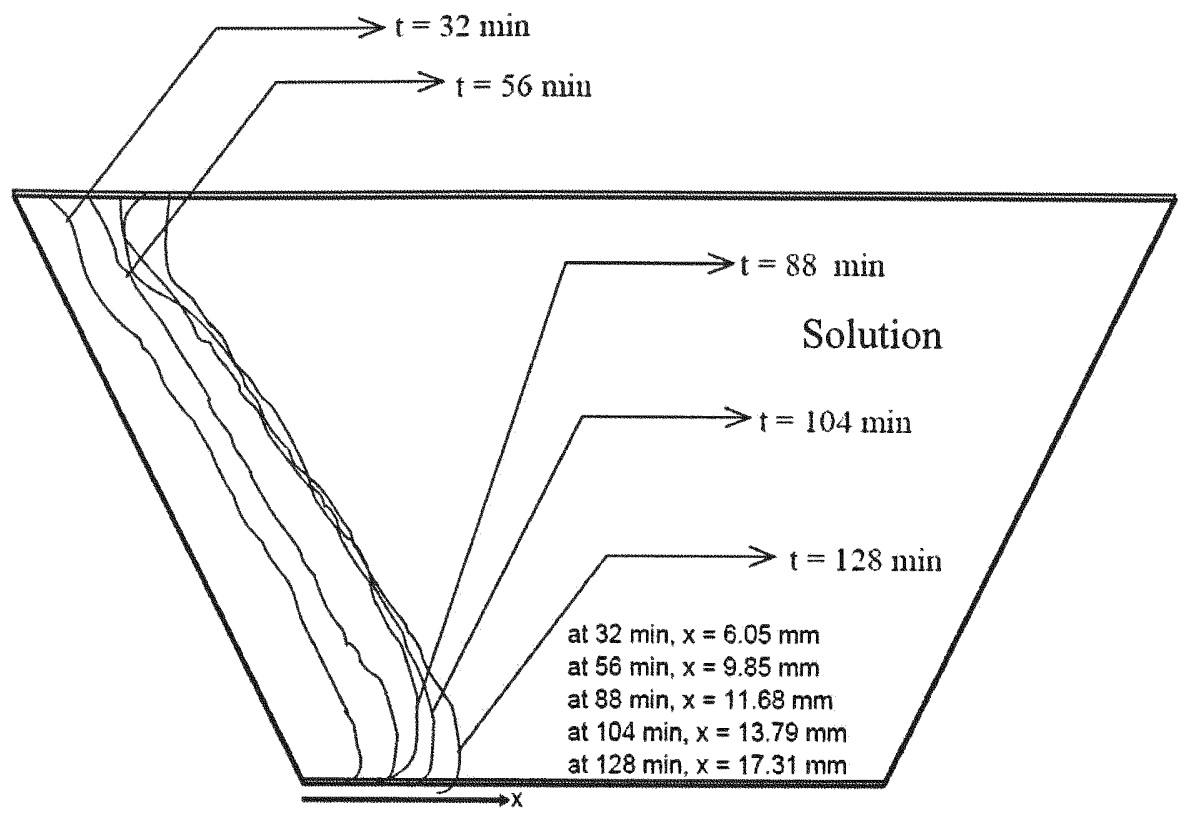

Figure 3.11 Solidification Contours for $19.8 \% \mathrm{NH}_{4} \mathrm{Cl}-\mathrm{H}_{2} \mathrm{O}$ :

One cooled side, $T_{L}=-30{ }^{\circ} \mathrm{C}, \mathrm{T}_{R}=+20^{\circ} \mathrm{C}$.

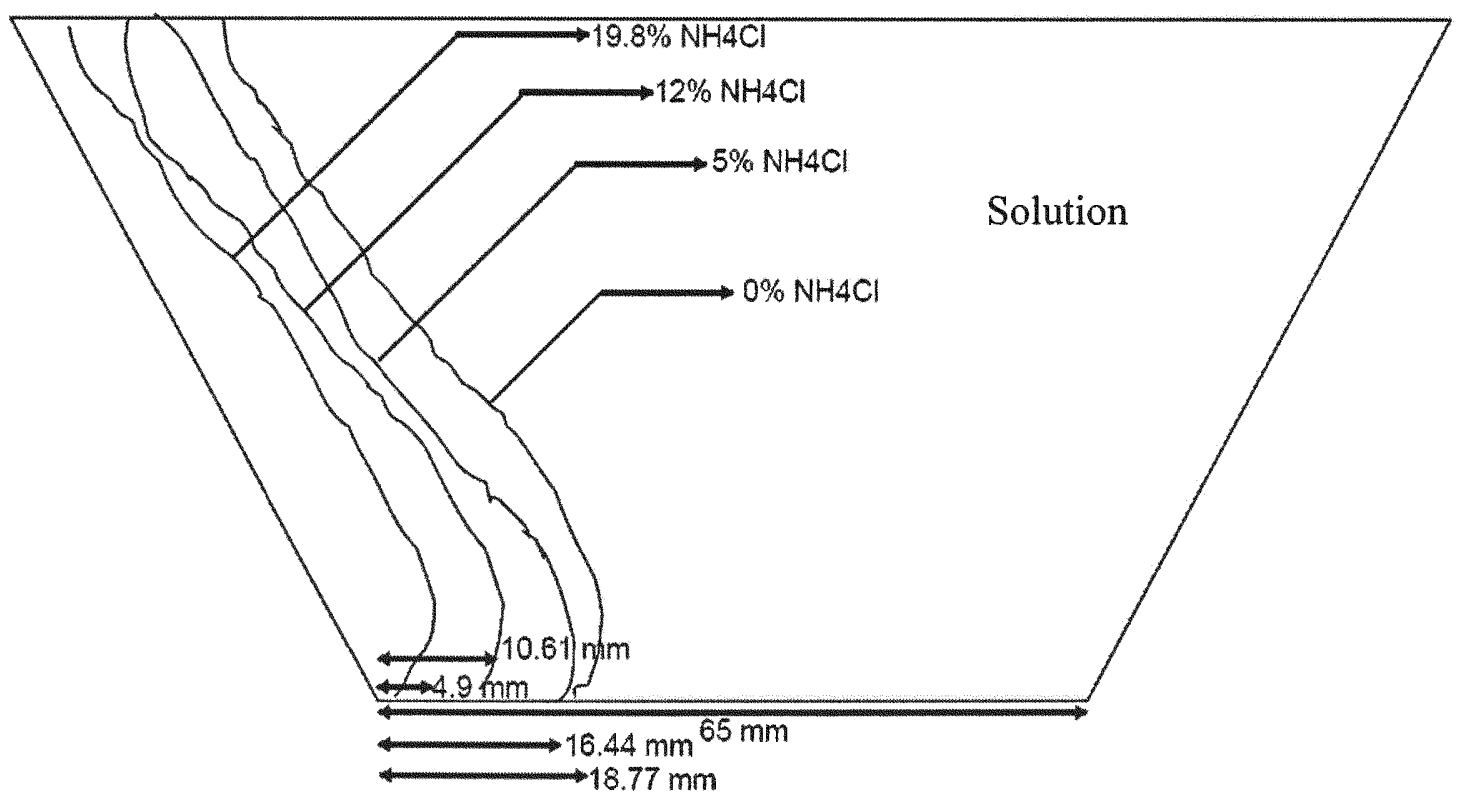

Figure 3.12 Solidification Contours for Different Concentrations at $t=56 \mathrm{~min}$;

$$
T_{L}=-30^{\circ} \mathrm{C} \& T_{R}=+20^{\circ} \mathrm{C}
$$


The frozen layer thickness is measured from the PIV images and this thickness of the frozen layer will be used to calculate the velocity of the moving interface (liquid/solid). Figures 3.13 and 3.14 shows the results of the frozen layer thickness at $\mathrm{Y}=$ $37 \mathrm{~mm}$ for different initial concentrations at different times and for different boundary conditions $\mathrm{T}_{\mathrm{R}}=+20{ }^{\circ} \mathrm{C}, \mathrm{T}_{\mathrm{L}}=-30{ }^{\circ} \mathrm{C} \&-20{ }^{\circ} \mathrm{C}$ respectively and observed a fast increase of the thickness of the frozen layer at the beginning of the solidification process but the solidification process slows down after 128 minutes. Figure 3.17 shows that the frozen layer thickness depends on the position inside the cavity $(Y=110 \mathrm{~mm}, 55 \mathrm{~mm}, 0 \mathrm{~mm})$.

$$
\text { Moving Interface Velocity }=\frac{\text { Frozen Layer Thickness }\left(\delta_{t}\right)}{\operatorname{Time}(t)}
$$

From the frozen layer thickness obtained using the PIV images, moving interface velocity is calculated using the following equation. Figures 3.15 and 3.16 shows the results of the moving liquid-solid interface at $\mathrm{y}=37 \mathrm{~mm}$ for different initial concentrations at different times. From Figures 3.13 to 3.17 , it is shown clearly that the thickness of the frozen layer increases with time, and as the initial concentration increases, the time needed to get the same thickness of frozen layer increases. The velocity of the moving liquid-solid interface for the binary solution increases rapidly during the first hour of the solidification process. The velocity of the moving interface decreases when increasing the initial concentrations. These results show that the solidification process is slower with an increase in the initial concentration levels of the binary solution. The equilibrium phase diagram of ammonium chloride-water solution also supports this observation. The initial concentration level plays a significant role in the solidification process. 


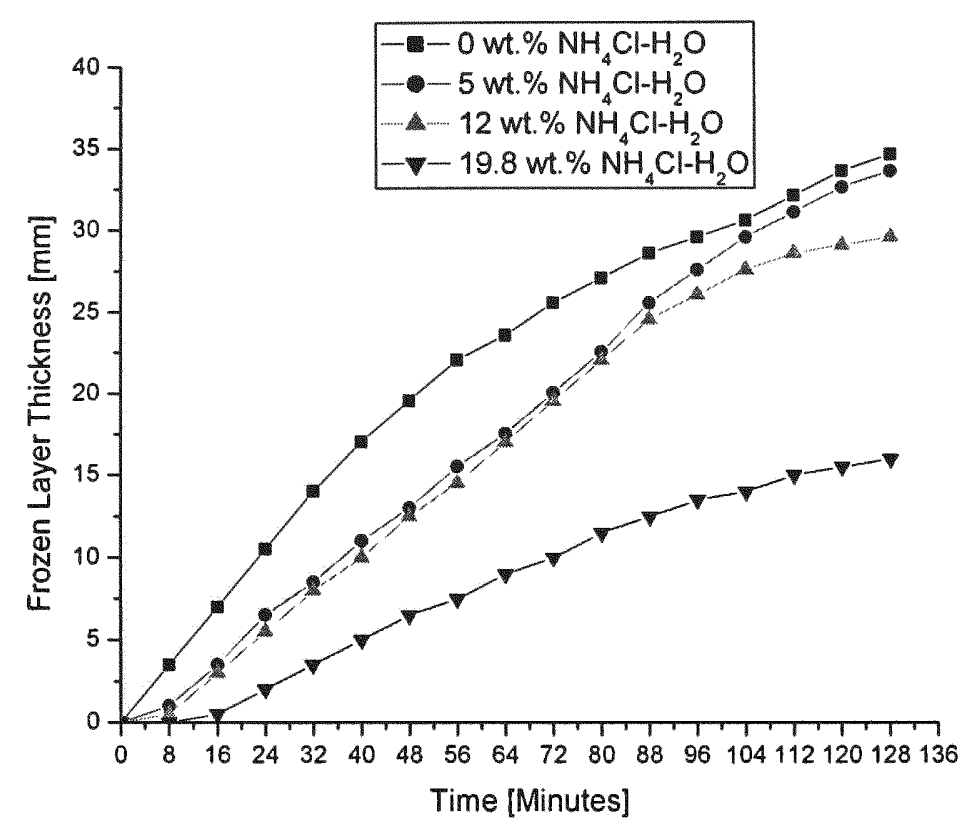

Figure 3.13 Effect of initial concentration on thickness of the frozen layer $(\mathrm{Y}=37 \mathrm{~mm})$ : One cooled side, $T_{L}=-30^{\circ} \mathrm{C}, T_{R}=+20^{\circ} \mathrm{C}$.

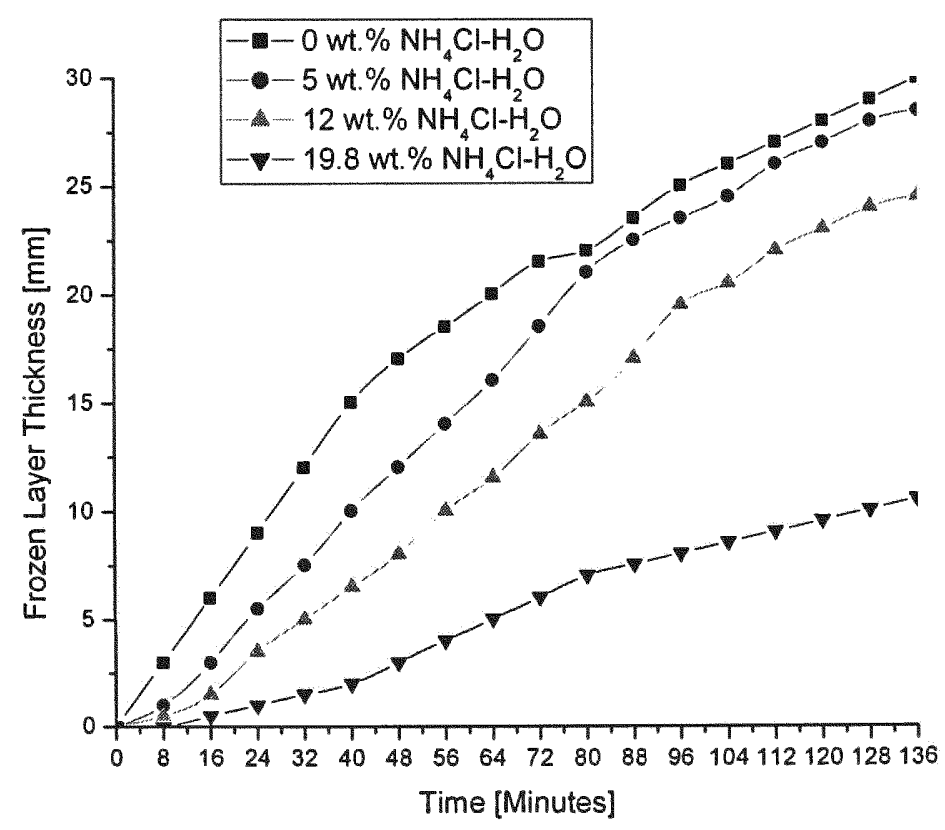

Figure 3.14 Effect of initial concentration on thickness of the frozen layer $(\mathrm{Y}=37 \mathrm{~mm})$ : One cooled side, $T_{L}=-20^{\circ} \mathrm{C}, T_{R}=+20^{\circ} \mathrm{C}$. 


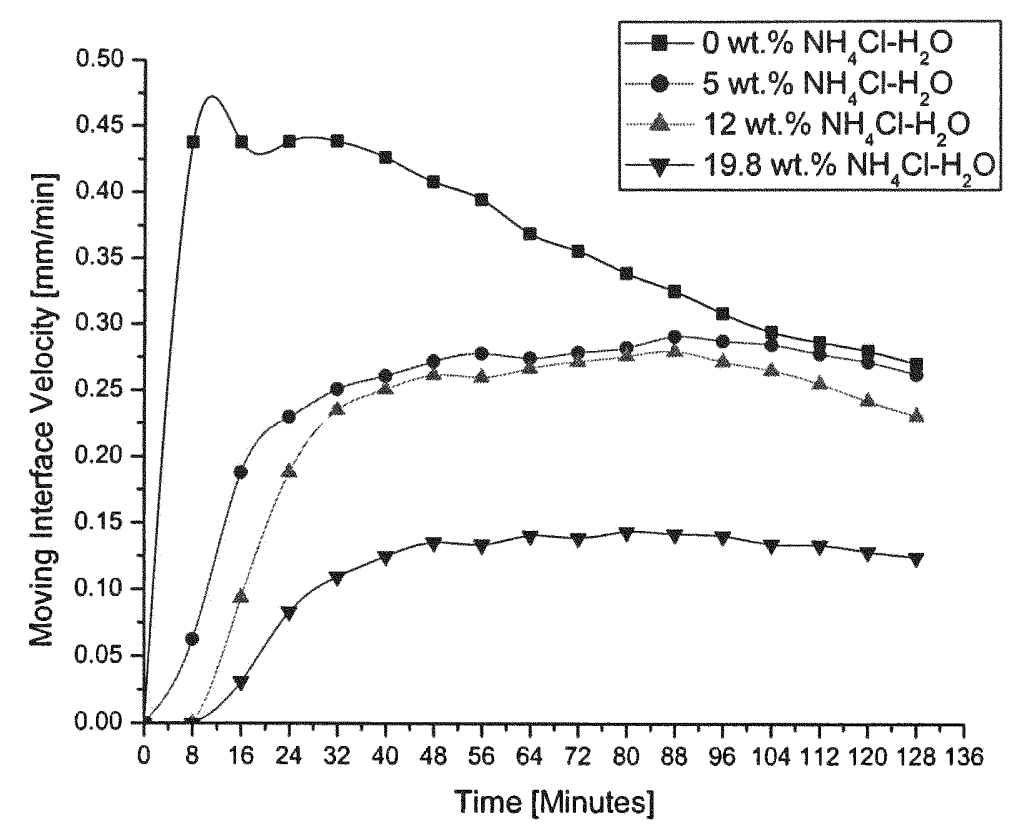

Figure 3.15 Effect of initial concentration on Velocity of Moving Interface ( $Y=37 \mathrm{~mm})$ : One cooled side, $T_{L}=-30^{\circ} \mathrm{C}, T_{R}=+20^{\circ} \mathrm{C}$.

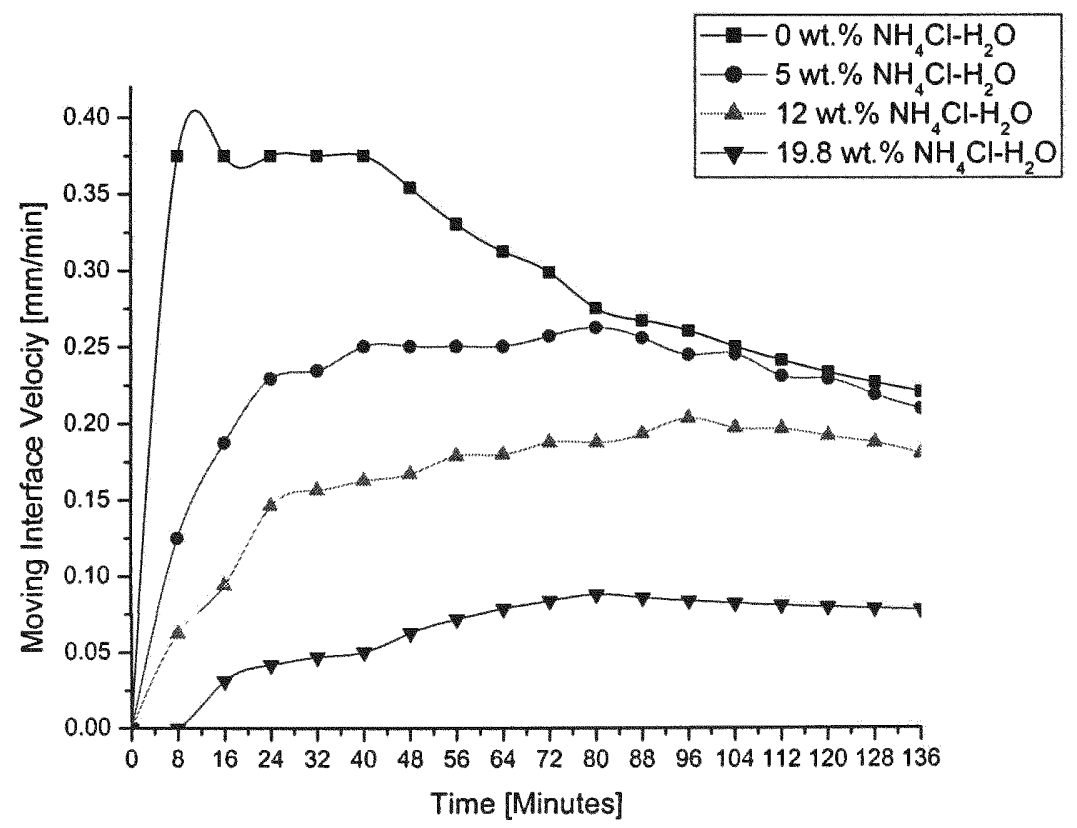

Figure 3.16 Effect of initial concentration on Velocity of Moving Interface ( $\mathrm{Y}=37 \mathrm{~mm})$ : One cooled side, $T_{L}=-20^{\circ} \mathrm{C}, T_{R}=+20^{\circ} \mathrm{C}$. 


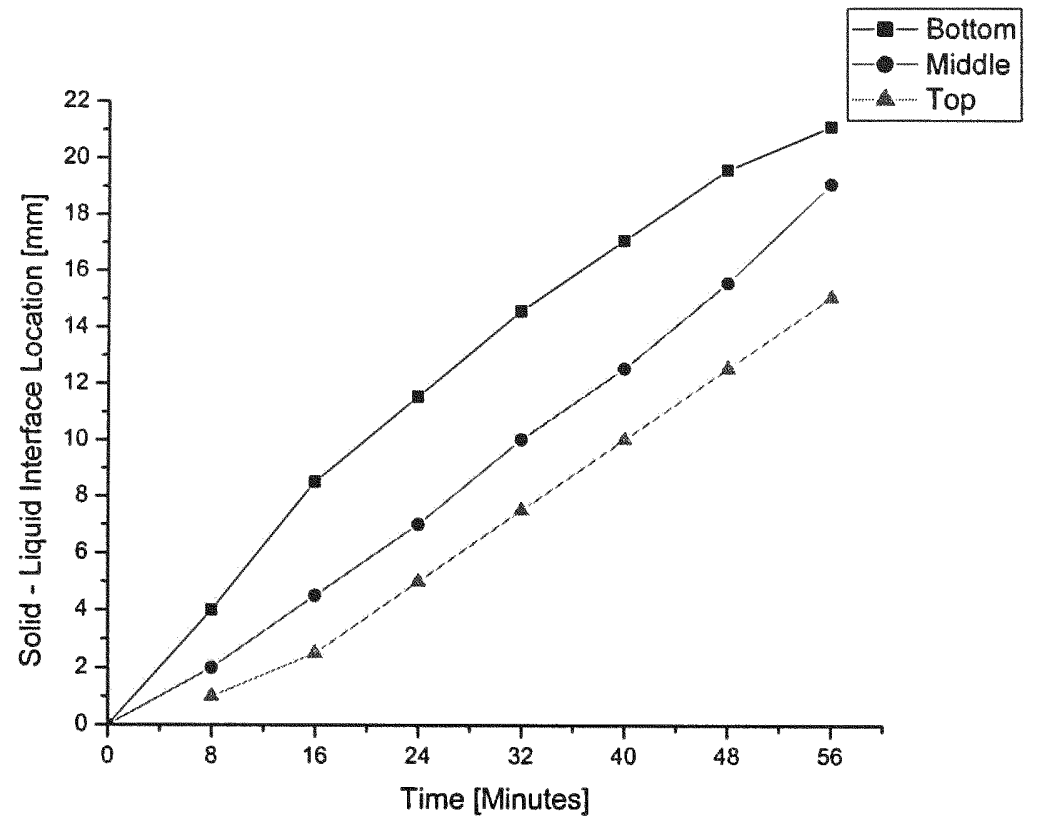

Figure 3.17 Frozen layer thickness at three different positions in the cavity: Pure Water; One cooled side, $\mathrm{T}_{\mathrm{L}}=-30^{\circ} \mathrm{C}, \mathrm{T}_{\mathrm{R}}=+20^{\circ} \mathrm{C}$.

It is observed that the moving interface velocity is increasing for first few minutes of the experiments and then it is decreasing gradually. This process can be explained with the help of heat rate which is defined as

$$
\text { Heat Rate }=\frac{\Delta T}{\Delta t}=\frac{T_{\text {liq }}-T_{\text {sol }}}{8 \text { Minutes }}
$$

Figure 3.18 shows the temperature profiles for liquid region and solid region and Figure 3.19 shows the heat rate profile for pure water with one wall cooled to $-30{ }^{\circ} \mathrm{C}$ and another maintained at $+20{ }^{\circ} \mathrm{C}$. It is observed that the heat rate decreases with time and which is mainly responsible for solidification process. Figure 3.19 shows that how the moving interface velocity decreases with decrease in heat rate. Figure 3.20 shows the reason why the moving interface velocity decreases with time. 


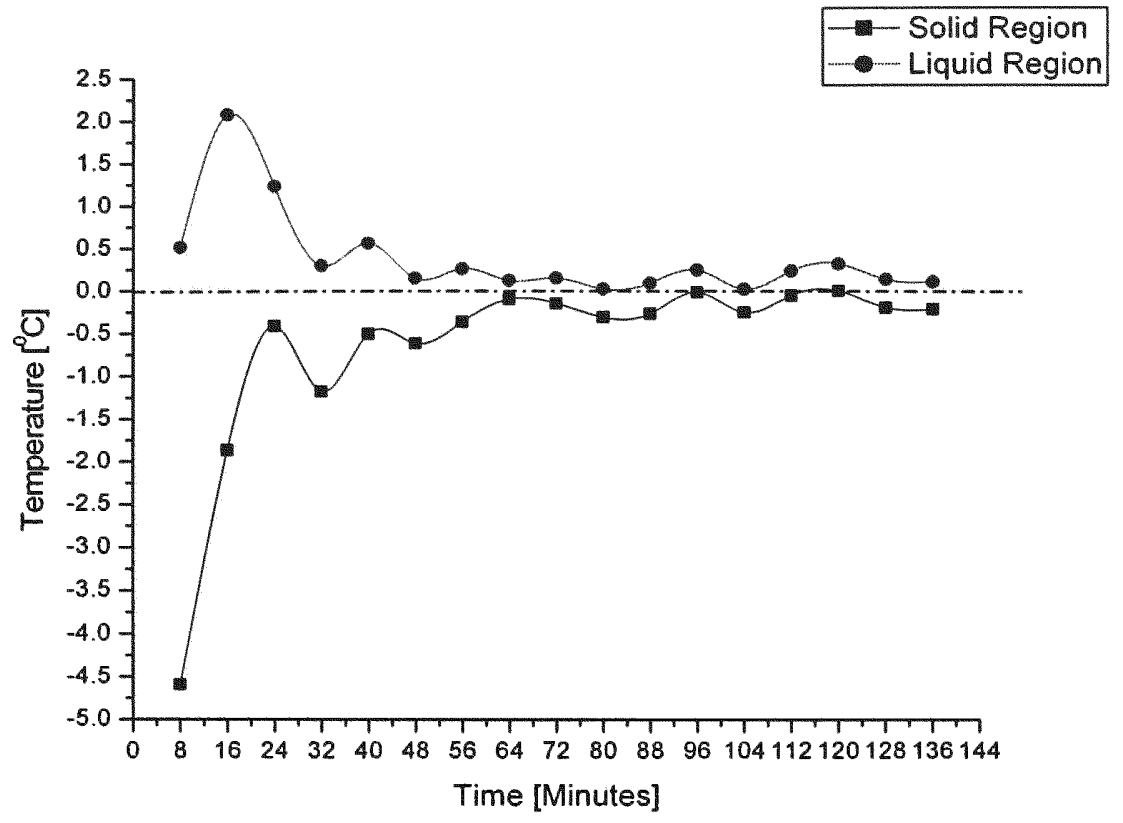

Figure 3.18 Solidus and Liquidus Temperatures with Time $(\mathrm{Y}=37)$, Pure Water; One cooled side, $\mathrm{T}_{\mathrm{L}}=-30^{\circ} \mathrm{C}, \mathrm{T}_{\mathrm{R}}=+20^{\circ} \mathrm{C}$.

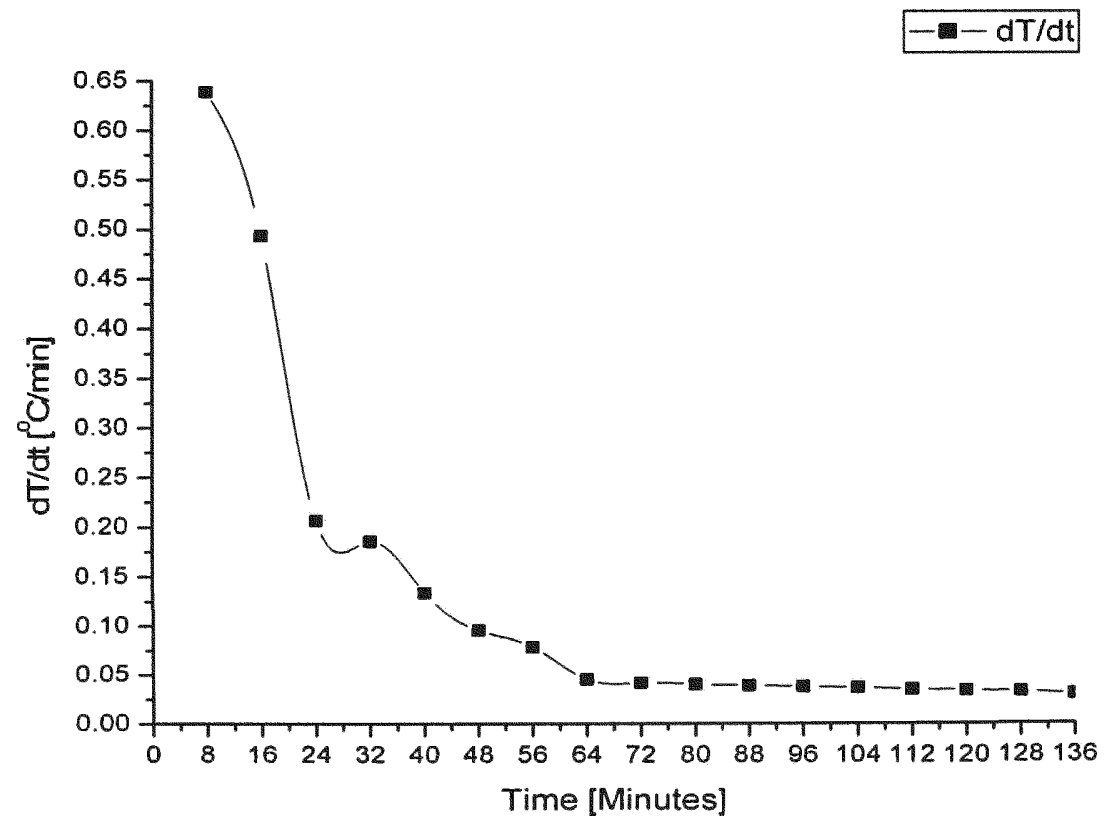

Figure 3.19 Variation of heat rate with Time ( $Y=37)$, Pure Water; One cooled side, $\mathrm{T}_{\mathrm{L}}=-30^{\circ} \mathrm{C}, \mathrm{T}_{\mathrm{R}}=+20^{\circ} \mathrm{C}$. 
(a)

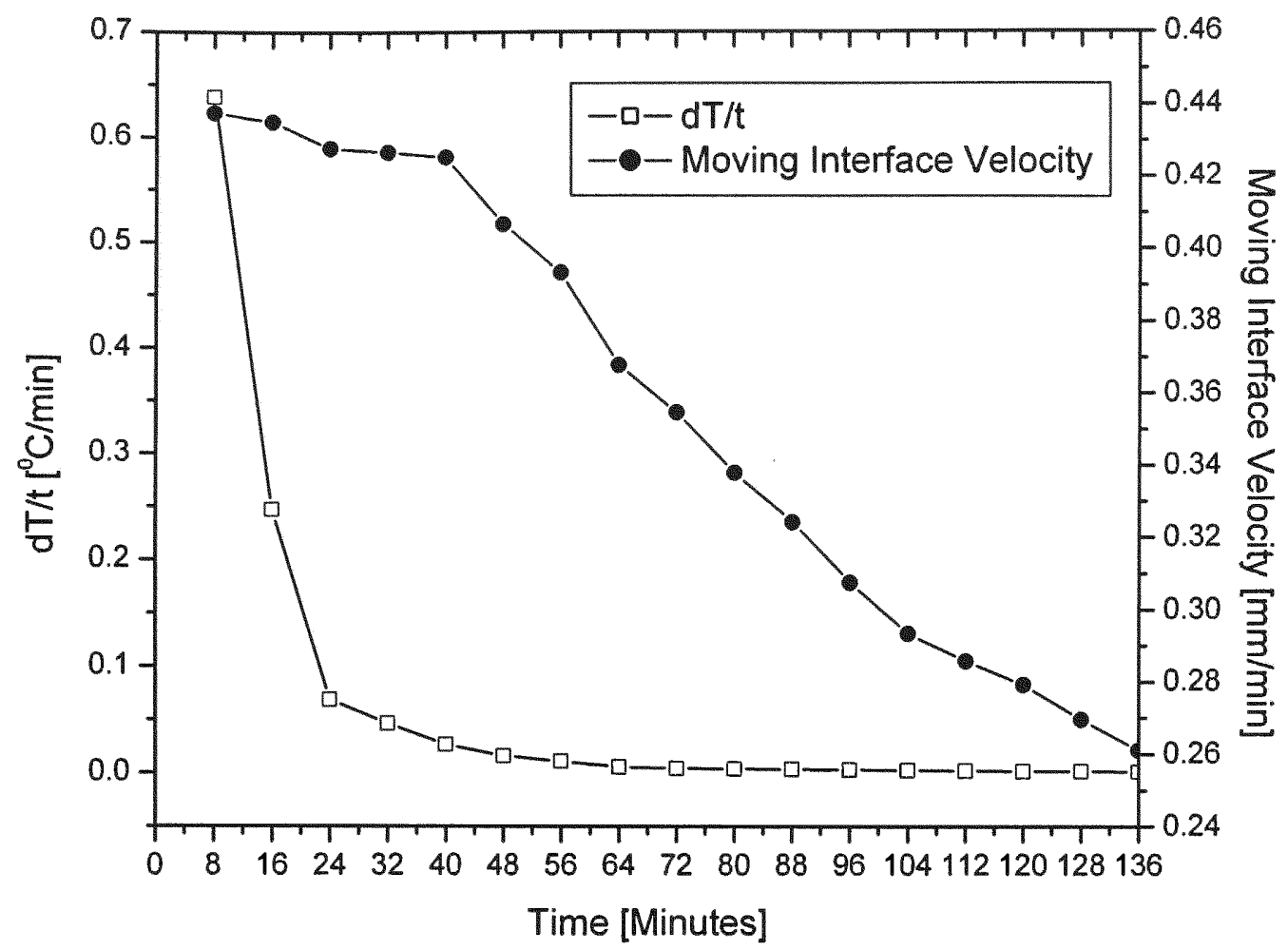

(b)

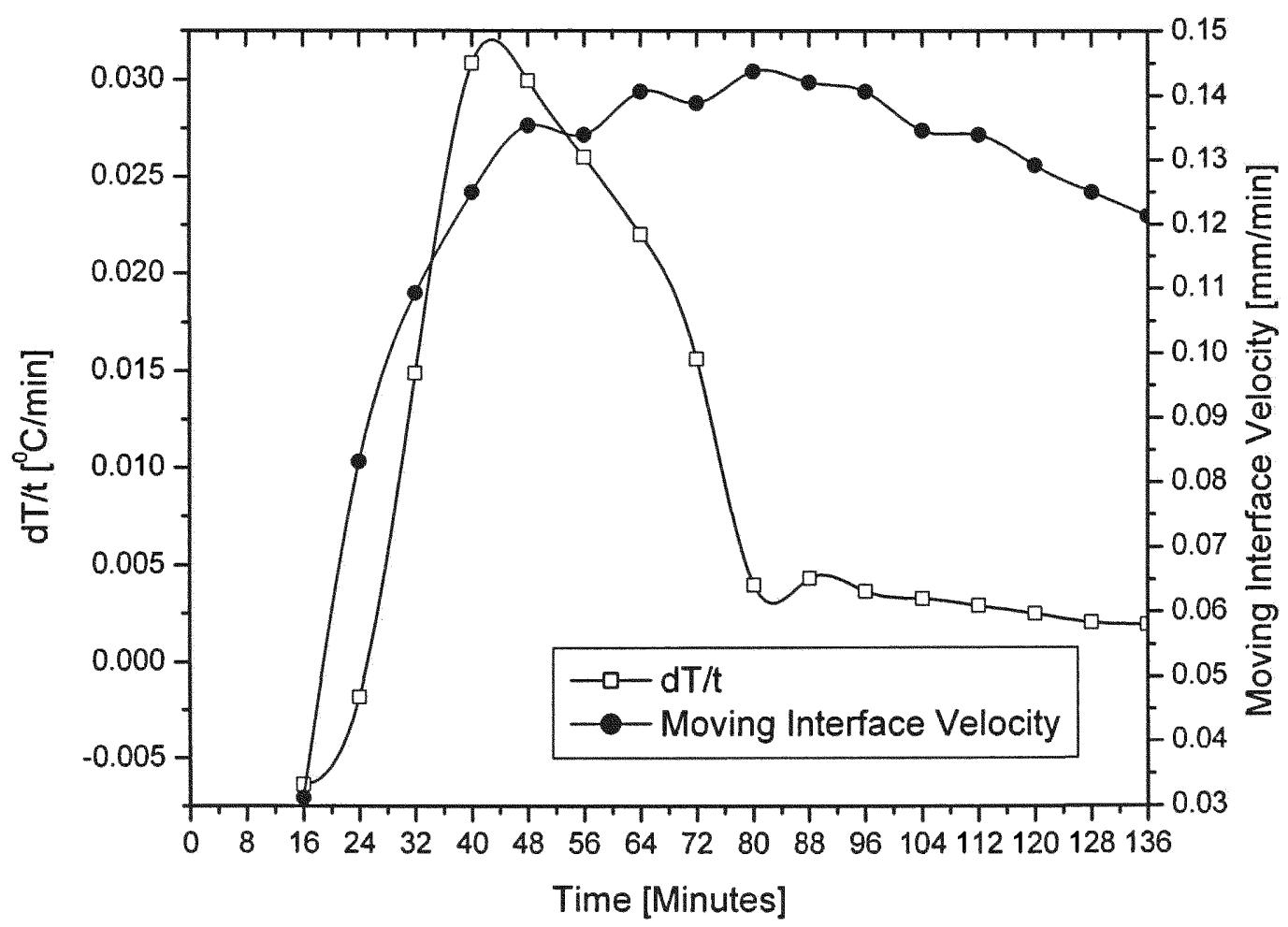

Figure 3.20 Variation of heat rate and Moving Interface Velocity with Time $(\mathrm{Y}=37)$ One cooled side, $T_{L}=-30^{\circ} \mathrm{C}, \mathrm{T}_{\mathrm{R}}=+20^{\circ} \mathrm{C}$. 
The PIV images shown in Figures 3.1 to 3.4 are used to get the velocity vectors in the melt. Figure 3.21 shows the instantaneous velocity vectors during the solidification of pure water when one wall is cooled to $-30{ }^{\circ} \mathrm{C}$ and other is maintained at $+20{ }^{\circ} \mathrm{C}$. At the beginning of the solidification process $(t=8 \mathrm{~min})$, the liquid flowed upward from the bottom of the cavity to the free water surface. It is noted that the upper water surface is in contact with air trapped in the cavity. The images show that the liquid flows at high velocities from the left cold plate to the right hot plate for the bottom half of the cavity and from the hot plate to the cold plate for the upper part of the cavity. After the solidification has proceeded for some time $(\mathrm{t}=32$ and $56 \mathrm{~min})$, a thicker frozen layer was formed near the left cold plate of the chamber. The velocity vectors show two main flow circulation regions. The first large circulation flow is driven by abnormal convection (negative buoyancy effect) and has a counter-clockwise circulation. The liquid flows from the left cold plate to the right hot plate for the bottom half of the cavity and from the hot plate to the cold plate for the upper part of the cavity. It transports the hot liquid up to the top and back to the bottom of the cavity. Interaction of the hot liquid with the freezing front causes melting and depletion of the freezing plane. The second flow circulation region, due to normal convection (positive buoyancy effect), is located in the lower part of the cavity. There, a clockwise circulation transports the cold liquid up along the adjacent ice surface and back to the bottom along the isotherm of the density extreme. The competing effects of positive and negative buoyancy forces result in a flow with these two distinct circulations. The water circulation modifies the heat balance at the interface. The convective heat transfer between both upper and lower regions seems to be limited mainly to the upper left corner of the cavity. Hence, the phase front that is only 
initially flat, with time, becomes strongly deformed. The shape of the freezing front reproduces this interaction, almost increasing the ice growth rate at the bottom. The results obtained in this study for pure water are in good agreement with those obtained previously by Giangi et al., (1990) using numerical and experimental studies. After approximately one-and-one-half hours of solidification, the thickness of the freezing layer is almost the same at the top and bottom of the cavity. The first large counterclockwise circulation flow is still present and is shifted toward the bottom of the cavity, but the small clockwise circulation flow that is transporting the cold liquid up along the adjacent ice surface disappears. The convection flow patterns during the solidification of binary $\left(\mathrm{NH}_{4} \mathrm{Cl}-\mathrm{H}_{2} \mathrm{O}\right)$ solution with various concentrations when one wall is cooled to -30 ${ }^{0} \mathrm{C}$ and other is maintained at $+20{ }^{\circ} \mathrm{C}$ are shown in Figure 3.22 to 3.24 . This figure shows the morphology and flow patterns in the fluid region at the sub-eutectic $(\mathrm{C}<19.8 \%)$ and at the eutectic region $\left(\mathrm{C}_{\mathrm{e}} \sim 19.8 \%\right)$. The convection flow patterns are different for different initial concentrations which can be seen in Figure 3.25. For pure water, where the natural convection is only due to thermal gradient (no solutal gradient), and two circulation flows are present after one hour of solidification: one counter-clockwise circulation flow located at the bottom left of the cavity and one counter-clockwise large circulation flow. At the end of the solidification process $(t=128 \mathrm{~min})$, only the large counter-clockwise circulation flow is present. By increasing the initial concentration of ammonium chloride solution, the clockwise circulation flow obtained at $\mathrm{t}=56 \mathrm{~min}$ for the pure water disappears, and the large counter-clockwise circulation flow is converted to two or more small counter-clockwise circulation flows. In convection of a singlecomponent fluid (pure water), the buoyancy force associated with temperature fluctuation 
drives the flow. Heat is advected with the convective flow and also diffuses in the liquid. For ammonium chloride solution, both thermal and solutal buoyancy forces push fluids and accelerate the flow. In a mixture of fluids of different densities, buoyancy may be created by either heat or concentration gradients, both of which are transported advectively and diffusively. In the case of ammonium chloride - water mixtures, ammonium chloride diffuses much more slowly than heat, and because of this difference in time scales, the two can get out of phase, resulting in oscillatory convection. In these mixtures, there is a large Soret effect, in which the diffusion of ammonium chloride in the mixture is driven by the temperature gradient (the ammonium chloride is pumped by the temperature gradient). Depending on the mixture, the Soret coefficient can be negative or positive, meaning that ammonium chloride can be driven toward the hotter or the colder region of the cavity. 


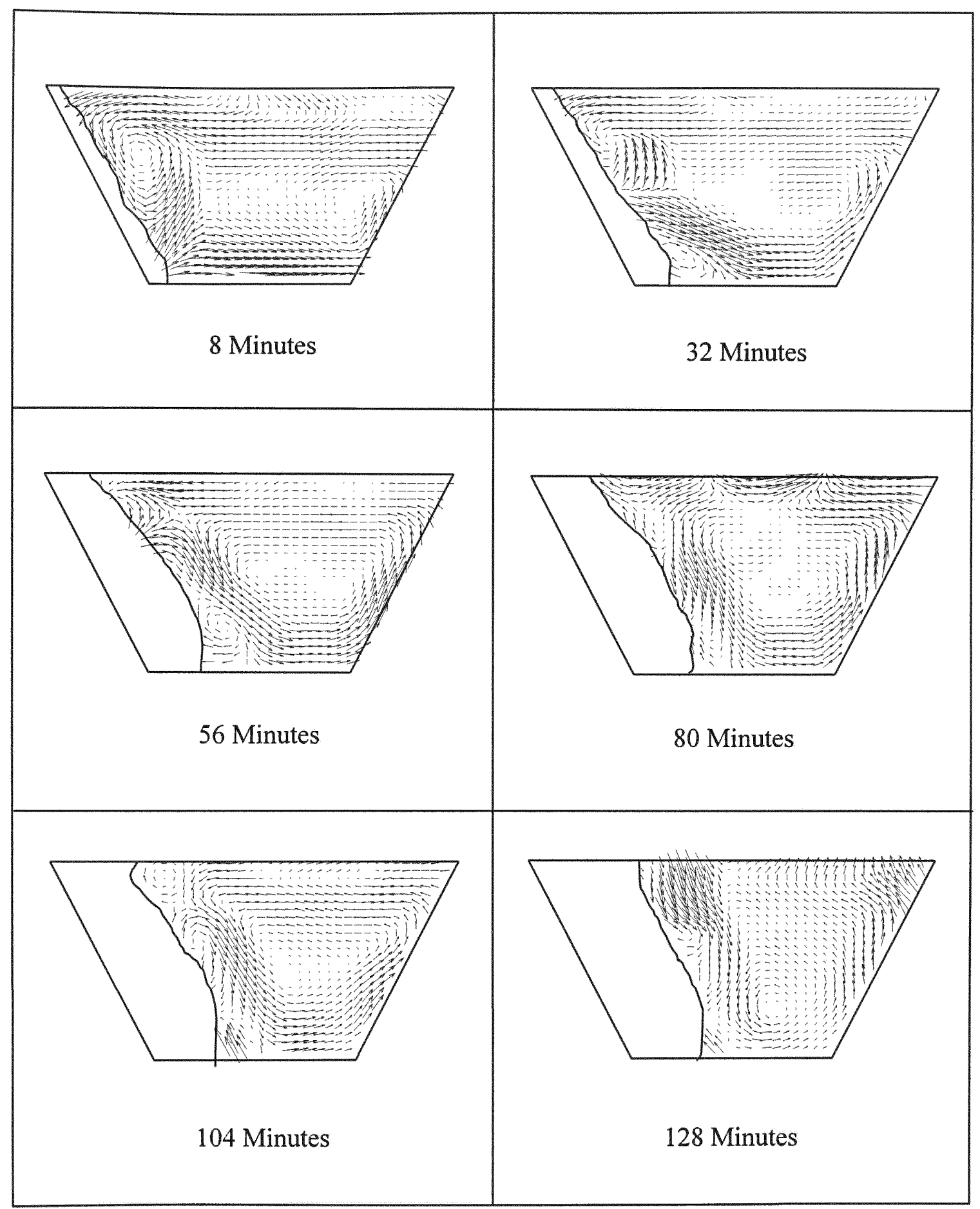

Figure 3.21 Velocity Vectors in the melt during the solidification of water: One cooled side, $T_{L}=-30^{\circ} \mathrm{C}, \mathrm{T}_{\mathrm{R}}=+20^{\circ} \mathrm{C}$. 


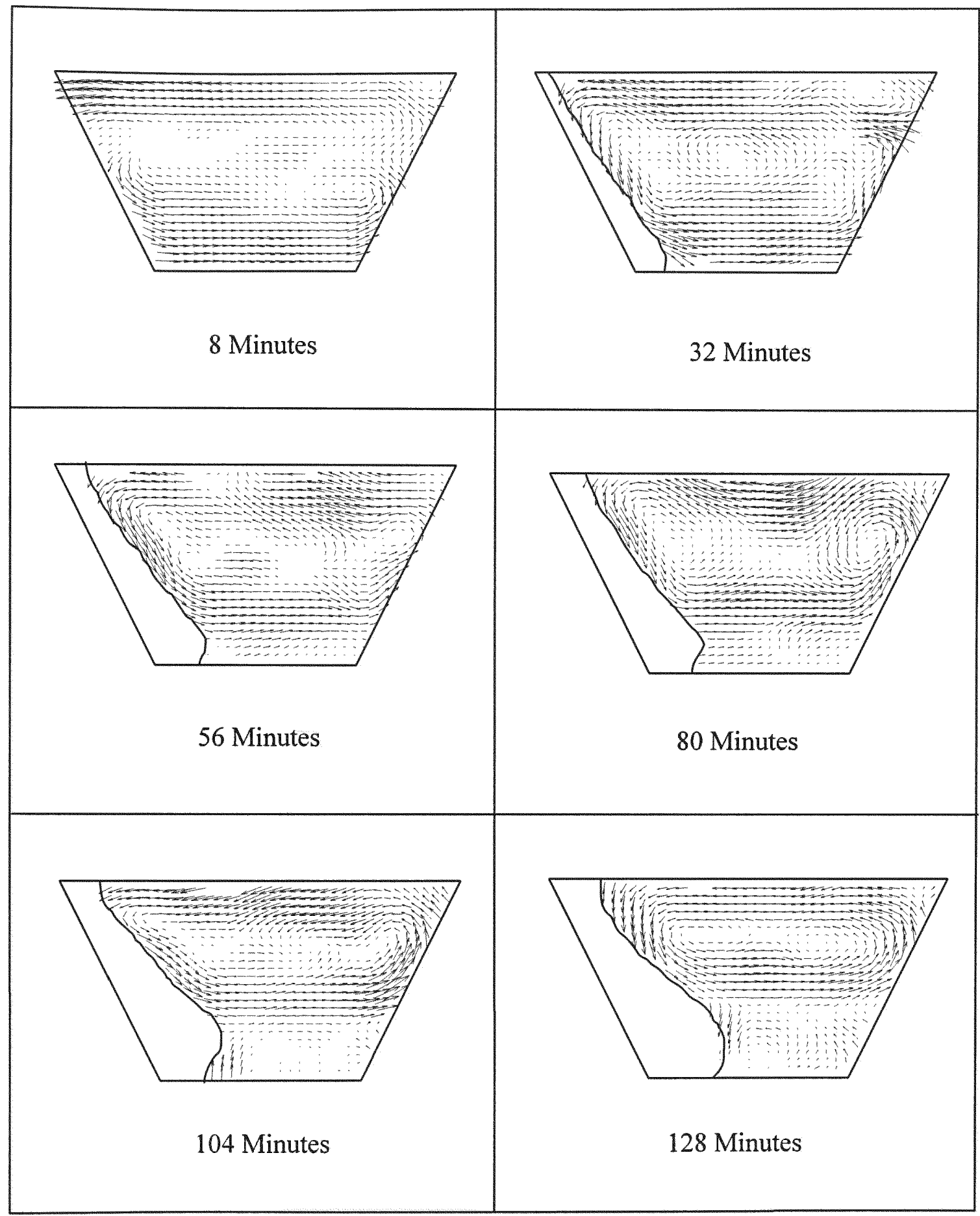

Figure 3.22 Velocity Vectors in the melt during the solidification of $5 \mathrm{Wt}$. $\% \mathrm{NH}_{4} \mathrm{Cl}-\mathrm{H}_{2} \mathrm{O}$ : One cooled side, $T_{L}=-30^{\circ} \mathrm{C}, \mathrm{T}_{\mathrm{R}}=+20^{\circ} \mathrm{C}$. 


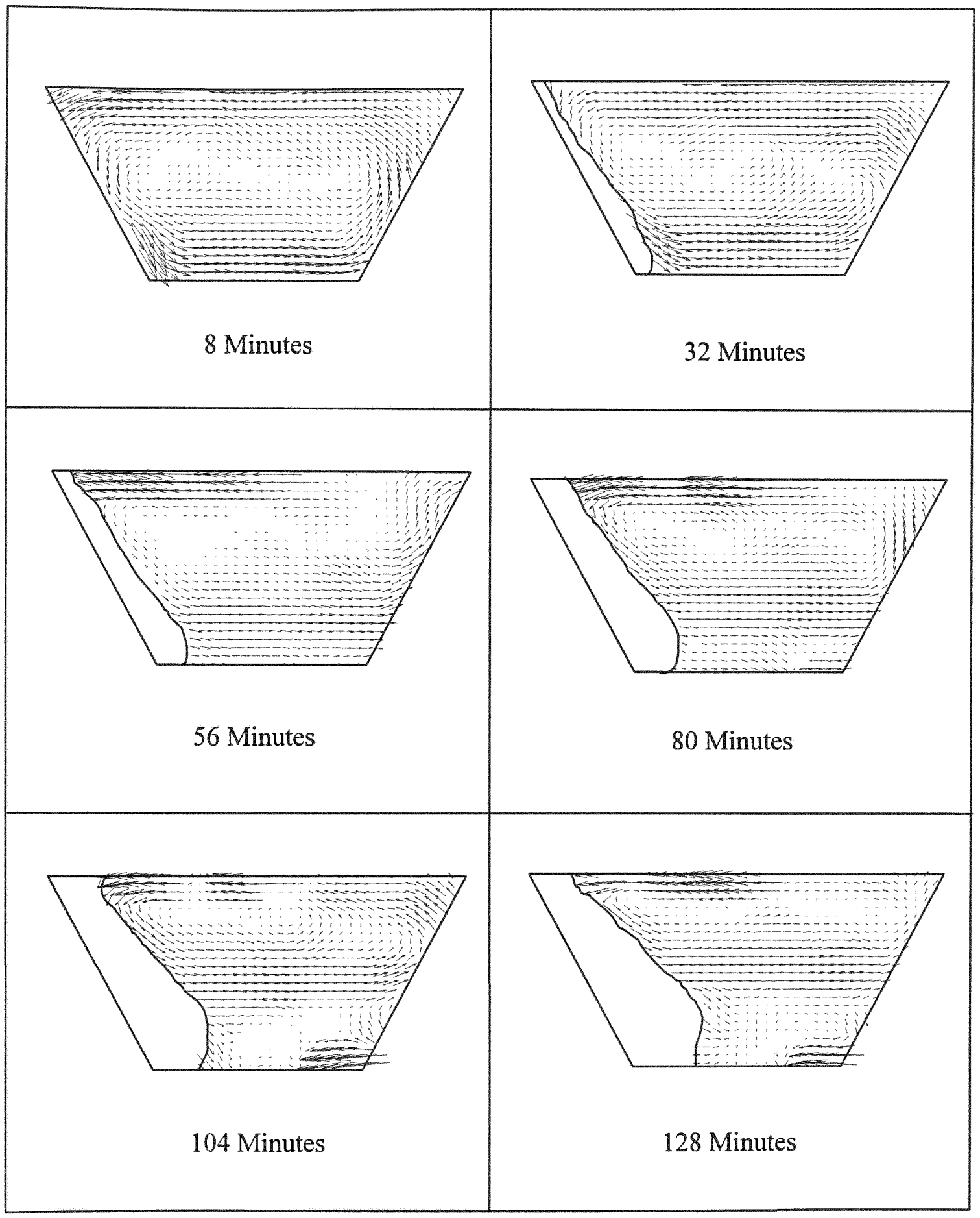

Figure 3.23 Velocity Vectors in the melt during the solidification of $12 \mathrm{Wt}$. $\% \mathrm{NH}_{4} \mathrm{Cl}-\mathrm{H}_{2} \mathrm{O}$ : One cooled side, $T_{L}=-30^{\circ} \mathrm{C}, \mathrm{T}_{\mathrm{R}}=+20^{\circ} \mathrm{C}$. 


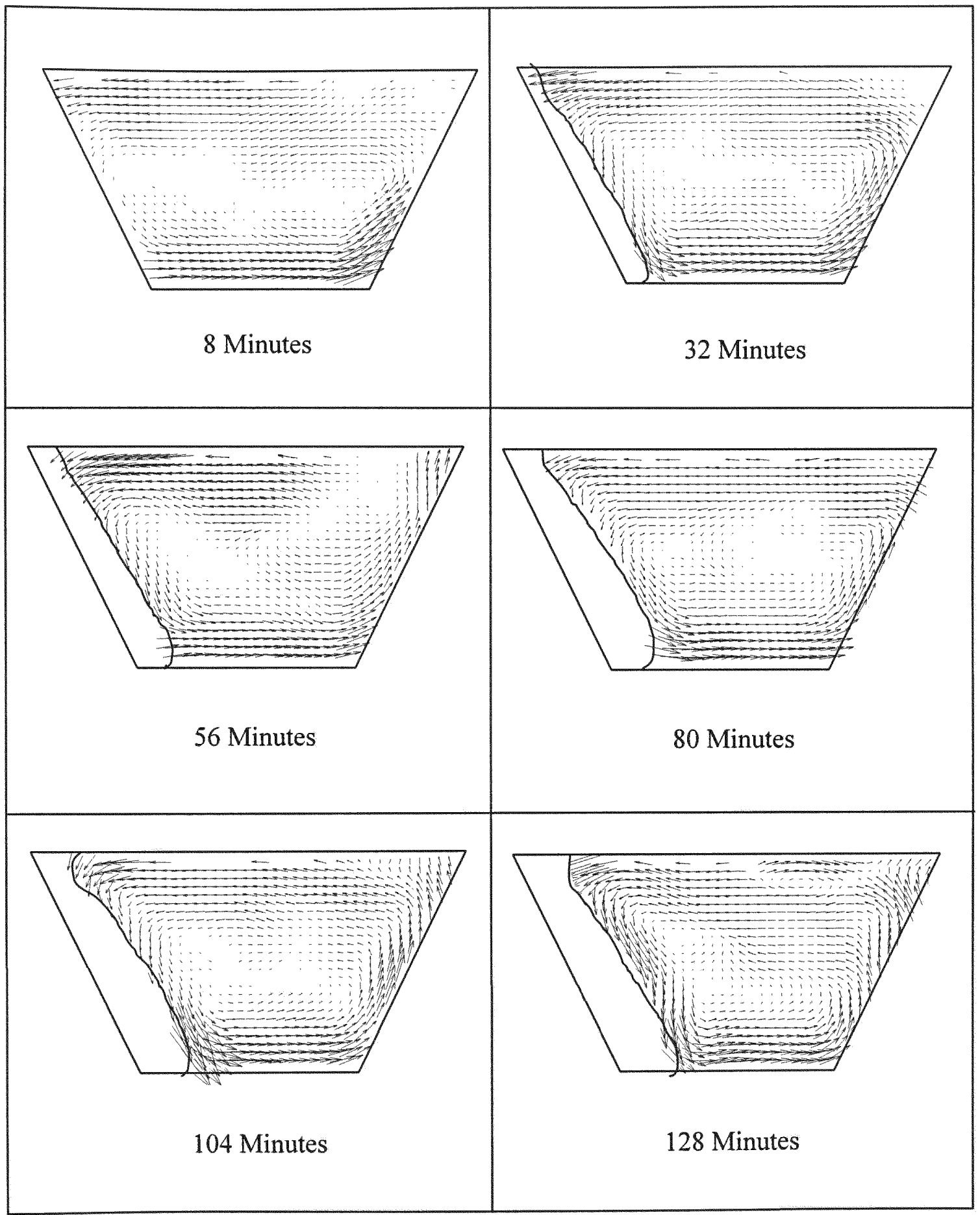

Figure 3.24 Velocity Vectors in the melt during the solidification of $19.8 \mathrm{Wt} . \% \mathrm{NH}_{4} \mathrm{Cl}-\mathrm{H}_{2} \mathrm{O}$ : One cooled side, $T_{L}=-30^{\circ} \mathrm{C}, \mathrm{T}_{\mathrm{R}}=+20^{\circ} \mathrm{C}$. 


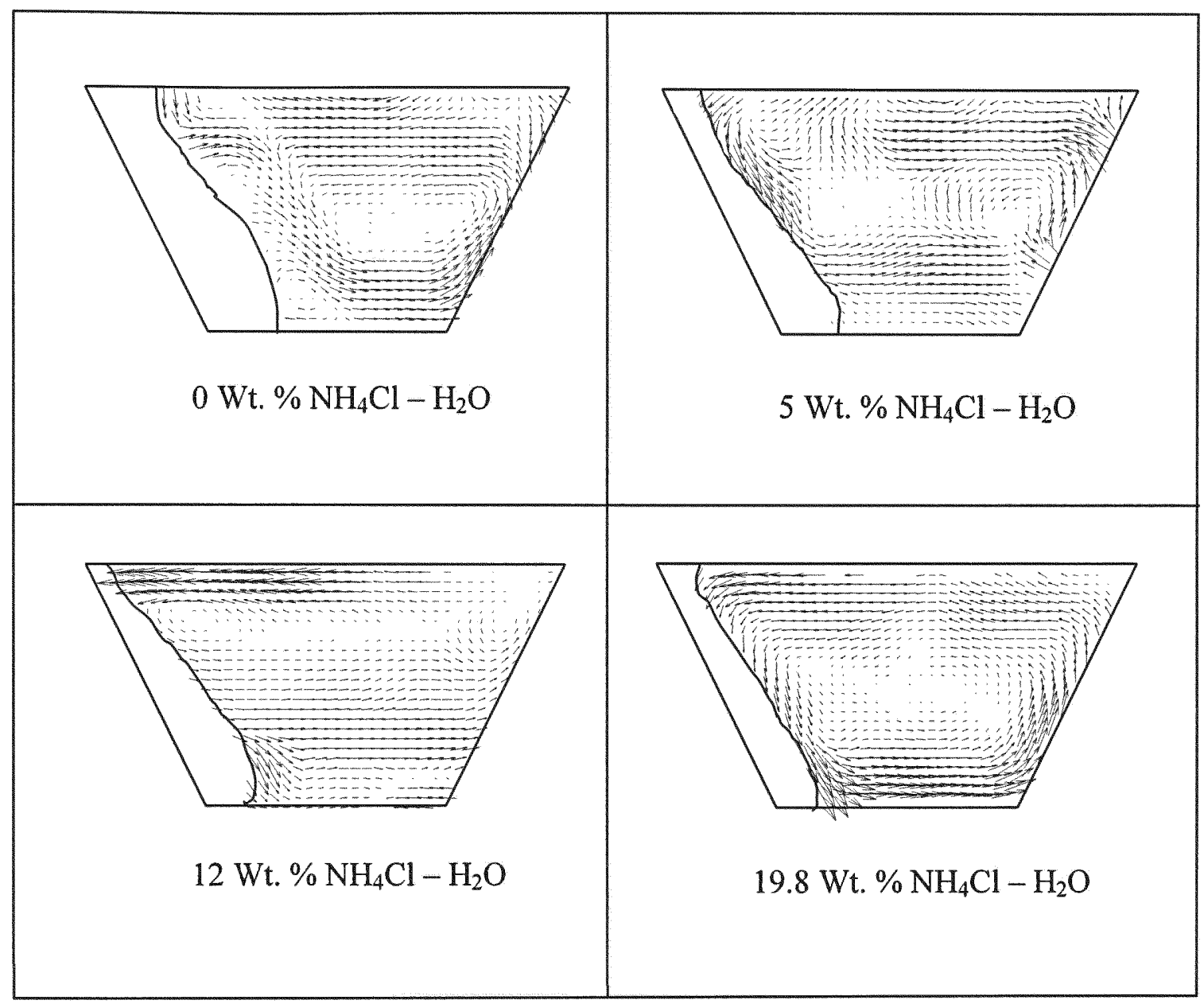

Figure 3.25 Velocity Vectors showing the effect of the Initial Concentration on the Solidification Process; One cooled side: Time $(t)=64$ Minutes, $T_{L}=-30^{\circ} \mathrm{C}, T_{R}=+20^{\circ} \mathrm{C}$. 
The temperature distribution inside the cavity varies with initial concentration. The effect of initial concentration on the temperature distribution is studied for different boundary conditions. Figures 3.26 to 3.30 show the effect of initial concentration on the temperature distribution at different times and with different boundary conditions. Figure 3.26 show the how the temperature distribution changed with the initial concentration at 16 minutes when one wall is cooled to $-30{ }^{\circ} \mathrm{C}$ and another is maintained at room temperature. Figures $3.27 \& 3.28$ show the effect of initial concentration on the temperature distribution inside the cavity at 72 and 128 minutes respectively when one wall is cooled to $-30{ }^{\circ} \mathrm{C}$ and another is maintained at room temperature. Figures 3.29 and 3.30 shows the change in temperature in the cavity with change in concentration at 72 minutes when one wall is cooled to $-20{ }^{\circ} \mathrm{C}$ and $-10{ }^{\circ} \mathrm{C}$ respectively.

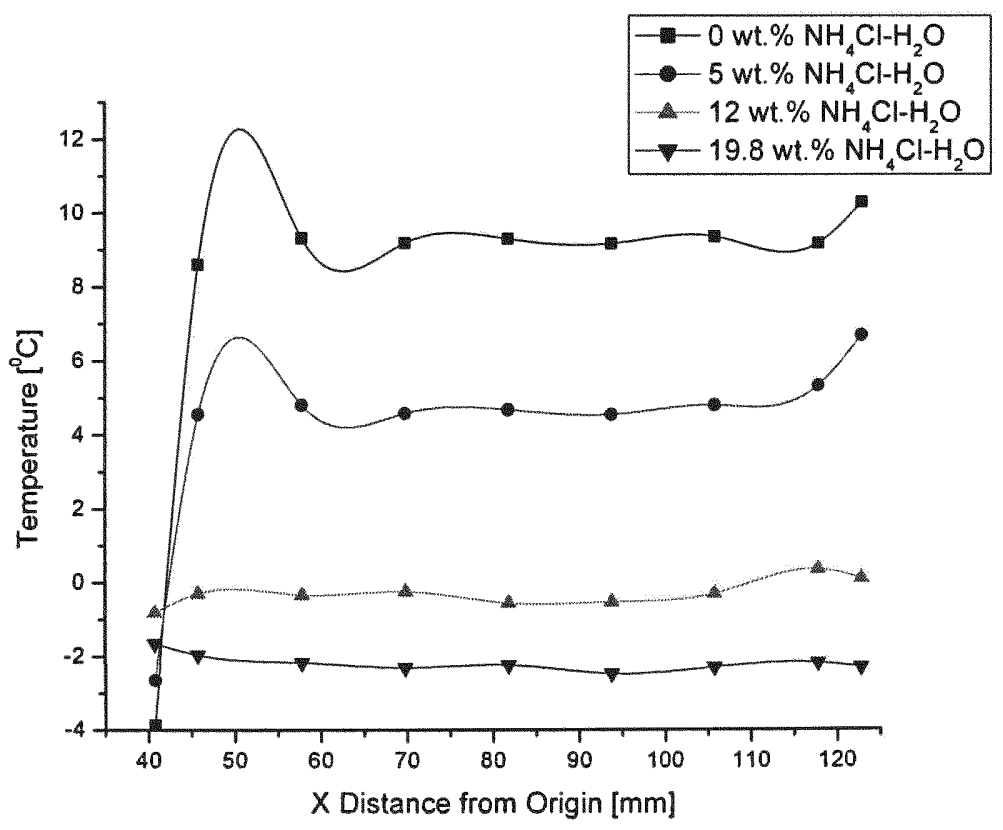

Figure 3.26 Effect of Initial Concentration on Temperature Distribution inside the cavity; $Y=37 \mathrm{~mm}$; One wall Cooled; Time $(t)=16$ Minutes, $T_{L}=-30^{\circ} \mathrm{C} ; T_{R}=+20^{\circ} \mathrm{C}$. 


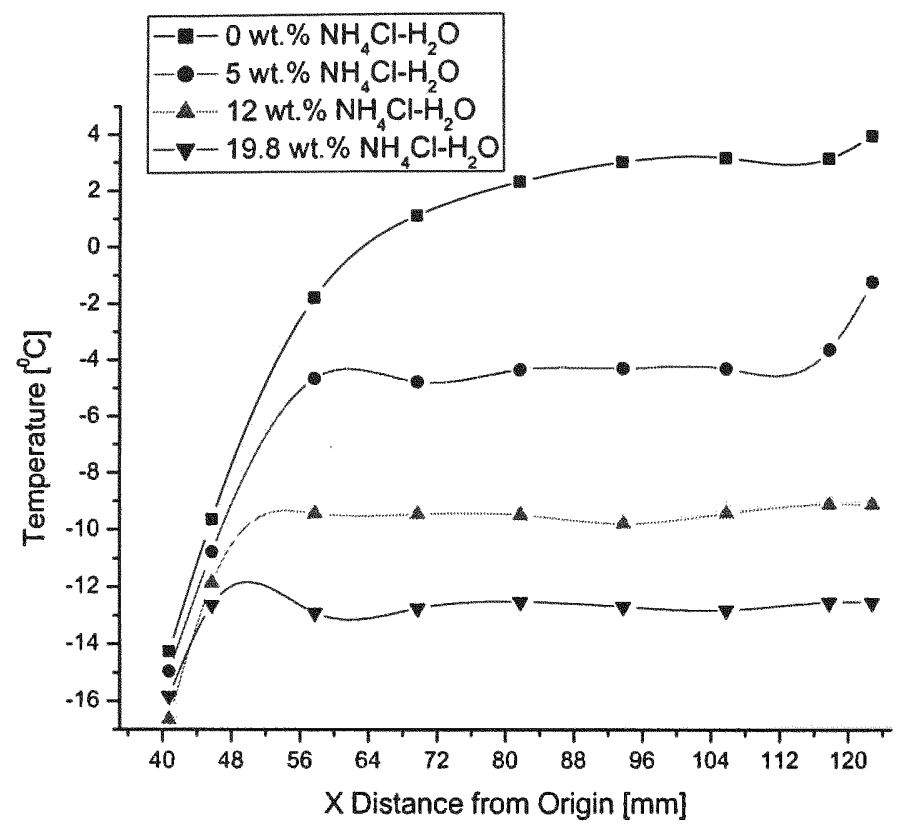

Figure 3.27 Effect of Initial Concentration on Temperature Distribution inside the cavity; $Y=37 \mathrm{~mm}$; One wall Cooled; Time $(t)=72$ Minutes, $T_{L}=-30{ }^{\circ} \mathrm{C} ; T_{R}=+20^{\circ} \mathrm{C}$.

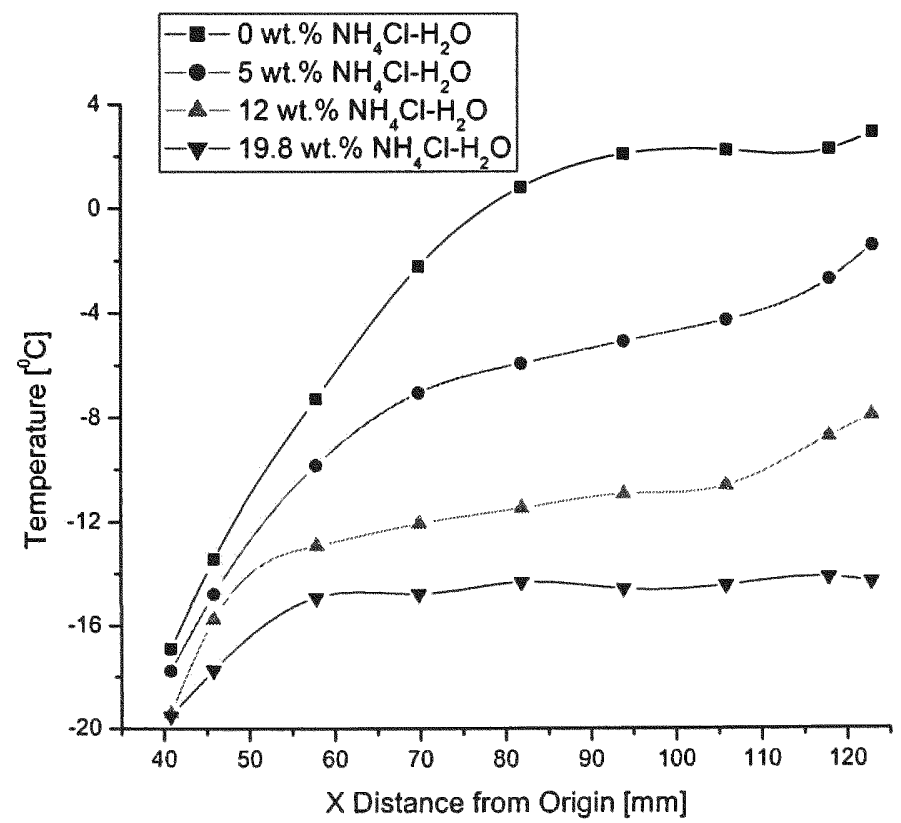

Figure 3.28 Effect of Initial Concentration on Temperature Distribution inside the cavity; $Y=37 \mathrm{~mm}$; One wall Cooled; Time $(t)=128$ Minutes, $T_{L}=-30^{\circ} \mathrm{C} ; T_{R}=+20^{\circ} \mathrm{C}$. 


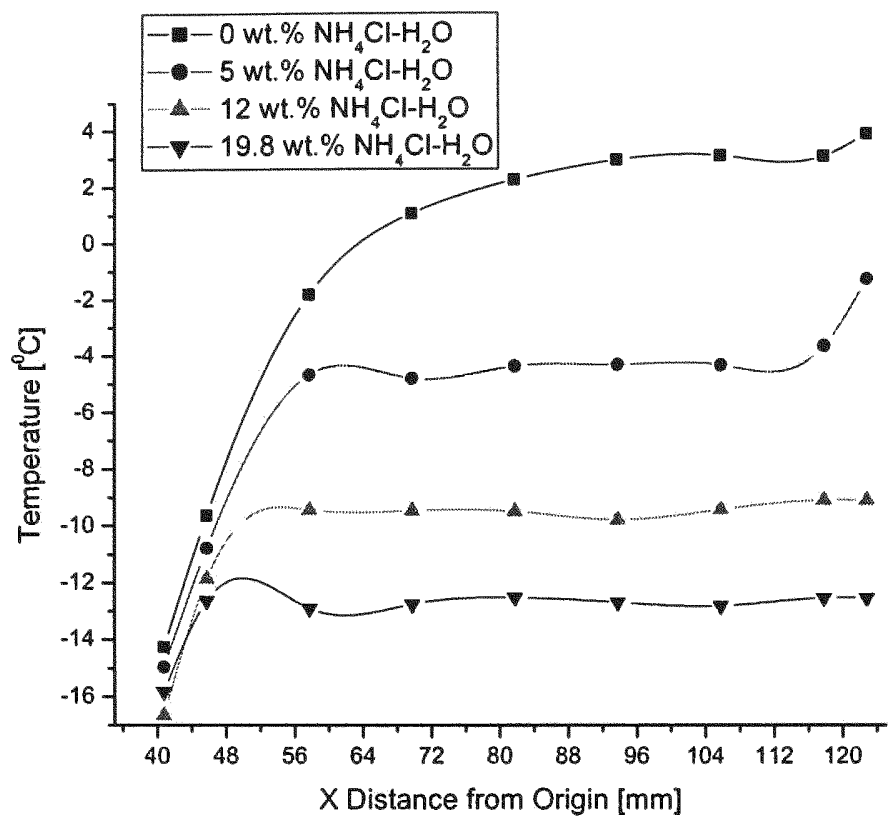

Figure 3.29 Effect of Initial Concentration on Temperature Distribution inside the cavity; $Y=37 \mathrm{~mm}$; One wall Cooled; Time $(t)=72$ Minutes, $T_{L}=-20^{\circ} \mathrm{C} ; T_{R}=+20^{\circ} \mathrm{C}$.

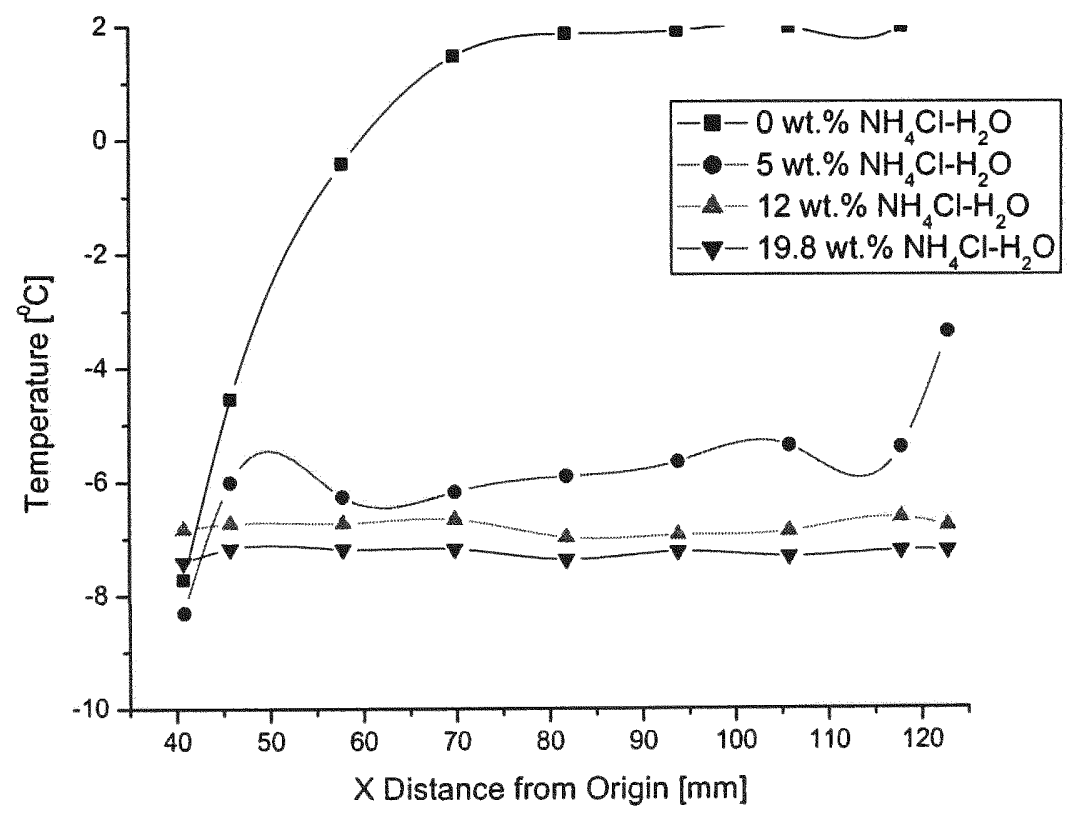

Figure 3.30 Effect of Initial Concentration on Temperature Distribution inside the cavity; $Y=37 \mathrm{~mm}$; One wall Cooled; Time $(t)=72$ Minutes, $T_{L}=-10^{\circ} \mathrm{C} ; T_{R}=+20^{\circ} \mathrm{C}$. 


\subsubsection{Effect of Initial Concentration - Two Wall Cooled}

Figure 3.31 shows the PIV images obtained during the solidification of pure water when left and right side walls are cooled at $-30^{\circ} \mathrm{C}$. Figures $3.32,3.33$, \& 3.34 shows the PIV images obtained during the solidification of $5 \%, 12 \%$, \& $19.8 \% \mathrm{NH}_{4} \mathrm{Cl}-\mathrm{H}_{2} \mathrm{O}$ solution respectively when both walls are maintained at $-30{ }^{\circ} \mathrm{C}$. We observe that the frozen layer thickness is more when compared to one wall cooled at $-30{ }^{\circ} \mathrm{C}$ (Figure 3.1 ). We also observe that the frozen layer thickness on both sides are same as the maintained temperatures on both sides are same and also we observe the same phenomena that observed in one wall cooled i.e., solid formation decreases as the concentration increases.

The effect of initial concentration on solidification process with different boundary conditions can be seen in Figure 3.35 \& Figure 3.36. Figure 3.35 shows the PIV images of solidification process of $\mathrm{NH}_{4} \mathrm{Cl}-\mathrm{H}_{2} \mathrm{O}$ with different concentrations at 64 minutes (middle of the experiment) when both side walls are cooled at $-30{ }^{\circ} \mathrm{C}$. Figure 3.36 shows the solidification process of $\mathrm{NH}_{4} \mathrm{Cl}-\mathrm{H}_{2} \mathrm{O}$ with different concentrations at 64 minutes (middle of the experiment) when one wall is cooled at $-30{ }^{\circ} \mathrm{C}$ and other wall is cooled to $-10^{\circ} \mathrm{C}$. 


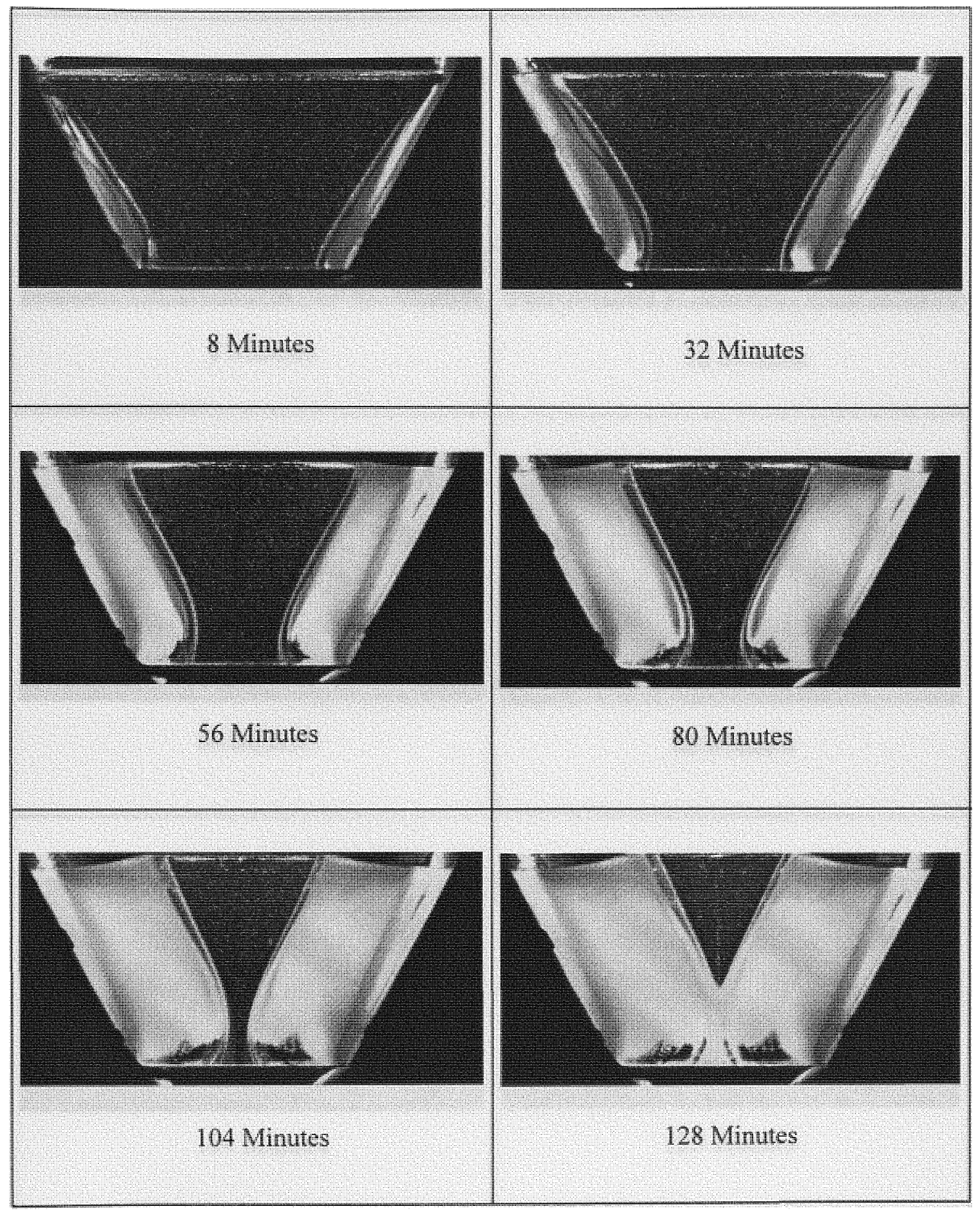

Figure 3.31 PIV Images of the solidification of water: Two Wall cooled side, $T_{L}=T_{R}=-30^{\circ} \mathrm{C}$. 


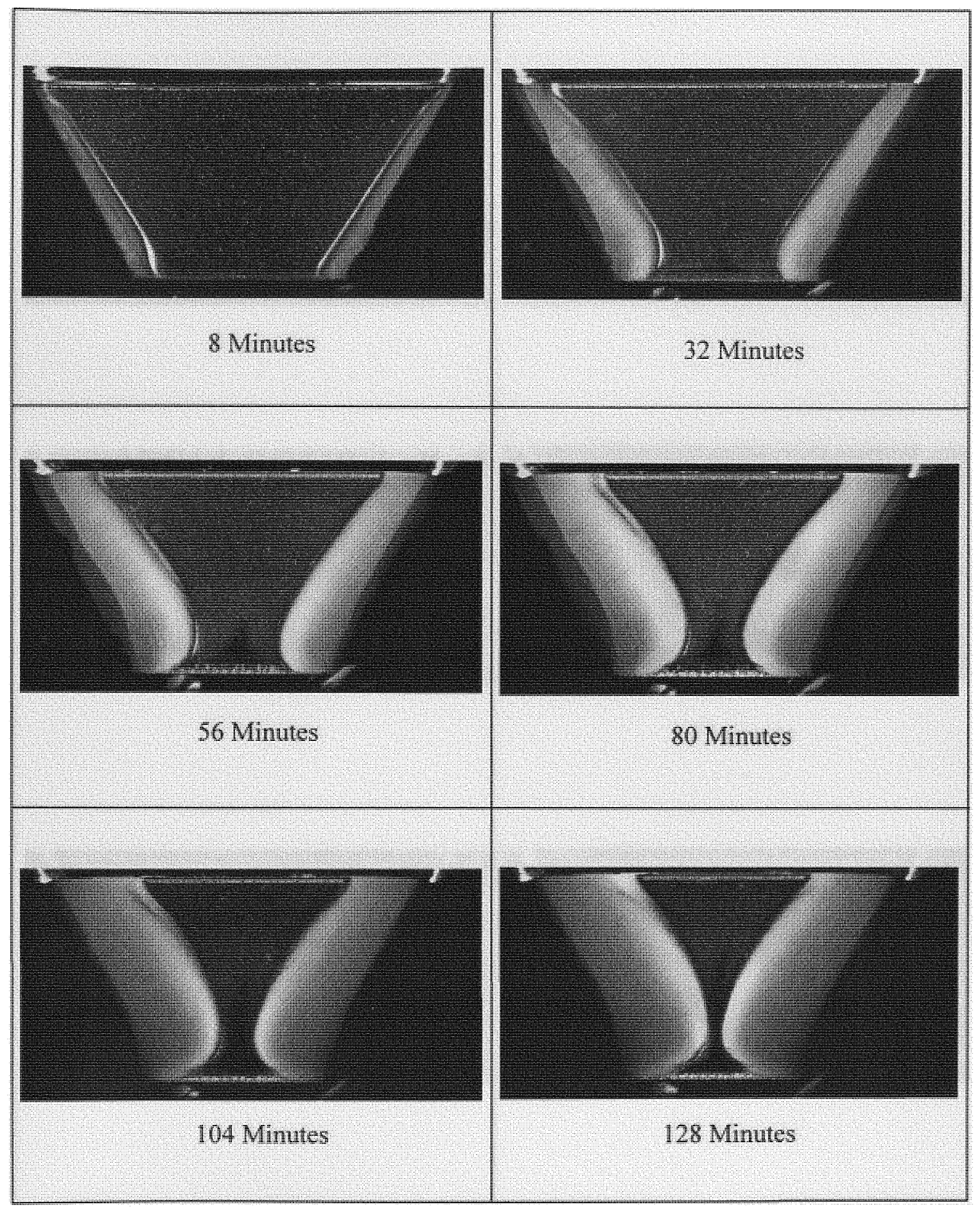

Figure 3.32 PIV Images of the solidification of $5 \% \mathrm{NH}_{4} \mathrm{Cl}-\mathrm{H}_{2} \mathrm{O}$ :

Two Wall cooled side, $T_{L}=T_{R}=-30^{\circ} \mathrm{C}$. 


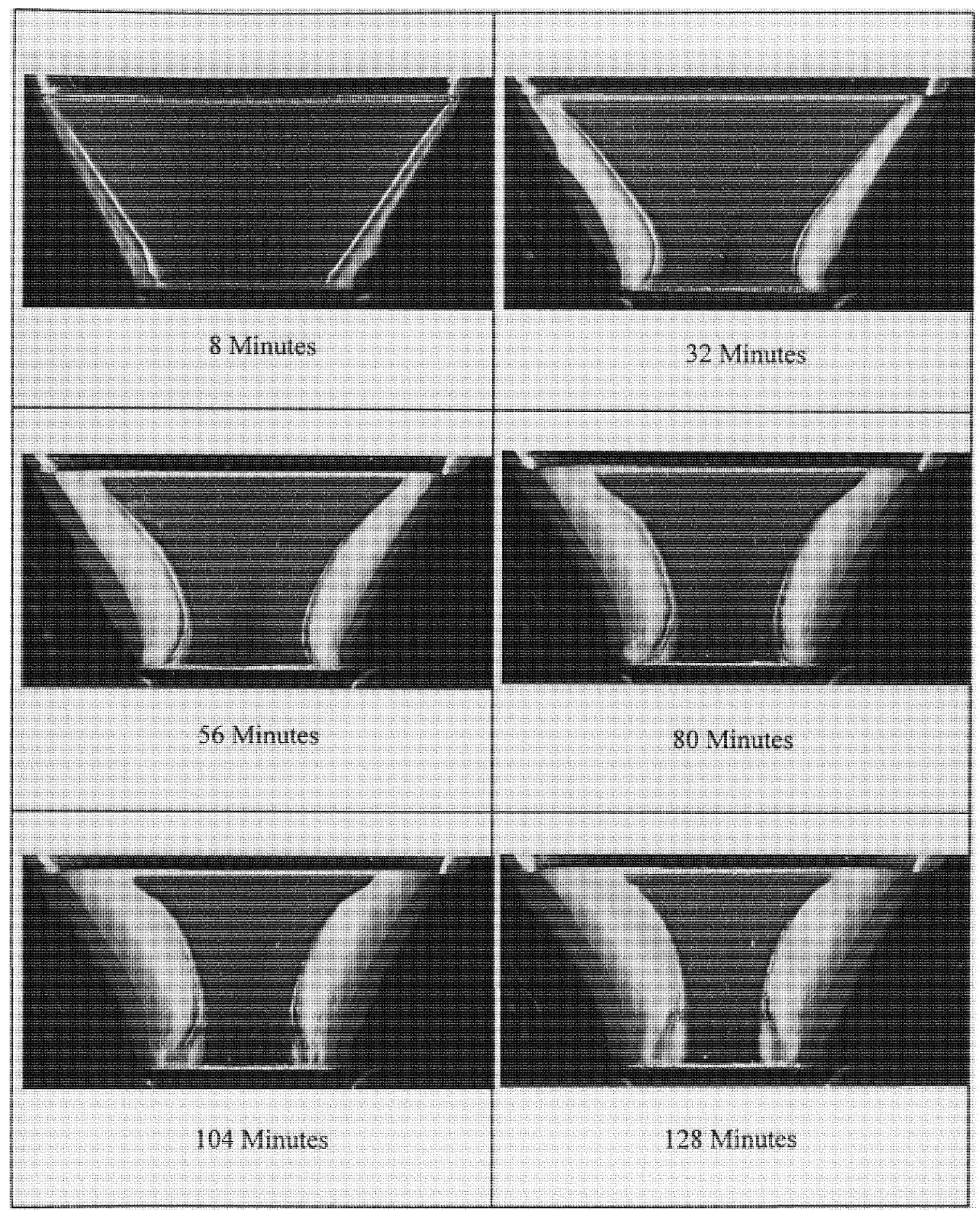

Figure 3.33 PIV Images of the solidification of $12 \% \mathrm{NH}_{4} \mathrm{Cl}-\mathrm{H}_{2} \mathrm{O}$ :

Two Wall cooled side, $T_{L}=T_{R}=-30^{\circ} \mathrm{C}$. 


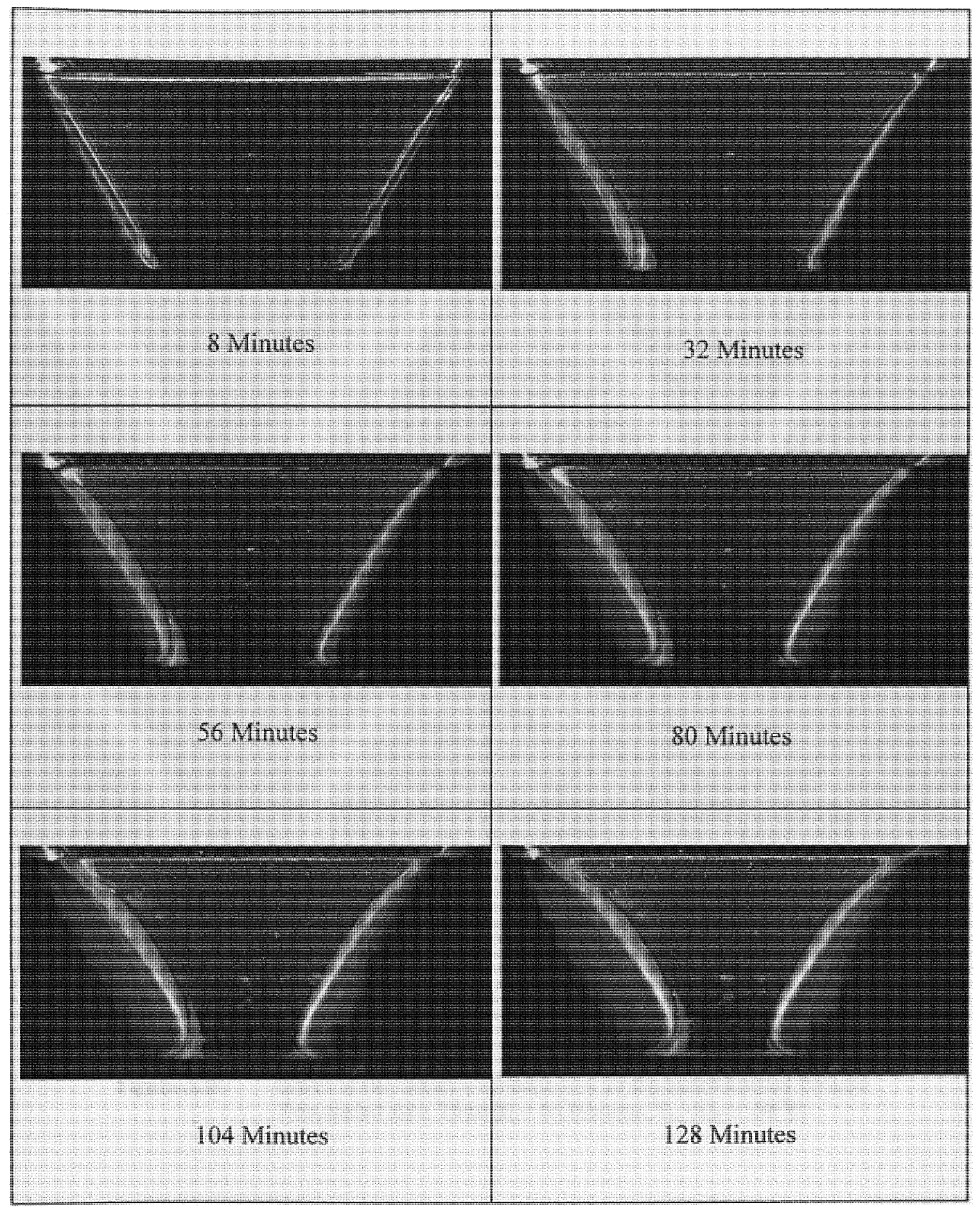

Figure 3.34 PIV Images of the solidification of $19.8 \% \mathrm{NH}_{4} \mathrm{Cl}-\mathrm{H}_{2} \mathrm{O}$ :

Two Wall cooled side, $T_{L}=T_{R}=-30^{\circ} \mathrm{C}$. 


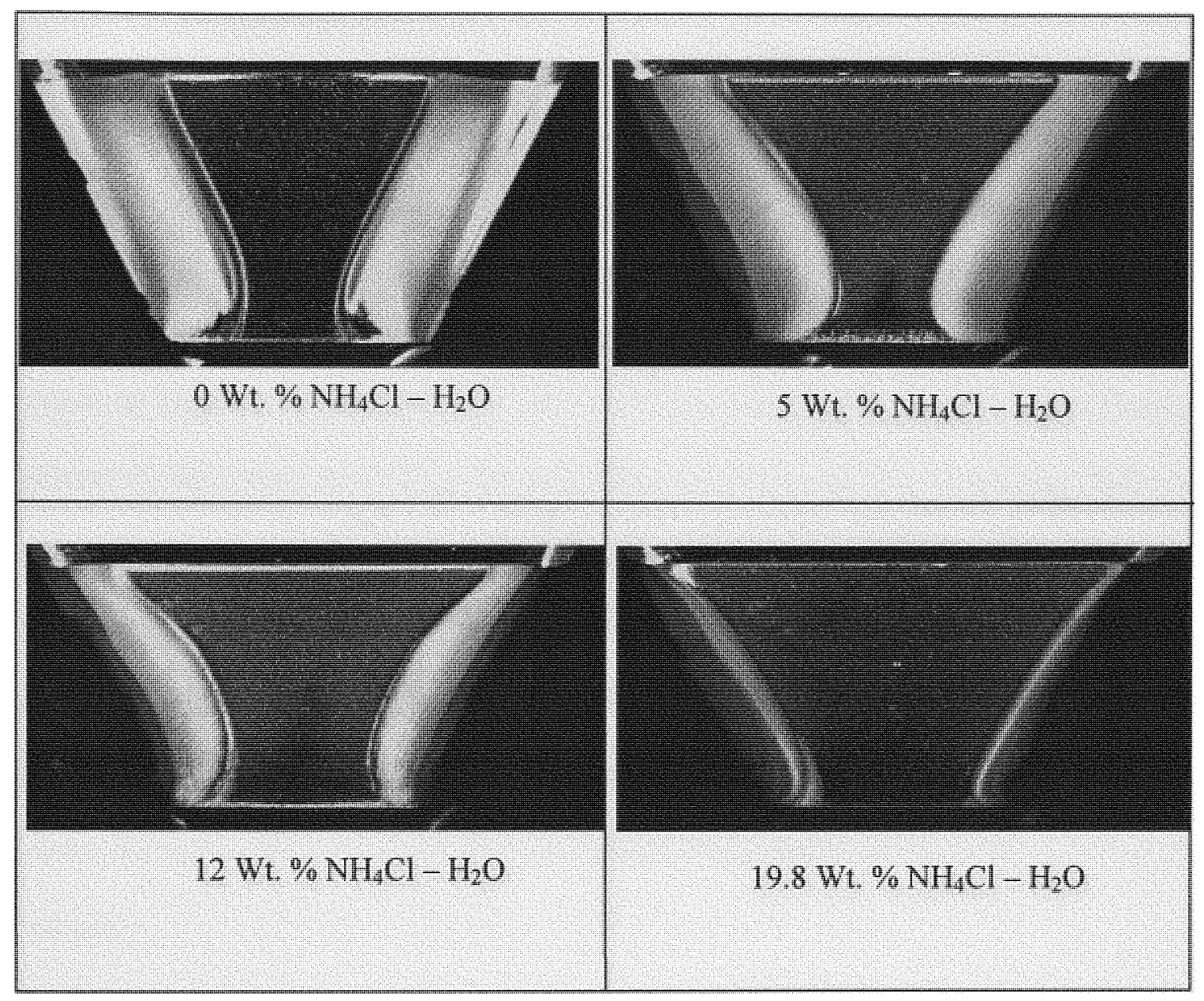

Figure 3.35 Effect of the Initial Concentration on the Solidification Process Two cooled side: Time $(t)=64$ Minutes, $T_{L}=T_{R}=-30{ }^{\circ} \mathrm{C}$. 


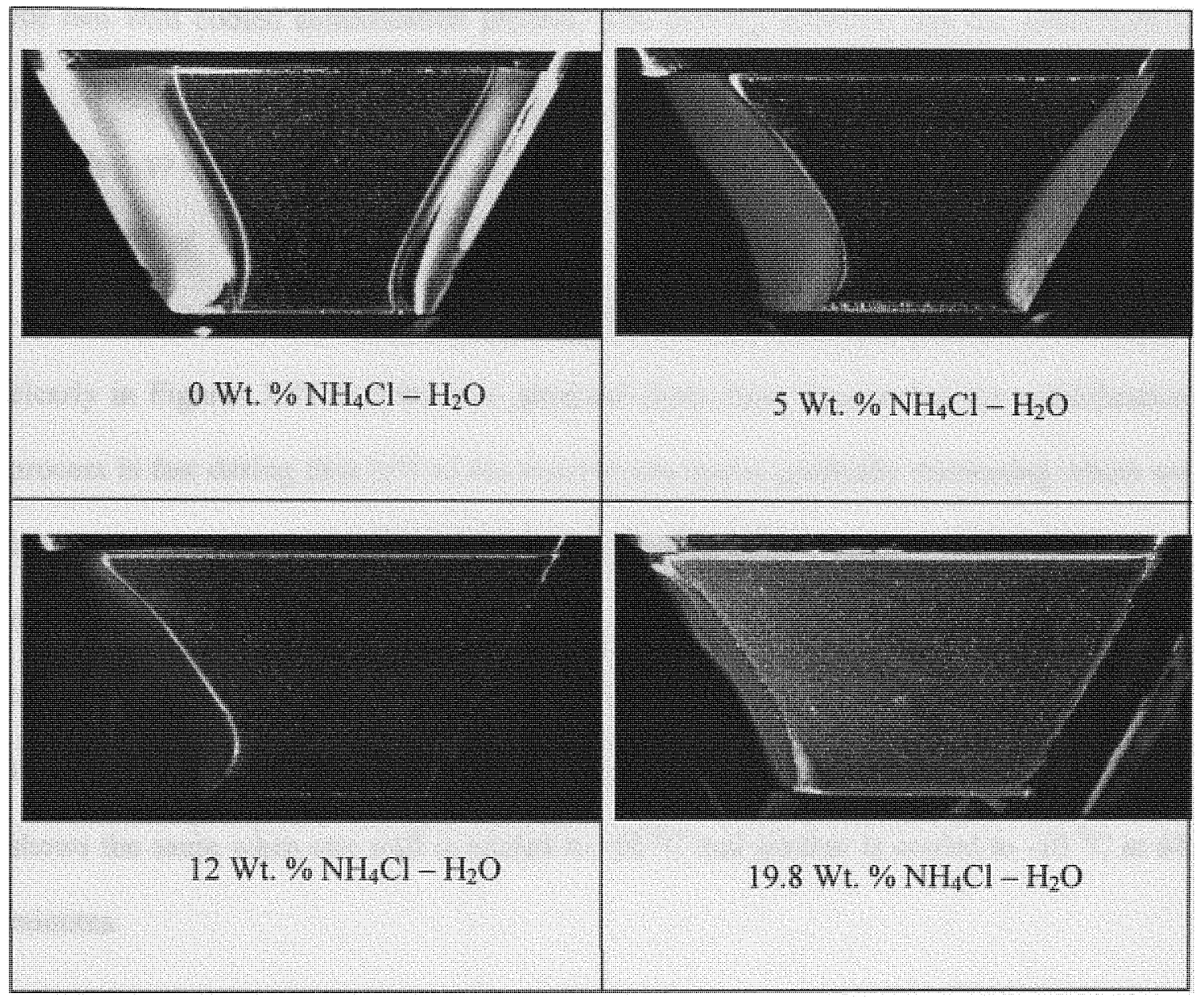

Figure 3.36 Effect of the Initial Concentration on the Solidification Process Two cooled side: $T$ ime $(t)=64$ Minutes, $T_{L}=-30^{\circ} \mathrm{C} \& T_{R}=-10^{\circ} \mathrm{C}$. 
Figures 3.8 to 3.12 show the solidification contours for different concentration when one wall is cooled. Similarly Figures 3.37 to 3.42 show the solidification contours for different concentrations when two walls are cooled. Figures 3.31 to 3.36 show the PIV images which show the location of the seeding particles and also the ice formation for two wall cooled solidification process. The moving interface and the solidification can be well understood by looking at the solidification contours for different times. Figures 3.37 to 3.40 show the solidification contours at different times for $0 \%, 5 \%, 12 \%$, and $19.8 \%$ of $\mathrm{NH}_{4} \mathrm{Cl}-\mathrm{H}_{2} \mathrm{O}$ solutions respectively when both the walls are cooled to $-30{ }^{\circ} \mathrm{C}$. It is seen that the frozen layer formed on both the walls are same and also shown clearly in Figures $3.47 \& 3.48$. It is observed from these figures that the solidification process is fast during first half of the experiments and is gradually decreasing which we have seen from the moving interface velocity profiles (Figures $3.49 \& 3.50$ ). Figure 3.41 \& 5.42 shows the effect of initial concentration on solidification process for different boundary conditions. Figure 3.41 shows the effect of initial concentration on the solidification process when both walls are cooled to $-30{ }^{\circ} \mathrm{C}$ at 64 minutes. Figure 3.42 shows the same when one wall is cooled to $-30{ }^{\circ} \mathrm{C}$ and another is cooled to $-10{ }^{\circ} \mathrm{C}$ at 64 minutes. 


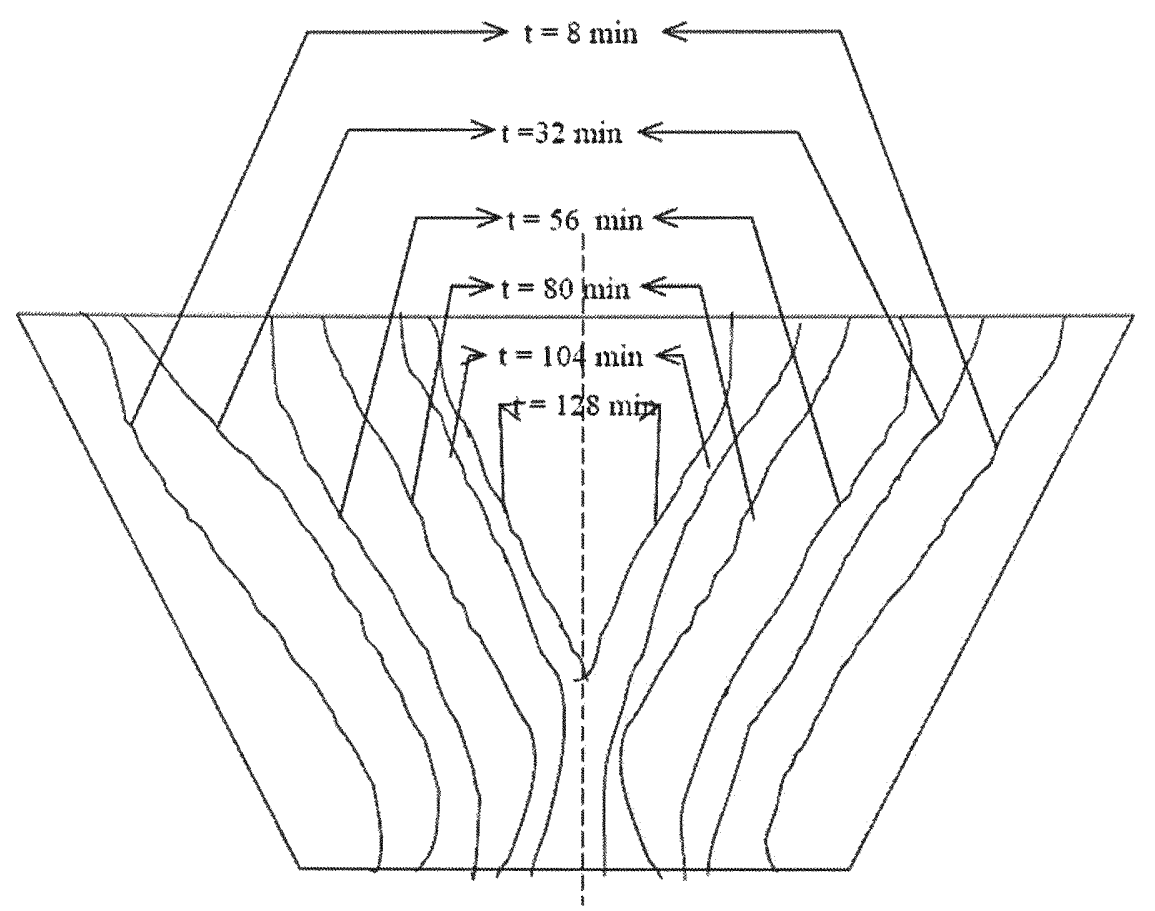

Figure 3.37 Solidification Contours for water: $T$ wo wall cooled, $T_{L}=T_{R}=-30^{\circ} \mathrm{C}$.

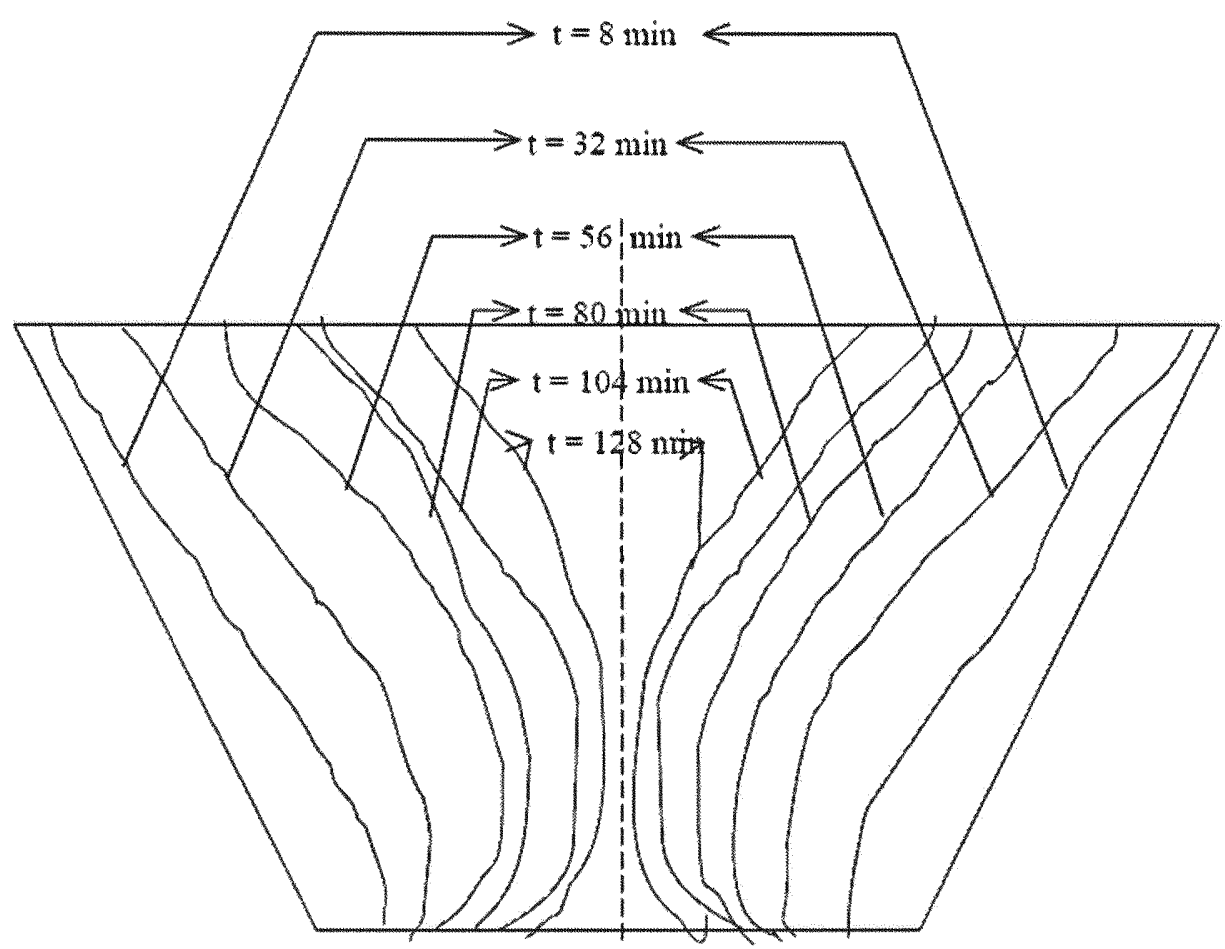

Figure 3.38 Solidification Contours for $5 \% \mathrm{NH}_{4} \mathrm{Cl}-\mathrm{H}_{2} \mathrm{O}$ :

Two wall cooled, $\mathbf{T}_{L}=\mathbf{T}_{\mathrm{R}}=-30^{\circ} \mathrm{C}$. 


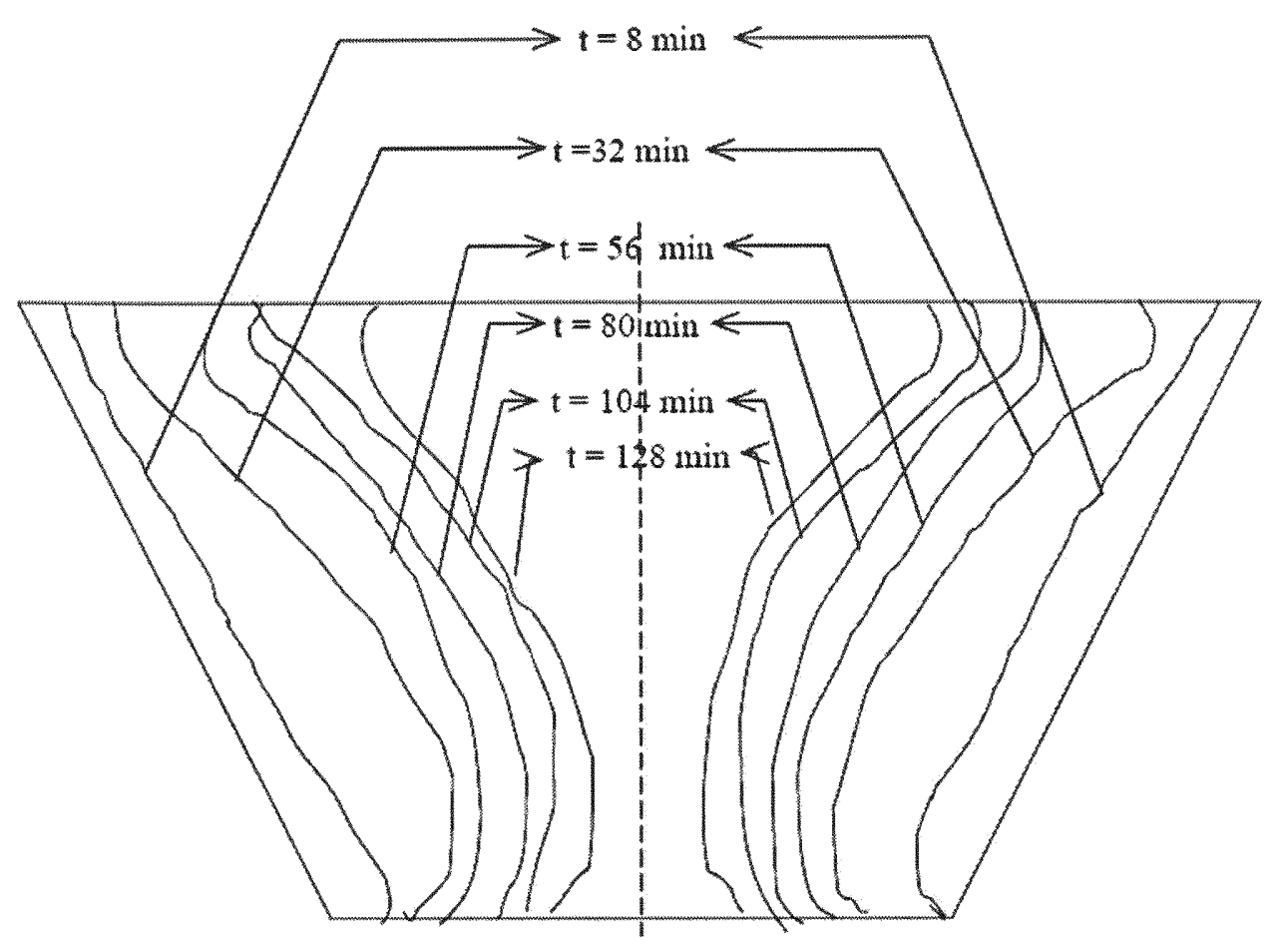

Figure 3.39 Solidification Contours for $12 \% \mathrm{NH}_{4} \mathrm{Cl}-\mathrm{H}_{2} \mathrm{O}$ :

Two wall cooled, $T_{L}=T_{R}=-30^{\circ} \mathrm{C}$.

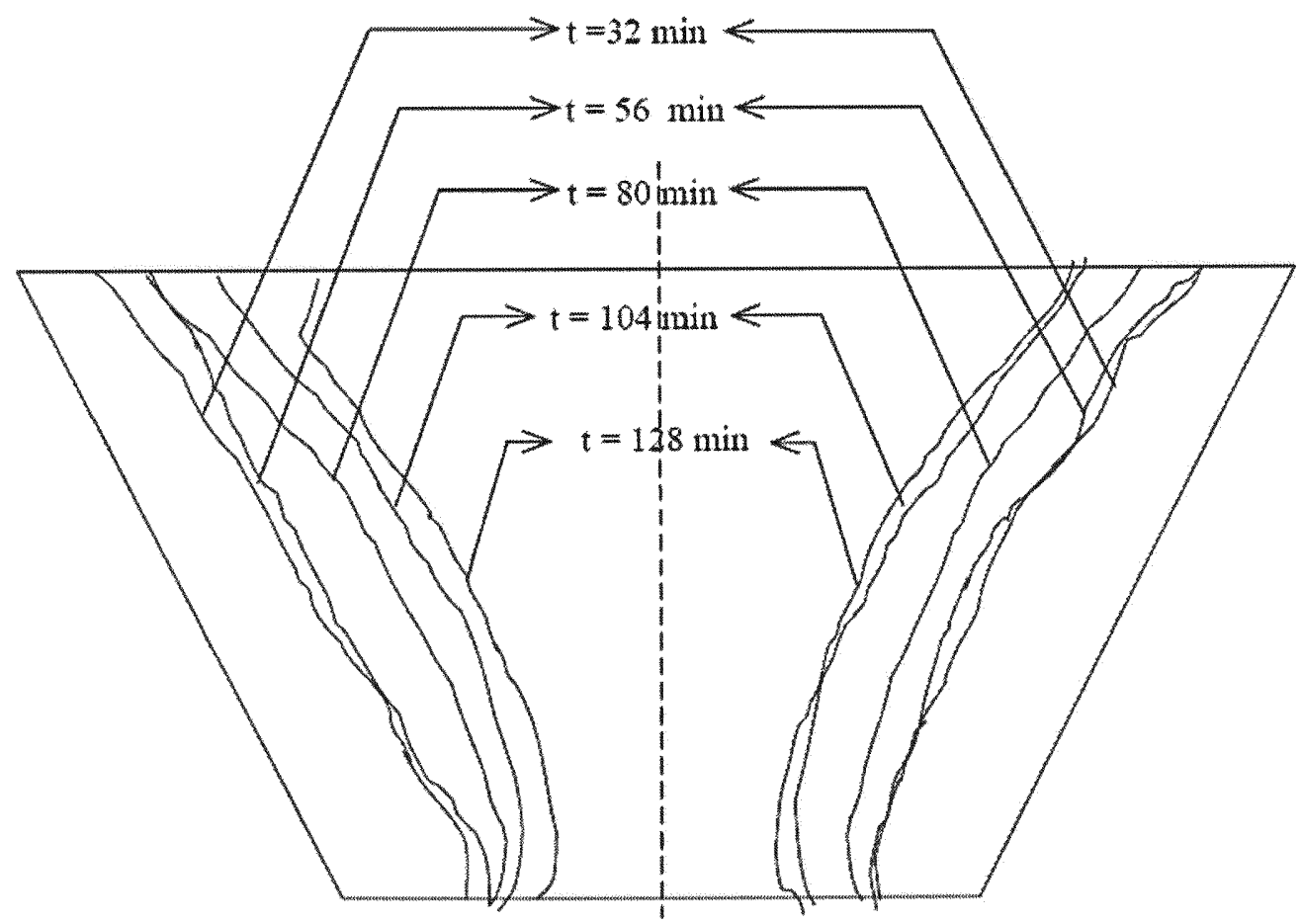

Figure 3.40 Solidification Contours for $19.8 \% \mathrm{NH}_{4} \mathrm{Cl}-\mathrm{H}_{2} \mathrm{O}$ :

Two wall cooled, $T_{L}=T_{R}=-30^{\circ} \mathrm{C}$. 


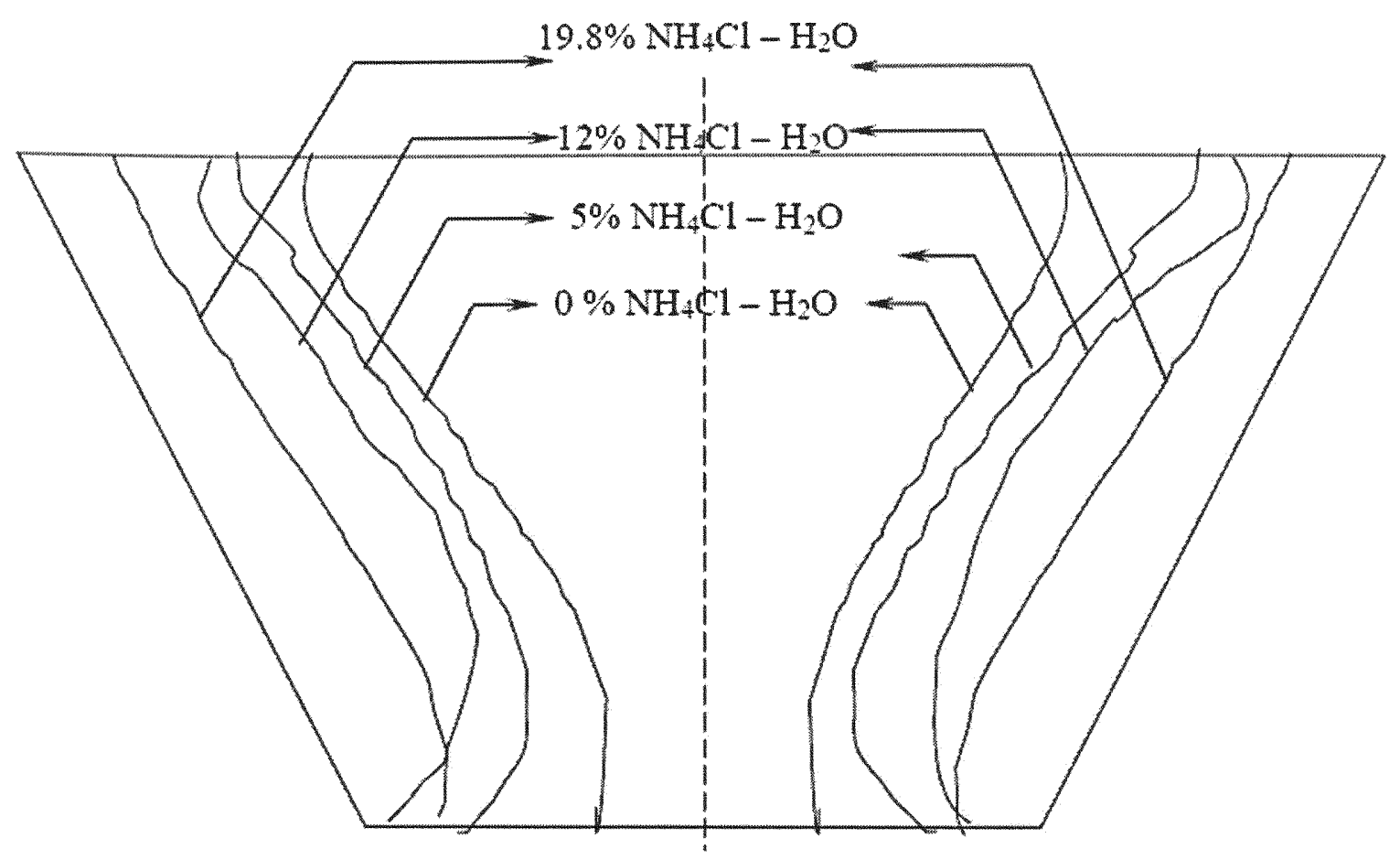

Figure 3.41 Solidification Contours for Different Concentrations at $t=64 \mathrm{~min}$;

Two Wall Cooled; $T_{L}=T_{R}=-30^{\circ} \mathrm{C}$

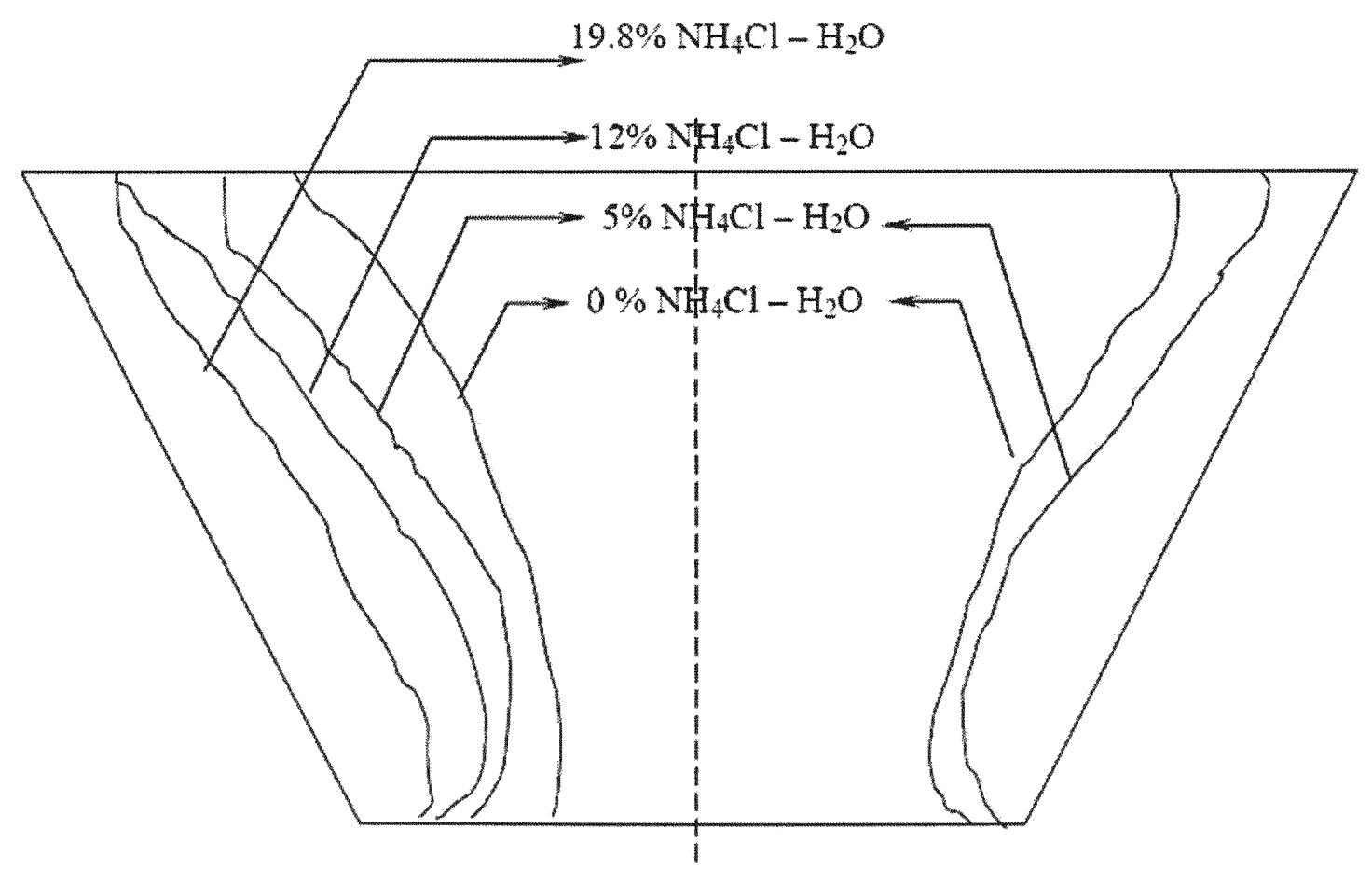

Figure 3.42 Solidification Contours for Different Concentrations at $t=64 \mathrm{~min}$;

Two Wall Cooled; $T_{L}=-30^{\circ} \mathrm{C} \& T_{R}=-10^{\circ} \mathrm{C}$ 
The frozen layer thickness on the left side wall which is measured from the PIV images when both walls are cooled to certain temperatures is shown in Figure $3.43 \&$ 3.44 and the moving interface velocity which is calculated from the frozen layer thickness is measured and show in Figure $3.45 \& 3.46$. All measurements were made at $\mathrm{Y}$ $=37 \mathrm{~mm}$ from the bottom of the chamber. Figures $3.43 \& 3.44$ shows the effect of initial concentration on the frozen layer thickness when one wall is cooled to $-30{ }^{\circ} \mathrm{C}$ and other is cooled to $-30{ }^{\circ} \mathrm{C} \&-10{ }^{\circ} \mathrm{C}$ respectively. Figures $3.45 \& 3.46$ shows the effect of initial concentration on the moving interface velocity when one wall is cooled to $-30{ }^{\circ} \mathrm{C}$ and other is cooled to $-30{ }^{\circ} \mathrm{C} \&-10{ }^{\circ} \mathrm{C}$ respectively. The observations made from these figures are similar to the observations made for one wall cooled. For the case where the two walls are cooled to $-30{ }^{0} \mathrm{C}$ the frozen layer thickness is same on both the sides and is shown in Figures $3.47 \&$ 3.48. Figure 3.47 shows the frozen layer thickness on left and right side walls for $0 \%$ and $12 \% \mathrm{NH}_{4} \mathrm{Cl}-\mathrm{H}_{2} \mathrm{O}$ mixture when both walls are cooled to -30 ${ }^{0} \mathrm{C}$. Figure 3.48 shows the frozen layer thickness on left and right side walls for $5 \%$ and $19.8 \% \mathrm{NH}_{4} \mathrm{Cl}-\mathrm{H}_{2} \mathrm{O}$ mixture when both walls are cooled to $-30{ }^{\circ} \mathrm{C}$. Similarly the moving interface velocities on left and right walls for these cases are shown in Figures 3.49 \& 3.50 . 


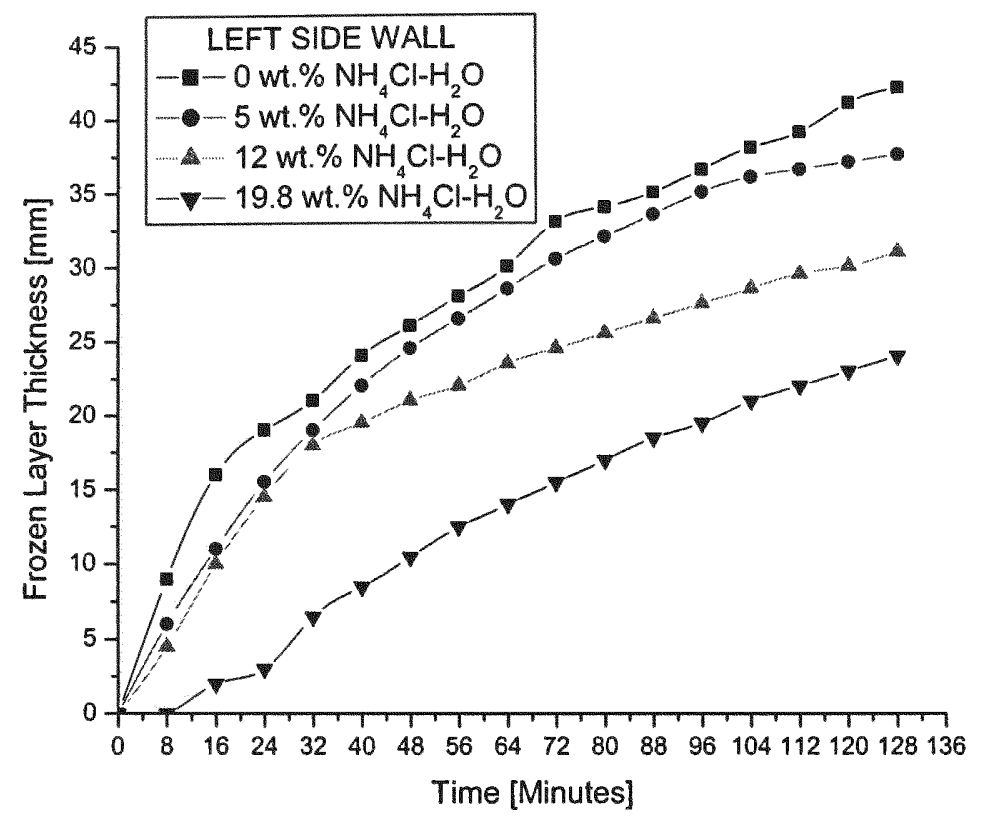

Figure 3.43 Effect of initial concentration on thickness of the frozen layer $(Y=37 \mathrm{~mm})$ : Two wall cooled, $T_{L}=T_{R}=-30^{\circ} \mathrm{C}$

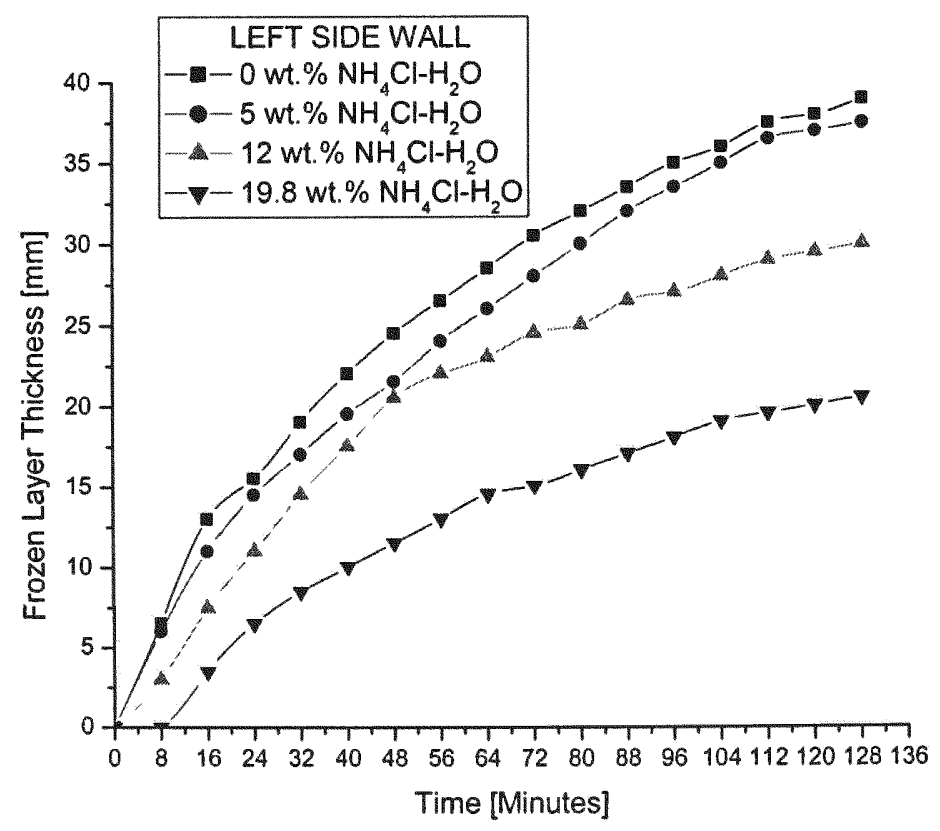

Figure 3.44 Effect of initial concentration on thickness of the frozen layer ( $Y=37 \mathrm{~mm})$ : Two wall cooled, $T_{L}=-30^{\circ} \mathrm{C}, T_{R}=-10^{\circ} \mathrm{C}$. 


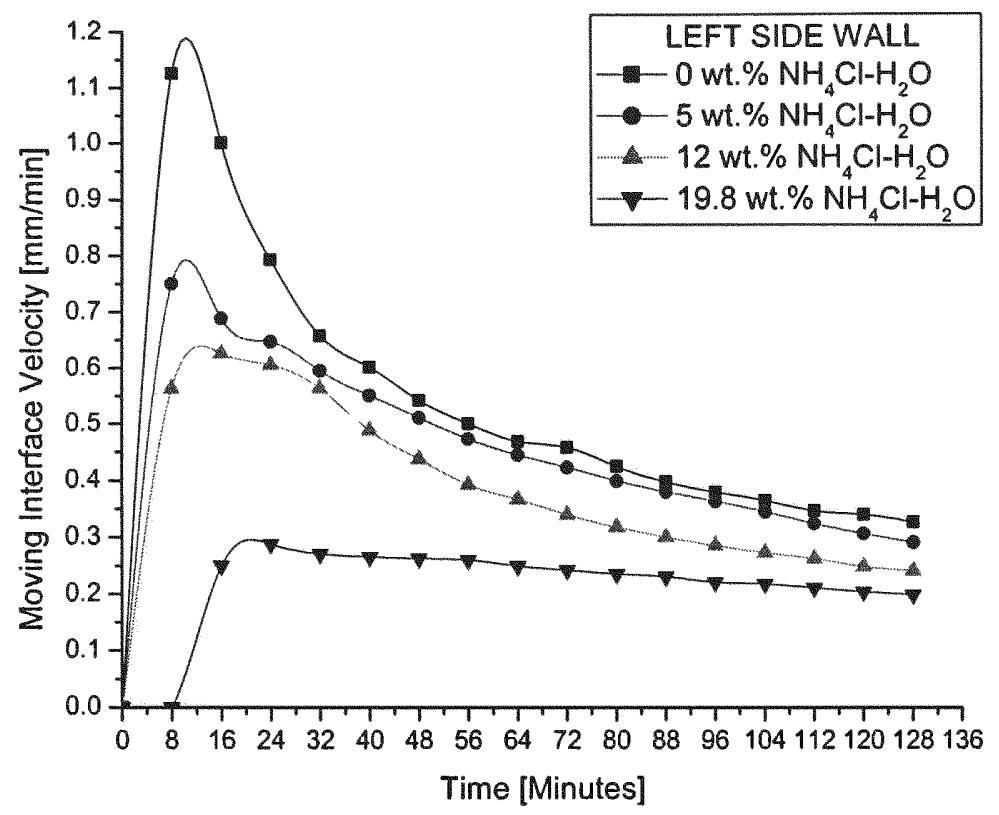

Figure 3.45 Effect of initial concentration on Velocity of Moving Interface $(Y=37 \mathrm{~mm})$ : One cooled side, $T_{L}=T_{R}=-30^{\circ} \mathrm{C}$.

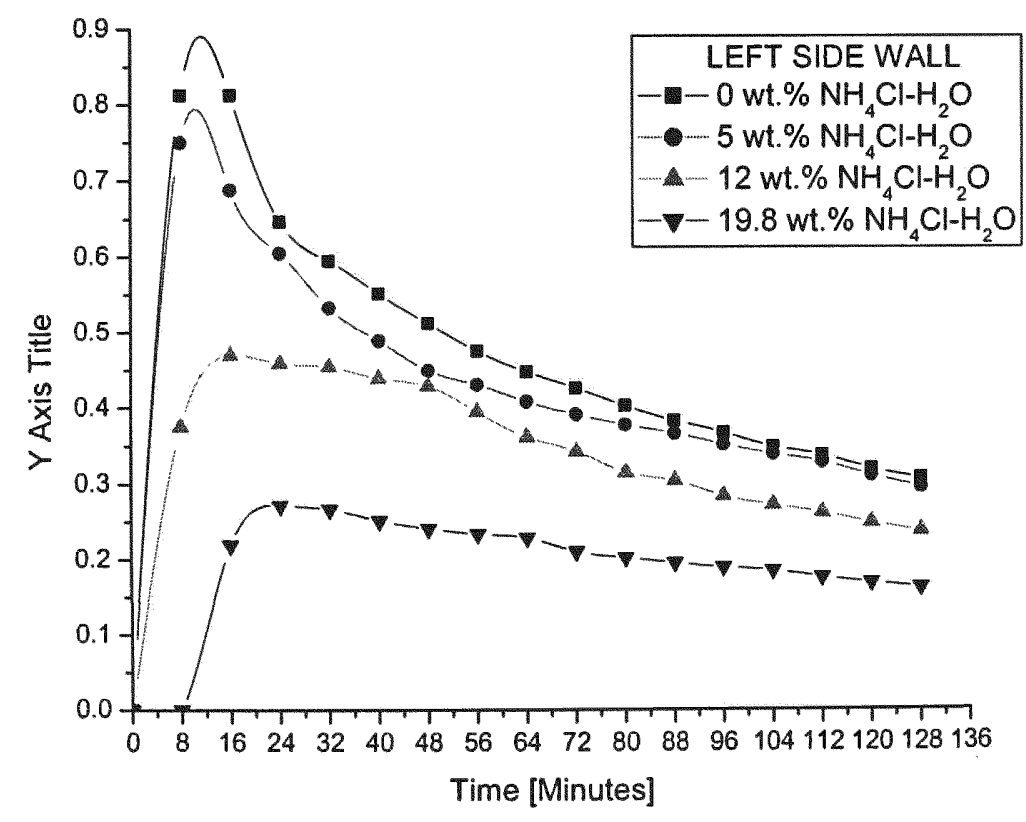

Figure 3.46

Effect of initial concentration on Velocity of Moving Interface ( $Y=37 \mathrm{~mm}$ ): Two wall cooled, $T_{L}=-30^{\circ} \mathrm{C}, \mathrm{T}_{R}=-10^{\circ} \mathrm{C}$. 


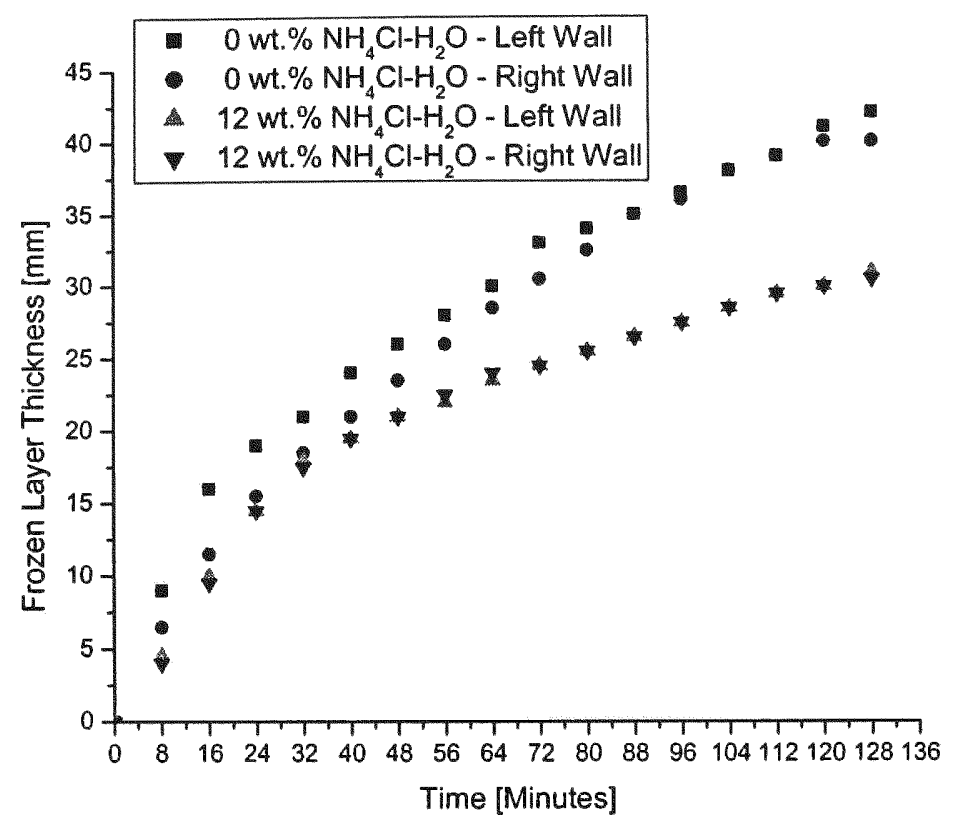

Figure 3.47 Frozen layer thickness on left and right side walls: $0 \% \& 12 \% \mathrm{NH}_{4} \mathrm{Cl}-\mathrm{H}_{2} \mathrm{O}$; Two wall cooled side, $T_{L}=T_{R}=-30^{\circ} \mathrm{C}$.

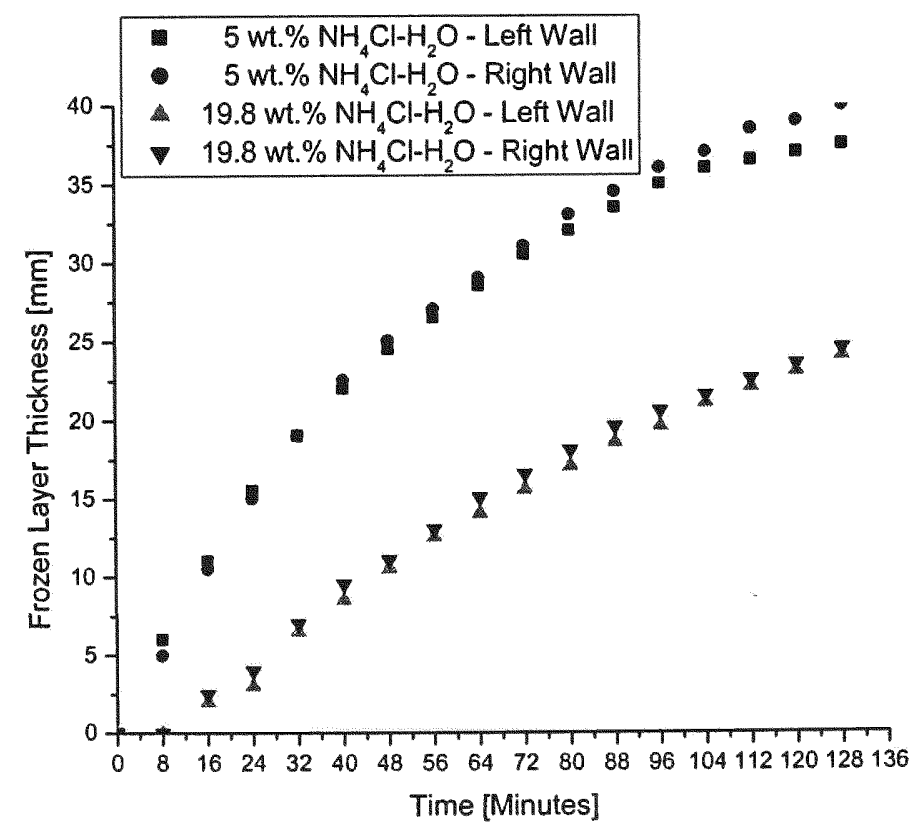

Figure 3.48 Frozen layer thickness on left and right side walls: $5 \%$ \& $19.8 \% \mathrm{NH}_{4} \mathrm{Cl}-\mathrm{H}_{2} \mathrm{O}$; Two wall cooled side, $T_{L}=T_{R}=-30^{\circ} \mathrm{C}$. 


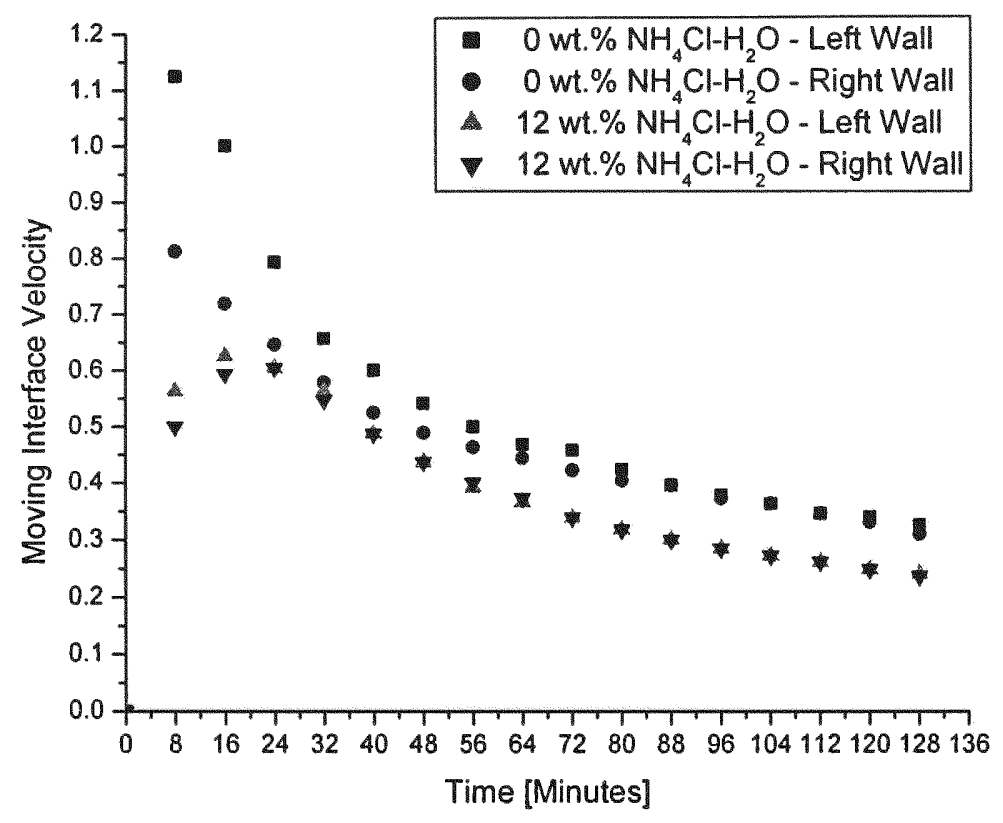

Figure 3.49 Moving Interface Velocity on left and right side walls: $0 \%$ \& $12 \% \mathrm{NH}_{4} \mathrm{Cl}-\mathrm{H}_{2} \mathrm{O}$; Two wall cooled side, $T_{L}=T_{R}=-30^{\circ} \mathrm{C}$.

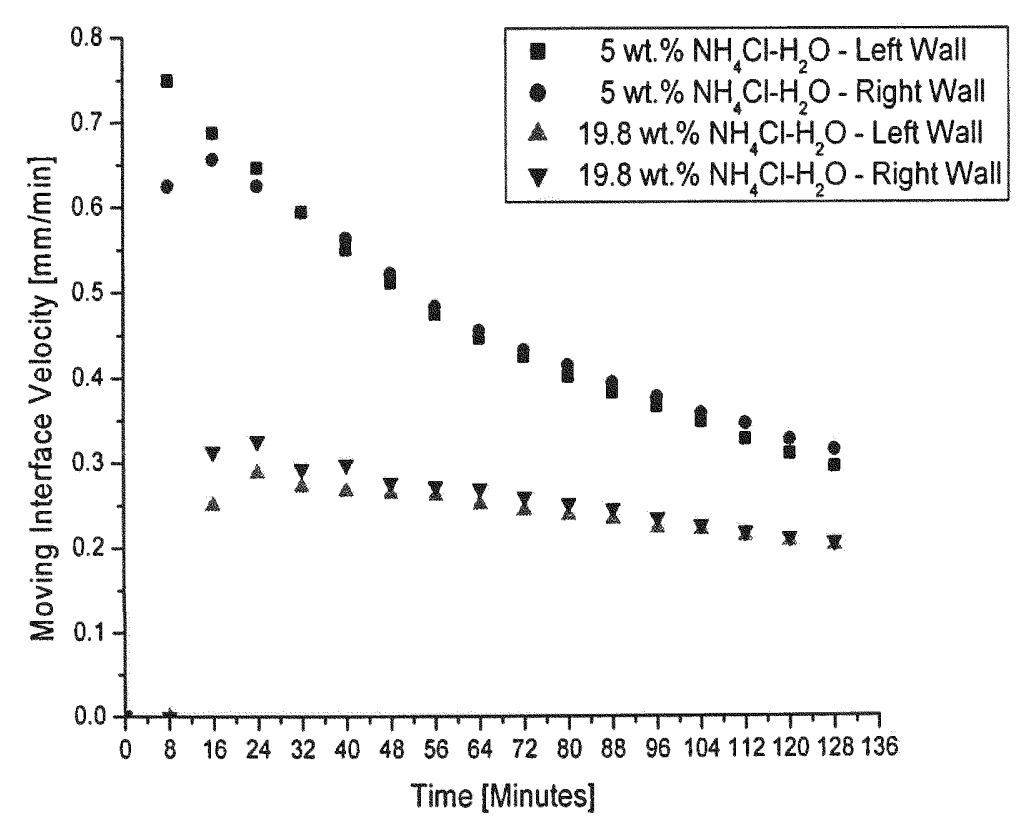

Figure 3.50 Moving Interface Velocity on left and right side walls: $5 \%$ \& $19.8 \% \mathrm{NH}_{4} \mathrm{Cl}-\mathrm{H}_{2} \mathrm{O}$; Two wall cooled side, $T_{L}=T_{R}=-30^{\circ} \mathrm{C}$. 
The convection flow patterns during the solidification of binary solution with various concentrations of $\mathrm{NH}_{4} \mathrm{Cl}-\mathrm{H}_{2} \mathrm{O}$ at different times with two cooled walls are shown in Figures 3.51 to 3.54. The convection flow pattern inside the cavity for the two cooled sides depends on the initial concentration, the two boundary temperatures (left and right sides), and the liquid-solid interfaces moving in opposite directions. It is noted that at the eutectic concentration and after one solidification process, two circulation flows are present at the bottom of the cavity: one counter-clockwise circulation flow located at the left part of the cavity and one clockwise circulation flow located to the right side of the cavity. They transport the hot liquid up to the top and back to the bottom of the chamber. Figure 3.51 shows the convection flow pattern during solidification of pure water when two walls are cooled to $-30{ }^{\circ} \mathrm{C}$ for different times. Figures 3.52 to 3.54 show the same for different concentrations $5 \%, 12 \%, 19.8 \% \mathrm{NH}_{4} \mathrm{Cl}-\mathrm{H}_{2} \mathrm{O}$ mixtures respectively. Solidification process has been studied with two wall cooled with different conditions i.e., 1) $T_{L}=T_{R}=-30^{\circ}$ C. 2) $T_{L}=-30^{\circ} \mathrm{C} \& T_{R}=-10^{\circ}$ C. Figure 3.55 and 3.56 shows the effect of initial concentration on the convection flow pattern for both the boundary conditions. 


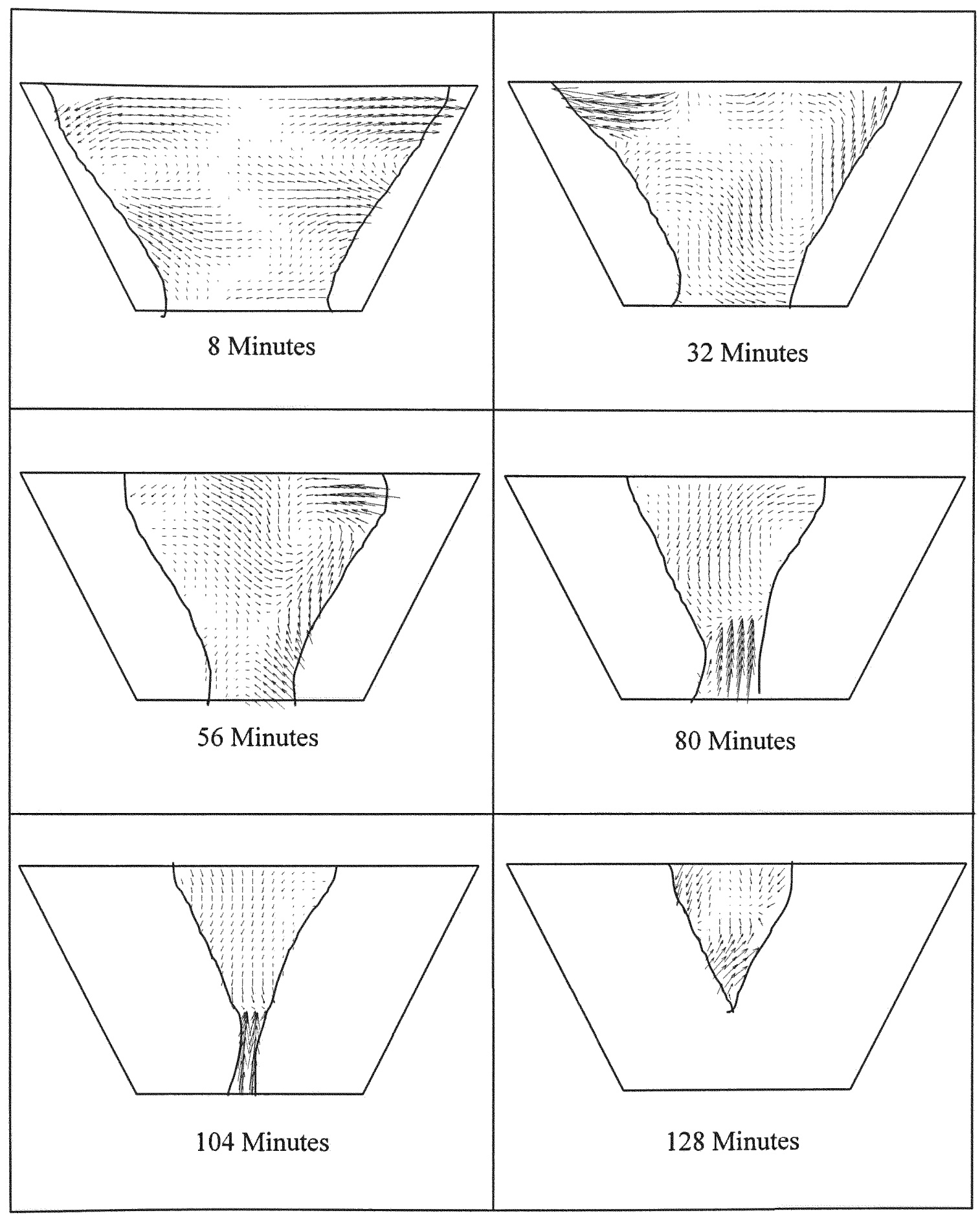

Figure 3.51 Velocity Vectors in the melt during the solidification of water: Two Wall Cooled, $T_{L}=T_{R}=-30^{\circ} \mathrm{C}$. 


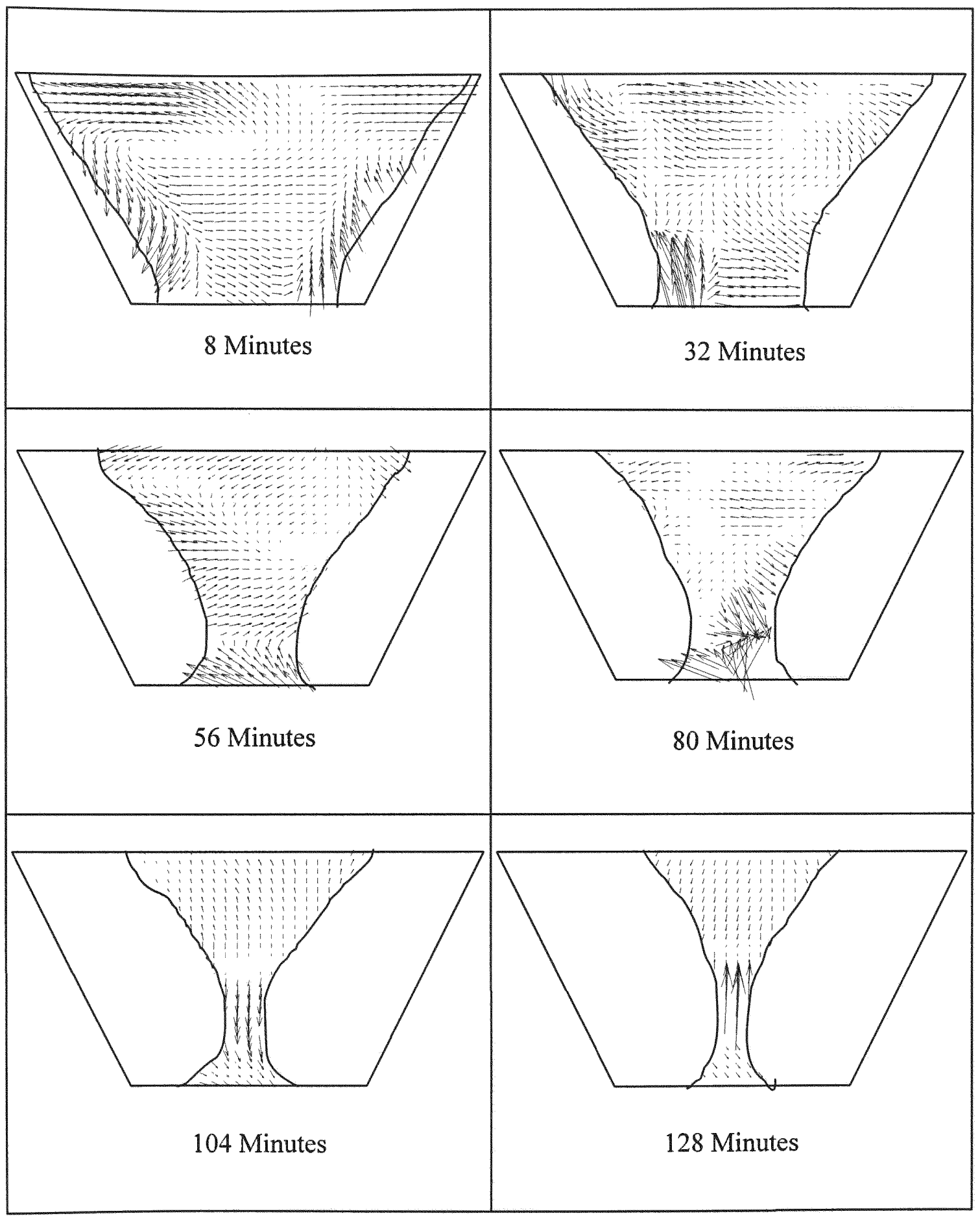

Figure 3.52 Velocity Vectors in the melt during the solidification of $5 \mathrm{Wt} \% \mathrm{NH}_{4} \mathrm{Cl}-\mathrm{H}_{2} \mathrm{O}$ : Two Wall Cooled, $T_{L}=T_{R}=-30^{\circ} \mathrm{C}$. 


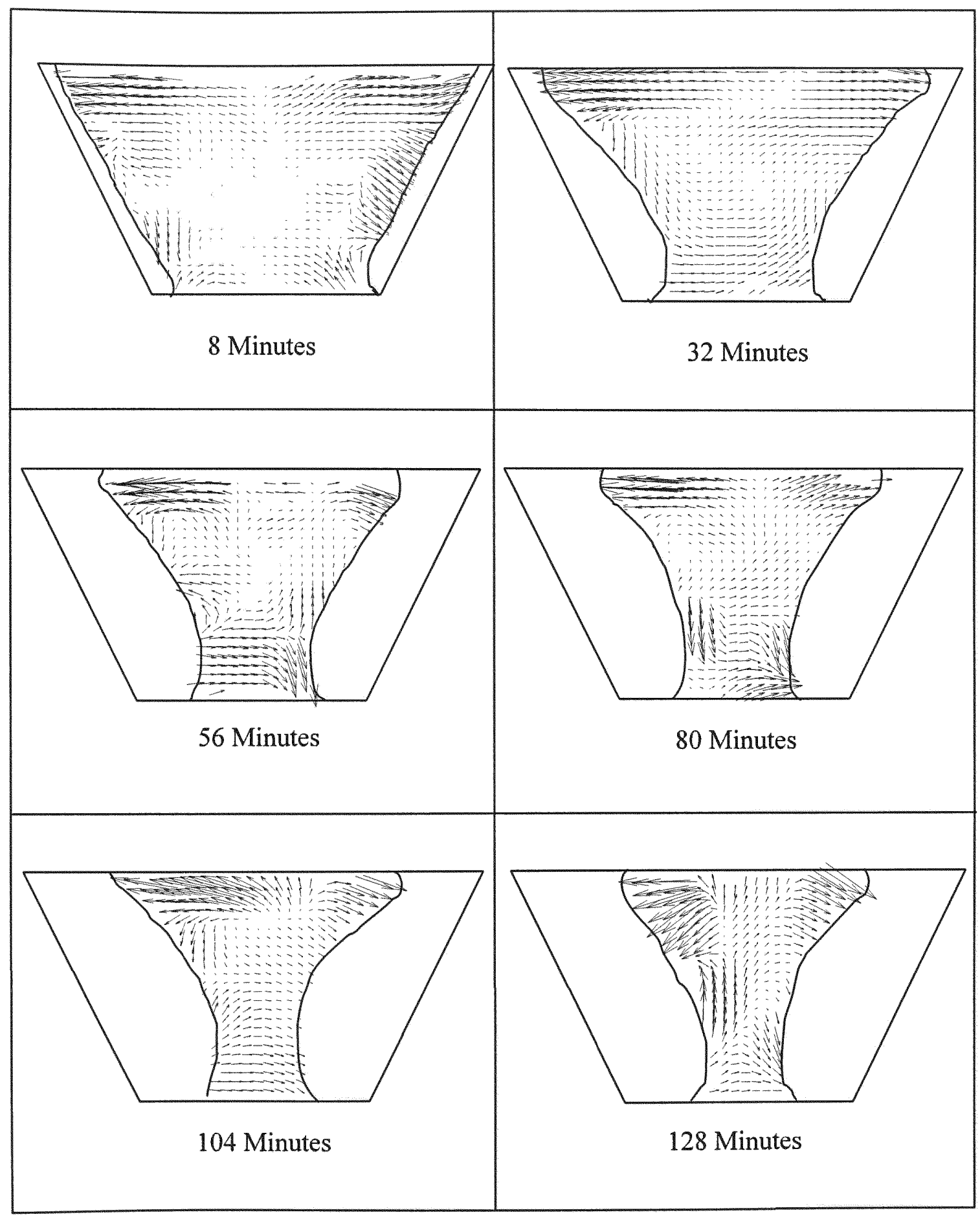

Figure 3.53 Velocity Vectors in the melt during the solidification of $12 \mathrm{Wt}$. $\% \mathrm{NH}_{4} \mathrm{Cl}-\mathrm{H}_{2} \mathrm{O}$ : Two Wall Cooled, $T_{L}=T_{R}=-30^{\circ} \mathrm{C}$. 


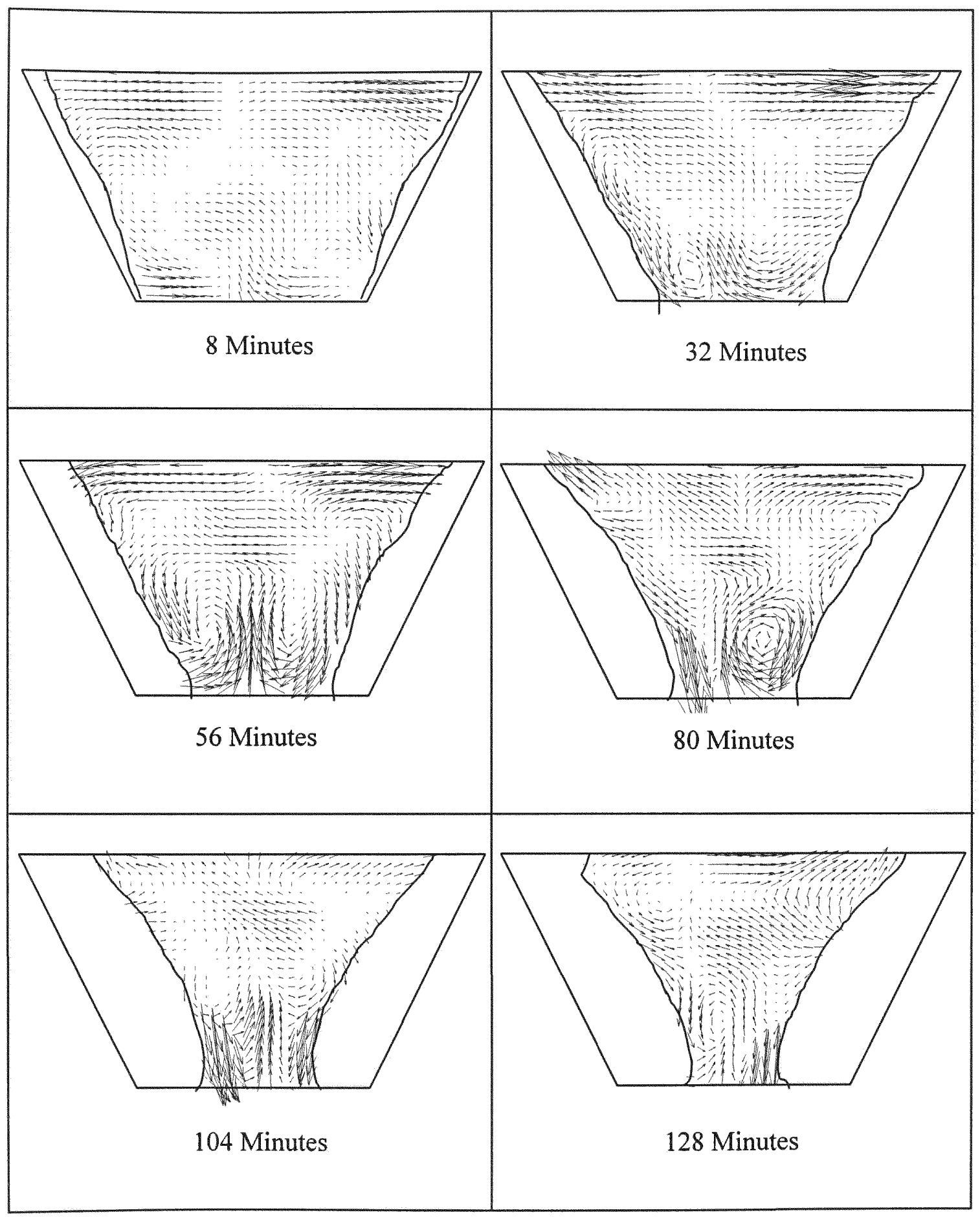

Figure 3.54 Velocity Vectors in the melt during the solidification of $19.8 \mathrm{Wt} \% \mathrm{NH}_{4} \mathrm{Cl}-\mathrm{H}_{2} \mathrm{O}$ : Two Wall Cooled, $T_{L}=T_{R}=-30^{\circ} \mathrm{C}$. 


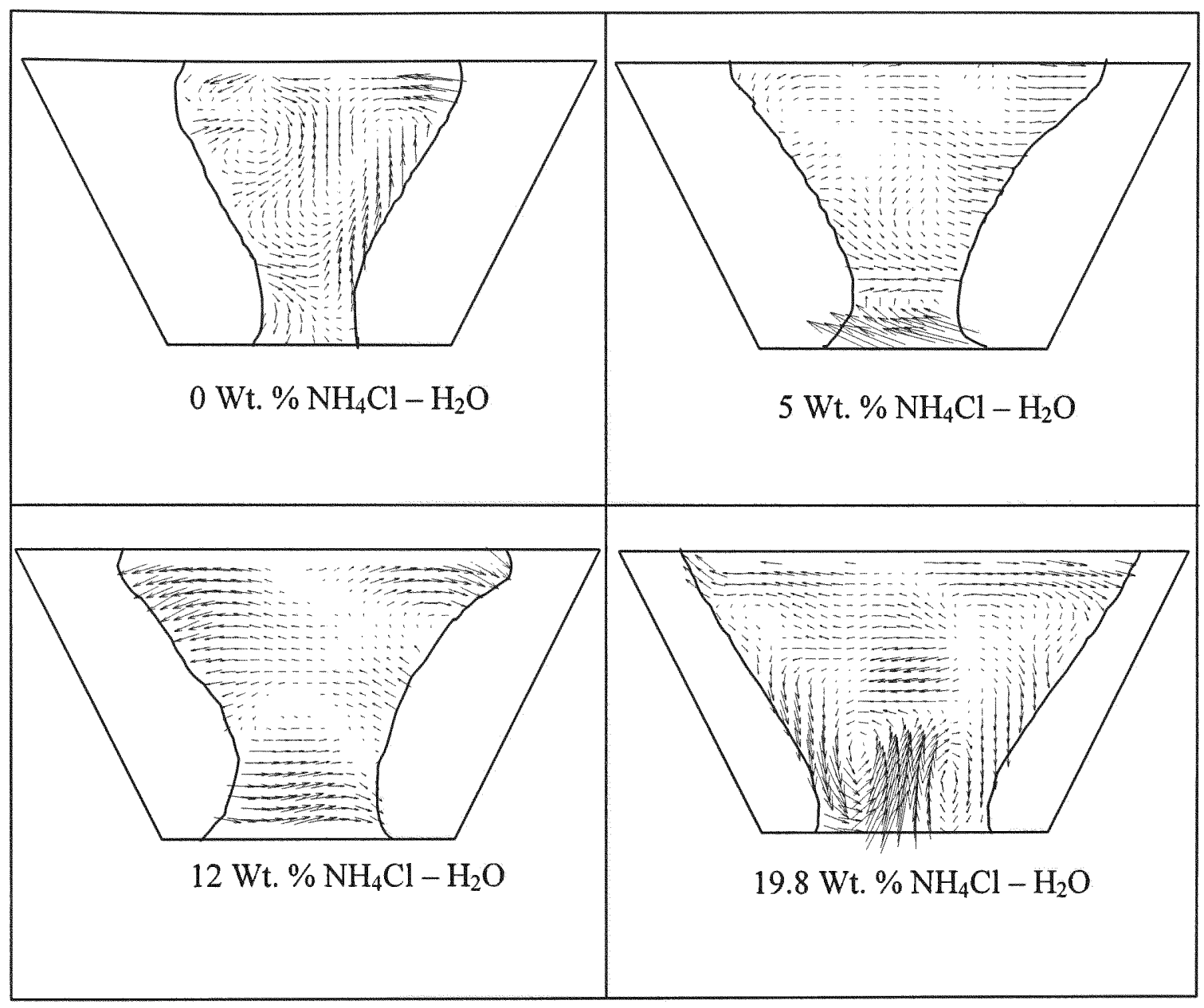

Figure 3.55 Velocity Vectors showing the effect of the Initial Concentration on the Solidification Process; Two Wall Cooled: Time $(t)=64$ Minutes, $T_{L}=T_{R}=-30^{\circ} \mathrm{C}$. 


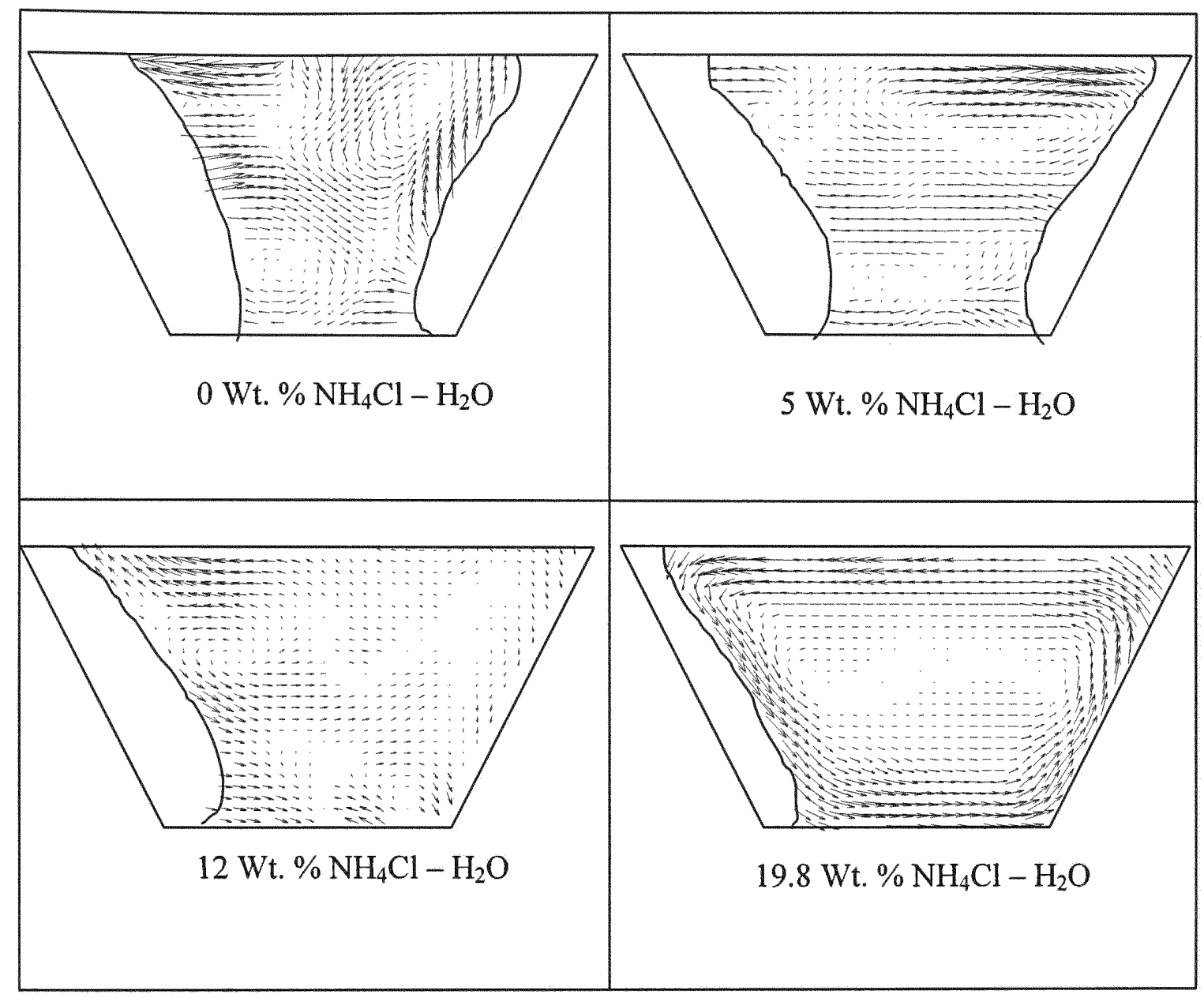

Figure 3.56 Velocity Vectors showing the effect of the Initial Concentration on the Solidification Process; Two Wall Cooled: Time $(t)=64$ Minutes, $T_{L}=-30{ }^{\circ} \mathrm{C}, \mathrm{T}_{\mathrm{R}}=-10^{\circ} \mathrm{C}$. 
The effect of initial concentration on the temperature distribution is studied and represented in Figures 3.57 to 3.59. Figure 3.57 shows the temperature distribution inside the cavity at $\mathrm{Y}=37 \mathrm{~mm}$ from bottom at time $(t)=16$ minutes when both walls are cooled to a same temperature $T_{L}=T_{R}=-30{ }^{\circ} \mathrm{C}$. Similarly Figures $3.58 \& 3.59$ shows the effect of initial concentration on temperature distribution at $\mathrm{Y}=37$ at time $(\mathrm{t})=72$ and 128 minutes respectively. Figures 3.60 to 3.61 shows the effect of initial concentration on the temperature distribution inside the cavity at $\mathrm{Y}=37 \mathrm{~mm}$ at time $(\mathrm{t})=72$ and 128 minutes respectively when one wall is cooled to $-30{ }^{\circ} \mathrm{C}$ and another is cooled to $-10{ }^{\circ} \mathrm{C}$.

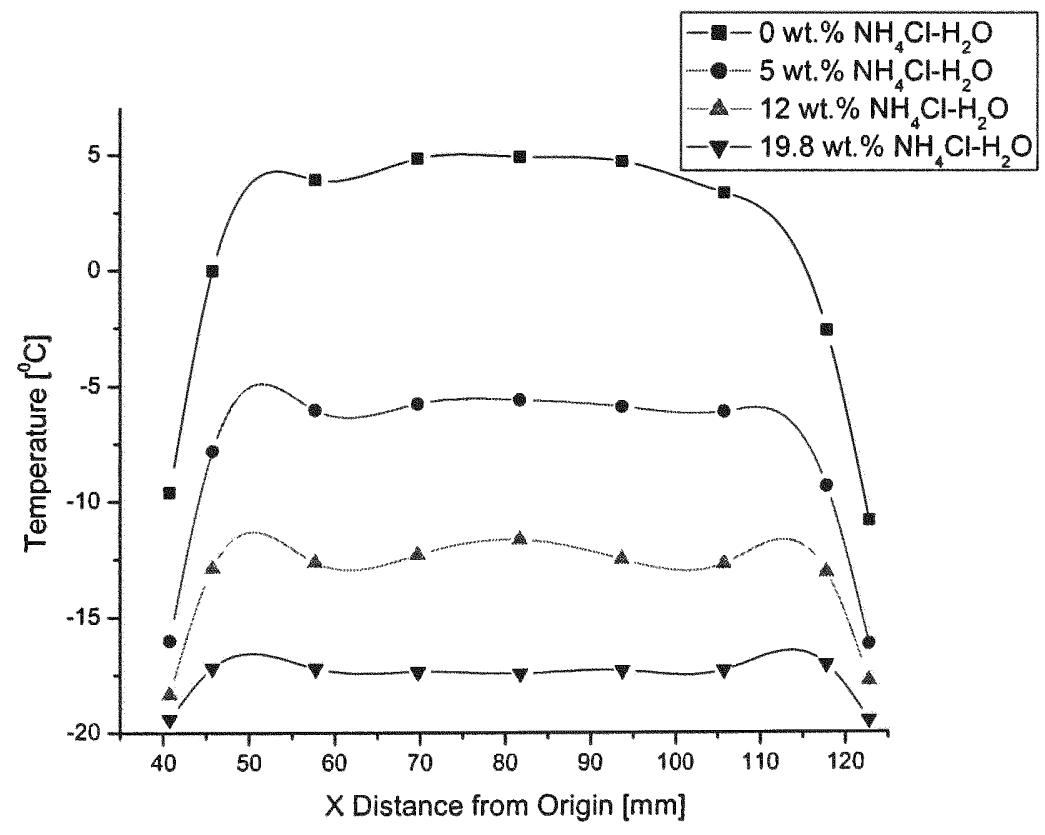

Figure 3.57 Effect of Initial Concentration on Temperature Distribution inside the cavity; $Y=37 \mathrm{~mm}$; Two wall Cooled; Time $(t)=16$ Minutes, $T_{L}=T_{R}=-30^{\circ} \mathrm{C}$. 


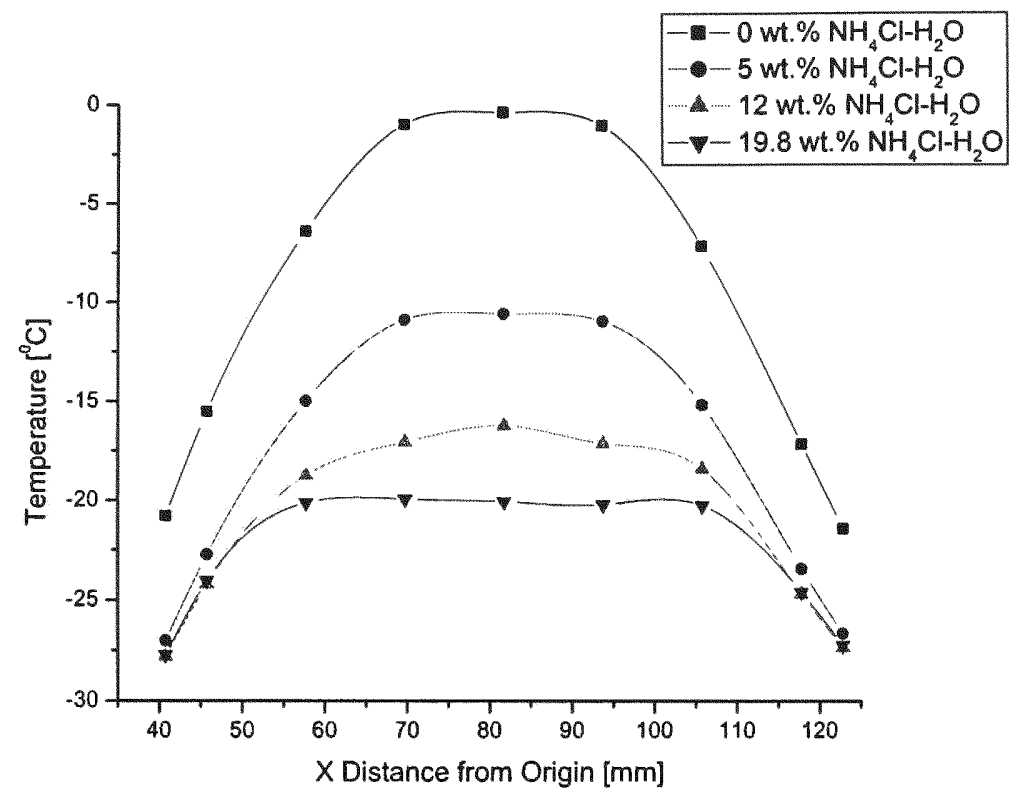

Figure 3.58 Effect of Initial Concentration on Temperature Distribution inside the cavity; $Y=37 \mathrm{~mm}$; Two wall Cooled; Time $(t)=72$ Minutes, $T_{L}=T_{R}=-30^{\circ} \mathrm{C}$.

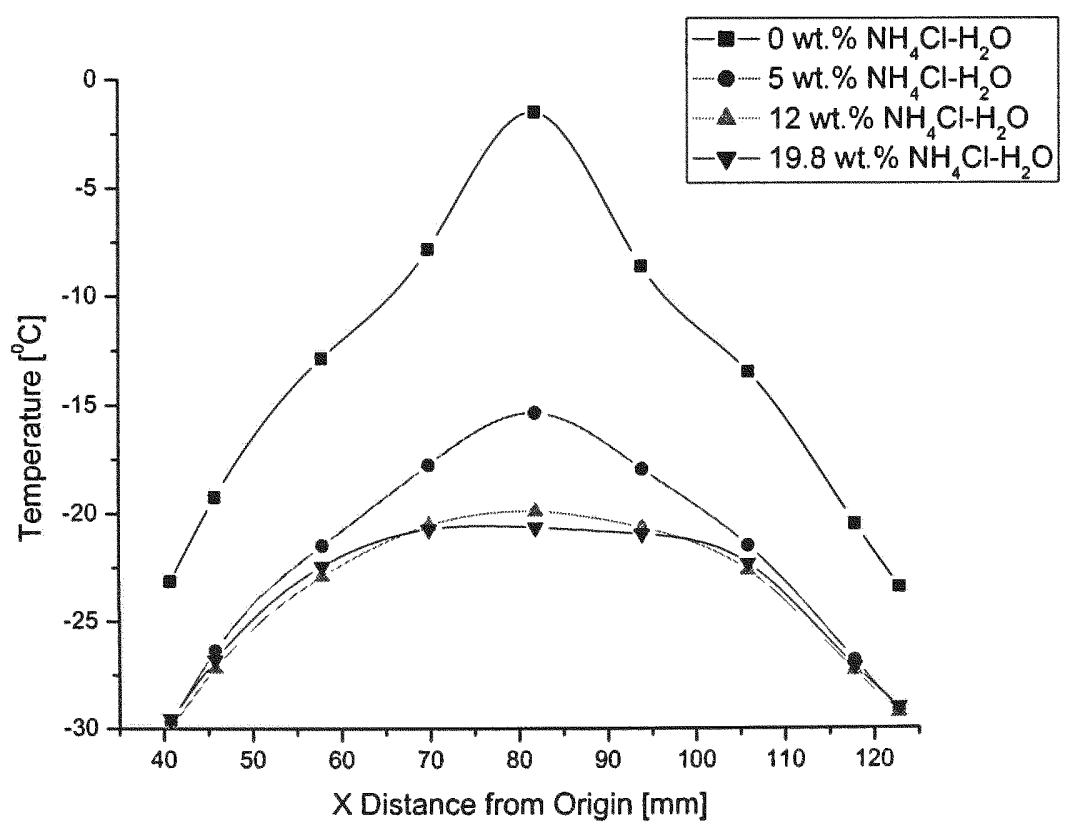

Figure 3.59 Effect of Initial Concentration on Temperature Distribution inside the cavity; $Y=37 \mathrm{~mm}$; Two wall Cooled; Time $(t)=128$ Minutes, $T_{L}=T_{R}=-30^{\circ} \mathrm{C}$. 


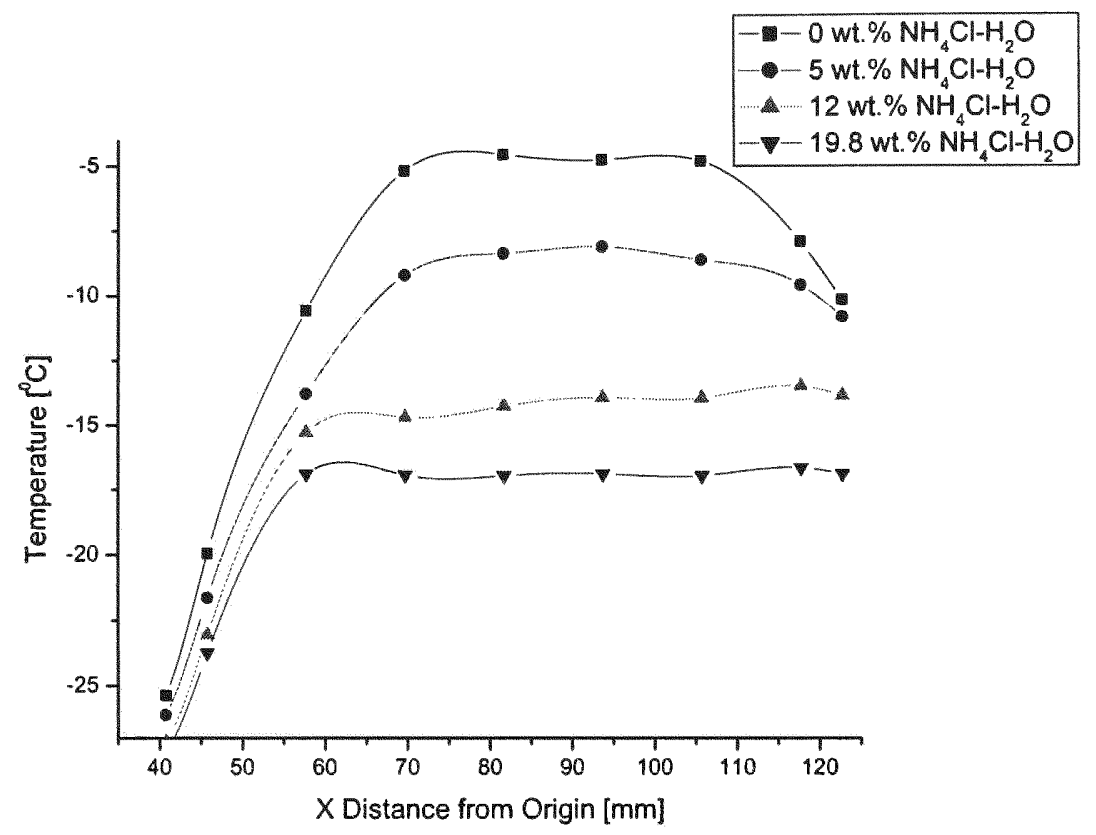

Figure 3.60 Effect of Initial Concentration on Temperature Distribution inside the cavity; $Y=37 \mathrm{~mm}$; Two wall Cooled; Time $(t)=72$ Minutes, $T_{L}=-30^{\circ} \mathrm{C} ; T_{R}=-10^{\circ} \mathrm{C}$.

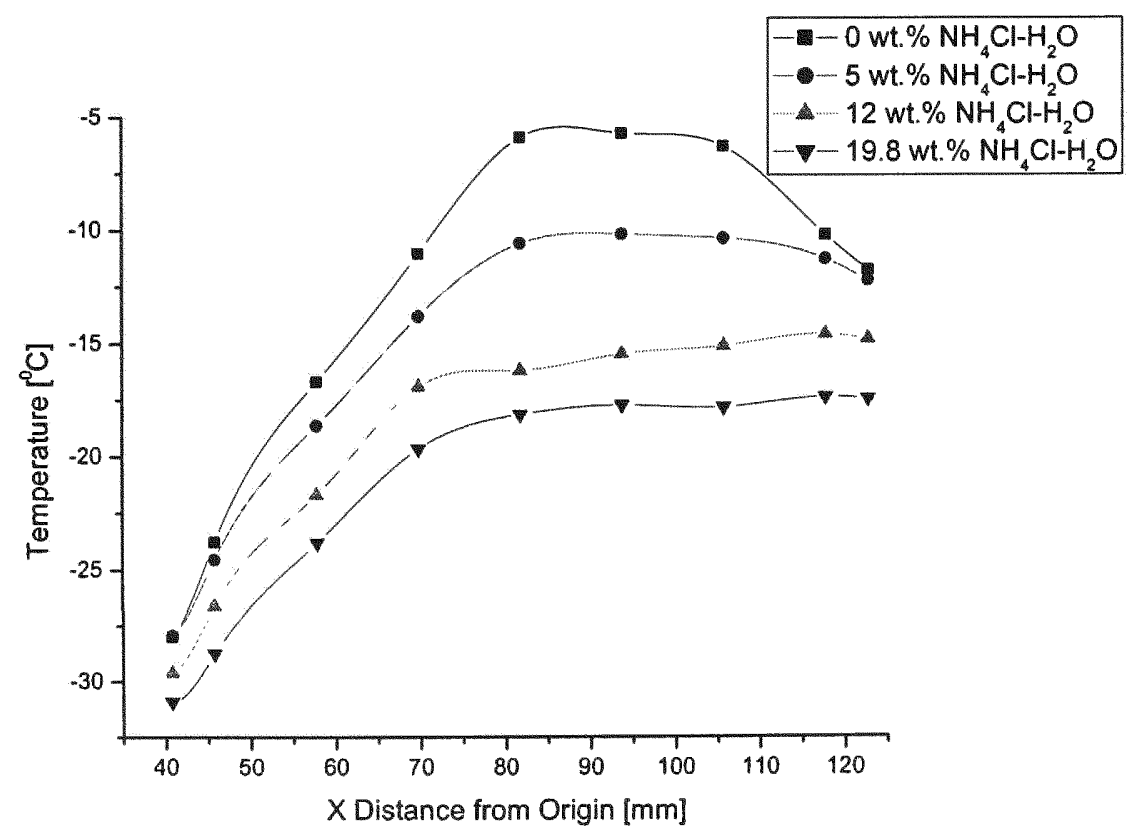

Figure 3.61 Effect of Initial Concentration on Temperature Distribution inside the cavity; $Y=37 \mathrm{~mm}$; Two wall Cooled; Time $(t)=128$ Minutes, $T_{L}=-30^{\circ} \mathrm{C} ; T_{R}=-10^{\circ} \mathrm{C}$. 


\subsubsection{Effect of Initial Boundary Conditions}

In the previous sections we discussed how the initial concentration affects the solidification process by analyzing PIV images, velocity vectors and also by observing the solid liquid interface and its velocity. Finally we observed the effect of initial temperature on the temperature distribution inside the cavity. In this section we will see how the initial boundary conditions effect the solidification process by analyzing PIV images, velocity vectors, solid - liquid interface and its velocity and finally with temperature distribution.

Figures 3.62 to 3.65 shows the PIV images for various concentrations $(0 \%$ $19.8 \%$ ) with various boundary conditions at time $(t)=24$ minutes. Figure 3.62 shows the PIV images for pure water for various boundary conditions at same time. It is observed that as the temperature on the cooling wall decreases the frozen layer formed is decreasing and there is a small effect of the right side temperature on the left side solidification which is discussed in further sections. Figure 3.63 to 3.65 shows the same for various concentrations $5 \%, 12 \%, 19.8 \%$ respectively. The PIV images obtained are useful to get an idea about the seeding particle position, velocity of the flow. Solidification contours are very useful to find the frozen layer thickness and moving interface velocity. Figures 3.66 to 3.69 shows the solidification contours with different boundary conditions for various concentrations $0 \%, 5 \%, 12 \%, 19.8 \%$ at time $(\mathrm{t})=72$ minutes. 


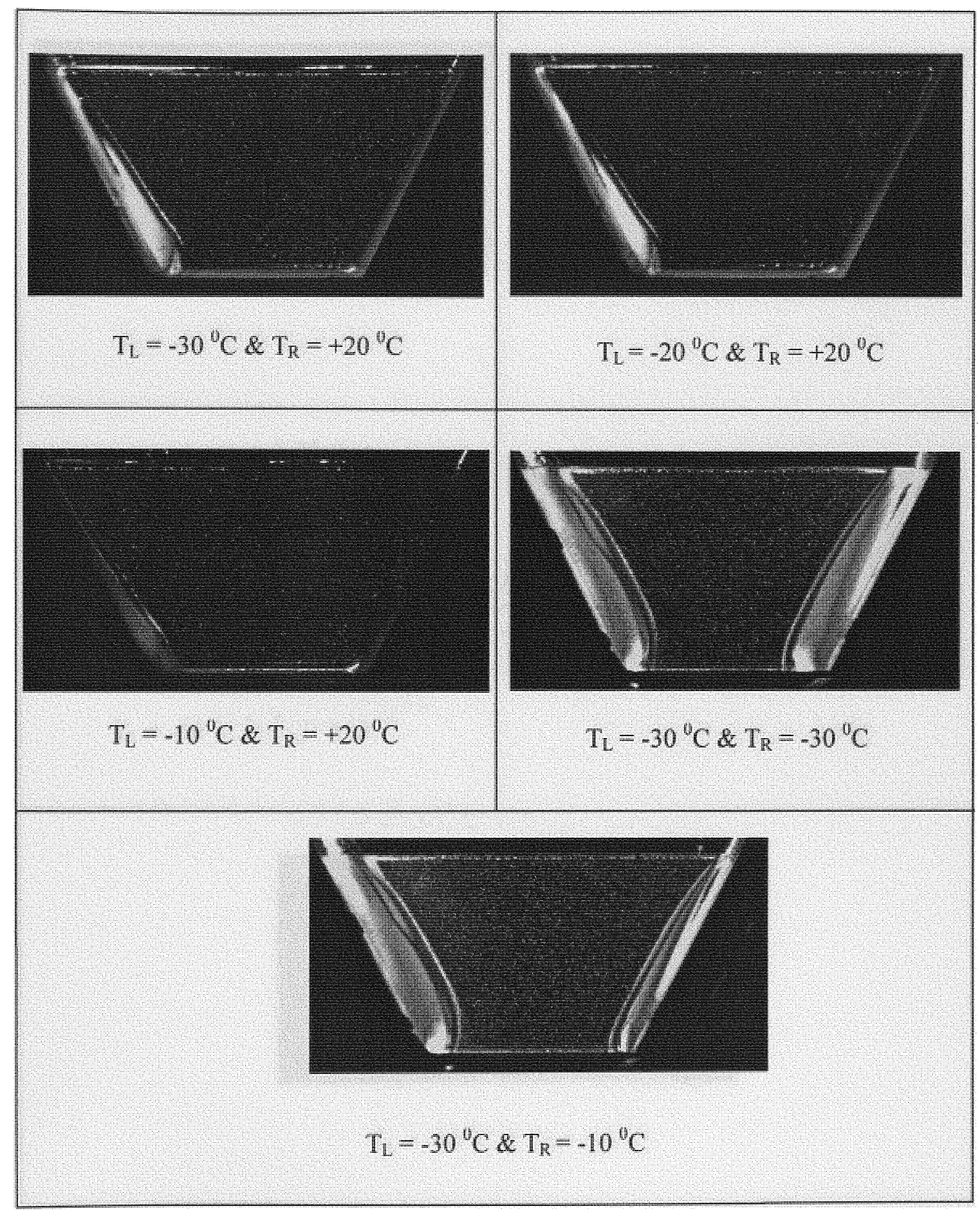

Figure 3.62 Effect of Initial Boundary Temperature on Solidification Process for Pure Water; Time $(t)=24$ Minutes. 


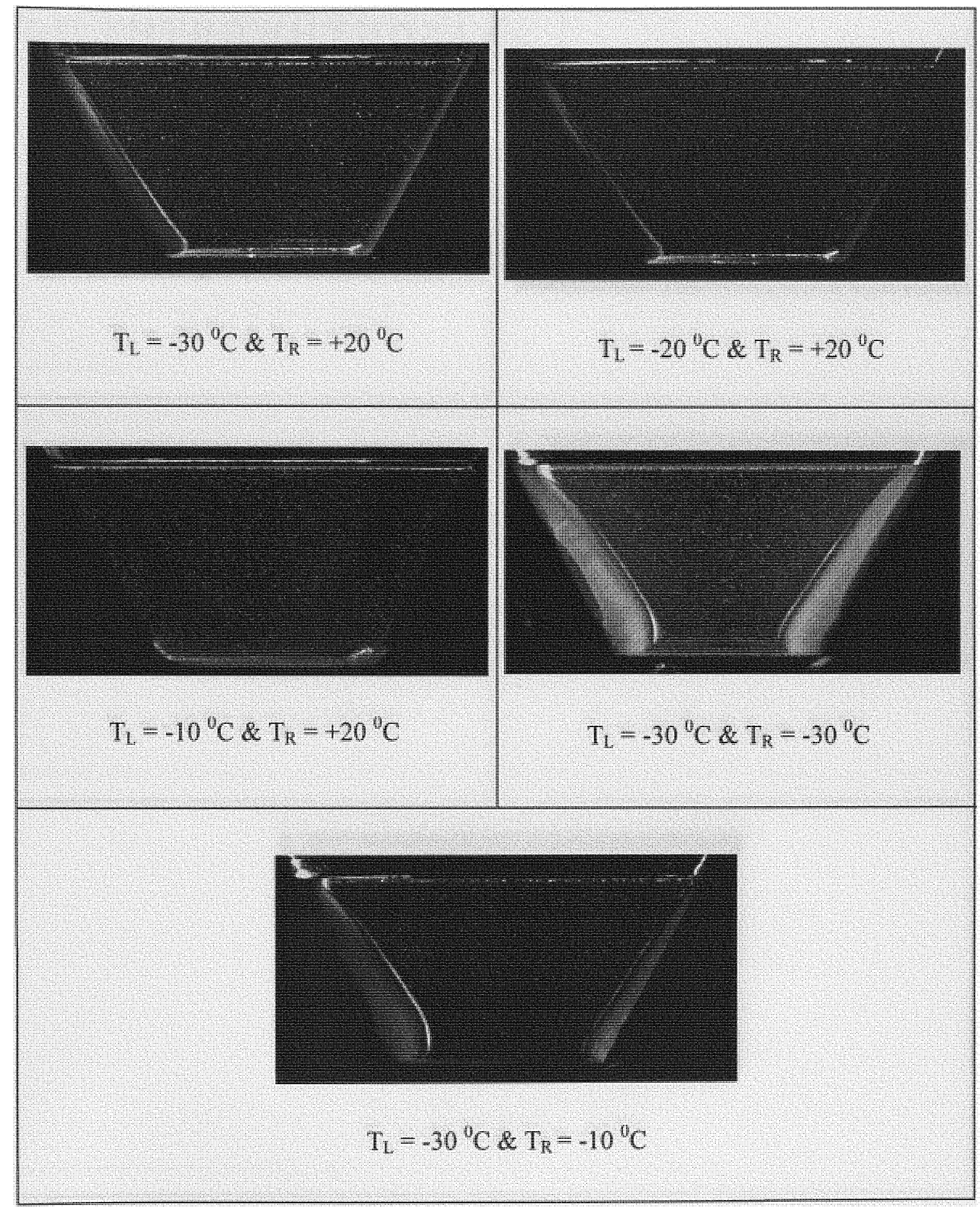

Figure 3.63 Effect of Initial Boundary Temperature on Solidification Process for $5 \% \mathrm{NH}_{4} \mathrm{Cl}-$ $\mathrm{H}_{2} \mathrm{O}$; Time $(\mathrm{t})=24$ Minutes. 


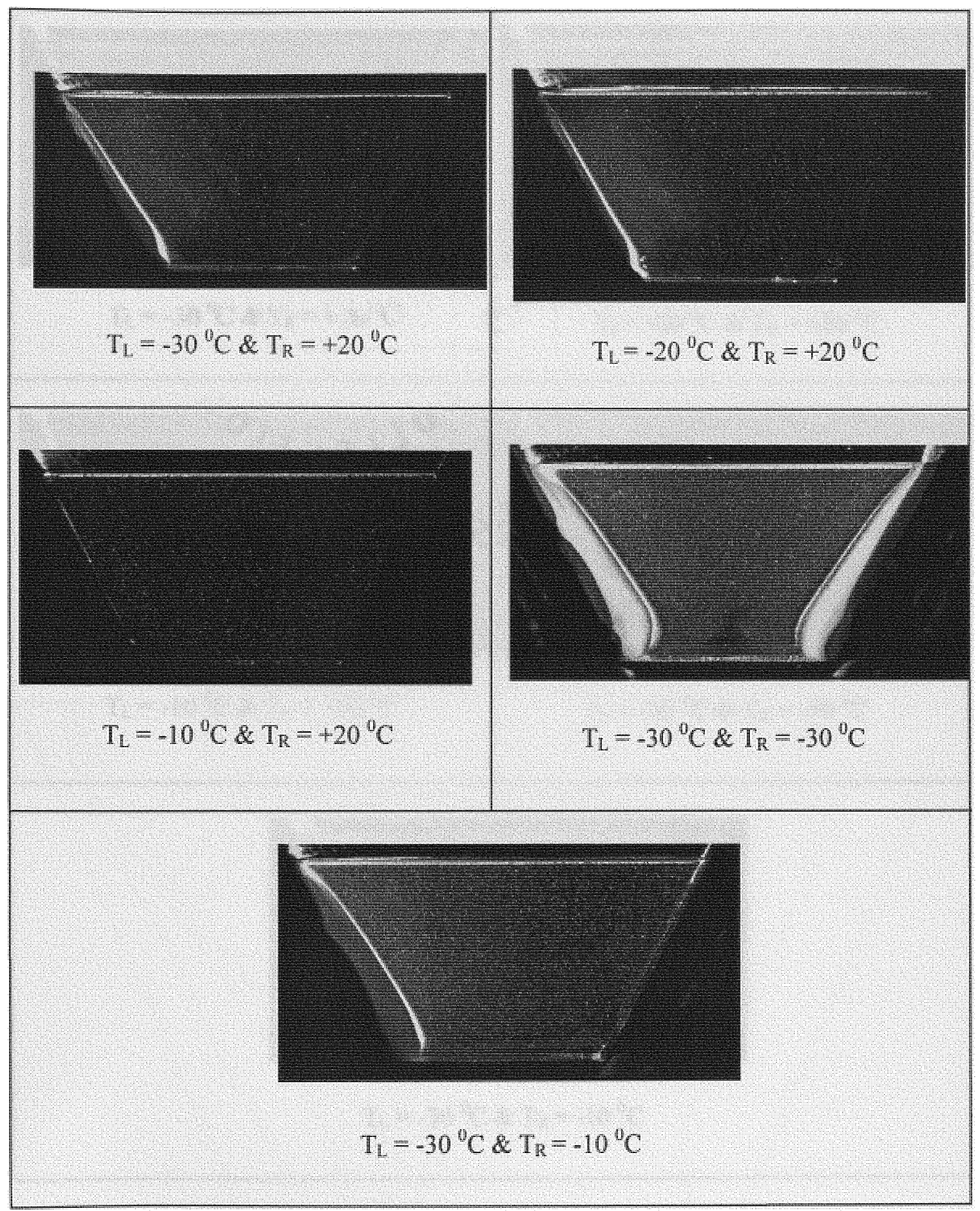

Figure 3.64 Effect of Initial Boundary Temperature on Solidification Process for $12 \% \mathrm{NH}_{4} \mathrm{Cl}$ $\mathrm{H}_{2} \mathrm{O}$; Time $(\mathrm{t})=24$ Minutes. 


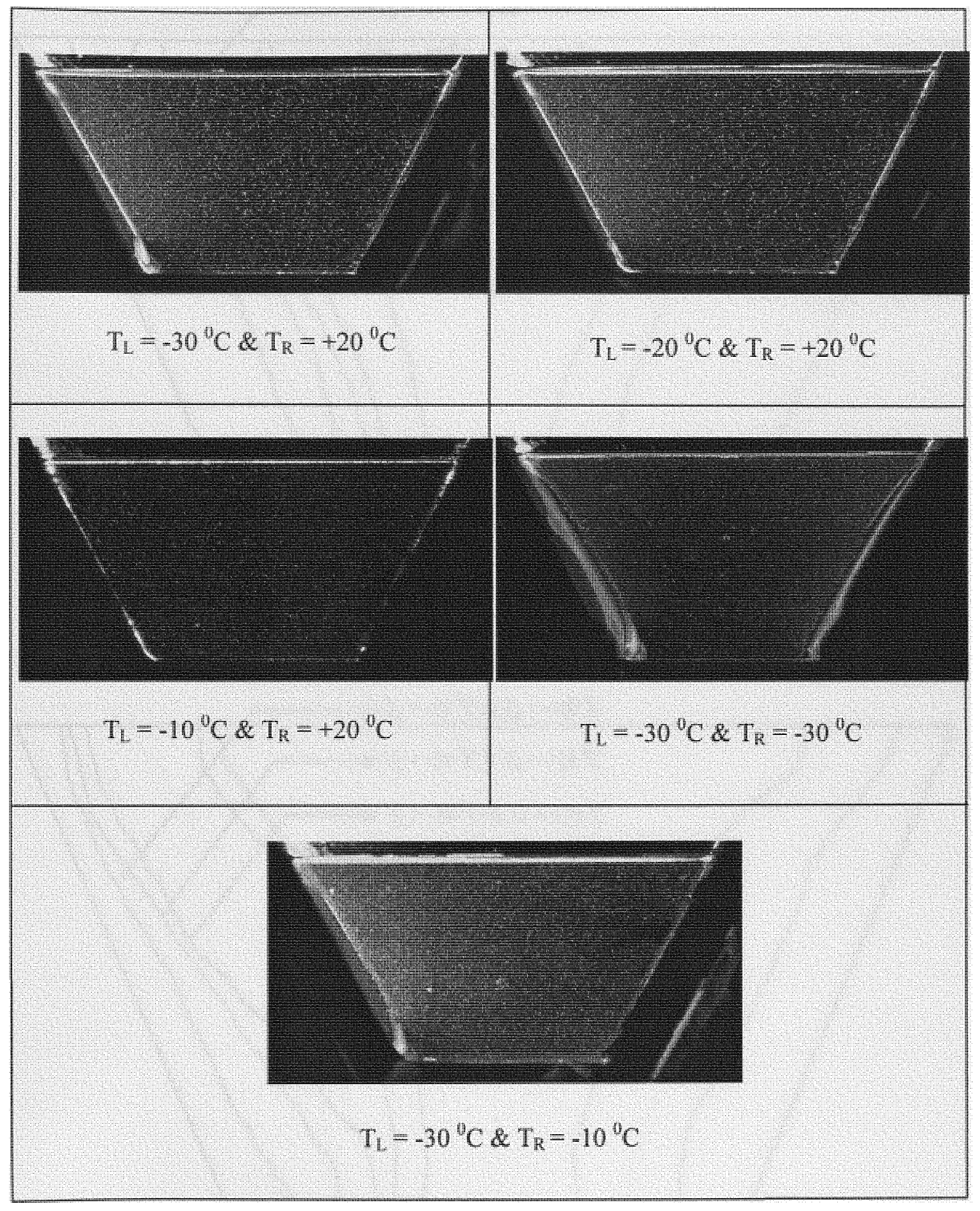

Figure 3.65 Effect of Initial Boundary Temperature on Solidification Process for $19.8 \% \mathrm{NH}_{4} \mathrm{Cl}$ $\mathrm{H}_{2} \mathrm{O}$; Time $(\mathrm{t})=24$ Minutes. 


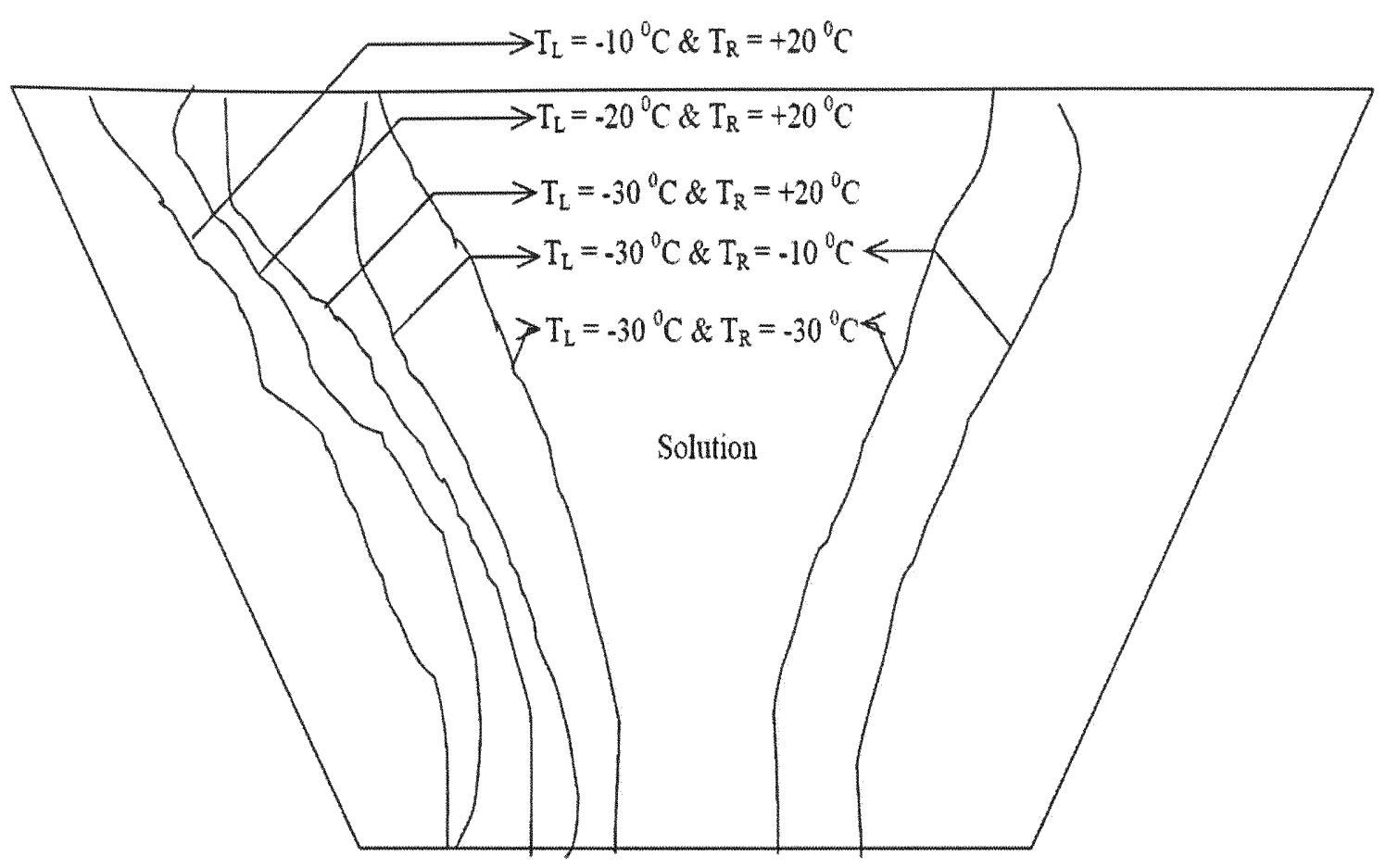

Figure 3.66 Solidification Contours showing the effect of Initial Boundary Condition; Pure Water at Time $(t)=72$ Minutes

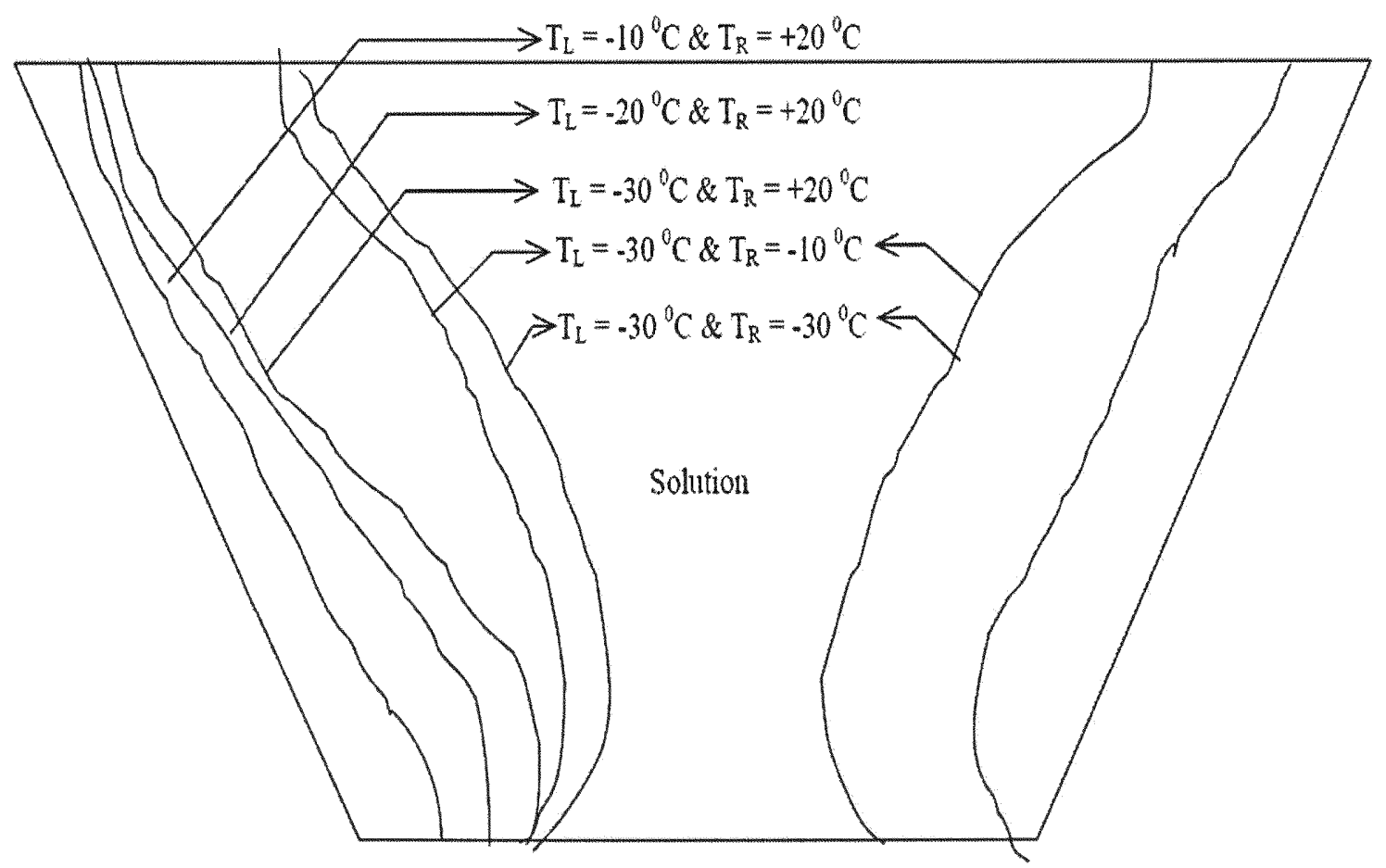

Figure 3.67

Solidification Contours showing the effect of Initial Boundary Condition; $5 \% \mathrm{NH}_{4} \mathrm{Cl}-\mathrm{H}_{2} \mathrm{O}$ at Time $(t)=72$ Minutes 


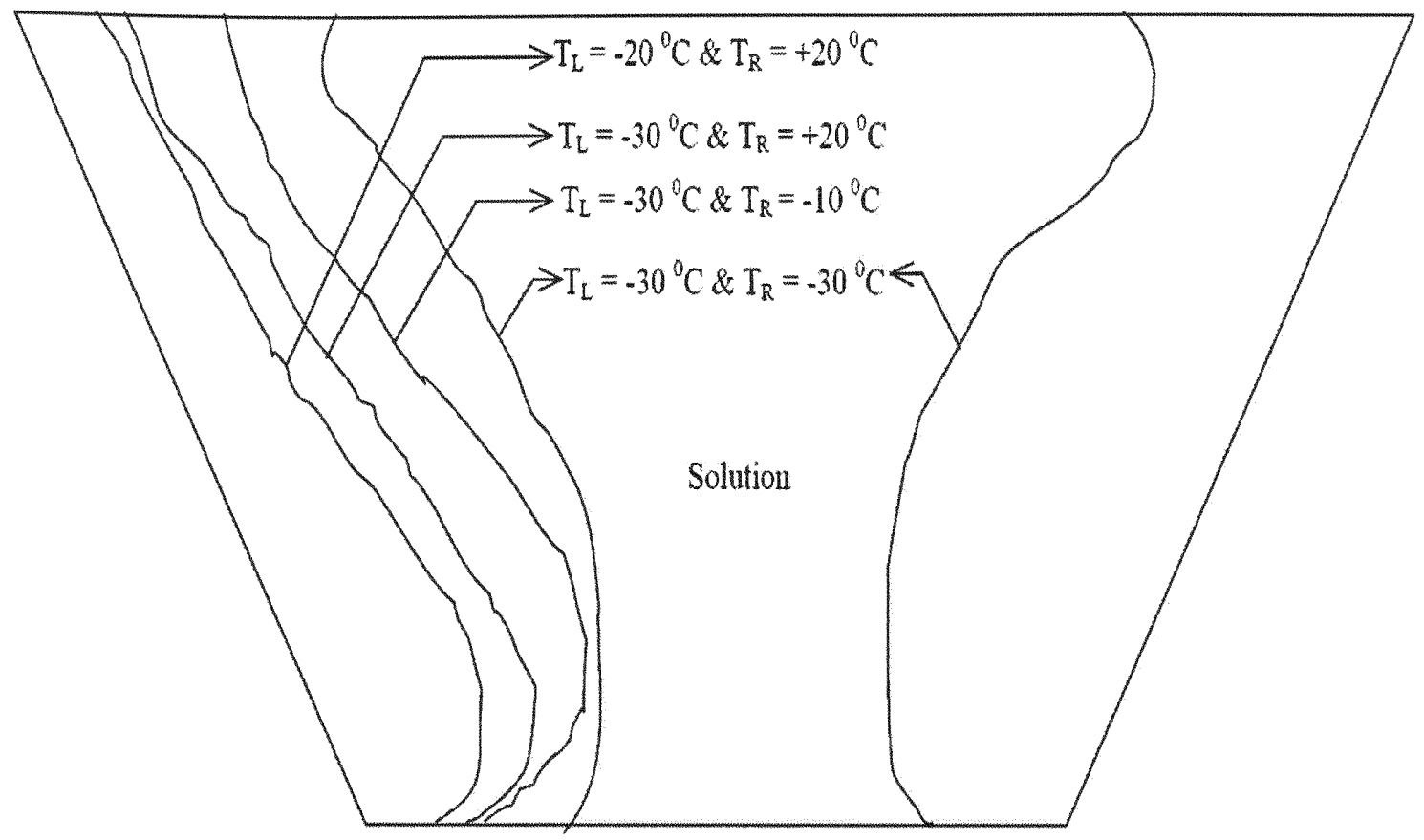

Figure 3.68 Solidification Contours showing the effect of Initial Boundary Condition; $12 \% \mathrm{NH}_{4} \mathrm{Cl}-\mathrm{H}_{2} \mathrm{O}$ at Time $(\mathrm{t})=72$ Minutes

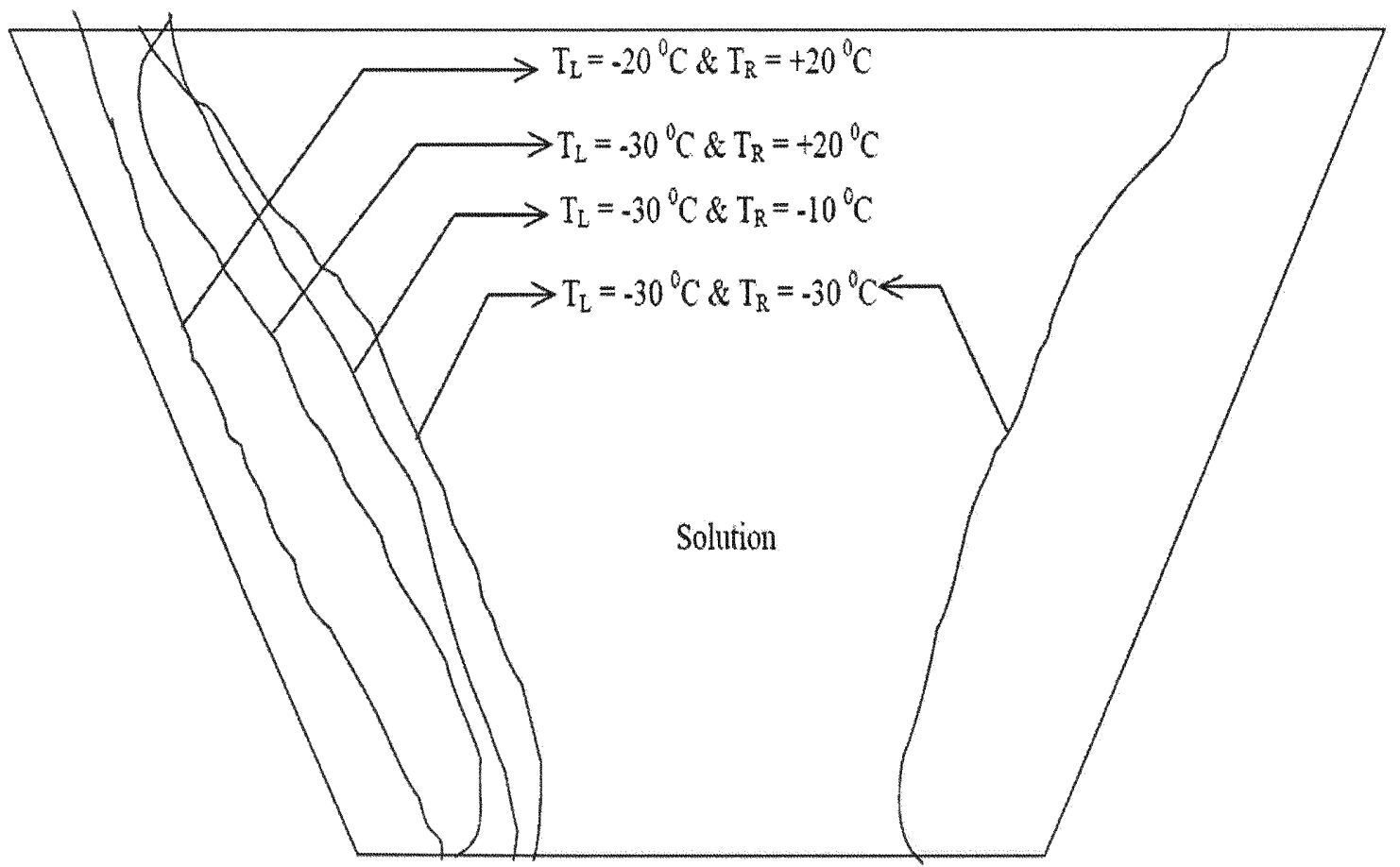

Figure 3.69 Solidification Contours showing the effect of Initial Boundary Condition; $19.8 \% \mathrm{NH}_{4} \mathrm{Cl}-\mathrm{H}_{2} \mathrm{O}$ at Time $(\mathrm{t})=72$ Minutes 
Figures 3.66 to 3.69 show the solidification contours for different concentrations with various boundary conditions at a particular time (72 minutes). Frozen layer thickness and moving interface velocity can be obtained from both PIV images and solidification contours. Figures 3.70 to 3.73 shows the effect of initial boundary conditions on the frozen layer thickness which included the data from both one wall cooled and two walls cooled. The frozen layer thickness is measured for different times at $\mathrm{Y}=37 \mathrm{~mm}$ on the left side wall. Figure 3.70 shows the effect of Initial BC's on the frozen layer thickness for pure water at $\mathrm{Y}=37 \mathrm{~mm}$. It is observed that the frozen layer thickness decreases with increase in temperature and also observed that the cooling on the right side wall enhances the solidification process on the left side wall. Figures 3.71 , $3.72 \& 3.73$ shows the effect of initial BC's on frozen layer thickness for $5 \%, 12 \%$, $19.8 \%$ respectively at $\mathrm{Y}=37 \mathrm{~mm}$.

Moving interface velocity can be obtained from frozen layer thickness at different times. Figures 3.74 to 3.77 shows the effect of initial BC's on the moving interface velocity at $\mathrm{Y}=37 \mathrm{~mm}$ for different concentrations. The observations made are similar to that of frozen layer thickness. Figure 3.74 shows the effect of Initial BC's on the moving interface velocity for pure water at $Y=37 \mathrm{~mm}$. Figures $3.75,3.76 \& 3.77$ shows the effect of initial BC's on moving interface velocity for $5 \%, 12 \%, 19.8 \%$ respectively at $\mathrm{Y}=37$ $\mathrm{mm}$. 


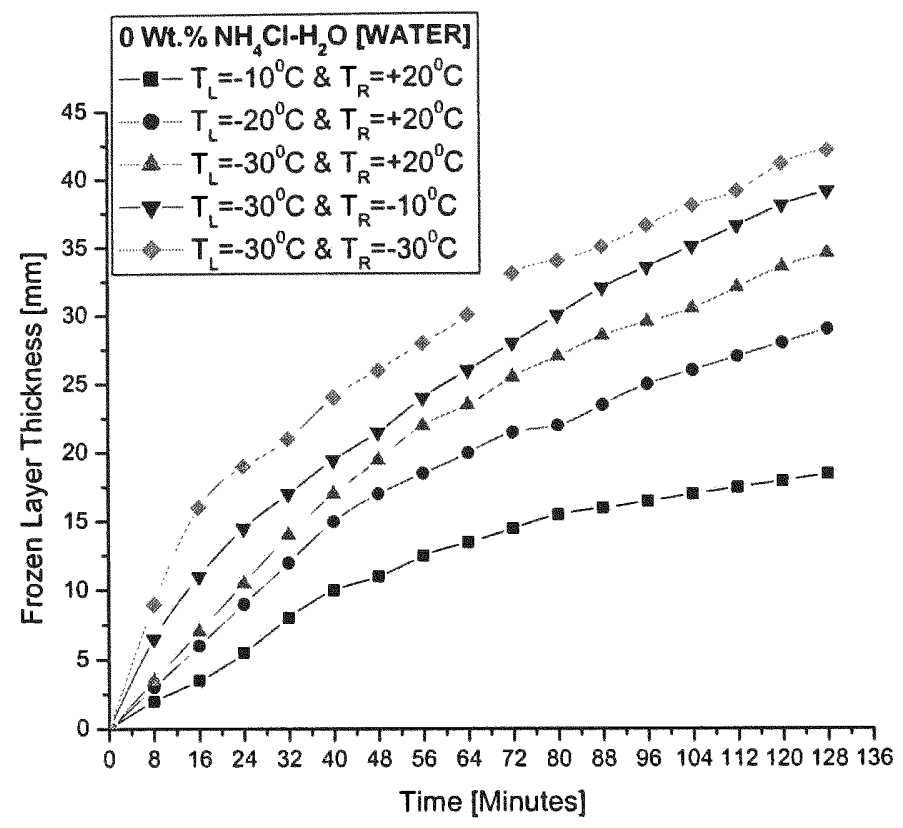

Figure 3.70

Effect of Initial Boundary Conditions on Frozen Layer thickness ( $Y=37 \mathrm{~mm})$ : Pure Water

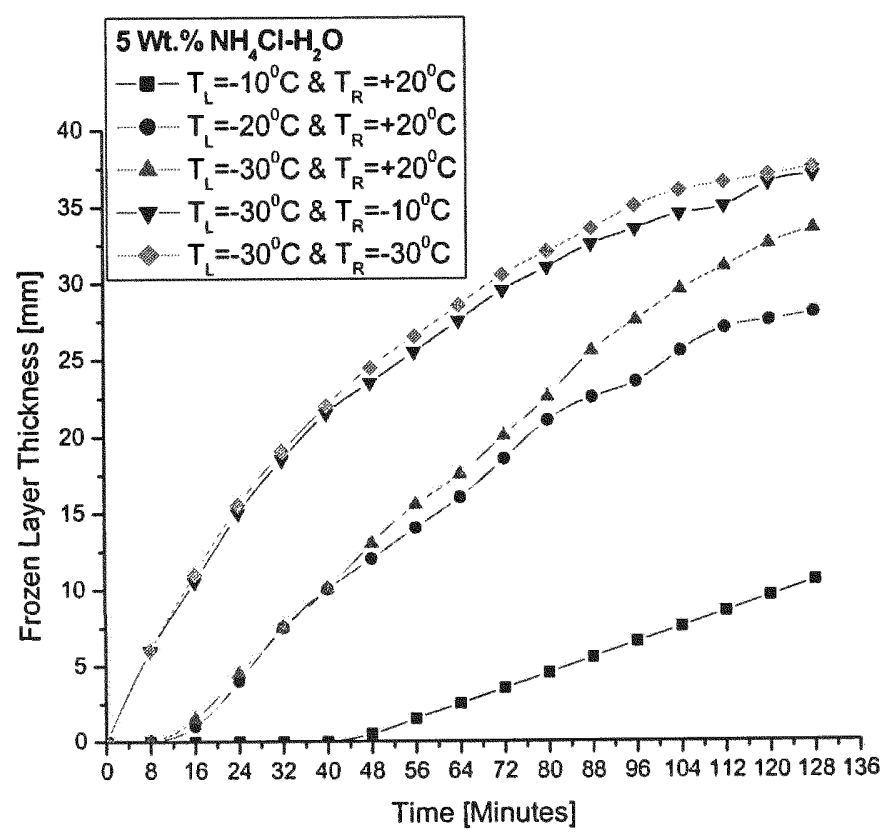

Figure 3.71 Effect of Initial Boundary Conditions on Frozen Layer thickness ( $\mathrm{Y}=37 \mathrm{~mm})$ : $5 \% \mathrm{NH}_{4} \mathrm{Cl}-\mathrm{H}_{2} \mathrm{O}$ 


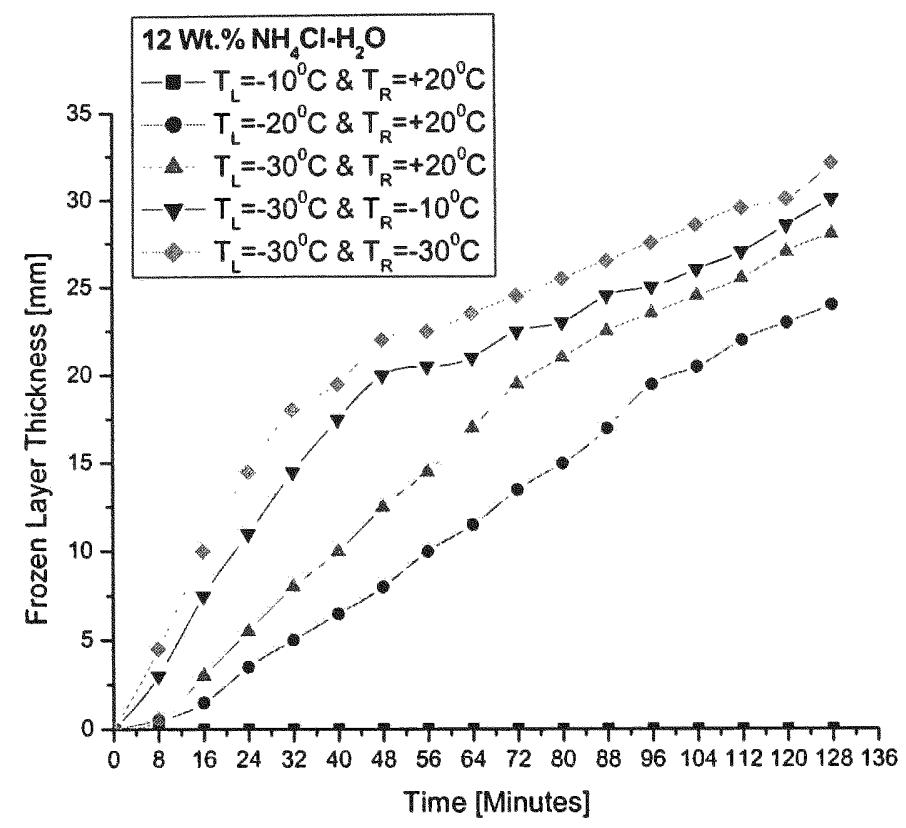

Figure 3.72 Effect of Initial Boundary Conditions on Frozen Layer thickness ( $\mathrm{Y}=\mathbf{3 7} \mathrm{mm})$ : $12 \% \mathrm{NH}_{4} \mathrm{Cl}-\mathrm{H}_{2} \mathrm{O}$

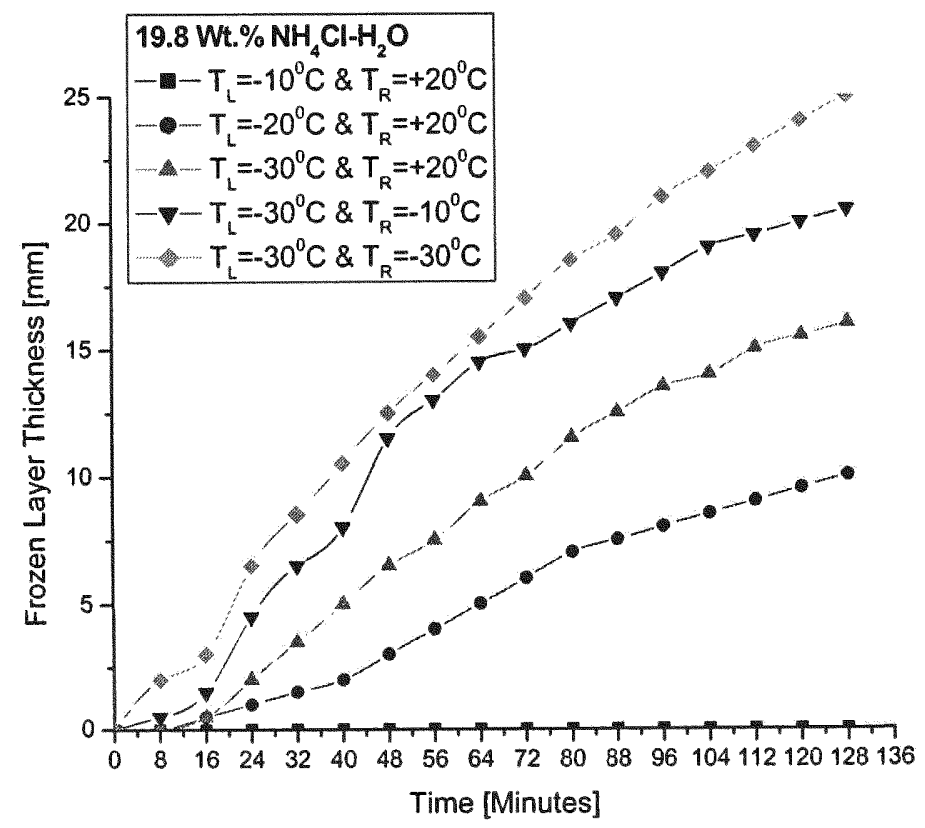

Figure 3.73 Effect of Initial Boundary Conditions on Frozen Layer thickness (Y=37 mm): $19.8 \% \mathrm{NH}_{4} \mathrm{Cl}-\mathrm{H}_{2} \mathrm{O}$ 


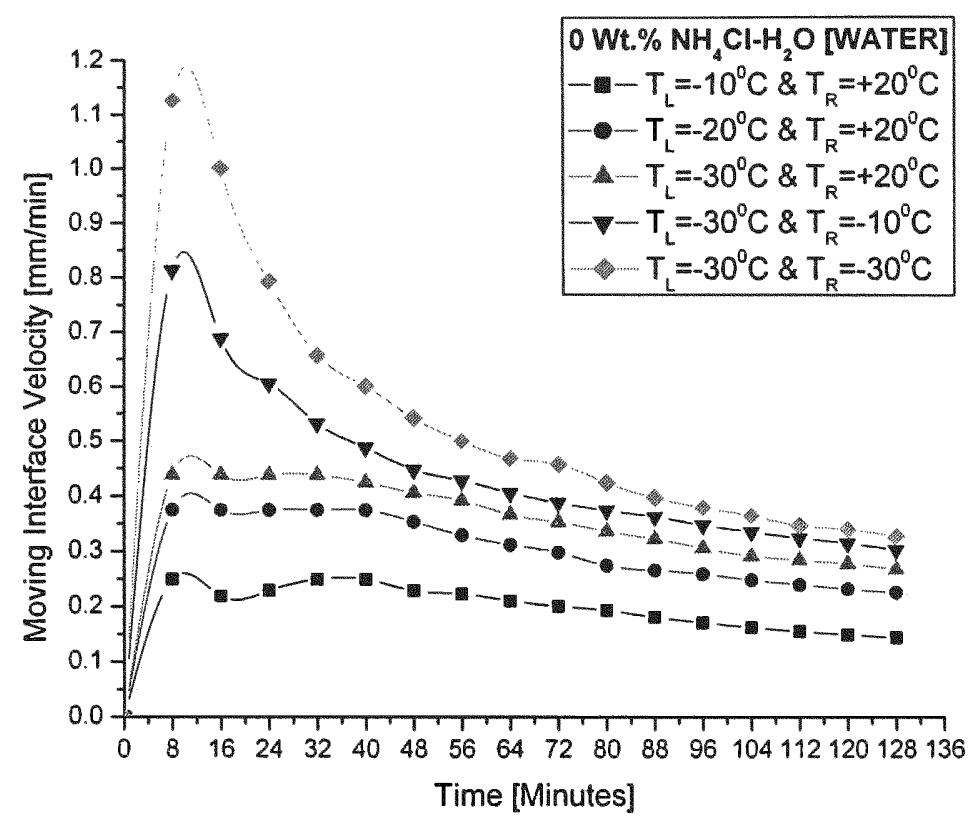

Figure 3.74 Effect of Initial Boundary Conditions on Velocity of Moving Interface ( $Y=37 \mathrm{~mm})$ : Pure Water

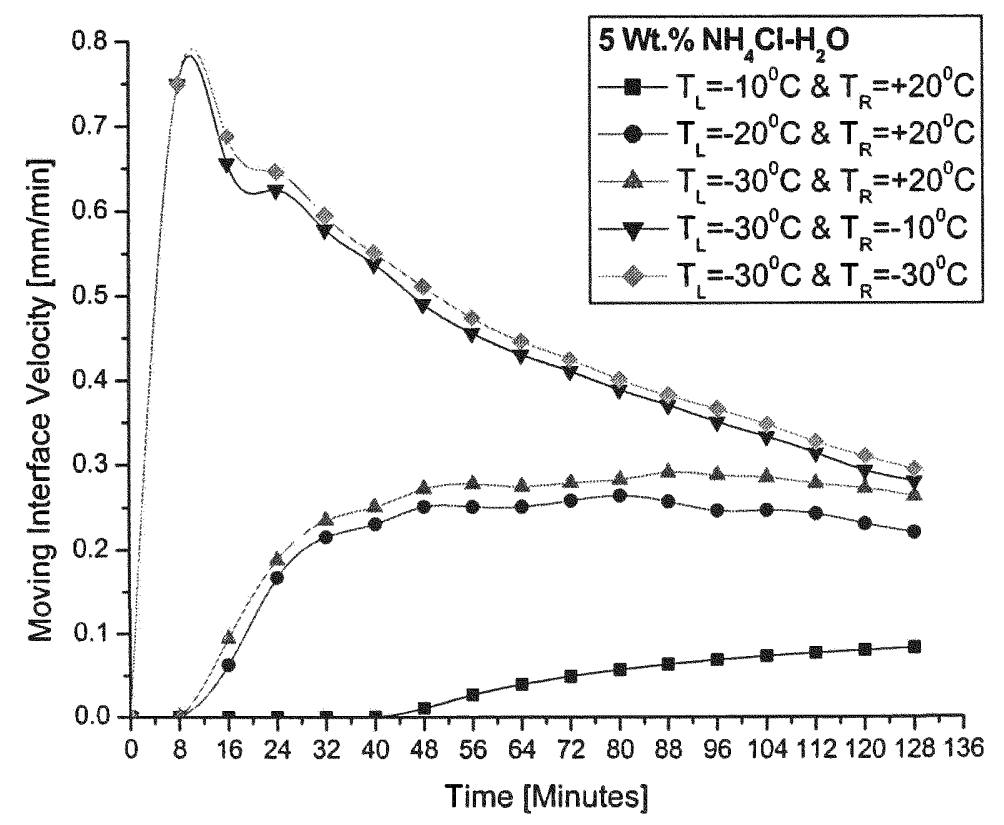

Figure 3.75 Effect of Initial Boundary Conditions on Velocity of Moving Interface ( $Y=37 \mathrm{~mm})$ : $5 \% \mathrm{NH}_{4} \mathrm{Cl}-\mathrm{H}_{2} \mathrm{O}$ 


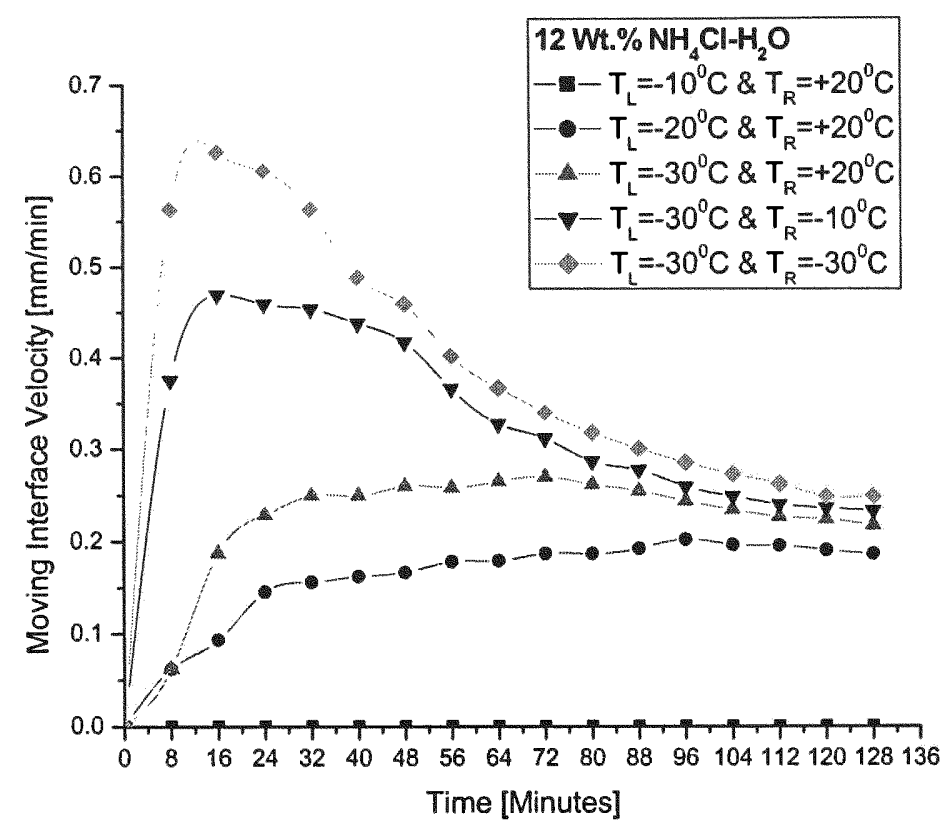

Figure 3.76

Effect of Initial Boundary Conditions on Velocity of Moving Interface ( $Y=37 \mathrm{~mm})$ : $12 \% \mathrm{NH}_{4} \mathrm{Cl}-\mathrm{H}_{2} \mathrm{O}$

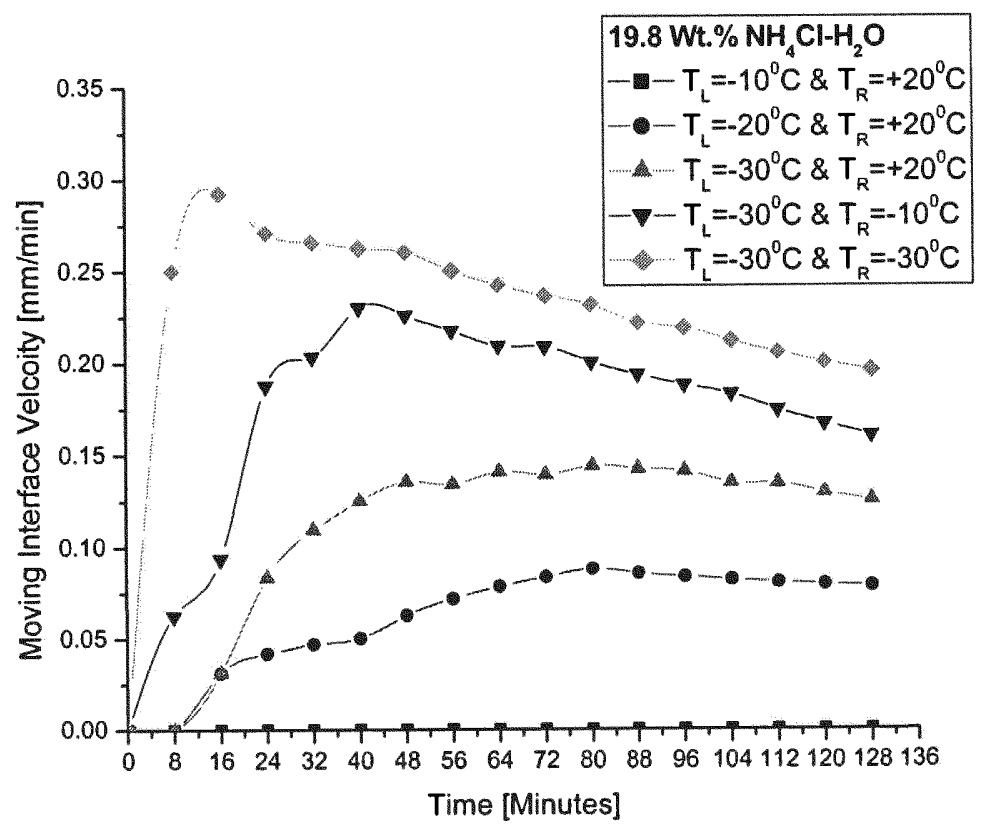

Figure 3.77 Effect of Initial Boundary Conditions on Velocity of Moving Interface ( $\mathrm{Y}=37 \mathrm{~mm})$ : $19.8 \% \mathrm{NH}_{4} \mathrm{Cl}-\mathrm{H}_{2} \mathrm{O}$ 
Convection flow patterns during the solidification process can be obtained from the PIV images shown in Figure 3.62 to 3.65 . Figure 3.78 to 3.81 show some of the data of convection flow patterns obtained for two walls cooled. Figure 3.78 show convection flow pattern at 72 minutes during solidification process of pure water for various boundary conditions (both one wall and two walls cooled). There is a big difference in the convection pattern among one wall and two walls cooled. For one wall cooled the convection patterns are two circulating flows in opposite directions one on top and one at bottom of the chamber but for two walls cooled the two counter clockwise circulating flows are located at the middle of the chamber.

Figures 3.79 to 3.81 show the convection flow pattern at 72 minutes during solidification process for various boundary conditions (both one wall and two walls cooled) for different concentrations i.e., $5 \%, 12 \%, 19.8 \%$ respectively. 


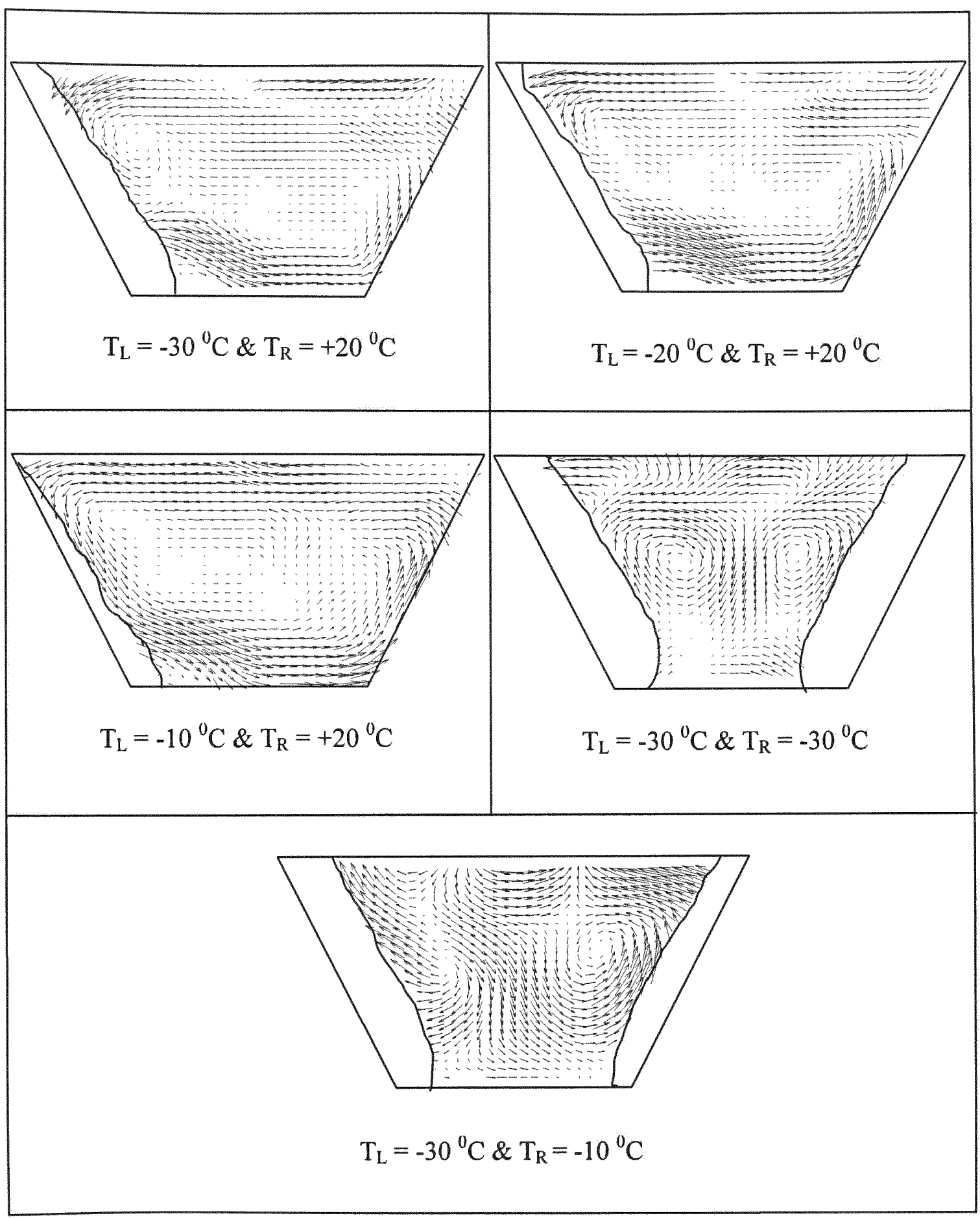

Figure 3.78 Effect of Initial Boundary Temperature on Convection Flow Pattern; Pure Water; Time $(t)=24$ Minutes. 


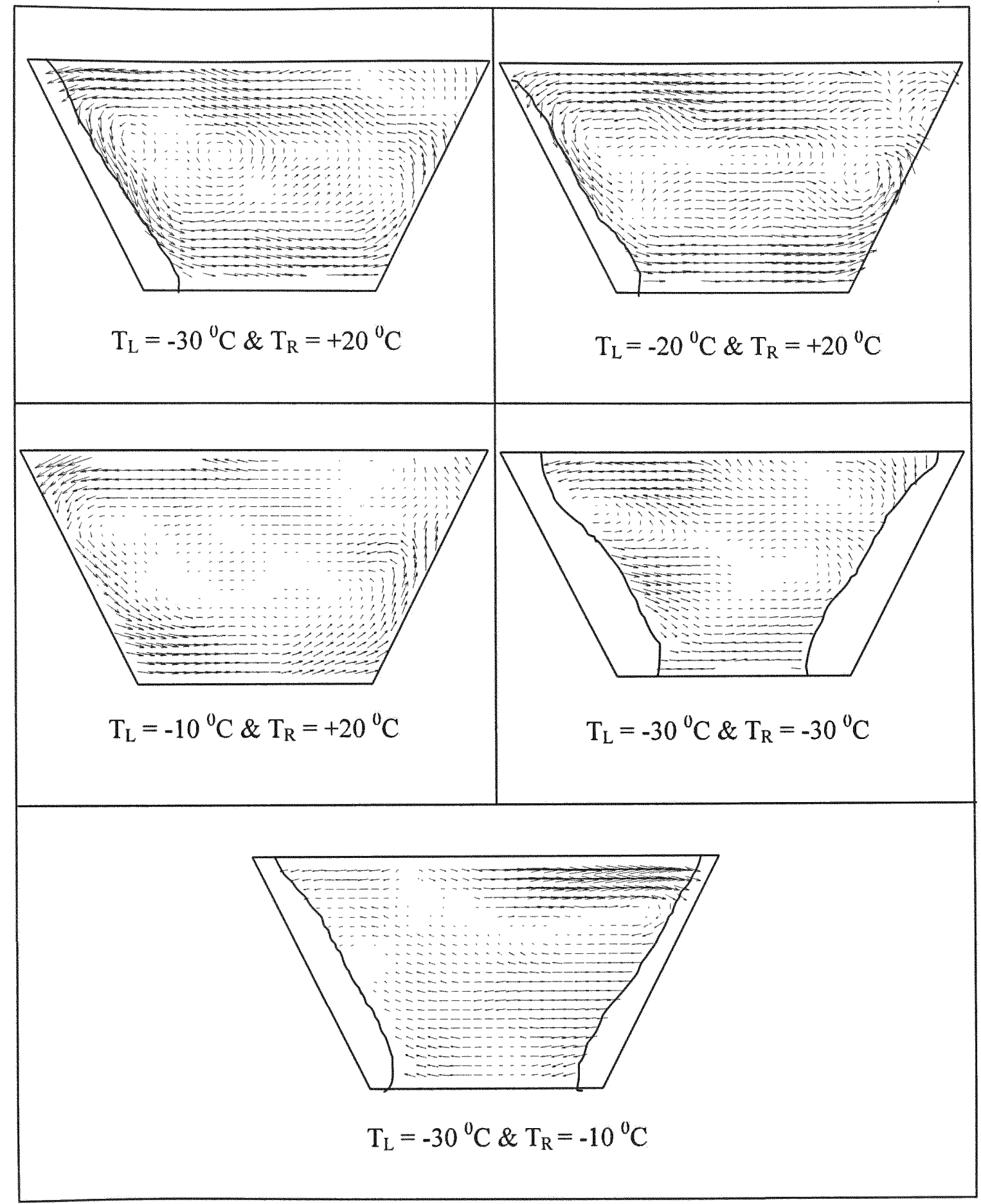

Figure 3.79 Effect of Initial Boundary Temperature on Convection Flow Pattern; $5 \% \mathrm{NH}_{4} \mathrm{Cl}-\mathrm{H}_{2} \mathrm{O}$; Time $(\mathrm{t})=24$ Minutes. 


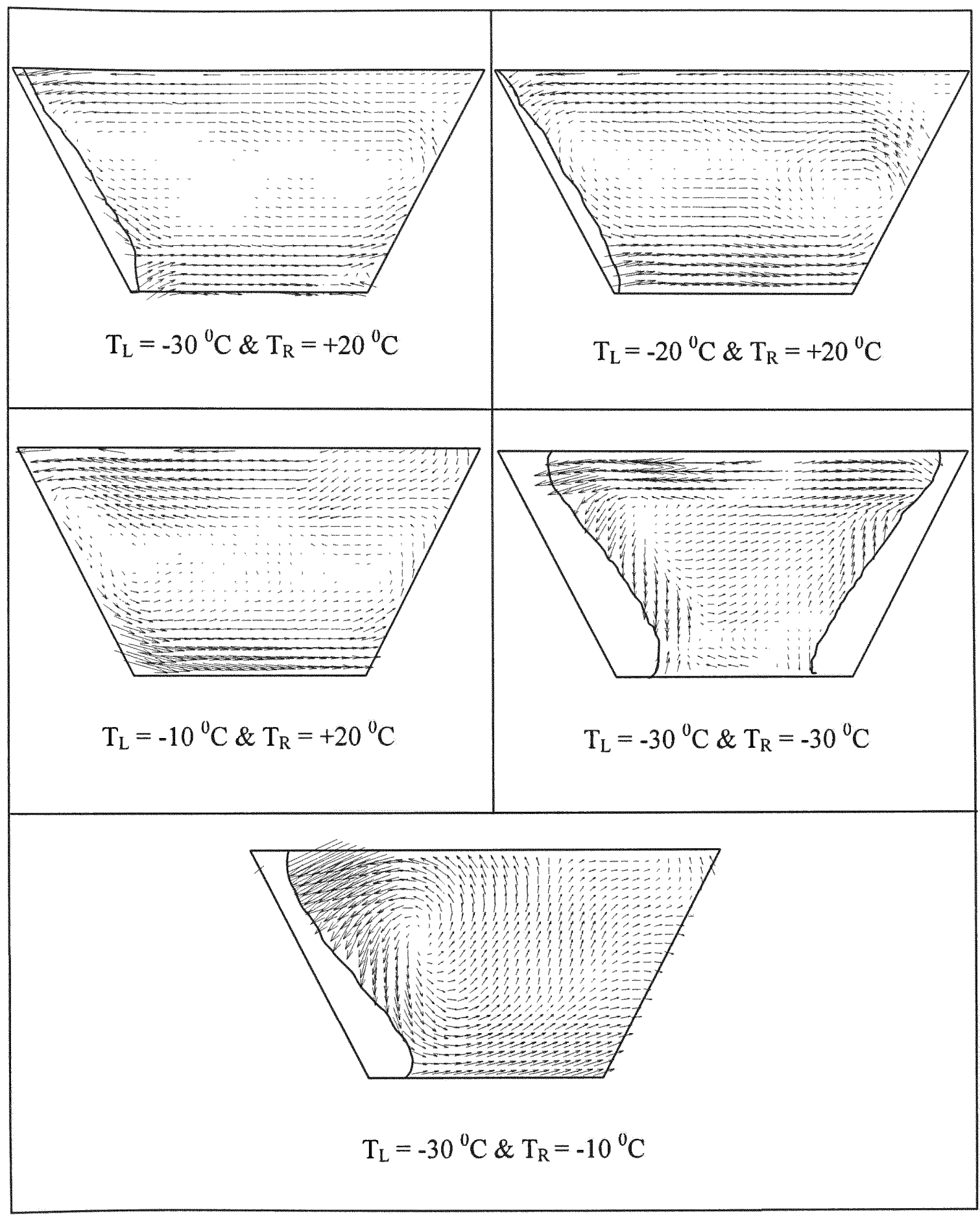

Figure 3.80 Effect of Initial Boundary Temperature on Convection Flow Pattern; $12 \% \mathrm{NH}_{4} \mathrm{Cl}-\mathrm{H}_{2} \mathrm{O}$; Time $(\mathrm{t})=24$ Minutes. 


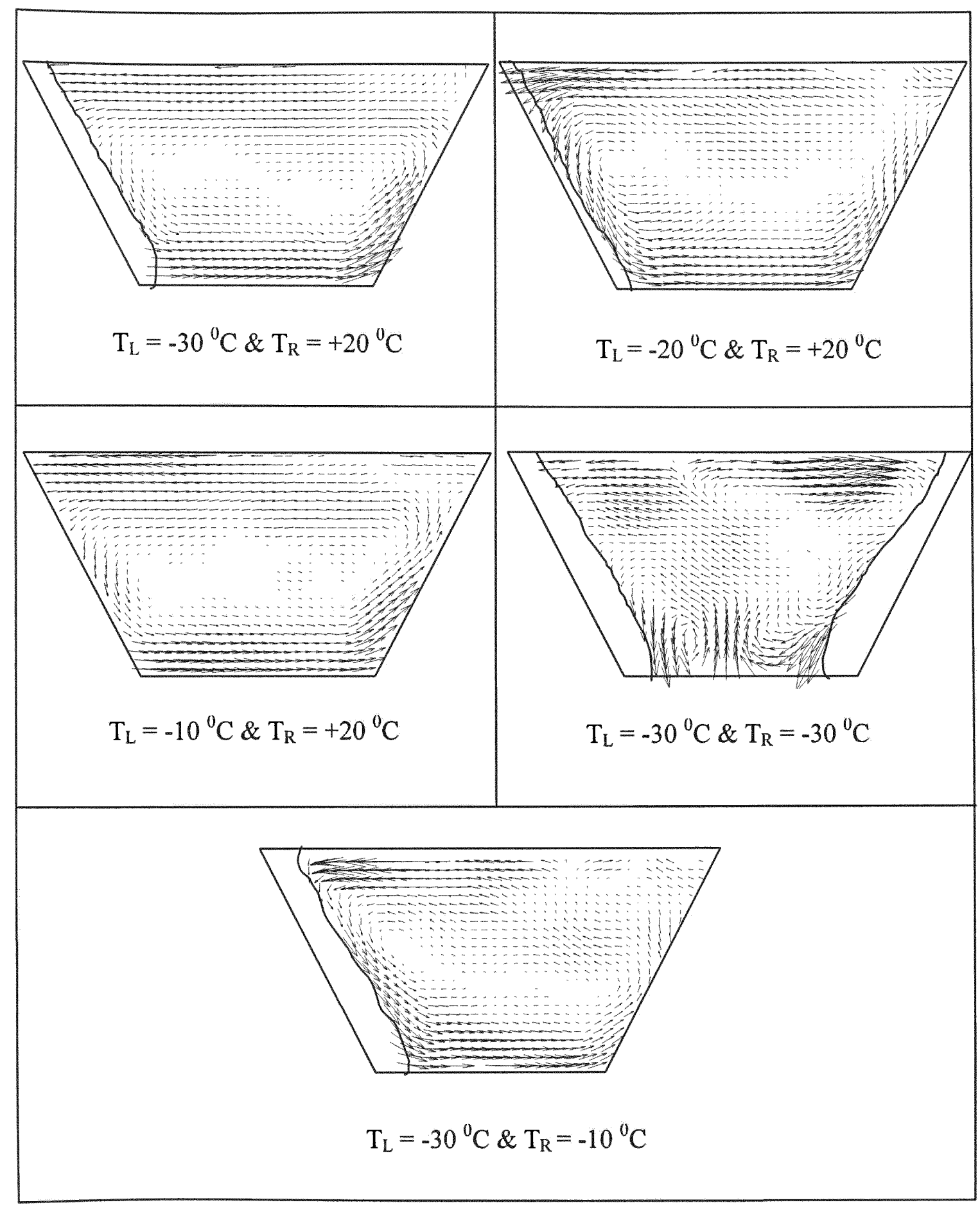

Figure 3.81 Effect of Initial Boundary Temperature on Convection Flow Pattern; $19.8 \% \mathrm{NH}_{4} \mathrm{Cl}-\mathrm{H}_{2} \mathrm{O}$; Time $(\mathrm{t})=24$ Minutes. 
The effect of initial boundary conditions on the temperature distribution is studied and represented in Figures 3.82 to 3.84 . Figure 3.82 shows the temperature distribution inside the cavity at $\mathrm{Y}=37 \mathrm{~mm}$ from bottom at time $(\mathrm{t})=40$ minutes for pure water. Similarly Figures $3.83 \& 3.84$ shows the effect of initial boundary conditions on temperature distribution at $\mathrm{Y}=37$ at time $(\mathrm{t})=72$ and 104 minutes respectively. It has been observed the same temperature distribution profiles for all the times. For two walls cooled also the temperature distribution is observed the same as one wall cooled.

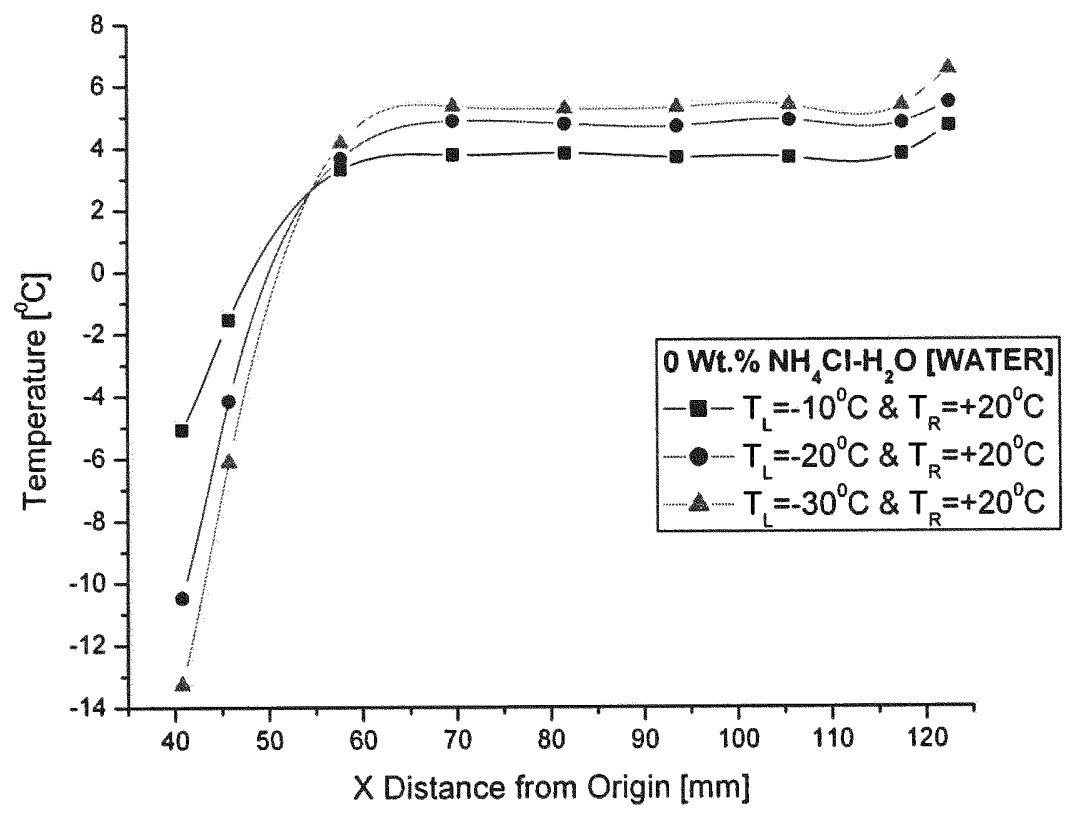

Figure 3.82 Effect of Initial Boundary Conditions on Temperature Distribution inside the cavity; $Y=37 \mathrm{~mm}$; Pure Water One wall Cooled; Time $(t)=40$ Minutes. 


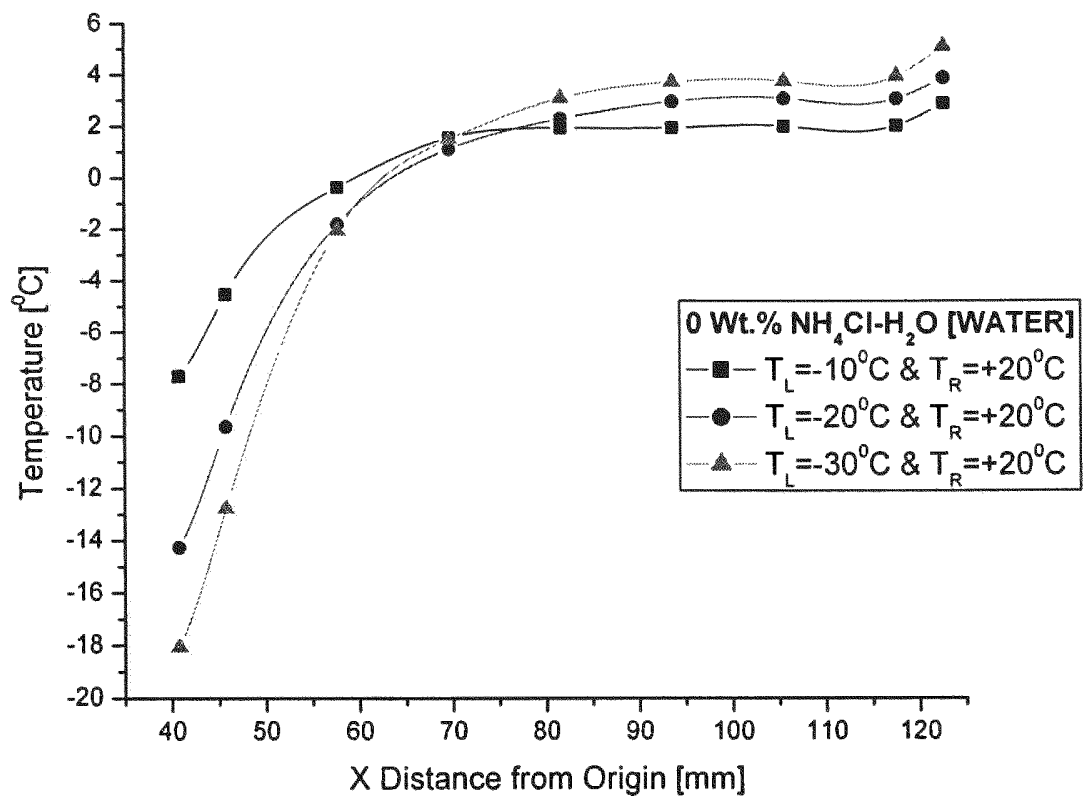

Figure 3.83 Effect of Initial Boundary Conditions on Temperature Distribution inside the cavity; $\mathrm{Y}=37 \mathrm{~mm}$; Pure Water One wall Cooled; Time $(t)=72$ Minutes.

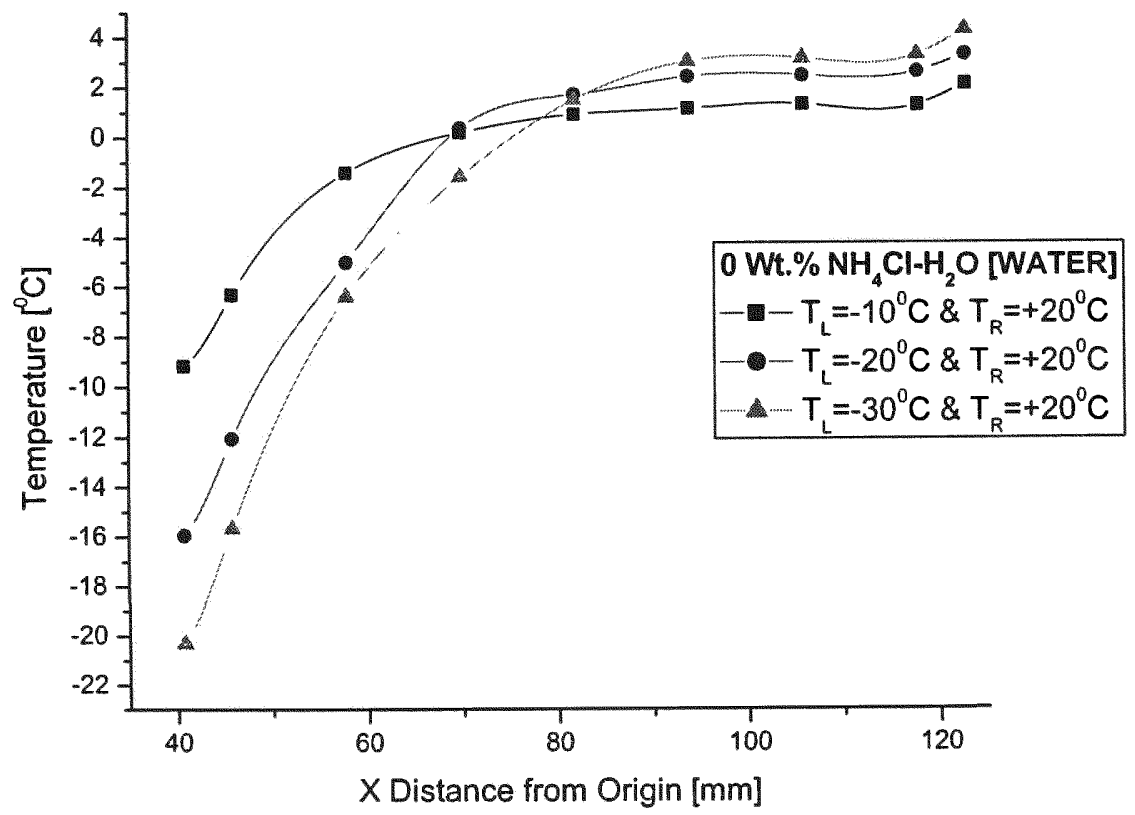

Figure 3.84 Effect of Initial Boundary Conditions on Temperature Distribution inside the cavity; $Y=37 \mathrm{~mm}$; Pure Water One wall Cooled; Time $(t)=104$ Minutes. 
Experiments were conducted to study the effect of boundary condition on one wall on the solidification process. The temperature on the right side wall is varied by maintaining the temperature on the left side wall constant. The temperature on the left side wall is maintained at $-30{ }^{\circ} \mathrm{C}$ and the temperature on the left side wall is varied from $+20{ }^{\circ} \mathrm{C}$ to $30{ }^{\circ} \mathrm{C}\left(+20{ }^{\circ} \mathrm{C},-10{ }^{\circ} \mathrm{C},-20{ }^{\circ} \mathrm{C},-25{ }^{\circ} \mathrm{C},-30{ }^{\circ} \mathrm{C}\right)$. Figures 3.85 to 3.87 show the change of frozen layer thickness with these boundary conditions. Figure 3.85 show the change of frozen layer thickness with temperature on the right side wall for different times. Figure $3.86 \& 3.87$ show the variation of frozen layer thickness for different temperatures on left and right side walls.

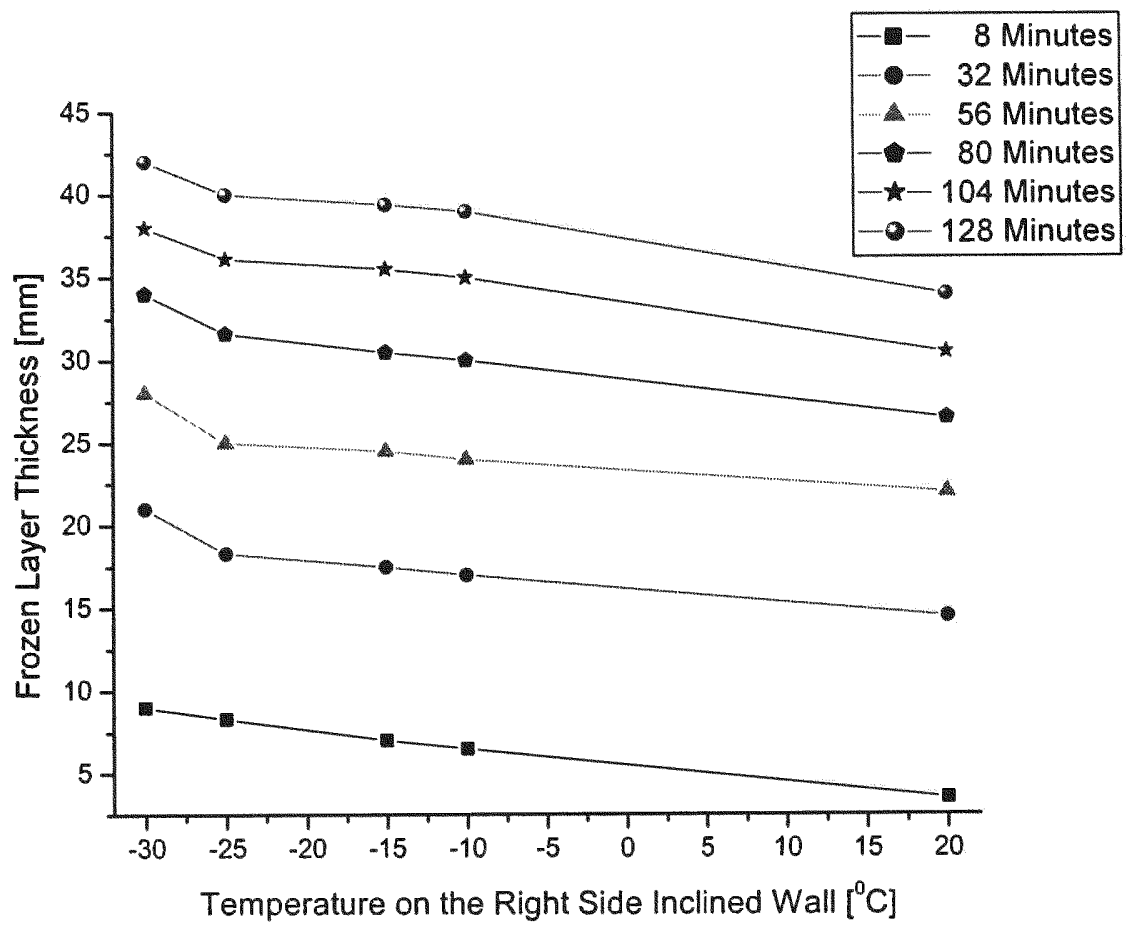

Figure 3.85 Effect of Temperature on right side wall on Frozen layer thickness; $\mathrm{Y}=\mathbf{3 7} \mathrm{mm}$; Pure Water; Two Wall Cooled $\left(\mathrm{T}_{\mathrm{L}}=-30^{\circ} \mathrm{C}\right)$ 
Frozen Layer Thickness on Left side Inclined Wall

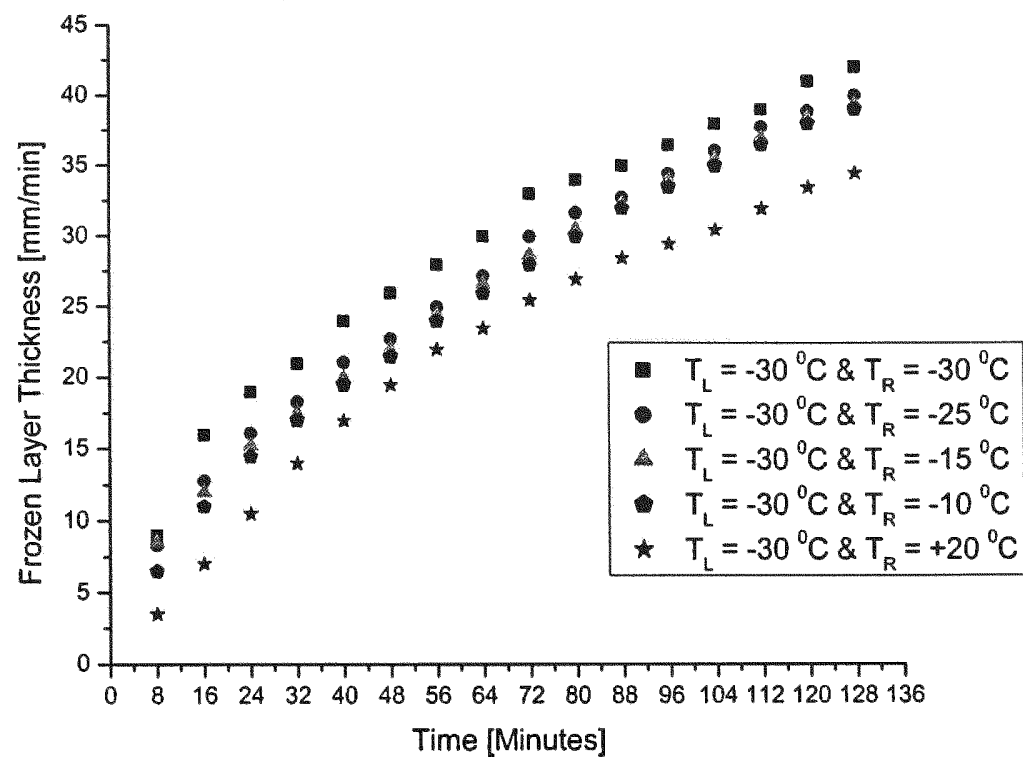

Figure 3.86 Effect of Temperature on Frozen layer thickness; $Y=37 \mathrm{~mm}$; Pure Water; Left side wall; Two Wall Cooled $\left(\mathbf{T}_{L}=-30^{\circ} \mathrm{C}\right)$

Frozen Layer Thickness on Right side Inclined Wall

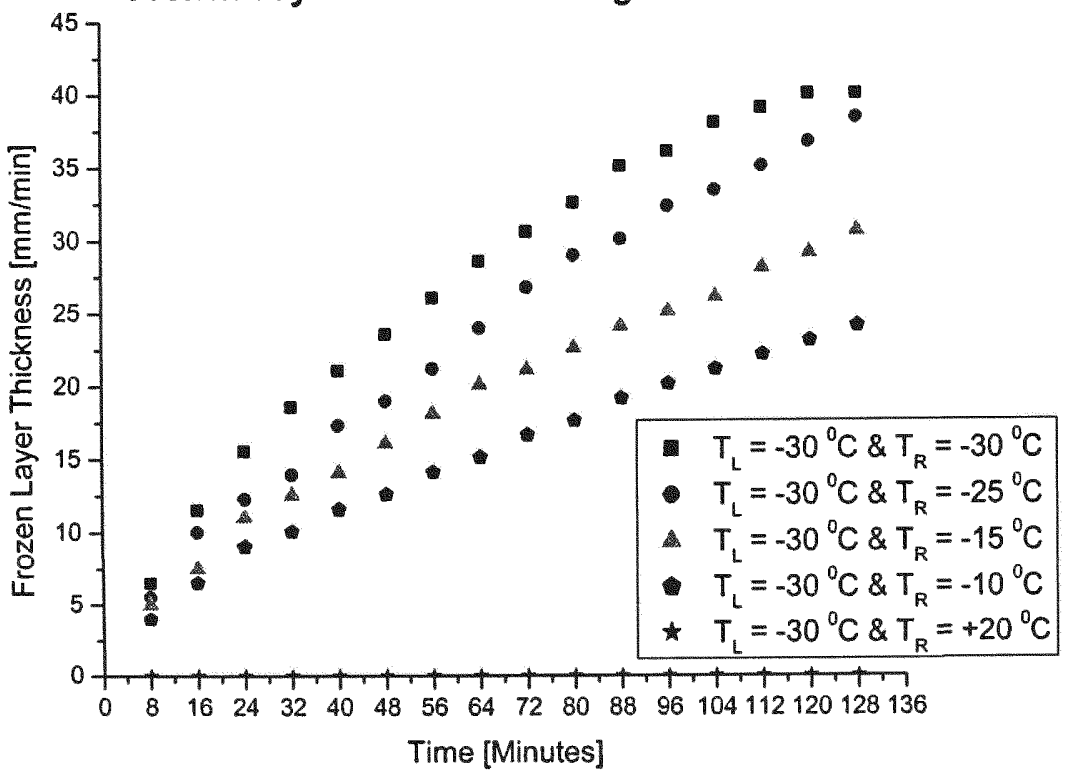

Figure 3.87 Effect of Temperature on Frozen layer thickness; $Y=37 \mathrm{~mm}$; Pure Water; Right side wall; Two Wall Cooled $\left(\mathrm{T}_{\mathrm{L}}=-30^{\circ} \mathrm{C}\right)$ 


\subsubsection{Temperature Distribution inside the cavity}

Simultaneous acquisition of the thermal field during the solidification process is of equal importance to the formation of the convection pattern. The temperature distribution at discrete locations in the solution and on the vertical cooling walls was monitored using thermocouples. Twenty-two thermocouples (type E) were used to measure the temperature of the solution inside the cavity, and ten thermocouples (type T) were used to measure the temperature at the hot and cold vertical plates (five thermocouples for each plate). The standard limit of uncertainty of type $\mathrm{E}$ thermocouples is $\pm 1.2{ }^{\circ} \mathrm{C}$. As the solidification process proceeds, the temperature of the solution near the cold wall decreases very rapidly. The temperature variation during the solidification process on the left and right side wall of the cavity is shown in Figure 3.88 for pure water when one wall is cooled to $-30{ }^{\circ} \mathrm{C}$ another is maintained at $+20{ }^{\circ} \mathrm{C}$. The temperature distribution inside the cavity during the solidification of water with one cooled side at $y=$ $37 \mathrm{~mm}$ and $\mathrm{y}=88 \mathrm{~mm}$ are shown in Figures 3.89 and 3.90 for pure water when one wall is cooled to $-30{ }^{\circ} \mathrm{C}$ another is maintained at $+20{ }^{\circ} \mathrm{C}$. It is noted that the temperature of the chiller is set to $-30{ }^{\circ} \mathrm{C}$. The temperatures of the cold and hot walls are set to $-30{ }^{\circ} \mathrm{C}$ and $20{ }^{\circ} \mathrm{C}$ respectively. The water at a temperature of $20{ }^{\circ} \mathrm{C}$ is then poured into the cavity. A few seconds are needed until the equilibrium is reached and data can be taken. As shown in Figure 3.89 , the temperature of the water at $\mathrm{t}=8$ minutes dropped from $20{ }^{\circ} \mathrm{C}$ to $12{ }^{\circ} \mathrm{C}$ for almost all the thermocouples except the thermocouple located near the cold wall that dropped from $20{ }^{\circ} \mathrm{C}$ to $3{ }^{\circ} \mathrm{C}$. The temperature of the solution for the thermocouple located close to the cold wall dropped from $3{ }^{\circ} \mathrm{C}$ to $-22{ }^{\circ} \mathrm{C}$ after two hours of the solidification process. Figure 3.90 shows the temperature distribution during the solidification of water 
for $\mathrm{Y}=88 \mathrm{~mm}$ (close to the free surface). It is noted that at the same time, the temperatures close to the bottom of the cavity or at $\mathrm{Y}=37 \mathrm{~mm}$ are smaller than the temperature close to the free surface and located at $Y=88 \mathrm{~mm}$. The free surface is in contact with ambient air inside the cavity. At this position the heat transfer between the air and the solution is more pronounced, which explains the high temperature of the solution at the top of the cavity. Figures 3.91 and 3.92 shows the temperature distribution at $\mathrm{Y}=37 \mathrm{~mm}$ and $88 \mathrm{~mm}$ with time for one wall cooled. Figures 3.93 and 3.94 show the temperature distributions during the solidification of water with two cooling walls at $\mathrm{Y}=$ $37 \mathrm{~mm}$ and $\mathrm{Y}=88 \mathrm{~mm}$. Figures 3.95 and 3.96 shows the temperature distribution at $\mathrm{Y}=$ $37 \mathrm{~mm}$ and $88 \mathrm{~mm}$ with time for two walls cooled. As for the one cooled wall, the temperatures close to the bottom of the cavity $(\mathrm{Y}=37 \mathrm{~mm})$ are smaller than the one close to the top $(\mathrm{Y}=88 \mathrm{~mm})$ where the free liquid surface is in contact with the ambient air. As expected, the temperature of the solution decreases rapidly with the two-cooled side of the cavity. 


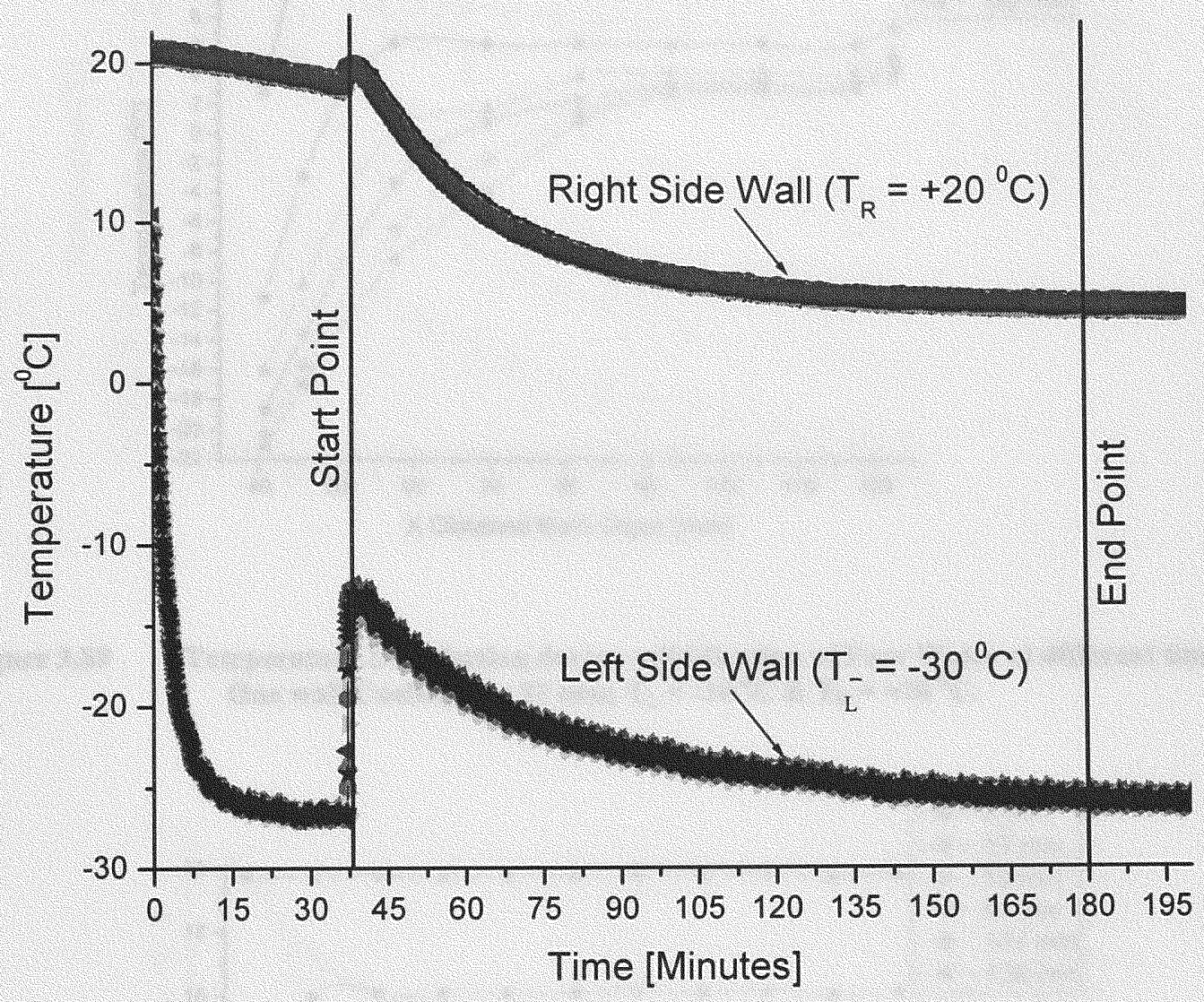

Figure 3.88 Temperature variation during solidification process on left and right side wall of the cavity; One wall Cooled; $T_{L}=-30^{\circ} \mathrm{C} \& \mathrm{~T}_{R}=+20^{\circ} \mathrm{C}$. 


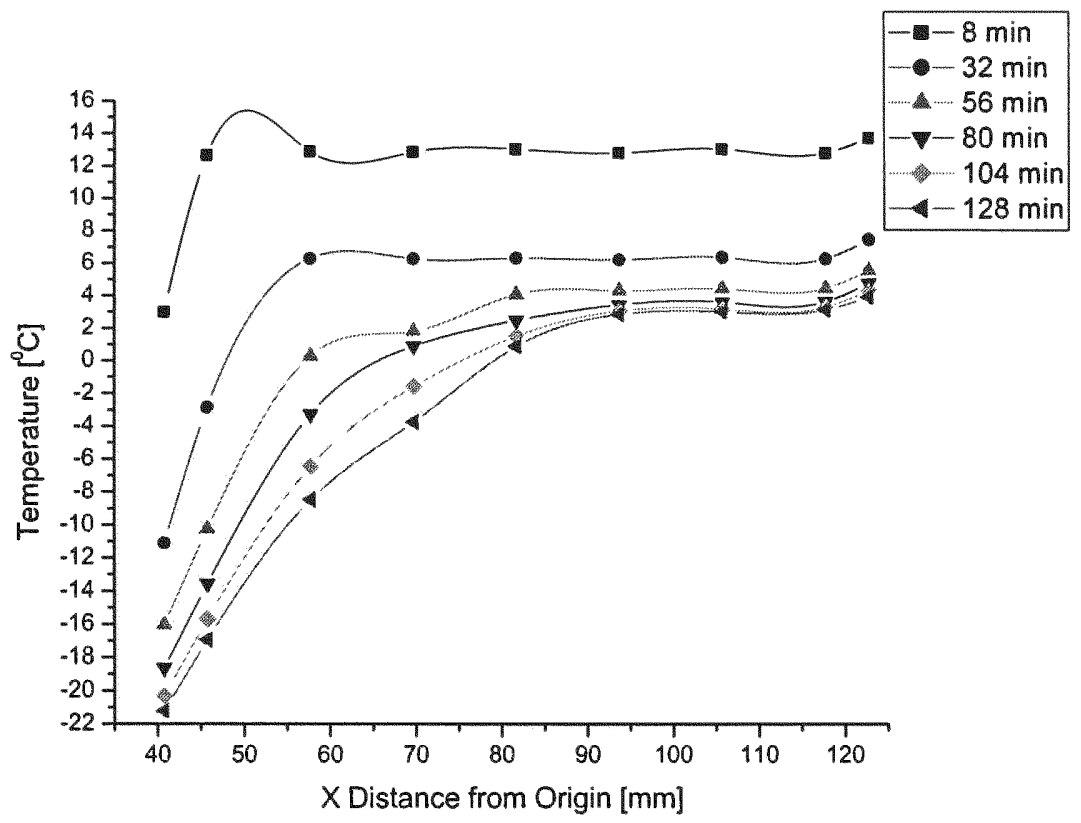

Figure 3.89

Temperature Distribution during solidification of Pure Water at different times; One wall Cooled; $Y=37 \mathrm{~mm} ; \mathrm{T}_{\mathrm{L}}=-30^{\circ} \mathrm{C} \& \mathrm{~T}_{\mathrm{R}}=+20^{\circ} \mathrm{C}$.

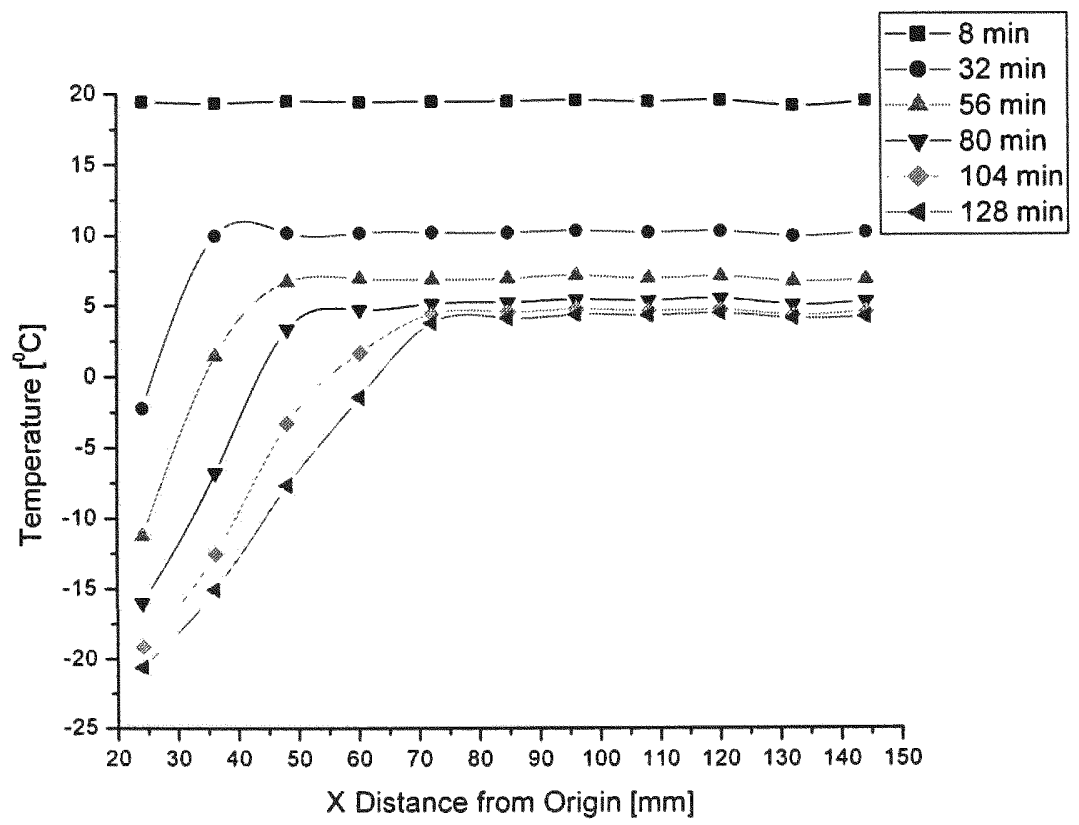

Figure 3.90 Temperature Distribution during solidification of Pure Water at different times; One wall Cooled; $Y=88 \mathrm{~mm} ; \mathrm{T}_{\mathrm{L}}=-30^{\circ} \mathrm{C} \& \mathrm{~T}_{\mathrm{R}}=+20^{\circ} \mathrm{C}$. 


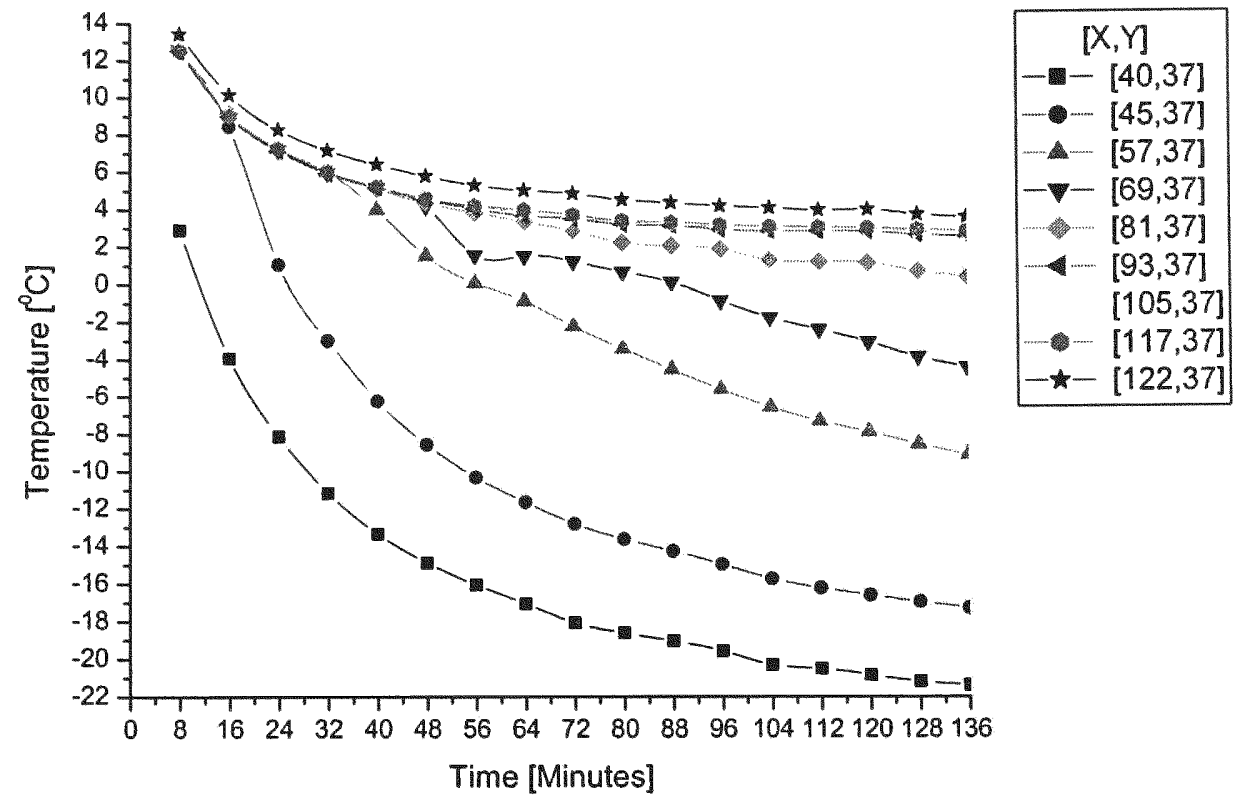

Figure 3.91 Temperature Distribution during solidification of Pure Water at different Positions; One wall Cooled; $Y=37 \mathrm{~mm} ; \mathrm{T}_{\mathrm{L}}=-30^{\circ} \mathrm{C} \& \mathrm{~T}_{\mathrm{R}}=+20^{\circ} \mathrm{C}$.

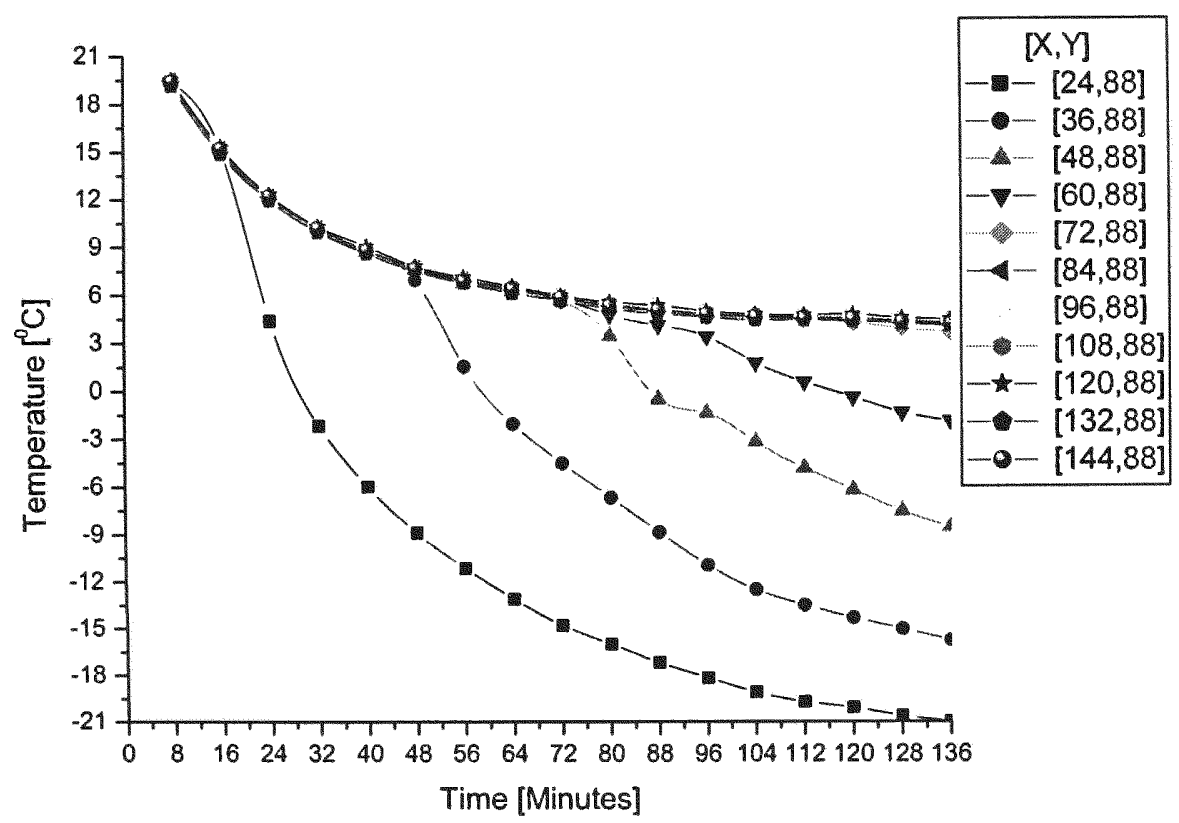

Figure 3.92 Temperature Distribution during solidification of Pure Water at different Positions; One wall Cooled; $Y=88 \mathrm{~mm} ; T_{\mathrm{L}}=-30^{\circ} \mathrm{C} \& \mathrm{~T}_{R}=+20^{\circ} \mathrm{C}$. 


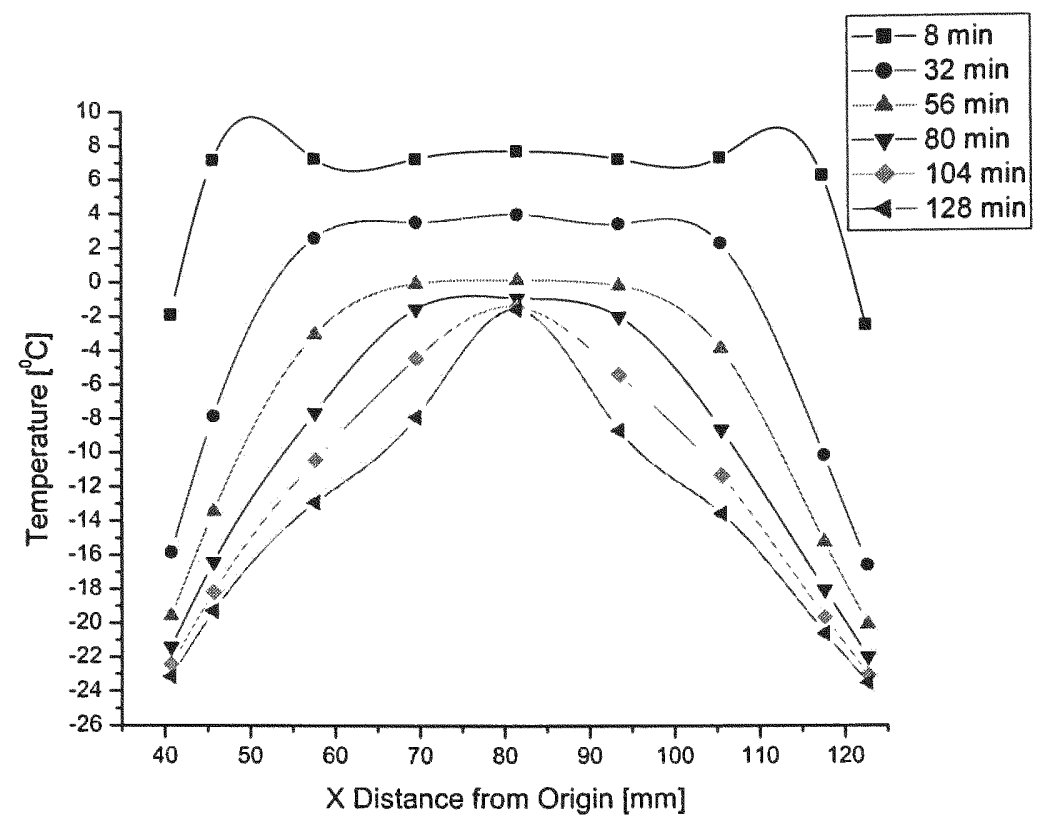

Figure 3.93 Temperature Distribution during solidification of Pure Water at different Times; Two walls Cooled; $Y=37 \mathrm{~mm} ; T_{L}=-30^{\circ} \mathrm{C} \& T_{R}=-30^{\circ} \mathrm{C}$.

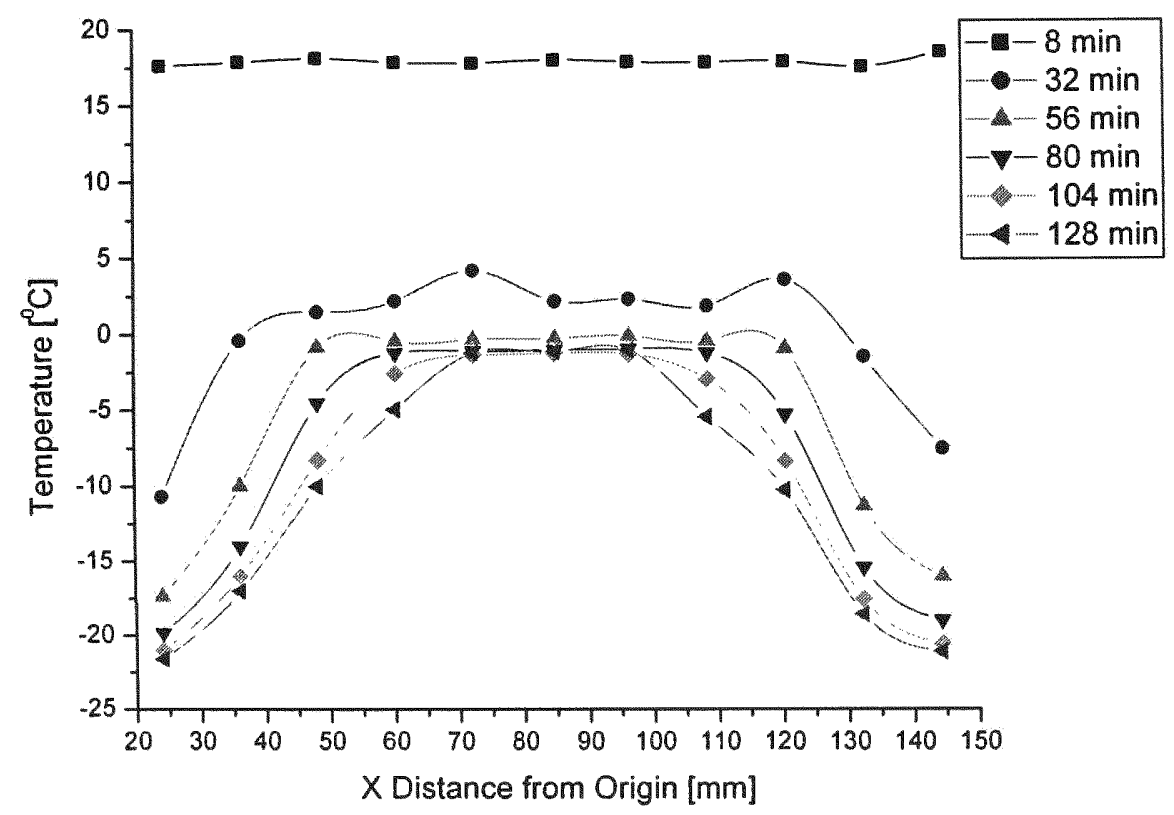

Figure 3.94 Temperature Distribution during solidification of Pure Water at different Times; Two walls Cooled; $Y=88 \mathrm{~mm} ; \mathrm{T}_{\mathrm{L}}=-30^{\circ} \mathrm{C} \& \mathrm{~T}_{\mathrm{R}}=-30^{\circ} \mathrm{C}$. 


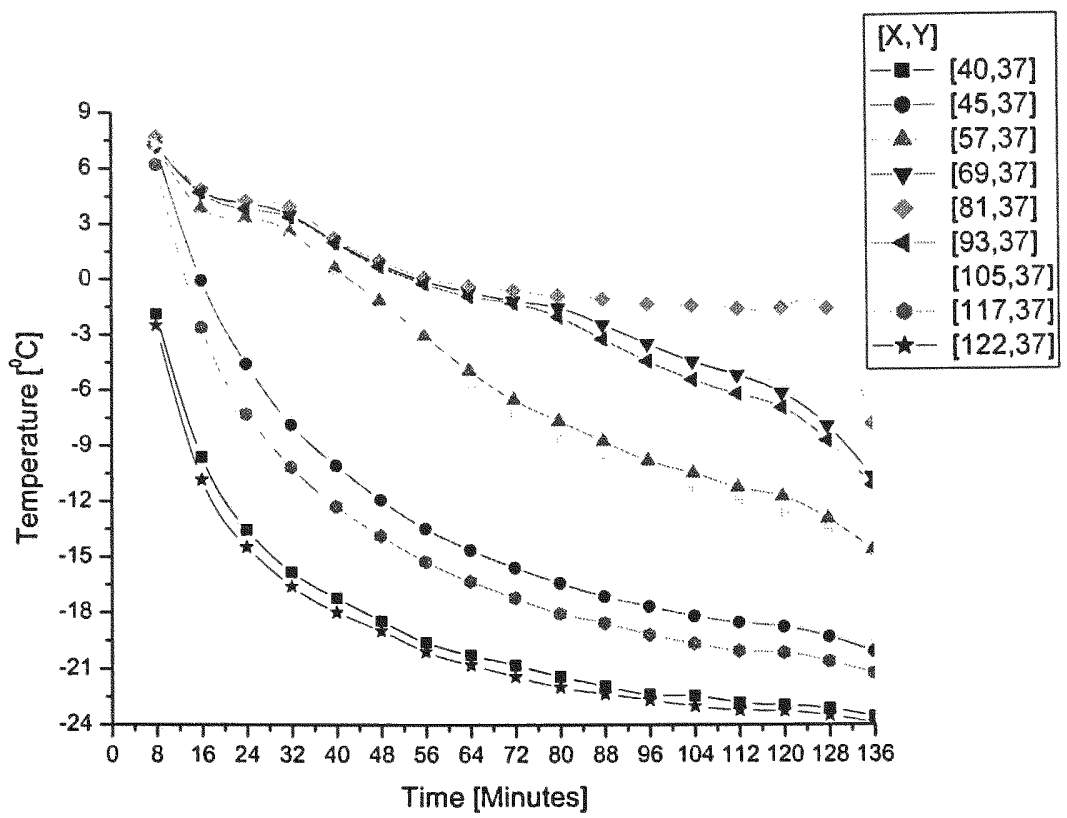

Figure 3.95 Temperature Distribution during solidification of Pure Water at different Positions; Two walls Cooled; $Y=88 \mathrm{~mm} ; \mathrm{T}_{\mathrm{L}}=-30^{\circ} \mathrm{C} \& \mathrm{~T}_{\mathrm{R}}=-30^{\circ} \mathrm{C}$.

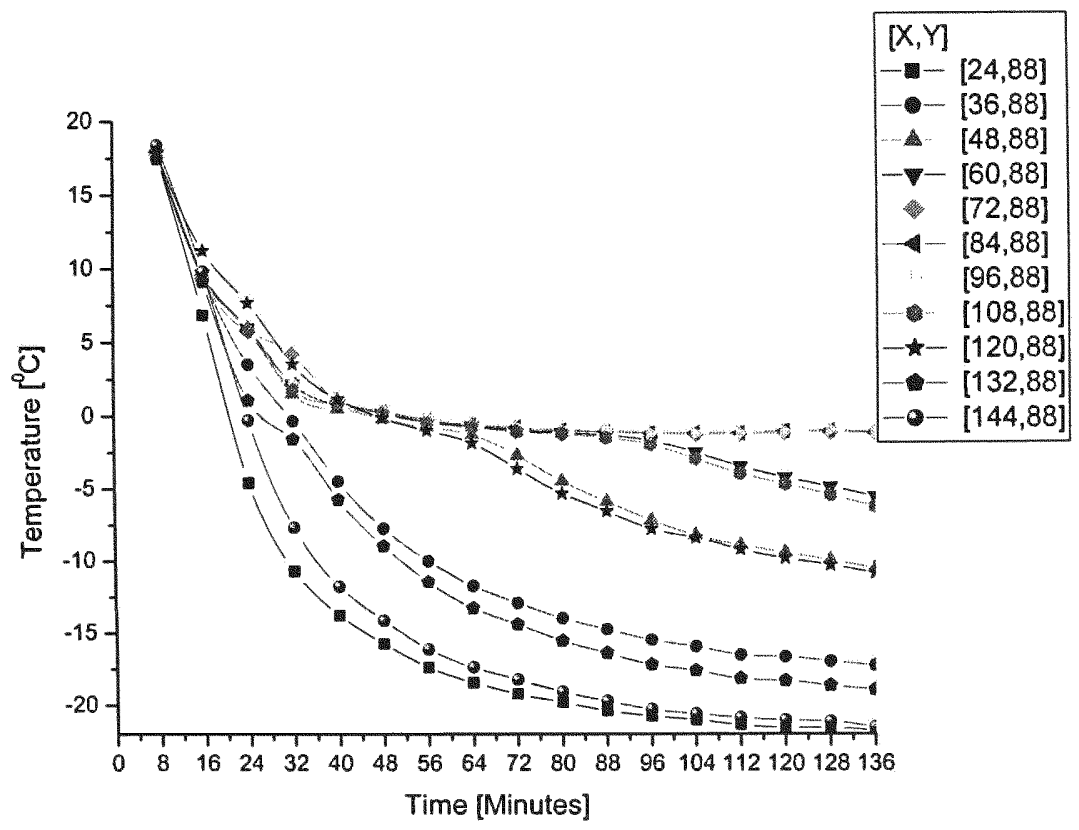

Figure 3.96

Temperature Distribution during solidification of Pure Water at different Positions; Two walls Cooled; $Y=88 \mathrm{~mm} ; T_{L}=-30^{\circ} \mathrm{C} \& T_{R}=-30^{\circ} \mathrm{C}$. 


\subsubsection{Comparison of Solidification process in Trapezoidal Cavity with Rectangular}

\section{Chamber}

Results obtained in this study were compared to the previous studies done by Ghenai et al. they studied the effect of double diffusive convection on solidification process of ammonium chloride solution in a rectangular enclosure. The cavity has inside dimensions of $83 \mathrm{~mm}$ in width, $105 \mathrm{~mm}$ in height and $96 \mathrm{~mm}$ in depth. The experimental setup used by Ghenai et al. is same as in this study. The test enclosure used by Ghenai is showed in Figure 3.97. The volume of the solution take in the cavity to study the effect is 500. Brief information explaining the difference in experimental setup between my work and Ghenai et al work is shown in a table 5.3.

Table 5.3 Comparison of Experimental setup among Trapezoidal and Rectangular Chambers

\begin{tabular}{|c|c|c|}
\hline Parameter & $\begin{array}{c}\text { Rectangular Chamber } \\
\text { Ghenai et al., (2003) }\end{array}$ & $\begin{array}{c}\text { Trapezoidal Chamber } \\
\text { Duggirala et al., (2004) }\end{array}$ \\
\hline Height & 105 & 130 \\
\hline Width & 83 & Top: 165 \\
Bottom: 65
\end{tabular}


(a)

Top: Black cover with slit for

Back Side:

flow illumination: $\mathrm{T}=20^{\circ} \mathrm{C}$

Plexighass

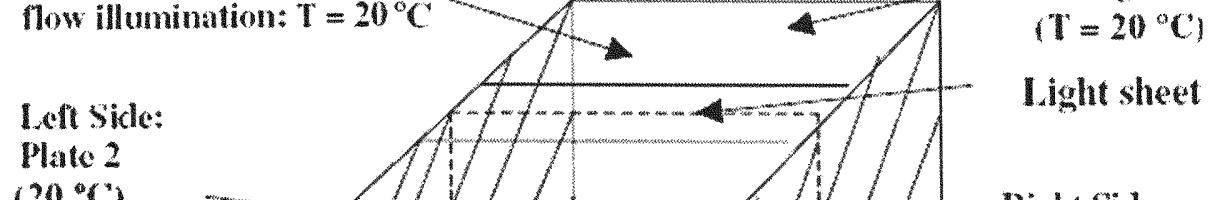

$\left(20^{\circ} \mathrm{C}\right)$

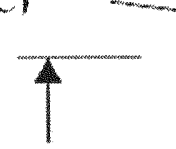

$105 \mathrm{~mm}$
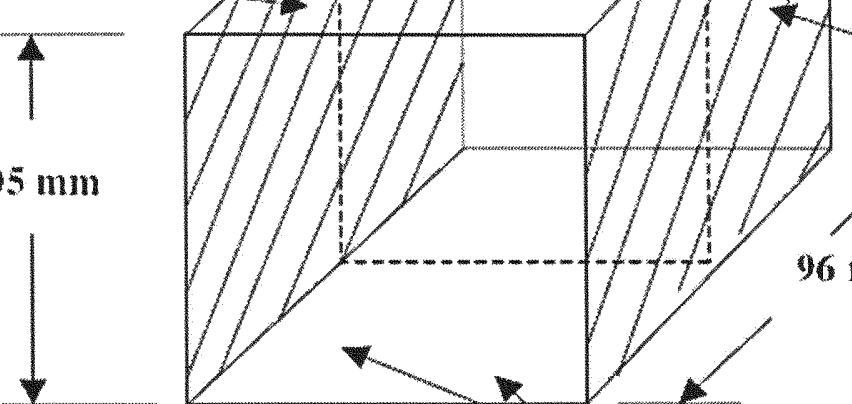

Right Side

Plate 1

$\left(-20^{\circ} \mathrm{C}\right)$

(b)

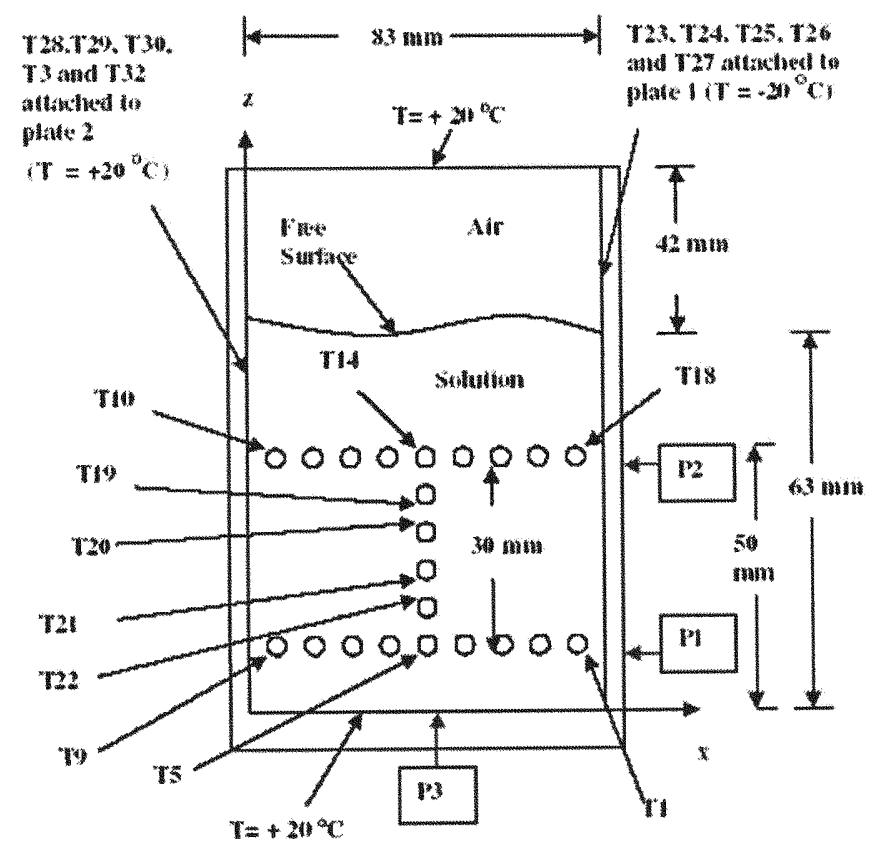

Figure 3.97 Schematic of the test enclosure and thermocouple positions (Rectangular Enclosure, Ghenai et al., 2003) 
Inorder to do a quantitative and qualitative comparison of solidification process among these two chambers,

1) Study the effect of volume on solidification process in a trapezoidal cavity

2) Study the effect of volume on solidification process in a rectangular cavity.

Several experiments are made using both trapezoidal and rectangular cavities for different volumes and following results were observed.

Figure 3.98 shows the effect of initial volume of the liquid mixture on volume of the frozen ice. We observe that the volume of the frozen ice is decreasing with the decrease in volume of the solution.

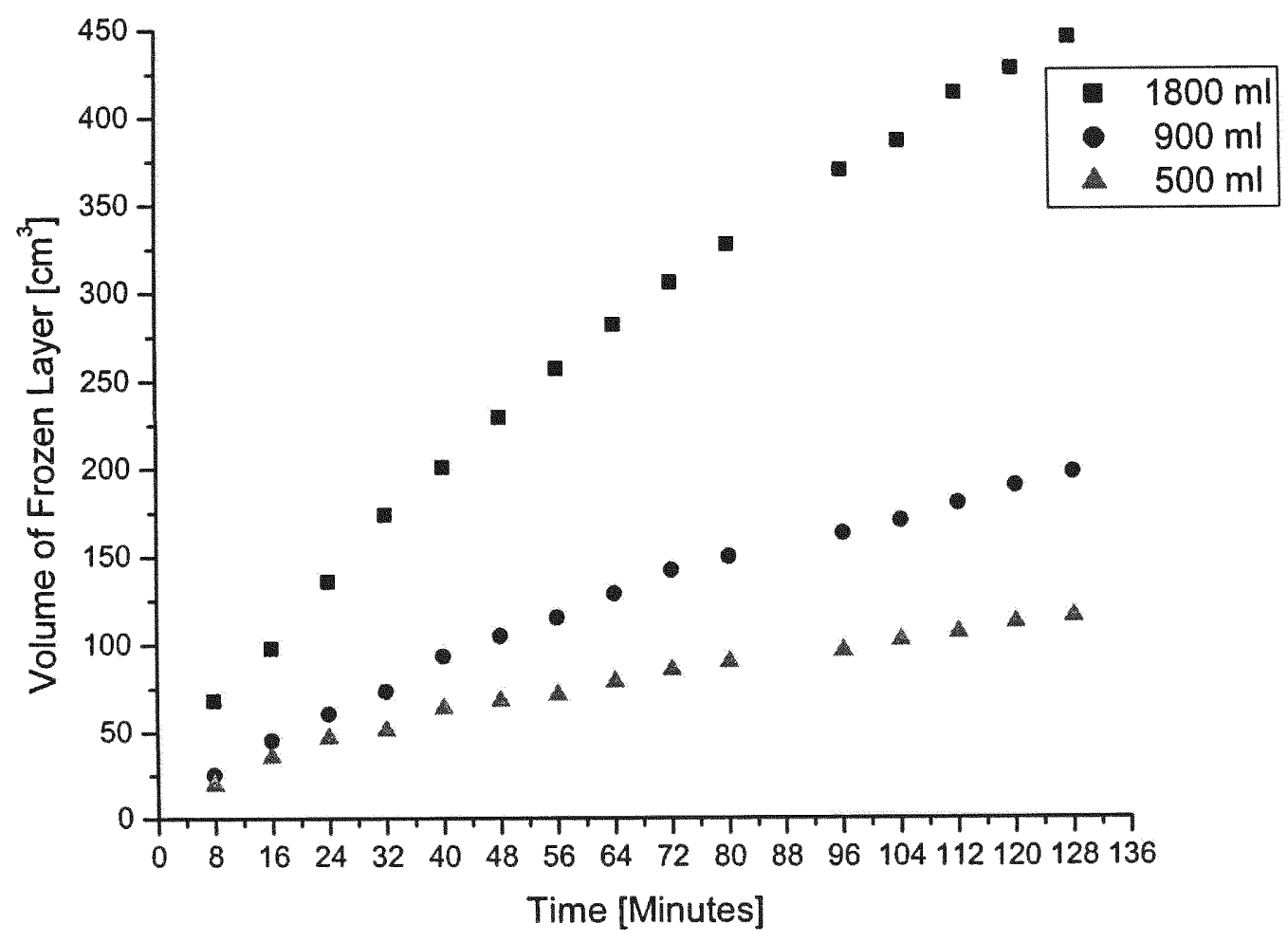

Figure 3.98 Effect of Volume of the Liquid on Volume of frozen ice for Trapezoidal Cavity 
A dimensionless number is used to study the effect of volume of liquid on solidification process. The dimensionless number is defined as the ratio of volume of the frozen ice to the volume of the liquid mixture.

$$
\text { Dimensionless Number }=\frac{V_{\text {Frozen }}}{V_{\text {Total }}}
$$

Figure 3.99 shows the effect of initial volume of the liquid mixture on the solidification process for trapezoidal chamber. We observe that the effect of initial volume is negligible on the solidification process.

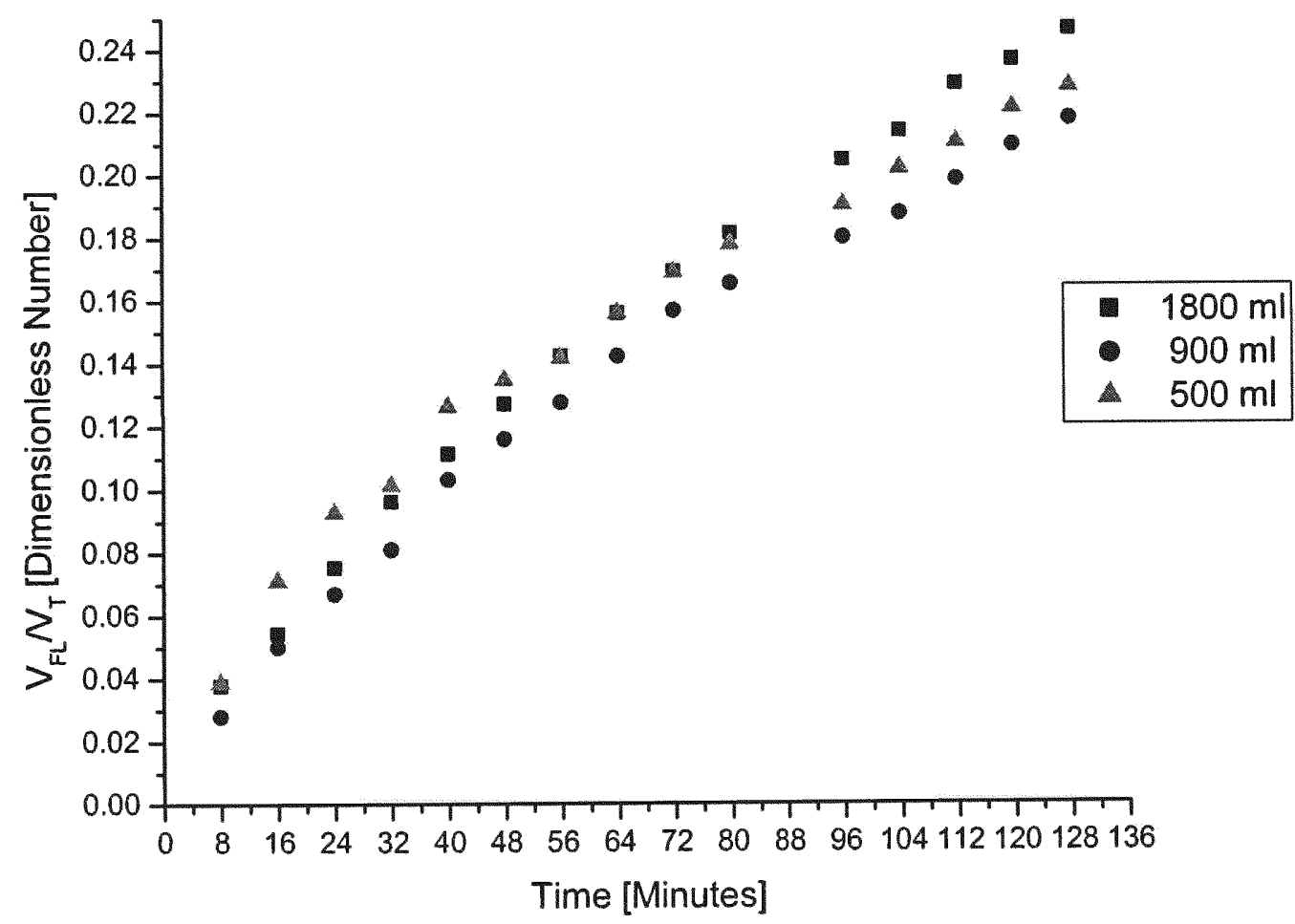

Figure 3.99 Effect of Volume of the Liquid Solidification Process for Trapezoidal Cavity 
We observed the similar format for the rectangular chamber. Figure 3.100 shows the comparison of solidification in a rectangular chamber to the trapezoidal chamber. The compared is for just 56 minutes.

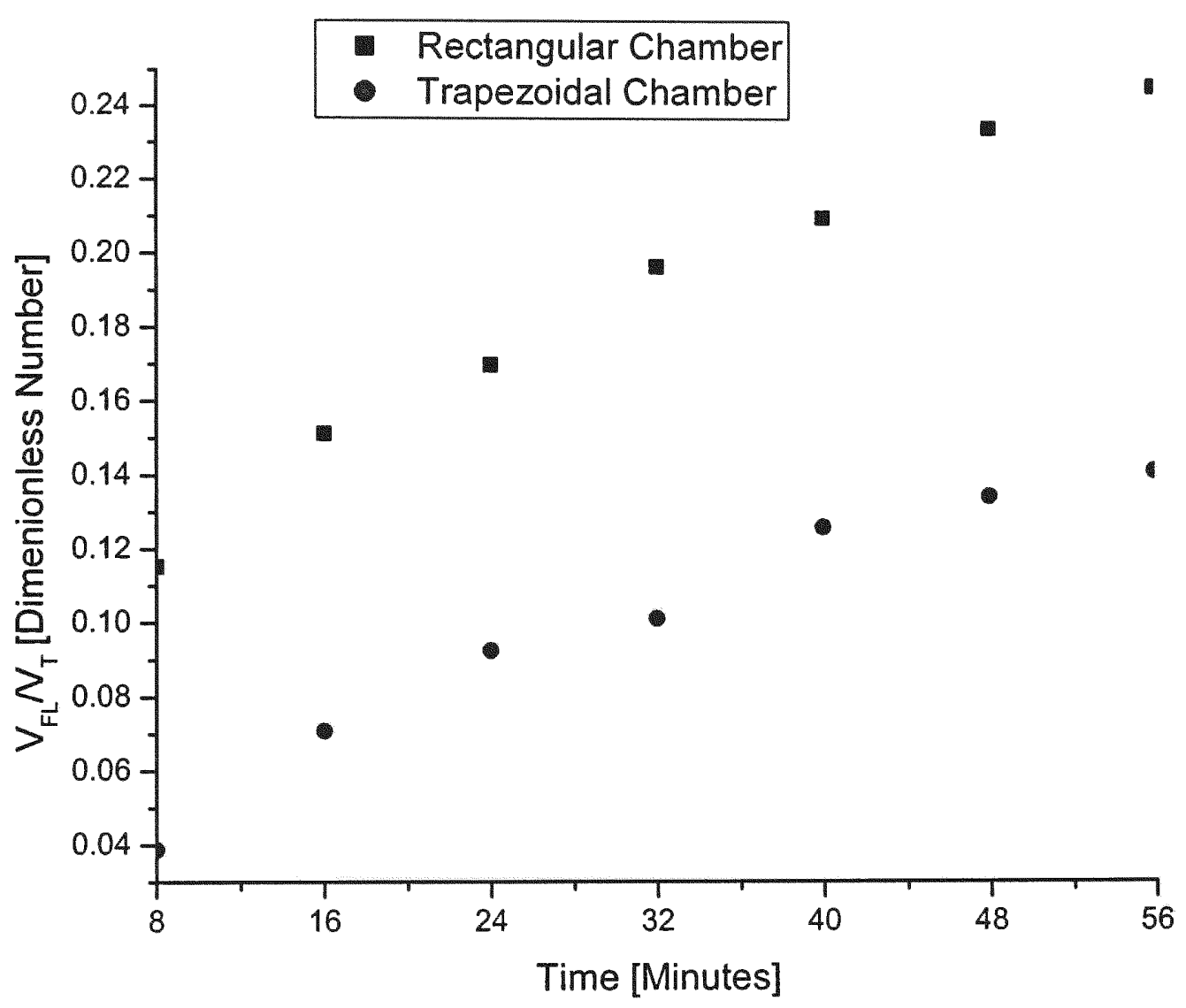

Figure 3.100 Comparison of Solidification Process among Trapezoidal and Rectangular Cavities.

Figure 3.101 \& 102 shows the difference in convection flow patterns during solidification process in rectangular and trapezoidal cavities for pure water and for different concentrations respectively. The convection flow patterns are same for both the chambers, but the magnitude of the velocity varies. 


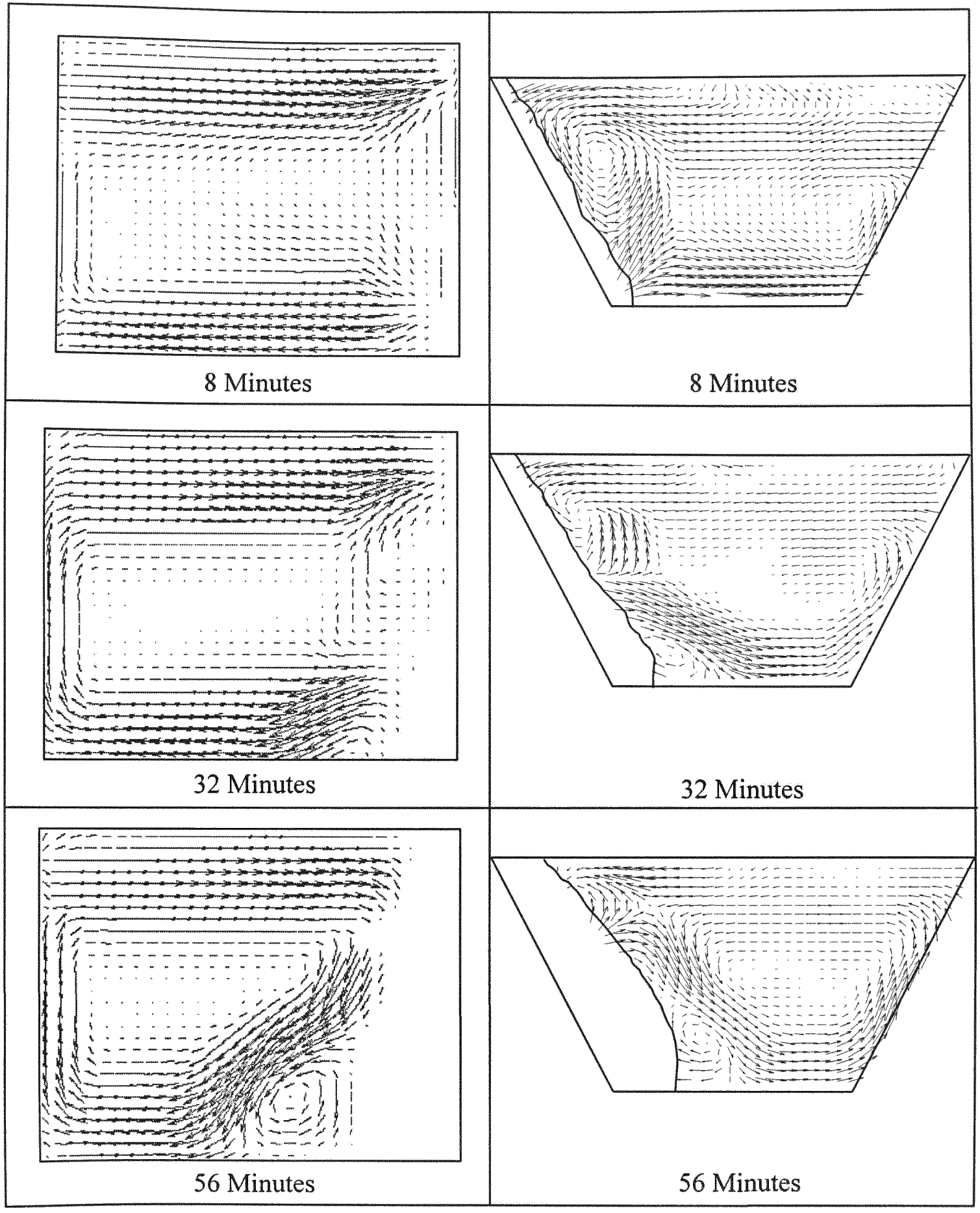

Figure 3.101 Comparison of Convection Patterns among Trapezoidal and Rectangular Cavities for Pure Water; $T_{L}=-30^{\circ} \mathrm{C} \& T_{R}=+20^{\circ} \mathrm{C}$ 


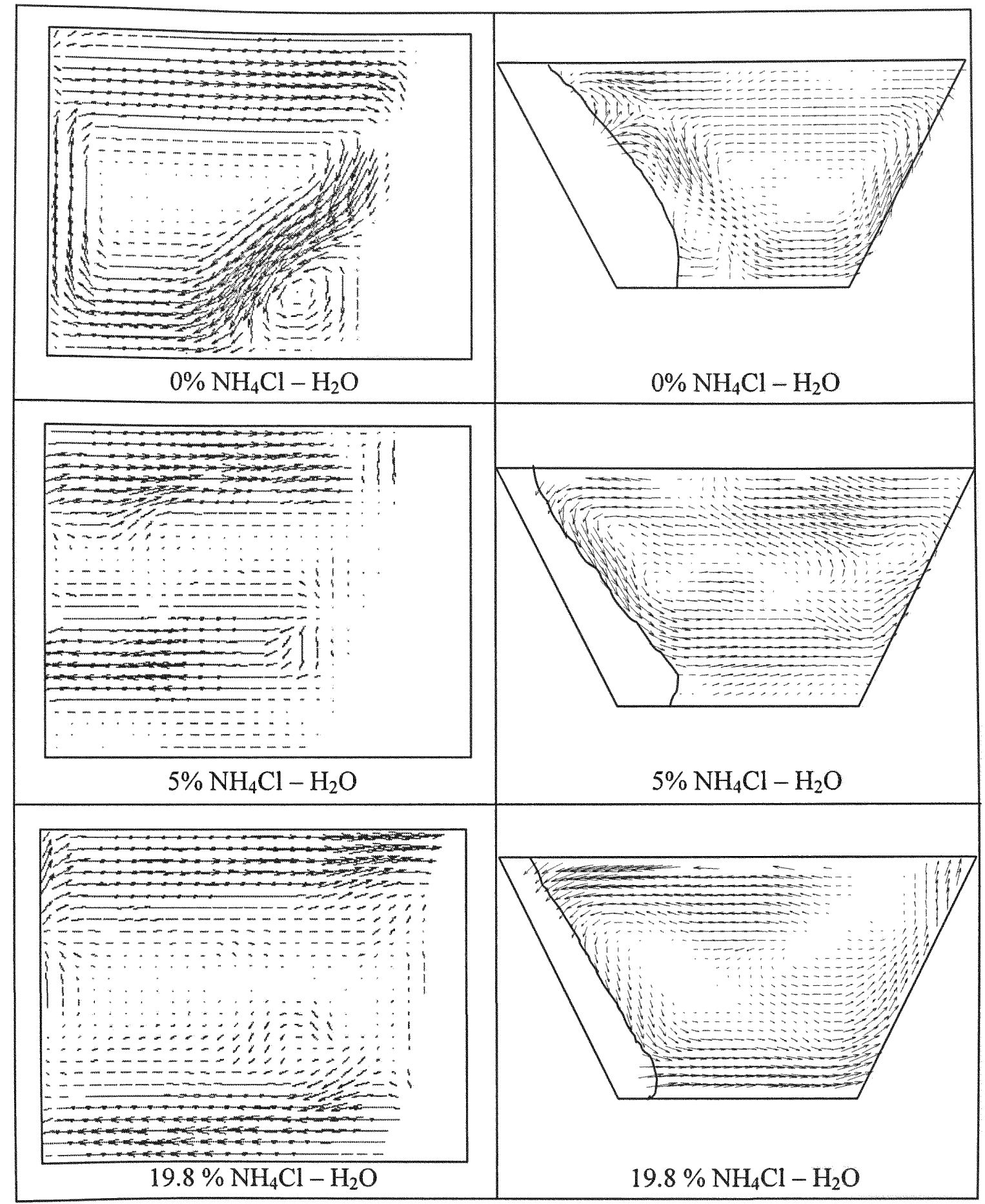

Figure 3.102 Comparison of Convection Patterns among Trapezoidal and Rectangular Cavities at time $(t)=56$ minutes; $T_{L}=-30^{\circ} \mathrm{C} \& T_{R}=+20^{\circ} \mathrm{C}$ 
The temperature readings inside the cavities are compared at same $\mathrm{X}$ and $\mathrm{Y}$ (dimensionless) location. The dimensionless numbers $\mathrm{X}^{\prime}$ and $\mathrm{Y}^{\prime}$ are calculated as follows $X^{\prime}=\frac{\text { Thermocouple X Position (From the Wall) }}{\text { Width of Chamber }} ; Y^{\prime}=\frac{\text { Thermocouple Y Position }}{\text { Height of the Liquid }}$ Position 1 is taken at $\mathrm{Y}=20 \mathrm{~mm}$ and $37 \mathrm{~mm}$ for the rectangular and trapezoidal chambers respectively. Position 2 is taken at $\mathrm{Y}=50 \mathrm{~mm}$ and $88 \mathrm{~mm}$ for the rectangular and trapezoidal chambers respectively. Temperature readings re compared among rectangular and trapezoidal chambers for positions 1 and 2 at $\mathrm{X}^{\prime}=0.1,0.2$. Figure 3.103 shows the temperature variation with time at $\mathrm{X}^{\prime}=0.1$ and $\mathrm{Y}^{\prime}=0.32$ for both rectangular chamber and trapezoidal chamber. Figure 3.104 shows the temperature variation with time at $\mathrm{X}^{\prime}=0.2$ and $\mathrm{Y}^{\prime}=0.32$ for both rectangular chamber and trapezoidal chamber. Figure 3.105 shows the temperature variation with time at $\mathrm{X}^{\prime}=0.1$ and $\mathrm{Y}^{\prime}=0.793$ for both rectangular chamber and trapezoidal chamber. Figure 3.106 shows the temperature variation with time at $\mathrm{X}^{\prime}=0.1$ and $\mathrm{Y}^{\prime}=0.793$ for both rectangular chamber and trapezoidal chamber. It is observed from these four figures that the solution is cooling faster in rectangular chamber than the trapezoidal chamber. The reason for this cooling are

1) Effect of inclined wall on the solidification process which is seen clearly in figure 3.100 .

2) The volume of the solution which is used in rectangular chamber is less compared to the volume in trapezoidal chamber. 


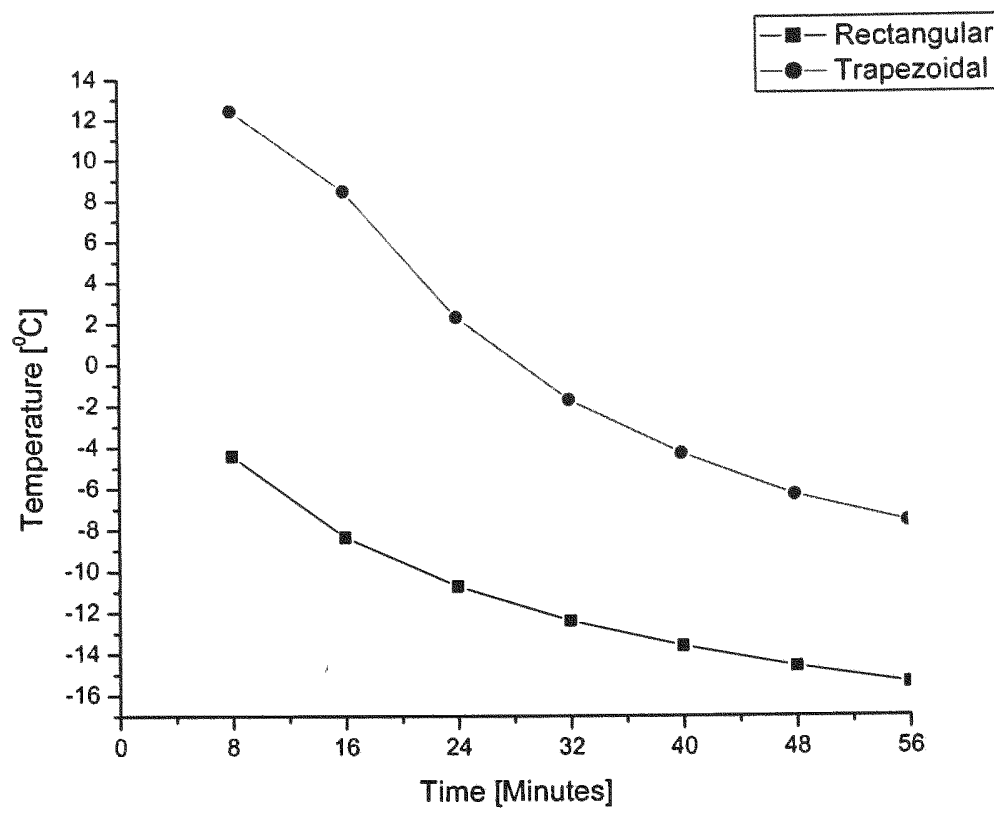

Figure 3.103 Comparison of Temperature among Trapezoidal and Rectangular Cavities at $\mathrm{X}^{\prime}=0.1 \& \mathrm{Y}^{\prime}=0.32 ; \mathrm{T}_{\mathrm{L}}=-20^{\circ} \mathrm{C} \& \mathrm{~T}_{\mathrm{R}}=+20^{\circ} \mathrm{C}$

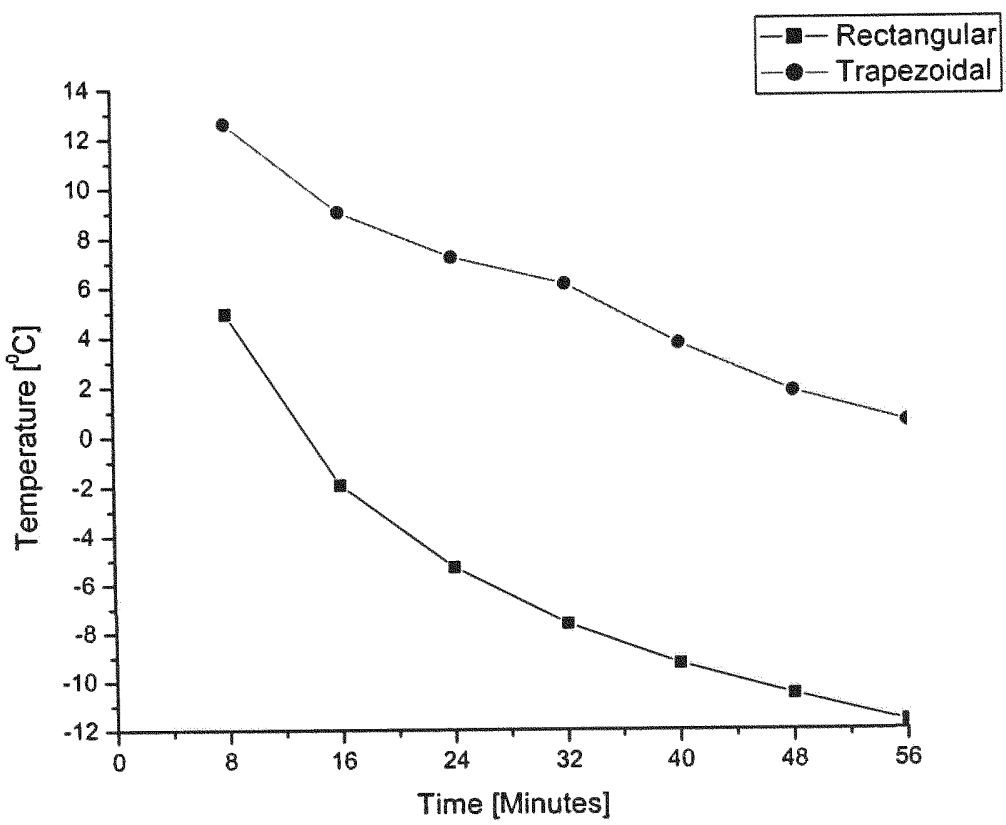

Figure 3.104 Comparison of Temperature among Trapezoidal and Rectangular Cavities at $X^{\prime}=0.2 \& Y^{\prime}=0.32 ; T_{L}=-20^{\circ} \mathrm{C} \& T_{R}=+20^{\circ} \mathrm{C}$ 


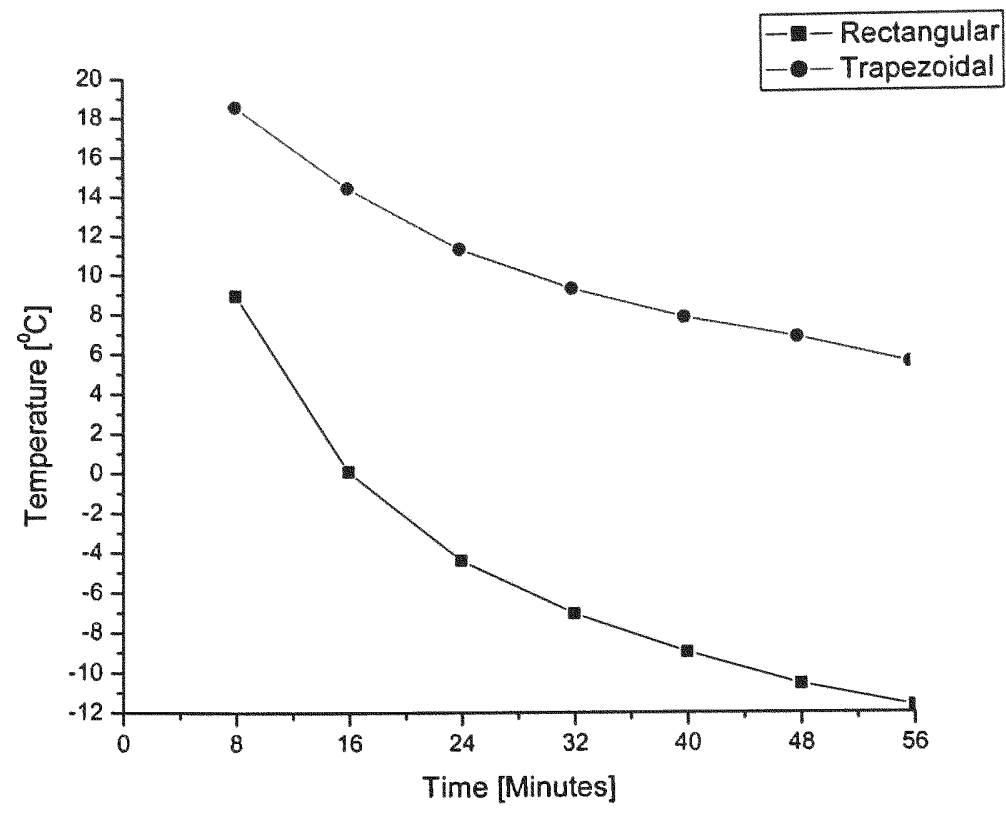

Figure 3.105 Comparison of Temperature among Trapezoidal and Rectangular Cavities at $\mathrm{X}^{\prime}=0.1 \& \mathrm{Y}^{\prime}=0.793 ; \mathrm{T}_{\mathrm{L}}=-20^{\circ} \mathrm{C} \& \mathrm{~T}_{\mathrm{R}}=+20^{\circ} \mathrm{C}$

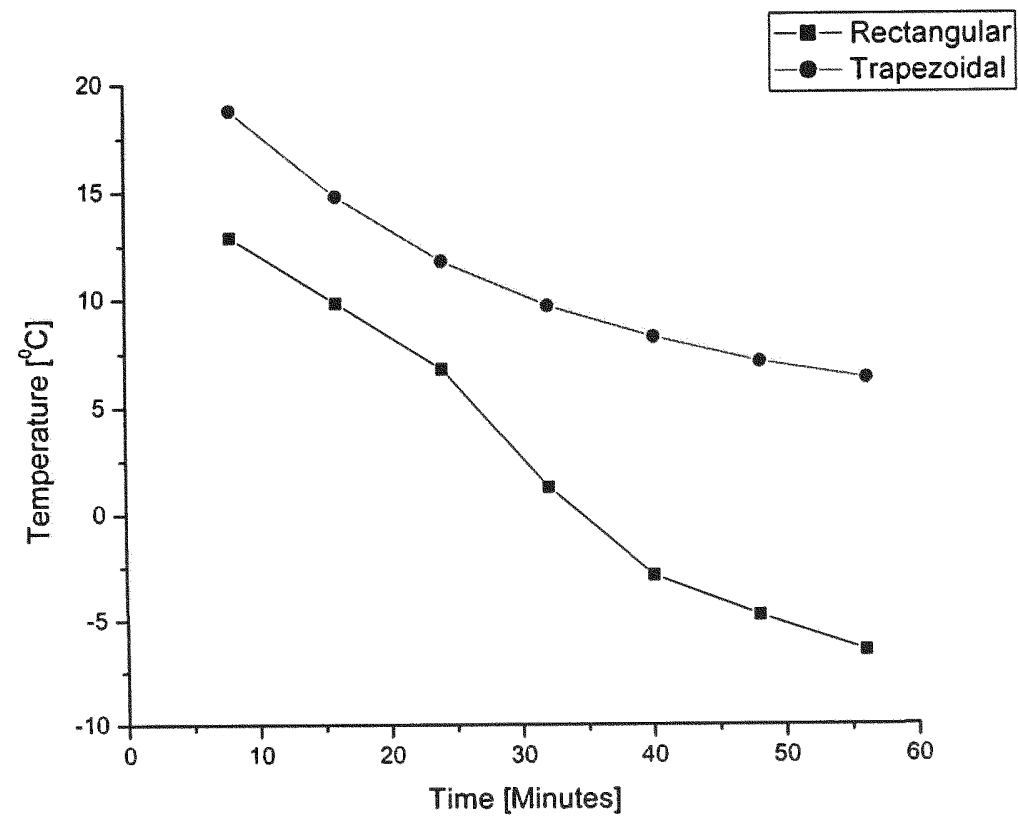

Figure 3.106 Comparison of Temperature among Trapezoidal and Rectangular Cavities at $\mathrm{X}^{\prime}=0.2 \& \mathrm{Y}^{\prime}=0.793 ; \mathrm{T}_{\mathrm{L}}=-20^{\circ} \mathrm{C} \& \mathrm{~T}_{\mathrm{R}}=+20^{\circ} \mathrm{C}$ 


\subsection{SUMMARY AND CONCLUSIONS}

The solidification process was investigated both experimentally in this study. The solidification process of a binary mixture was simulated experimentally in a trapezoidal cavity with transparent ammonium chloride and water solution. The cavity was not filled completely with the solution, and air was present inside the cavity between the free surface of the solution and the top of the cavity. The thermal boundary conditions tested in this study are the following: (1) One sidewall of the cavity was cooled, and the other side was kept constant at $20{ }^{\circ} \mathrm{C}$; and (2) Two sidewalls are cooled simultaneously at the same or different temperatures. The effect of the initial concentration and cooling conditions on the solidification process was investigated. In this study Particle Image Velocimetry (PIV) was used to visualize the flow fields during the solidification of the binary mixture. The velocity distributions in the melt and the thickness of the frozen layer for different time steps were obtained from the PIV images. Temperature distribution inside the cavity and in the hot and cold plates was monitored by thermocouples. The effect of initial boundary condition of one wall on the solidification on the opposite wall is analyzed. The results obtained in this study were compared with the previous research done in rectangular chamber.

Following are the conclusions drawn from this study.

1) The process of solidification is slower with an increase in initial concentration levels of the binary solution. The equilibrium phase diagram of ammonium chloride-water solution also supports this observation. For the binary mixture, the convection flow is due to both thermal and solutal gradients. By increasing the initial 
concentration of ammonium chloride, the convection flow of the melt inside the cavity increases, which will reduce the movement of the liquid-solid interface.

2) As the concentration increases, the time needed to get the same thickness of frozen layer increases. The growth rate of the frozen layer and the velocity of the moving solid-liquid interface decreases with as the initial concentration of the binary mixture increases.

3) The temperature measurements have shown that the temperatures at the bottom of the cavity are lower than those at the top. The liquid free surface at the top of the cavity is in direct contact with the ambient air since the cavity was not filled completely. The convective heat transfer between both upper and lower regions seems to be limited mainly to the upper part of the cavity. The shape of the freezing front reproduces this interaction, with high ice growth rate at the bottom.

4) The effect of initial concentrations of the temperature distributions has shown that an increase of the initial concentration of ammonium chloride will reduce the temperature in the melt significantly.

5) The initial concentration level has a significant effect on flow patterns. For one cooled side and for pure water, where the natural convection is only due to thermal gradient (no solutal gradient), only a counter-clockwise circulation flow is present with liquid flowing from cold to hot walls and from the bottom to the top of the cavity. In convection of a single component fluid, the buoyancy force associated with temperature fluctuation drives the flow. Heat is advected with the convective flow and also diffuses in the liquid. For low initial concentration ( $5 \%$ and $12 \%$ ), where both thermal and solutal gradients are present, there are two circulation flows: a counter-clockwise circulation 
flow located at the upper part of the cavity and a clockwise circulation flow near the bottom of the cavity. Both the thermal and solutal buoyancy forces push fluids and accelerate the flow. For the solidification process near the eutectic region $\left(C_{e}=19.8 \%\right)$, where the concentration of ammonium chloride is higher and where the effect of buoyancy induced by solutal gradient is more dominant, the clockwise circulation flow situated at the upper part of the cavity disappears, and there is the presence of two counter-clockwise circulation flows.

6) The flow pattern, the shape and thickness of the frozen layer, and the moving liquid-flow interface depends on thermal boundary conditions and initial concentration but also on the way in which the cavity is cooled, i.e., one or two cooled sides. The flow patterns for the two cooled sides are different from one cooled side. In the two cooled sides, the solution or the melt is affected by the two solid-liquid interfaces moving in opposite directions. The thickness of the frozen layer at the end of the solidification process $(t=136 \mathrm{~min})$ for the two cooled sides $\left(\mathrm{T}_{\mathrm{L}}=\mathrm{T}_{\mathrm{R}}=-30{ }^{\circ} \mathrm{C}\right)$ is about $70 \%$ larger that the thickness of one cooled side $\left(\mathrm{T}_{\mathrm{L}}=-30{ }^{\circ} \mathrm{C}\right.$ and $\left.\mathrm{T}_{\mathrm{R}}=+20{ }^{\circ} \mathrm{C}\right)$. The initial concentration and boundary temperatures are used to control the flow pattern in the melt, the solid-liquid interface movement, and the shape and thickness of the solid region during the solidification process to obtain the desired quality of the final product.

7) As the temperature on the right side inclined wall decreases (getting cooler) from $+20{ }^{\circ} \mathrm{C}$ to $-25{ }^{\circ} \mathrm{C}$ the frozen layer thickness on the left side inclined wall increased gradually. There observed a steep increase in frozen layer thickness on the left side inclined wall when the temperature on the right side inclined wall is decreased from $-25{ }^{\circ} \mathrm{C}$ to $-30{ }^{\circ} \mathrm{C}$. The results obtained are used to compare with the previous research 
done on solidification process in a rectangular chamber by Ghenai et al., (2003). We observe that the volume of the initial mixture poured in the cavity has a negligible effect on the solidification process and also observed that the inclined wall plays a vital role in the solidification process. A dimensionless number is used to compare among the two chambers and is shown that the rectangular chamber is more effective than that of a trapezoidal chamber. The solidification process in rectangular chamber is nearly 3 times faster than in the trapezoidal chamber. 


\subsection{RECOMMENDATIONS}

From practical experience gained in this research, areas were encountered where current technology was either unavailable or too costly to properly conduct detailed enough experimentation to quantify some results. Unfortunately, some of this quantification is needed to produce better statistical models for numerical predictions that will more realistically model actual systems. From this foregoing research, the following recommendations are made for improving experimental methodologies:

i) The use of the thermocouple grid on the rear wall of the test section gave a relatively high temporal resolution with small spatial resolutions for the measurement of boundary layers ensuing from bulk fluid movement at the solidus interface, tracking of solidus and liquidus fronts, and measurements of thermal gradient in the melt. However, the areas where more detailed temperature measurements are needed, such as in the interdendtritic region where undercooling exists, were not possible at this time. The development of a non intrusive technique is needed to measure these small temperature variations that occur between primary dendrite arms. One possible suggestion is the innovative use of the encapsulated liquid crystals which have been proven to be successful in the melt regions during solidification.

ii) The aspect ratio should be varied to investigate its effects on the freezing process and to identify the characteristic lengths which affects the formulation of the problem.

iii) Study the growth of frozen layer with the external forces such as ultrasonic vibrations which cause melt flow during solidification. 
iv) Develop a control system that controls the phase interface motion with the boundary temperatures.

v) Finally, the research should progress to solidification of ternary systems for the purpose of predicting the behavior of current and new multicomponent alloys. 


\section{REFERENCES}

Beckerman, C. and Viskanta, R., 1988, "Double Diffusive Convection during Dendritic Solidification of a Binary Mixture," PCH Physico Chemical Hydrodynamics, Vol.10, pp. $195-213$.

Beckermann, C., Ramadhyani, S., and Viskanta, R., 1987, "Natural convection flow and heat transfer between a fluid layer and a porous layer inside a rectangular enclosure," ASME Journal of Heat Transfer Transactions, Vol. 109, pp. 363 370.

Bennon, W.D. and Incropera, F.P., 1987 a, "A Continuum Model for Momentum Heat and Species Transport in Binary Solid - Liquid Phase Change Systems - I. Model Formulation," International Journal of Heat and Mass Transfer, Vol.30, pp. 2161 $-2170$

Bennon, W.D. and Incropera, F.P., 1987 b, "A Continuum Model for Momentum Heat and Species Transport in Binary Solid - Liquid Phase Change Systems - II. Application to Solidification in a Rectangular Cavity," International Journal of Heat and Mass Transfer, Vol.30, pp. $2171-2187$.

Braga, S.L. and Viskanta, R., 1990, "Solidification of a Binary Solution on a Cold Isothermal Surface," International Journal of Heat and Mass Transfer, Vol.33, pp. $745-745$.

Cao, W.Z. and Poulikakos, D., 1990, "Solidification of an Alloy in a Cavity Cooled Through its Top Surface," International Journal of Heat and Mass Transfer Vol.33, pp. $427-434$.

Chellaiah, S. and Viskanta, R., 1987, "Freezing of Salt Solutions on a Vertical Wall," Experimental Heat Transfer, Vol.1, pp. $181-195$.

Chellaiah, S. and Waters, R.A., and Zampino, M.A., 1991, Solidification of an Aqueous Salt Solution in the Presence of Thermosolutal Convection," Proceedings of the Third ASME - JSME Thermal Engineering Conference, Vol.2, pp. 165 - 174.

Christenson, M.S. and Incropera, F.P., 1989 a, "Solidification of an Aqueous Ammonium Chloride Solution in a Rectangular Cavity - I, Experimental Study," International Journal of Heat and Mass Transfer Vol.32, pp. 47-68.

Christenson, M.S., Bennon, W.D. and Incropera, F.P., 1989 b, "Solidification of an Aqueous Ammonium Chloride Solution in a Rectangular Cavity - II, Numerical Study," International Journal of Heat and Mass Transfer Vol.32, pp. 69 - 79. 
Cole, G.S. and Bolling, G.F., 1965, "The Importance of Natural Convection in Casting," Transactions of the Metallurgical Society of AIME, vol. 233, pp. 1568 - 1572.

Copley, S.M., Giamei, A.F., Johnson, S.M. and Hornbecker, M.F., 1970, "The Origin of Fleckles in Unidirectionally Solidified Castings," Metallurgical Transactions, Vol.1 pp. $2193-2204$.

DeZego, S., Jones, W.K. Jr., Dong, Z., and Ebadian, M. A., 1996, "Experimental Study of the Effects of Thermal and Solutal Convection in the Continuous Cast of a Binary Mixture," to be presented in Winter Annual Meeting, Atlanta; Submitted to Int. J. Heat and Mass Transfer.

Dong, Z.F., and Ebadian, M.A., 1994, "Investigation of Double Diffusive Convection in a Trapezoidal Enclosure," J. Heat Transfer, Vol. 116, pp. $492-495$.

Duggirala, R.K., Sirpal, P., Lin, C.X., and Ghenai, C., 2004, "Effect of Boundary Conditions and Initial Concentration on the Solidification of Binary Mixture in Trapezoidal Cavity," 2004 ASME International Mechanical Engineering Congress, Paper\# IMECE 2004 - 61743

Duggirala, R.K., Lin, C.X., Ghenai, C., 2004, "Investigation of Double Diffusive Convection during the Solidification of Binary Mixture in a Trapezoidal Cavity," to be submitted to Experiments in Fluids Journal.

Fang, L.J., Cheung, F.B., Linehan, J.H. and Pedersen, D.R., 1984, "Selective Freezing of A Dilute Salt Solution on A Cold Ice Surface," ASME Journal of Heat Transfer, Vol. 106, pp.385-393.

Fisher, K.M., 1981, "The Effects of Fluid Flow on the Solidification of Industrial Casting," PCH Physico Chemical Hydrodynamics, Vol. 2, no.4, pp. $311-326$.

Flemings, M.C., 1974, "Solidification Processing," McGraw-Hill, New York.

Fukusako, S., and Seki, N., 1987, "Fundamental Aspects of Analytical and Numerical Methods on Freezing and Melting Heat Transfer Problems," in Annual Review of Numerical Fluid Mechanics and Heat Transfer, Vol.1, pp. 351 - 402.

Ghenai, C., Mudunuri, A., Lin, C.X., and Ebadian, M. A., 2003, "Double-diffusive convection during solidification of a metal analog system $\left(\mathrm{NH}_{4} \mathrm{Cl}-\mathrm{H}_{2} \mathrm{O}\right)$ in a differentially heated cavity," Experimental Thermal and Fluid Science, Vol.28,p.p $23-35$

Ghenai, C., Duggirala, R.K., Lin, C.X., and Ebadian, M.A, 2003 "Characterization of Convection Patterns during Solidification Process Using Particle Image Velocimetry," ASME Heat Transfer conference, HT2003 - 47241 
Ghenai, C., Duggirala, R.K., Lin, C.X., and Ebadian, M.A., 2004, "Experimental Investigation of Fluid Flow and Phase Moving Interface during the Solidification of Binary Mixture in Trapezoidal Cavity," 2004 ASME Heat Transfer/Fluids Engineering Summer Conference, Paper\# HT-FED 2004 - 56404.

Giangi, M., Stella, F., and Kowalewski, T.A., 1990, "Phase change problems with free convections: fixed grid numerical simulation," Computing and Visualization in Science, Vol. 2, pp. $123-130$.

Grange, B.W., Viskanta, R. and Stevenson, W.H, 1976, "Diffusion of Heat and Solute during Freezing of Salt Solutions," International Journal of Heat and Mass Transfer, Vol.19, pp. $373-384$.

Hale, N.W. Jr. and Viskanta, R., 1980, "Solid-Liquid Phase-Change Heat Transfer and Interface Motion in Materials Cooled or Heated from Above or Below," International Journal of Heat and Mass Transfer, Vol. 23, pp. $283-292$.

Hayashi, Y. and Komori, T., 1989, "Investigation of Freezing of Salt Solutions in Cells," ASME Journal of Heat Transfer, Vol. 101, pp. $459-464$.

Hunt, J.D. and Jackson, K.A., 1966, Trans. AIME, Vol. 236, pp. 843

Huppert, H.E. and Sparks, R.S.J., 1984 "Double-diffusive convection due to crystallization in magmas," A. Rev. Earth Planet. Sci., Vol. 12, pp. $11-37$.

Huppert, H.E. and Turner, J.S., 1980, "Ice Blocks Melting into a Salinity Gradient," J. Fluid Mechanics, Vol. 100, pp. $367-384$.

Huppert, H.E. and Worster, M.G., 1985, "Dynamic Solidification of a Binary Melt," Nature, Vol. 314, pp. $703-703$.

Huppert, H.E., 1990, "The fluid mechanics of solidification," J. Fluid Mech., Vol. 212, pp. $209-240$.

Kerr, R.C., Woods, A.W., Worster, M.G. and Huppert, E.H., 1989, "Disequilibrium and Macrosegregation during Solidification of a Binary Melt," Nature, Vol. 340, pp. $357-362$.

Kim, D.H., and Brown, R.A., 1989, "Models for Convection and Segregation in the Growth of HgCdTe by the Vertical Bridgeman Method," J. Crystal Growth, Vol. 96, pp. $609-627$.

Korber, Ch., Scheiwe, M.W. and Wollhover, K., 1983, "Solute Polarization during Planaar Freezing of Aqueous Salt Solutions," International Journal of Heat and Mass Transfer, Vol. 26, pp. 1241 - 1253. 
Kowalewski, T.A., Cybulski, A., and Rebow, M., 1988, "Particle image velocimetry and thermometry in freezing water," 8th International Symposium in Flow Visualization, pp. $24.1-24.4$.

Leitch, A.M., 1989, "Evolution of a Binary System Crystallizing in a Confined Region," International Journal of Heat and Mass Transfer, Vol. 32, pp. 2087 - 2098.

McCay, M.H., Hopkins, J.A., and McCay, T.D., 1995," Relationship between flow direction and dentric growth rate in $\mathrm{NH}_{4} \mathrm{Cl}-\mathrm{H}_{2} \mathrm{O}$," Metallurgic and Materials Transactions, Vol.26A, p.p227.

McCay, M.H., Hopkins, J.A., and McCay, T.D., 1994, "Convective flow effects on diffusion layers during $\mathrm{NH}_{4} \mathrm{Cl}-\mathrm{H}_{2} \mathrm{O}$ dentric solidification, Journal of crystal growth," Vol. 144, p.p. $346-352$.

Nishimura, T., Fujiwara, M., Horie, N., and Miyashita, H., 1991, Int. J. Heat Mass Transfer, Vol. 34, pp. $2663-2668$.

Ostrach, S., 1983, "Fluid Mechanics in Crystal Growth - The 1982 Freeman Scholar Lecture," J. Fluids Engineering, Vol. 105, pp. 5-20.

Sample, A.K., and Hellawell, A., 1984, "The Mechanism of Formation and Prevention of Channel Segregation during Alloy Solidification," Metallurgical Transactions, Vol. 15 A, pp. $2163-2173$.

Streat and Wineberg, 1974, "Macrosegragation During Soldiification Resulting from Density Difference in the Liquid," Metallurgical Transactions, Vol.5, pp. 2539 2548.

Szekely, J. and Jassal, A.S., 1978, "An Experimental and Analytical Study of the Solidification of a Binary Dendritic System," Metallurgical Transactions, Vol. 9B, pp. $389-398$.

Terwilliger, J.P. and Dizio, S.F., 1970, "Salt Rejection Phenomena in the Freezing of Saline Solutions," Chemical Engineering Science, Vol. 25, pp. 1331 - 1349.

Tien, C. and Chao Yen, Y., 1966, "Approximate solution of a melting problem with Natural convection," Chem. Eng. Prog. Symp. Ser., Vol. 62, pp.166-172

Turner, J.S., and Gustafson, L.B., 1981, "Fluid Motions and Compositional Gradients Produced by Crystallization or Melting at Vertical Boundaries," J. Volcanol. Geotherm. Res., Vo. 11, pp. $93-125$. 
Viskanta, R., 1983, "Phase Change Heat Transfer, in Solar Heat Storage: Latent Heat Materials," Lane, G.A. ed., CRC Press, Boca Raton, Fl., Vol.1, pp. 153-222.

Viskanta, R., 1988, "Heat Transfer during Melting and Solidification of Metals," J. Heat Transfer, Vol. 110, pp. 1205-1219.

Wang, S.Y., Lin, C.X., and Ebadian, M.A., 1999 a, "Vortex flow of low concentration $\mathrm{NH} 4 \mathrm{Cl}-\mathrm{H} 2 \mathrm{O}$ solution during the solidification process," Int. J. Heat Mass Transfer, Vol. 42, pp. $4153-4163$.

Wang, S.Y., Lin, C.X., and Ebadian, M.A., 1999 b, "Study of double-diffusive velocity during the solidification process using particle image velocimetry," Int. J. Heat Mass Transfer, Vol. 42, pp. 4427 - 4445.

Wollhover, K., Korber, Ch., Scheiwe, M.W. and Hartmann, U., 1985, "Unidirectional Freezing of Binary Aqueous Solutions: Analysis of Trnsient Diffusion of Heat and Mass," International Journal of Heat and Mass Transfer, Vol. 28, pp. 761 769 .

Zampino, M.A., Waters, R.A., and Chellaiah, S., 1991 a, "Solidificatrion of a Binary Mixture in a Rectangular Cavity," in Fourth International Symposium on Transport Phenomena in Heat and Mass Transfer.

Zampino, M.A., Waters, R.A., and Chellaiah, S., 1991 b, "An Experimental Study of Freezing of Binary Mixtures," in National Heat Transfer Conference. 